\title{
Towards co-creation:
}

A design-led study of ecological shifts in the tidal margin. 


\section{ACKNOWLEDGEMENTS}

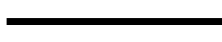

Many thanks to:

Hannah for your guidence

and support.

My family and friends for your words of encouragement.

And to Logan, for being with me every step of the way.

of the requirements for the

degree of Master of Landscape

Architecture [MLA]

Victoria University of Wellington

Te Herenga Waka, School of

Architecture

2021

Word count: 20,998.

All figures are author's own unless

stated otherwise. 

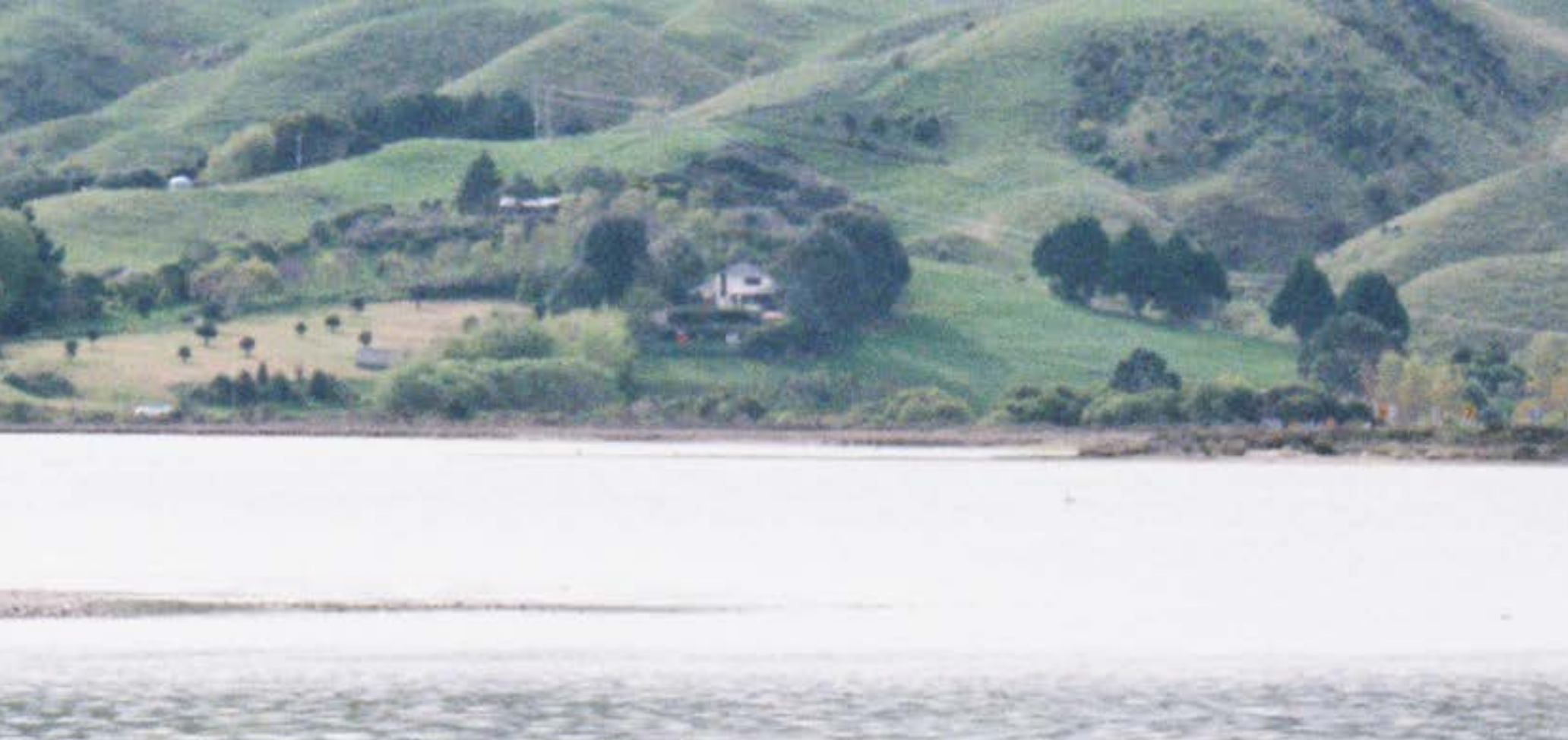

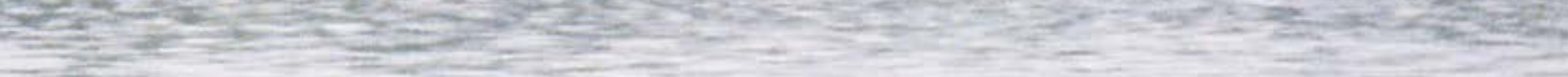
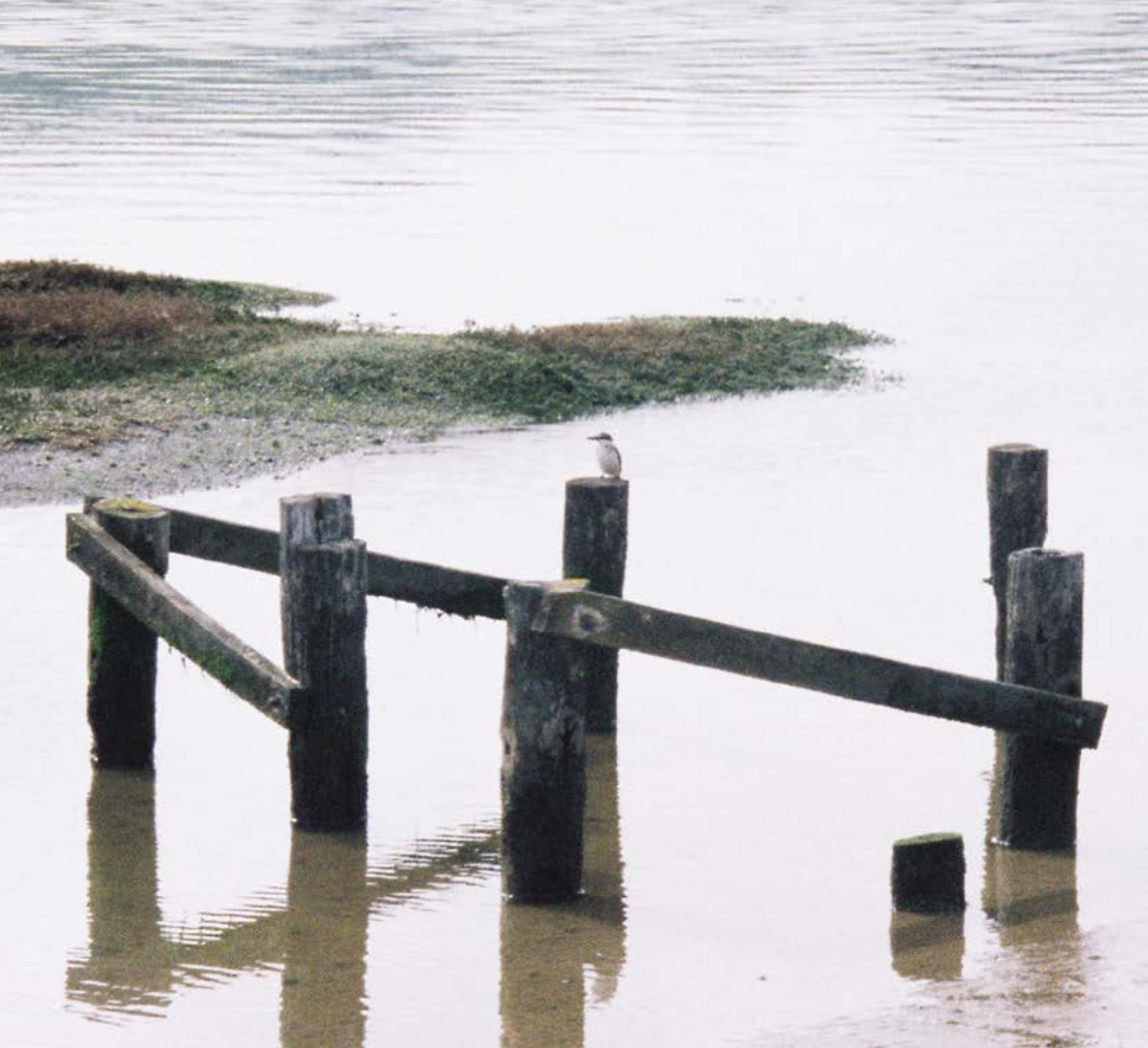
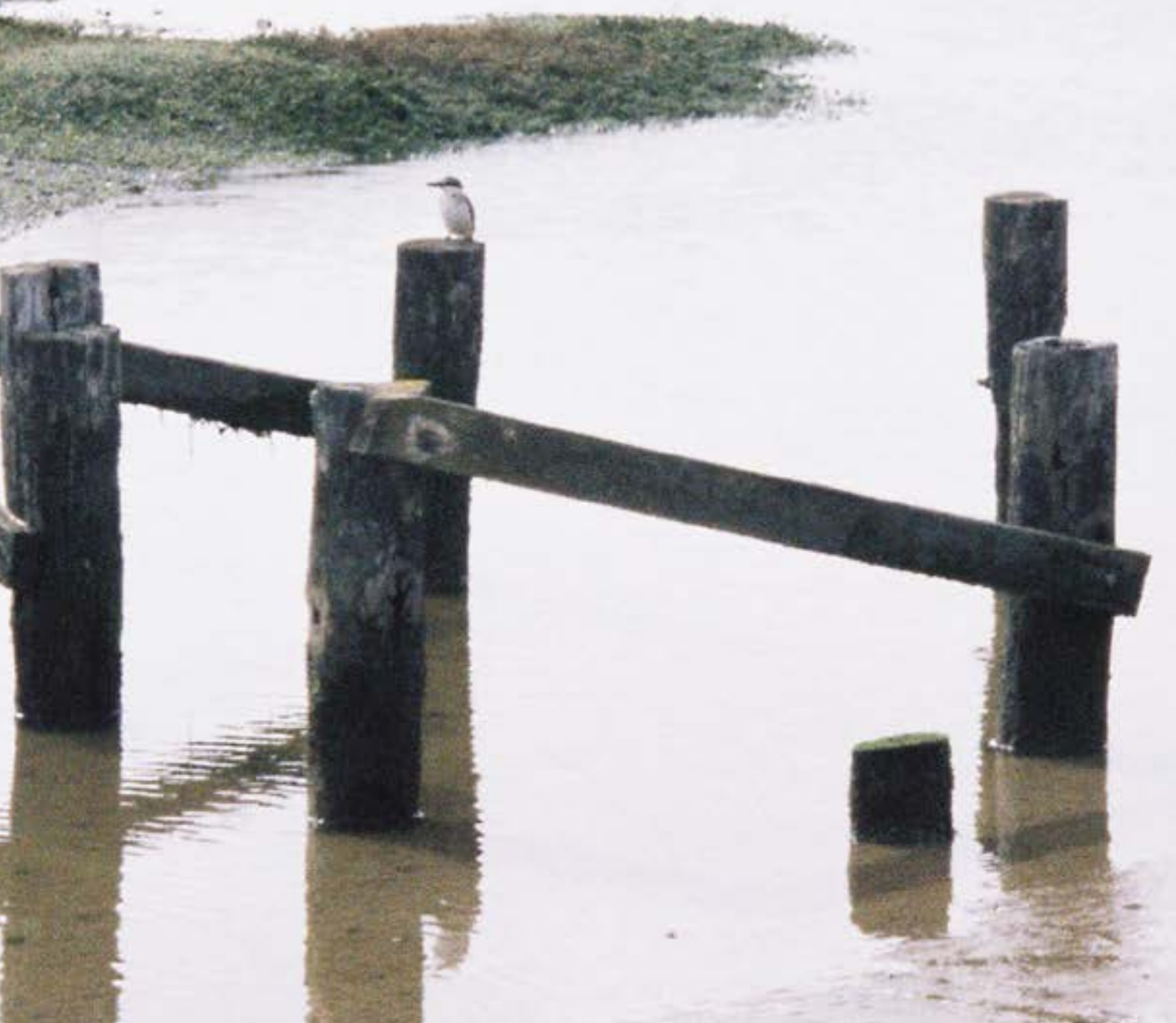

\section{Abstract.}

The ecological resilience of the intertidal margins of many cities is increasingly under pressure due to climatic shifts and urbanisation high-water ma species are prevented from migrating inland due to natural or man-made barriers This results in a phenomena known as 'coastal squeeze'.

Pauatahanui Inlet, Porirua supports a diverse ecosystem of aqua-fauna, micro invertebrates and wading birds that rely on the shallow saltmarsh habitat within the estuary. However, with sedimentation from the surrounding catchments slowly filling up the inlet along with and predicted tidal inundation from sea level rise, the future of this coastline is uncertain.

Rather than attempting to solve or secure a fixed future for the coastline, as is the prevailing anthropocentric response, this design led research seeks to respond to these human induced pressures by working with the cyclical phenological processes and ecological interactions occurring within the harbour. The research mbition is to co-create a shared public tidal realm.

This objective is tested through the design of a coastal boardwalk for the Pauatahanu Inlet. Unlike human-focused boardwalks, this infrastructure is designed with the capacity to adapt as the tidal edge shifts, in either direction, while facilitating movement for all forms of life to traverse the harbour. The research attempts to surpass perceived barriers between nature and culture with an emergent inquiry into the poetic nature of the site itself. Here landscape design practice is developed towards the creation of social capital as occurring between species, while ensuring the natural ecosystem (and the life it supports) has the capacity to adapt to potential climate related changes. 


\section{Contents}

\begin{tabular}{|c|c|c|}
\hline-00 & & $\begin{array}{l}\text { ABSTRACT } \\
\text { ACKNOWLEDGEMENTS } \\
\text { CONTENTS }\end{array}$ \\
\hline-01 & $\begin{array}{l}1.1 \\
1.2 \\
1.3 \\
1.4 \\
1.5 \\
1.6 \\
1.7\end{array}$ & $\begin{array}{l}\text { INTRODUCTION } \\
\text { PROPOSITION } \\
\text { MOTIVATION } \\
\text { AIMS + OBJECTIVES } \\
\text { RESEARCH QUESTION } \\
\text { METHODOLOGY } \\
\text { RESEARCH SCOPE }\end{array}$ \\
\hline-02 & $\begin{array}{l}2.1 \\
2.2 \\
2.3 \\
2.4 \\
2.5 \\
2.6\end{array}$ & $\begin{array}{l}\text { FRAMING THE PROBLEM FIELD } \\
\text { INTRODUCTION } \\
\text { LITERATURE REVIEW } \\
\text { - LANDSCAPE IN FLUX } \\
\text { - NON SOLUTIONISM } \\
\text { - SEA LEVEL RISE } \\
\text { - MORE THAN HUMAN/ } \\
\text { POST ANTHROPOCENE } \\
\text { - AESTHETICS } \\
\text { - LAND ART AND MATERIALITY } \\
\text { CRITICAL REFLECTION }\end{array}$ \\
\hline
\end{tabular}

SITE INVESTIGATION

DOCUMENTING THE LIFE OF THE INLET

- 06 PRELIMINARY DESIGN/ MATERIAL STUDIES

PRELIMINARY CONCEPT

$\begin{array}{lll}-03 & 3.1 & \text { CASE STUDIES } \\ & 3.2 & \text { KEY CONCEPTS } \\ & 3.3 & \text { FINDINGS }\end{array}$

FINDINGS 
01 -

Introduction. 


\section{Proposition}

INTRODUCTION:

Globally rising sea levels is a climate change induced phenomenon affecting the territory and viability of all forms of coastal life. Despite variabilities and uncertainties surrounding the future of coastal realm, there is no ignoring the fact that humans are very much entangled within the various natural, novel and social ecosystems, and their future trajectories.

Mindful of the types of spatial and habitat changes sea-level rise is imposing on all forms of life within the tidal margin this landscape design-led research

\section{asks how can attentiveness to forms} of sympioses in the coastal realm contribute to the creation of adaptive environments? It tests the capacity of landscape architectural practice to suppor socialecologies and the co-creation of spaces between humans and other forms of life, towards the ambition of a shared and resilient future in the face of global ecological uncertainty.

To this end, 'Towards co-creation: $\boldsymbol{A}$ design-led study of ecological shifts in the tidal margin' considers the possibility of coastal adaptation beyond prevailing anthropocentric practices that centre on the defence of human dominated territory. Increasing sea levels alter the spatial, and thus habitat conditions within intertidal margins calling any reliance upon spatial and territorial certainty into question. Whilst prevalent foreshore design practices stem from defence strategies in the maintenance of knowable and static coastal spaces, this design-led research works to embrace the manifestations of flux presented by sea level rising. However, how can landscape architecture practice within the complexity of such change? Detecting growing momentum within the landscape architectural discipline toward open-ended thinking as evidenced in non-solutionist design discourse and practices, ${ }_{3}$ this project embraces methods that work within the indeterminate futures presented by sea level rise. Situating itself at the coastal edge, the research explores methods of flexible design adaptation in response to the movement tideline as it migrates landward. Rather than attempting to resolve sea level rise, or secure a fixed future for the coast, the complex spatiotemporalites ${ }_{4}$ of the intertidal, along with humanity's relationship with the coastal edge that desires stability in the face of change are interrogated. Progressing this vantage through design the complex and dynamic interrelationships that form through cohabitation of the coastal landscape (human/nonhuman) are focussed. In this way the research reframes the 'problem' of sea level rise as a catalyst for positive landscape adaptation: a means to relinquish the industrialisation of the coastal edge and reclaim it as a public space for all forms of life to thrive and adapt, migrating with the changing landscape. Such an intent paves a practice of attentiveness to sympoiesis and co-creation with the non-human, and along with it, an ethic of care.

To test these ideas, the research uses design investigations to reinterpretate and reimagine a coastal walkway. The situation of Pauatahanui Inlet in Porirua City is used. Through design, ways to accommodate migrational movement (both organic and inorganic) are explored by allowing space for growth and decay, ebb and flow to occur. The research aims to find ways to augment the aesthetic qualities of these processes, framing the poetry of nature's rhythms as they occur. Proposed interventions within this environment thus work with the passage of time and phenological ${ }_{5}$ processes of observed life. Using material investigations these processes are mapped and recorded through time. Sited clay, shells and timber studies engage with the cyclical nature of life within an ecosystem, by highlighting how objects in a state of decay can create space for new life to emerge and take hold. Through this design process, the tactile and tangible qualities of the landscape are bought into play, intensifying the likelihood of relationships to unfold. Using enchantment and enhancing exposure to other forms of life the design prompts people to reassess their place in the world and their understanding of a resilient future.

What follows, sets out selected aspects of the design investigation, its outcomes and reflections.
1. Novel ecosystems are defined as 'ecosystems with biotic and/or abiotic N. B et.al. 2014. Novel ecosystems in the Anthropocene: a revision of the novel ecosystem concept for pragmatic applications. Ecology and Society 19(2): 12.

(2) not be mutually beneficial. See glossary p38. 3. Non solutionism seeks to design with change, rather than working against the perceived problem.

Spatiotemporalities: qualities experienced in - n lossary p38. 5. Phenological processes refer to the study . phenomena occurs periodically - often See glossary page38. 


\section{Motivation:}

Having lived all my life next to the sea, the sound of waves on the shore is as familiar and constant a voice to me as any other. There is something intriguing about its watery fluidity, the steadiness of tida rhythms and the dramatic changeability of its currents.

Undertaking this thesis while living on the Cook Strait, one of the most treacherous and unpredictable bodies of water in the world, it has never felt closer. Whilst it crashed through my lounge in the middle of April with $5 \mathrm{~m}$ swells that forcing evacuation in the middle of a lockdown pandemic, I was not deterred from my residence. In fact my respect for the ocean and its habitat grew, along with a sense of caution and greater appreciation for the forces of nature that can never be controlled. To dwell within the tidal zone and expect stability and consistency is a failure to understand the ocean at all. The ocean constantly throws up unique experiences and encounters, if we desire to be close to it, and rather than treating uncertainty as anomalous, design offers an opportunity to understand its associated risk.

As a self-serving species, humanscentered design often forgets this. We seek security through stability and anything that cannot be controlled is seen as a threat. An ethic of care must be developed that extends beyond 0 that extends beyond our species if we are to successfully adapt to our changin world. This thesis seeks to celebrate uncertainty and fluidity in order to create adaptive landscape design responses. Considering even the smallest of life forms, and their needs within the development of the wider landscape we must come to view the environment as something that is co-curated/created rather than as a blank canvas for our intervention.

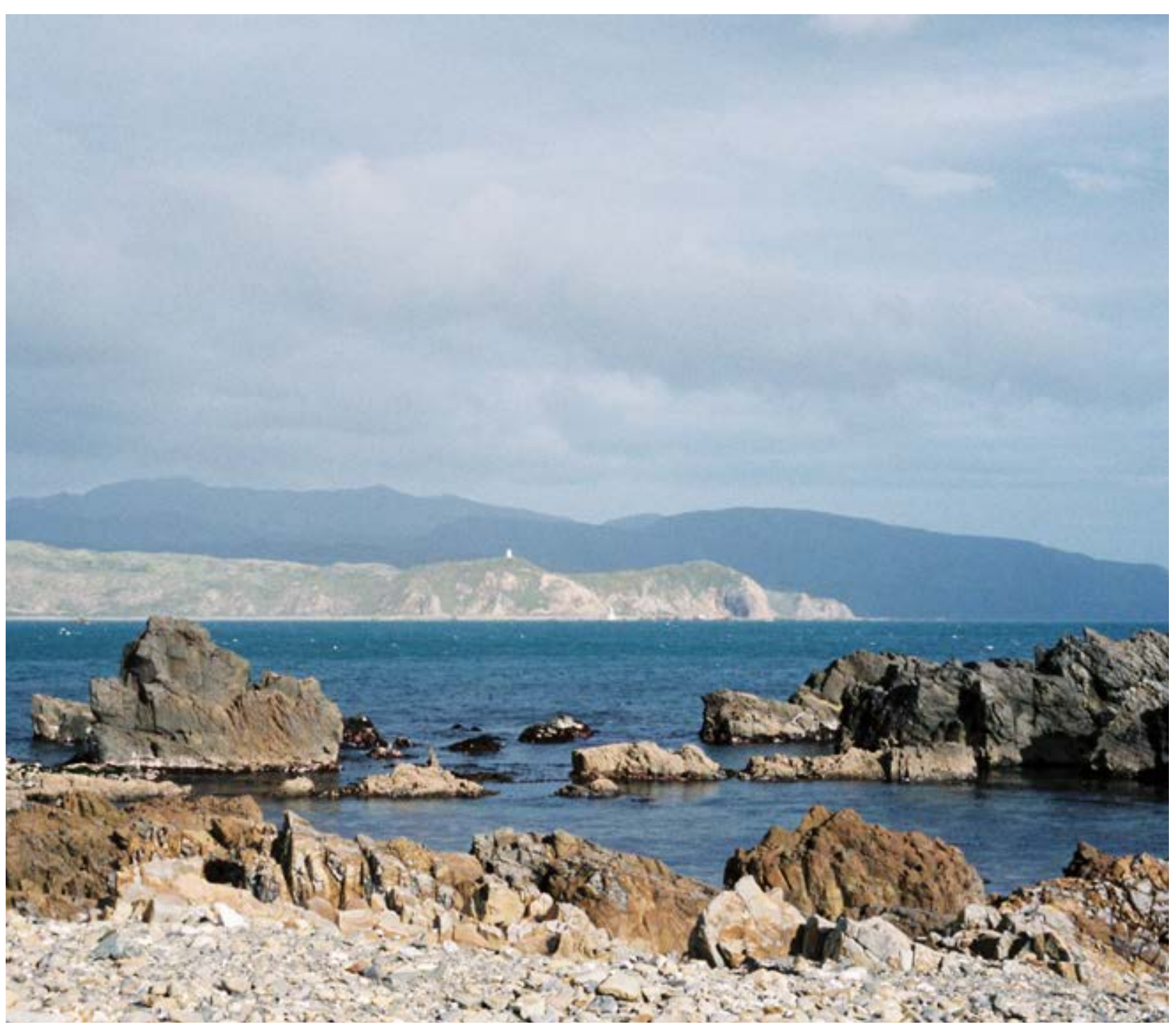




\section{Aims and objectives.}

Embracing the unpredictability of the

future, and dynamic fluidity of the

coastal edge, this research proposes

a designed intervention that adapts to

the changing tideline. This is explored

\section{through the design of a coastal walkway,} a conventionally simple landscape

intervention but with the potential to be conceptually reimagined. The pathway is designed to accommodate all forms of life with the tidal realm, thereby changing the way human and non-human users share the tidal edge.

Working alongside the vernacular processes present in Pauatahanui inlet, this design led research aims to:

- Create a publicly accessible tidal realm that facilitates movement for both organic and inorganic systems to traverse and cohabit.

- Embraces uncertainty by allowing the design to develop with and alongside the moving tidal edge rather than trying to fortify or 'fix' it through conventional stabilisation.

- Generate interventions to enhance the publics affective attunement to the site and its inhabitants through encounter - thus instigating an ethic of care within the community.
To do this the following objectives are undertaken:

- Develop a pathway loop around Pauatanahui's coastline, reclaiming the vehicular dominated edge for public recreation and habitat.

- Explore ways in which the materiality of the pathway adapts its purpose through time to suit the changing tidal edge, while still aiding the traversal of movement around the inlet.

- Enhance the potential for encounter between different species to occur, by way of proximity through sharing the coastal pathway.

RESEARCH QUESTIONS:

How can attentiveness to forms of sympoiesis in the coastal realm contribute to the co-creation of adaptive environments?

How can the materiality of pathway design respond to time?

\section{Scope -}

\author{
Scientific predictions of sea level rise \\ differ and are often generalised or vague. \\ The accelerating rate of climatic shifts, \\ the different systems at play at each site, \\ and further unknown potential contributing \\ factors that may arise make it incredibly \\ difficult to accurately forecast. However \\ for the purposes of this study a scope of \\ 150 years has been set ${ }_{6}$, offering possible \\ scenarios (as guided by the Ministry for the \\ Environments publications ${ }_{7}$ ) with adaptive \\ design responses explored accordingly. \\ This research focuses on the materiality \\ of the lives and relationships that will be \\ affected by dramatic changes along the \\ coastline. In that regard it differs from \\ prevailing discourse surrounding sea level \\ rise that emphasizes how sea level rise \\ will affect coastal urban developments \\ and how this might be mitigated. Instead, \\ detail and care are given to the needs of \\ those most immediately impacted by rising \\ water levels: those dwelling directly in the \\ intertidal zone who are reliant on shallow \\ waters and stable harbours for food and \\ shelter. Attention is thus drawn away from \\ human centered design to create a public \\ coastal realm for all forms of life to share \\ equally.
}




\section{Methodology -}

This research is mobilised by research through design $n_{8}$. This method is used to generate a critical inquiry into creative research by examining existing case studies through contextual inquiry, undertaking site specific investigations, modelling prototypes and testing design iterations. The research strategy is made up of the following key elements and their associated methods:

\section{Contextual inquiry:}

A contextual review of the disciplinary approach to sea level rise was undertaken study analysis. The literature outlined the prevailing approach to sea level rise, the associated problems with solutionist design trying to stabilise the edge and the implications of humans perceiving themselves as separate to the natural world. Noticing a movement toward nonMaterialism thinking, prompted me to look at how designers could work within observed processes making space for change to occur. Here is was prompted to consider how embodied immersion within andscapes and the aesthetics of such experience could be used to empower change by generating compassion for the landscape and wider systems. This possibility was investigated through the design of a coastal public realm that could facilitate movement for various forms of life in the face of sea level rise. through a literature review and case solutionist design thinking alongside New
To further the inquiry, existing coastal walkways were examined, with successful elements extrapolated to create a framework of key principles to support later design testing. Studies surrounding co-habitation were also explored to gain knowledge around different forms of encounter and proxemics studies guided by the question: how close can species get without either party feeling unsafe.

Site specific investigations:

To most appropriately address the research, a case-study within the unique conditions of the Pauatahanui Inlet was undertaken. This process begins by firs understanding the complex network of relations and territories overlapping and intersecting within the inlet.

Mapping and drawing methods are employed to catalogue and record user needs: this extends across human avifauna, aquatic life and coastal invertebrates. This strategy is used to find patterns within the landscape that begin to emerge by unpacking and layering different aspects that comprise the environment. To do this, data is collated from literature and scientific surveys (quantitative methodology)

tandem a sensitive and immersive investigative field work process (qualitative methodology) into existing site conditions is innovated. Attending to the rhythmic phenological patterns that occur within the harbour and its wider catchment, the research shifts 'site analysis' into embodied encounter and resulting reengaged here. This methodology acknowledges that bodily responses to affective encounters are a crucial part of producing knowledge ${ }_{10}$. Affective method requires researchers to engage kinaesthetically within their field of study and notate visceral sensations caused by intensities. Anthropologist Natasha Myers argues that this method is particularly important when undertaking research concerning nonhumans as it acknowledges them, not as passive recipients but as beings with their own agency, and thus enables an ethical approach that departs from pre-established hierarchies in studies.

In employing this method, extensive walking, driving and kayaking around the perimeter of estuary was undertaken, recorded and synthesised through practices of photography, moving image (film), sketching.

Such an approach generates speculative rather than routine ideas as to how these systems could be harnessed or highlighted, by way of the reimagined coastal walkway, to address impending effects rising sea levels on the intertidal ecology

Design testing begins through an exploration of material processes and the construction of several prototypical studies. These material studies are selected with the intention that they could be directly sourced from the landscape, processed (see chapter on material investigations) enchantment. 'Affective method,' is

\section{Modelling prototypes:}

and incorporated directly into the structural elements of the proposed design interventions. Prototypes of these material objects are placed in situ, exposed to the phenological rhythms of the on site for 6 months and record weathering patterns of the elements on their surface. Clay, timber and shells are selected for their natural porosity, lifespan, and potential to create habitat as they decay; they also have the potential to be synthesised into the design of the pathway as building materials. These studies engage with the materiality of the pathway and seek out how it might adapt over time to suit the changing environment.

\section{Design testing across scales}

The design of the pathway reflects the aims and objectives outlined in the introduction. An overall schematic plan addresses the pathways links to the wider catchment of Pauatahanui, while two focus areas: one along the northern coastline and one on the southern edge look at the design in far closer detail. These spatial and ecological investigations explore the means of generating coexistence in the design of the pathway and adaptive response through time

Research through design has been used for over 20 years within the design community inquiry that generates transferrable knowledge." Christopher Frayling, "Research in Art and Design," in RCA Research Papers 1, no. (London: Royal College of Art, 1993), 1-5. of practice in the context of fields such as science and technology which often place value on 'disembodied data' as opposed to emotional responses. See Mehrabi, Affective Method, New 10. This is because "feelings are not something abstract that happens inside a subject but they are affective performative bodily realities that happen in between bodies and through close 


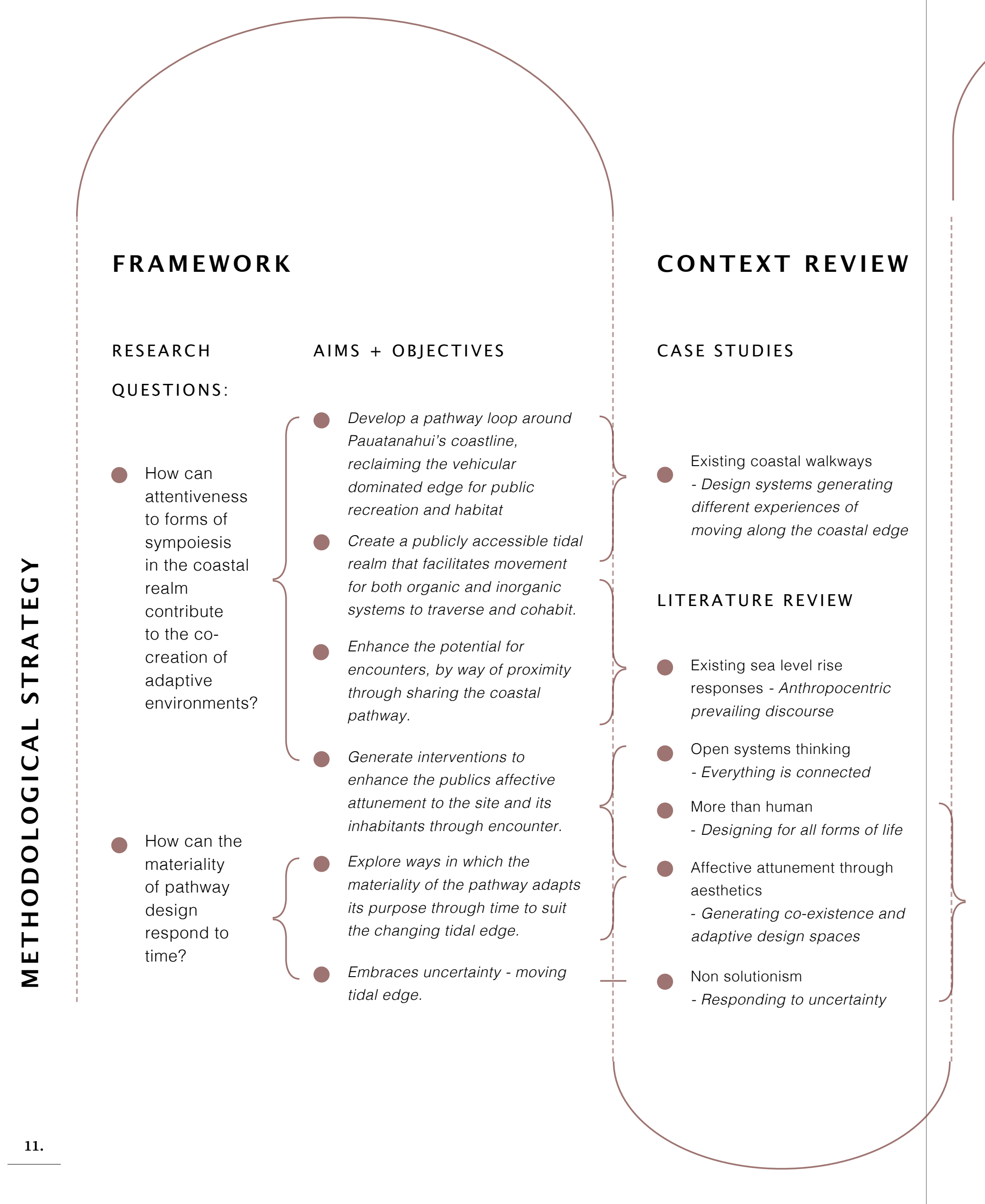

\section{SITE INVESTIGATION}

\begin{tabular}{l|l} 
QUANTITITVE & SYTHENSISED \\
& REPRESENTATION
\end{tabular}

DESIGN STUDY 2.

Literature

Data research

Scientfic surveys

Mapping

Mapping

Drawing

QUALITATIVE

Developing encounter as a method through affective methodology

Walking

Driving

Paddling (kayak)

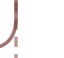
Critical reflection ...

\section{DESIGN STUDY 1}

Material construction

Placement in situ

Observation through time

Synthesis into design

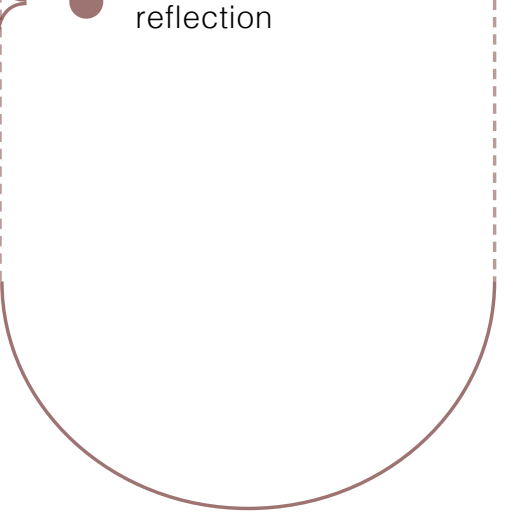

\section{DESIGN STUDY 3.}

Focus area: northern wetland<smiles>C=C</smiles>
Critical reflection ...-'

\section{DESIGN STUDY 4.}

Focus area: southern pathway<smiles>C=CC</smiles>

Critical reflection

CONCLUSION/

CRITICAL REFLECTION 
$02-$

Framing the Problem Field. 


\section{Discipline context}

INTRODUCTION:

This research composes its problem field around engaging with uncertainty and sitespecific phenomena through the discipline of landscape architecture. This disciplinary specific inquiry is extrapolated through the subfields of open systems thinking (landscape as flux), non-solutionism, more-than-human users, climate induced pressures (sea level rise), the ethics of encounter and proxemics, and the use of aesthetics and immersion in facilitating emotional connections. In drawing together these subfields of landscape architecture and related discourse, a particularised vantage of climate induced sea level rise is critically convened. What follows is a critical discussion of these respective sub-fields as relevant to this inquiry and its situatedness within the discourse of landscape architecture. The approach here, a discursive convening, is thus somewhat idiosyncratic cutting across conventional knowledge system boundaries.

\section{ANDSCAPE IN FLUX:}

Landscape Architecture as a relatively new profession emerging from Western epistemic traditions has inherited ideas of the natural and social or cultural world as distinct. Such a dichotomous tension, as a product of Enlightenment thought which produced and required the 'othering' of nature, continues to girder much of landscape theory and practice. ${ }_{11}$ However, with the rapid degradation of ecological systems as a direct result of human induced pressures, the mark of the Anthropocene on the earth can no longer be ignored.

French academics in the early 1980 's $s_{12}$ criticised the dichotomy of nature culture as anachronistic, proposing instead an image of a textured network, an assemblage which extends to all entities and systems, emphasising fluidity

exchangeability and multivalent systems. This discourse was incredibly influential in fields working with sociology as it allowed them to visualise complex interrelated systems and affect and has become the foundation of New Materialism. This field is establishing itself as cognisant of the human's entanglement within what is called nature, and is becoming influential in landscape architectural thought. What is at stake with this thinking, is a renewed conception of nature.

In 1997 James Corner ${ }_{13}$ described two types of nature: the first refers to the concept or idea of nature, a cultural construct that allows people to understand the natural world; the second is the nature which escapes human understanding, an ever-changing network of systems and lives, the interdependencies of which are a vast and complex unmediated flux what Corner states is "the actual cosmos". The first concept of nature reflects the ethic of the current instrumentalist (problem solving) approaches that aim to preserve nature and solve the problem of 'harmful' external influences Landscape architecture has adopted this approach as a means of preserving picturesque wilderness qualities as if entirely 'other' from the urban. Through retaining this distinction, responses have failed to understand the pervasive external influences of the relational world ${ }_{15}$ as is addressed in the second definition of nature; the more recent understanding of systems pervasive to landscape design.

Timothy Morton suggests the removal of the concept of nature entirely, arguing that as an artificial construc its definition is unclear, changing to suit various appropriations of the word.
Instead, he turns to the word biosphere distinguishing it as a spatiotemporal ecological collective" of things; a form of political organization that includes both humans and nonhuman species. This understanding of ecologies surpasses the nature-culture binary, dissolution is the key to understanding the complexities and nuances of the environment and human place within it. If we understand that we are not above these systems, then we must acknowledge that we need to work alongside them to adequately respond to change (through design).

11. The school of philosophy during this period This classical notion has long since influen the structure of the study of sociology and the production of knowledge.

2. Deleuze and Guattari's 'A Thousand theory as a framework for understanding social complexity and the expansive network of relations that make up the world. Latour expanded on this a few years later through the which acknowledged both nonhumans and humans as 'actants' within this expanded field as a means to dissolve the nature culture divide in spatial theory.

13. James Corner, and Alison Bick Hirsch. James Corner 1990-2010. New York: Princeton Architectural Press, 2014 see glossary p 38. ( Time" 2020 Architecture" Harvard Design Magazine No. 12 Sprawl and Spectacle. 2000. 
It is within this increasingly shifting environment that the discipline of andscape architecture finds itself now. Poised between art and science ${ }_{16}$ the role of the modern landscape architect has become one of creative problem solving (know how) and aesthetics (scenery). Corner $_{17}$ asserts that a greater focus on instrumental modes of ecology rather than creativity has led to mechanical and prescriptive methods. Grappling with the problems of climate change, many practitioners have focused their work on designing for resilience and adaptation; as evidenced by a resurgence in ecological thinking, using applied scientific principles to map, predict and manage ecological movement in technologically sophisticated ways. $_{18}$

However there appears to be a quandary around how to adequately design for an uncertain future; the more we try to intervene and stabilise the landscape, the more problems are exacerbated or compounded in less predictable ways. This tendency can be exampled by the impacts of hard protection and defensive strategies to mitigate sea level rise effects: take the orm of a bay, if one side has a constructed sea wall then wave action on the other side is likely to be exacerbated, causing greater erosion than before. Thus, the remedies to problems often entail dependencies that make situations worse. Milligan attributes this to difficulty around comprehending the complex interdependencies of environmental systems, and a tendency to allow ourselves the fiction of background stability when designing. He states most of us imagine migration as the movement of isolated things against a fixed background." However the background itself is also moving (the landscape).

In that regard we need to consider the landscape is constantly changing as: it is an ever-evolving matrix of interconnected natural processes and living beings interacting, colliding and influencing the environmental conditions around them. These processes are multiscalar and complex. By nature, the coastal environment shows this more readily; winds and tides are constantly changing its boundaries. Each day brings four tidal fluctuations of sediments, organisms, erosion and deposition that affects the fabric of the landscape in many imperceptible ways. Likewise, wider catchment conditions carry fine sediments and nutrients down from the hills to the sea through the watershed. As these components shift and evolve, so too does the structure of the landscape. James Corner was fascinated by the dynamism of ecological processes, this nonlinear migrational movement of the landscape, naming the land "terra fluxus" rather than "terra firma" solid ground.

A movement in New Materialist thinking in landscape architecture has sought to engage with the dynamic phenomena of shifting landscapes and move away rom reductive dualisms such as nature/ culture ${ }_{20}$. This practice advocates for a critique of global materialism, and centres around collective engagement toward the shared future of all forms of life in response to climate change. Key New Materialist theorist, Kaaran Barad addresses these phenomena through 'agential realism, stressing the nonhuman aspect of agency ${ }_{21}$ This concept refers to the agency held by an object that it is enacted through entanglement. For the researcher, employing this understanding creates an ethical approach to understanding the nature of the world as it unfolds around you, generating greater sensitivity to the world in its state of becoming. In this way, the way we encounter the world affects the way we respond to it.

Bennett, in a seminal new materialist work, argues that the premodern world of scientific and instrumental rationality has eclipsed a sense of wonder in engaging with the unknown, causing disenchantment with the world. ${ }_{23}$ Through the wonder of minor experiences, Bennett explores the use of 'encounter' as a means to enchant, instigating an ethic of generosity through affect. For Bennett enchantment involves a surprising novel encounter, one with which you did not expect, the bodily act of which tears you from your default 'sensorypsychic-intellectual disposition' affecting a sense of exhilaration or acute sensory awareness thus provoking new ideas and perspectives She states: "Enchantment is something that we encounter, that hits us, but it is also a comportment that can be fostered through deliberate strategies."

This research seeks to draw from Bennett's rationale in addressing new materialist principles through the design of a coasta realm that facilitates movement for all forms of life; hoping to enchant its users through the designed experience of an immersive pathway that heightens sensory awareness, tactile material engagement and the facilitation of encounter to engender an ethic of care.

6 John Beardsley, "A word for Landscape Architecture" Harvard Design Magazine No. Sprawl and Spectacle. 2000

17. James Corner, and Alison Bick Hirsch. Landscape Imagination: Collected Essays of Ames Corner 1990-201. New York: Prnceton

Ecology and Design: Parallel Genealogies. Ecological thinking remains a powerful lens for understanding complex adaptive systems.

(Environmental design in the Anthropotion Places Journal, 2015. 20. Kameron Sanzo. "New Materialism(s)" Genealogy of the post human, 2018. 22. Kaaren Barad. "Meeting the Universe Halfway: Quantum Physics and the Entanglement of Matter and Meaning" 2007. Jane Bennett. "The Enchantment of Modern Pp 3-16. 
SEA LEVEL RISE

Sea level rise has been labelled as a wicked problem. In other words: a problem that overwhelms existing practices through its social and ecological complexity, therefore they cannot be solved by the same tools and processes which are complicit in creating them. Coastlines have always moved; it is the very nature of their being. By fortifying the coastal edge, wildlife that rely on the intertidal zone are trapped between a wall and the rising sea unable to move landwards - resulting in a tidal squeeze. ${ }_{25}$ This investigation refuses such practices and instead considers designing with constant change. Issues surrounding the impacts this tidal squeeze will have on life within the intertidal margin give agency to this design inquiry, centring its focus around the tidal edge condition and its lack of stability.

The impacts of sea level rise on the landscape differ for each locality, and the visible responses will depend on several physical factors such as: sediment supply, wave climate, storm frequency, topography and terrestrial sediment $\mathrm{t}_{26}$ thus predicting future impacts is complex. However, it is predicted that over time these factors will be exacerbated by global warming, their regularity will increase and lead to permanent inundation of low-lying areas.

Design responses to stabilize vulnerable coastal margins against sea level rise have predominantly focused on the impact of flood inundation on human's settlements near the sea, implementing 'retreat' or 'blockade' techniques to manage the approaching tide ${ }_{27}$. Blockade techniques are either hardscape (built infrastructure) which can handle significant storm surge but are generally more expensive and ecologically destructive; or soft protection (ecological infrastructure) which utilises 'ecosystem services' such as plants or shell banks as a buffer to erosion. These systems have been applied to areas deemed most at risk of coastal erosion and storm surge. Often framed as a 'toolkit' of engineering solutions, these coasta a best-fit engineering basis. A form of extreme functionalism, these structures appear to have an air of permanency, however they really are only band aid solutions, without much longevity ${ }_{28}$. According to a report prepared by the Ministry for the Environment, managed retreat and adaptation are the only costeffective and feasible long-term option as the impacts of sea level rise are projected to continue to affect the coastlines for centuries.

The vulnerability of ecosystems and social communities need to be assessed, alon with their capacity for adaptation, when considering responses systems to sea level rise. Blockade approaches often fail to acknowledge or consider other forms of life (beyond humans) that rely on the shore margin for habitat. Coastal defence infrastructure such as seawalls and dykes exacerbate this divide by acting as barriers to coastal species migrating inland as tidal margins move steadily higher. This

TRADITIONAL SEA LEVEL RISE RESPONSE SYSTEMS RESIST - CONSTRCUTION OF HARD BARRIERS (BUILT INFRASTRUCTURE)

SUPER LeVEe Dikes SEAWALl SURGe barriers FLood WALL

2. ACCOMODATE - SOFT PROTECTION (ECOLOGICAL INFRASTRUCTURE)

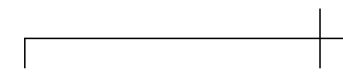

BEACH

NOURISHMENT

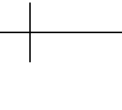

LIVING REAKWATERS
FLOOD ADAPTIVE
STRUCTURES
RETREAT will prove to be particularly catastrophic to aquatic life and avifauna that rely on shallow harbours for habitat, food, and as nurseries for their young.

By reclaiming the tidal edge as a public realm, we can remove impediments to migration and provide space for both organic and inorganic systems to shift along with the changing tideline. In this way design can embrace uncertainty, removing the focus of coastline

stabilisation, to working with responsive

design interventions that adapt through

time, facilitating both public recreation and habitat.
24. John FitzGibbon and Kennith O Mensah, 25. Dante Tono and Gail Chmura. Assessing Coastal Squeeze of Tidal Wetlands (Journal of Coastal Research, 2013), 1049-106. 26. RG Bell, TM Hume, DM Hicks. "Planning for The Ministry for the Environment, New Zealand

7. Sibyl Bloomfield, Inhabiting the Shifting Edge: Increasing the Adaptive Capacity of Coastal Sand Splic Communiles in a Changing 28. RG Bell, TM Hume, DM Hicks. "Planning for Climate Change Effects on Coastal Margins" The Ministry for the Environment, New Zealand, 2001. 
NON SOLUTIONISM

A newly formed tendency identified within contemporary landscape practice is what can be in short hand called nonsolutionism. Non solutionism points to a range of practices that do not seek to ignore issues within the landscape but rather reframe the way we address them through design adaption. Nonsolutionism was conceived to address a methodological tendency within the practice of landscape architecture toward overly instrumental and solutionist thinking. This tendency often overlooks the complexities of landscape systems and reduces multivalent ecosystems down to a few easily comprehensible networks of systems. Holmes describes how this tendency is manifested in three ways ${ }_{29}$. Firstly, solutionists look past aspects within the landscape which are socially or ecologically important but are not deemed problems. Secondly, when problems are perceived they apply a 'best fit' approach rom a toolkit of existing solutions, which do not always suit the context of the site. And thirdly, unsolvable problems are either avoided, or interpreted as 'solvable' which may lead to unintended consequences occurring from design interventions. To go beyond the limitations of these endencies, this research attempts a detailed and immersive researc investigation into the phenological processes at play within the site, using these to create site specific design responses to fit the ecological systems. Existing sea level rise strategies are learned from and adapted, but not implemented in a 'best fit' solution, nor is a solution to be sought, rather measures implemented to provide room for adaption to take place.

The nature of 'solution based' strategies is that they imply solvability. It frames changing landscapes, such as oncoming sea level rise, as 'problems which need to be solved'. This creates a tendency to treat the landscape as fragile and something o be saved. However, in reality it is a denial to willingly change our actions and humanity's fear of unforeseen failure that drives this need.

It is evident the dominant contemporary design paradigm is to evade failure at all costs and use ever more complex technological simulations to predict and mitigate future risk. The fields that organise urban planning: Architecture, politics and infrastructural engineering all reward stability, and therefore are juxtaposed against the fluid landscape in which they intervene. Holmes describes this conflict "between stabilizing structures and environmental forces; between economies that seek continuity and landscapes that are constantly migrating ." Thus, initial attempts to resolve climate related problems within landscape architecture have focused on controlling landscape processes, 'fixing' environments against change or 'failure' that might pose risk to humanities way of life. However, these processes are often normal landscape migration, framed as problems because they highlight human vulnerability.

In their short film 'Failure' ${ }_{31}$ Medel and

Cantrall posit that failure is at the heart of landscape, as the complexity of

\section{he environment is multivalent to the}

extent that it beguiles prediction. They

suggest that by embracing failure, we can

develop systems that are less fragile and

therefore more resilient to unknown futures.

This requires a paradigm shift within the

discipline of landscape architecture:

by relinquishing efforts to predict and

protect against movement we can create

adaptive designs that celebrate movement

and complexity, working alongside these

processes rather than attempting to

stabilise them.

Non solutionism does not seek to ignore issues within the landscape. Rather it

proposes reframing the way we address

by engaging directly with 'site.' By

undertaking an immersive and discrete

investigation in the landscape, we can

begin to understand how complex

relationships are formed, unique to each

locality. By attending to these processes

and many lives within the tidal realm and providing space for these relationships to unfold (both organic and inorganic), a form of sympoiesis $_{32}$ is enabled. The designer can thereby work alongside the haturat processes occuring on site and natural processes occur ing on site and allowing for migration of the landscape, rather than attempting to 'fix' these process as they occur, by means of conventional stabilisation techniques. $_{33}$

Rob Holmes. "The Problem with Solutions," aces Journal (2020)

blem with Solutions, Places Journal (2020). Ch. This film was part of an exhibition in Chicago. Emma Medell and Bradley Cantral 32. See glossary P38,

3. A 'tool kit' of design solution 
AFFECT WITHIN

METHODOLOGY

dentifying the conventional epistemologies of the nature/culture divide as giving

priority to detached forms of knowledge

scholars have tried to create theoretical

frameworks that allow designers to relate

to the complexity of the landscape and the

interconnected lives of those who dwell

within it.

Assemblage theory, coined by Deleuze and Guattari, is an analytical tool used to understand the complexity of interrelationships and connections forming and dissolving within the landscape. Assemblages are experienced through differentiations in space which can be sensed; perceived bodily or are physically observable, termed affect. This often indicates shifts in agency that occur through the interaction of lives affecting one another, including humans and nonon within the landscape, designers can begin to comprehend the compounding forces at play within the landscape, both organic and inorganic, and develop design strategies that work alongside these processes.

Affect is particularly pertinent to this research. For humans and animals to coexist in close proximity without hierarchy, both parties must be able to maintain a distance at which they feel safe and undisturbed by the other. These boundaries may be slowly dissolved over time as mutual curiosity and understanding increase, and a sense of danger recedes. Understanding the tolerance of each individual species to one another in terms of affect (or proxemics ${ }_{34}$ ) is crucial to creating informed design decisions that directly address the range of users and their needs.

Assemblage theory and affective method whilst differ somewhat in their approaches, share an overarching ethic: they consider all life forms as equal participants within social systems, with the capacity to influence their surroundings consciously or inadvertently as 'affects' ${ }_{35}$ By implementing such frameworks, researchers are able to shift perceptions around the separation of nature and culture while rejecting human exceptionalism. Linquist ${ }_{36}$ asserts that this allows researchers to "enact political and environmental change through the shifting of individual perspective.

Affective methodology was developed as a strategy to investigate affective processes in relation to empirical studies; noticing an increasing number of academic works engaging with affective processes. ${ }_{37}$ This method is defined by Knudsen and stage as "(1) asking research questions and formulating research agendas relating to affective processes, for (2) collecting or producing embodied data and for (3) making sense of this data in order to produce academic knowledge." ${ }_{38}$

These approaches are helpful in gaining insight into the complexity of the field in which we work as landscape architects.

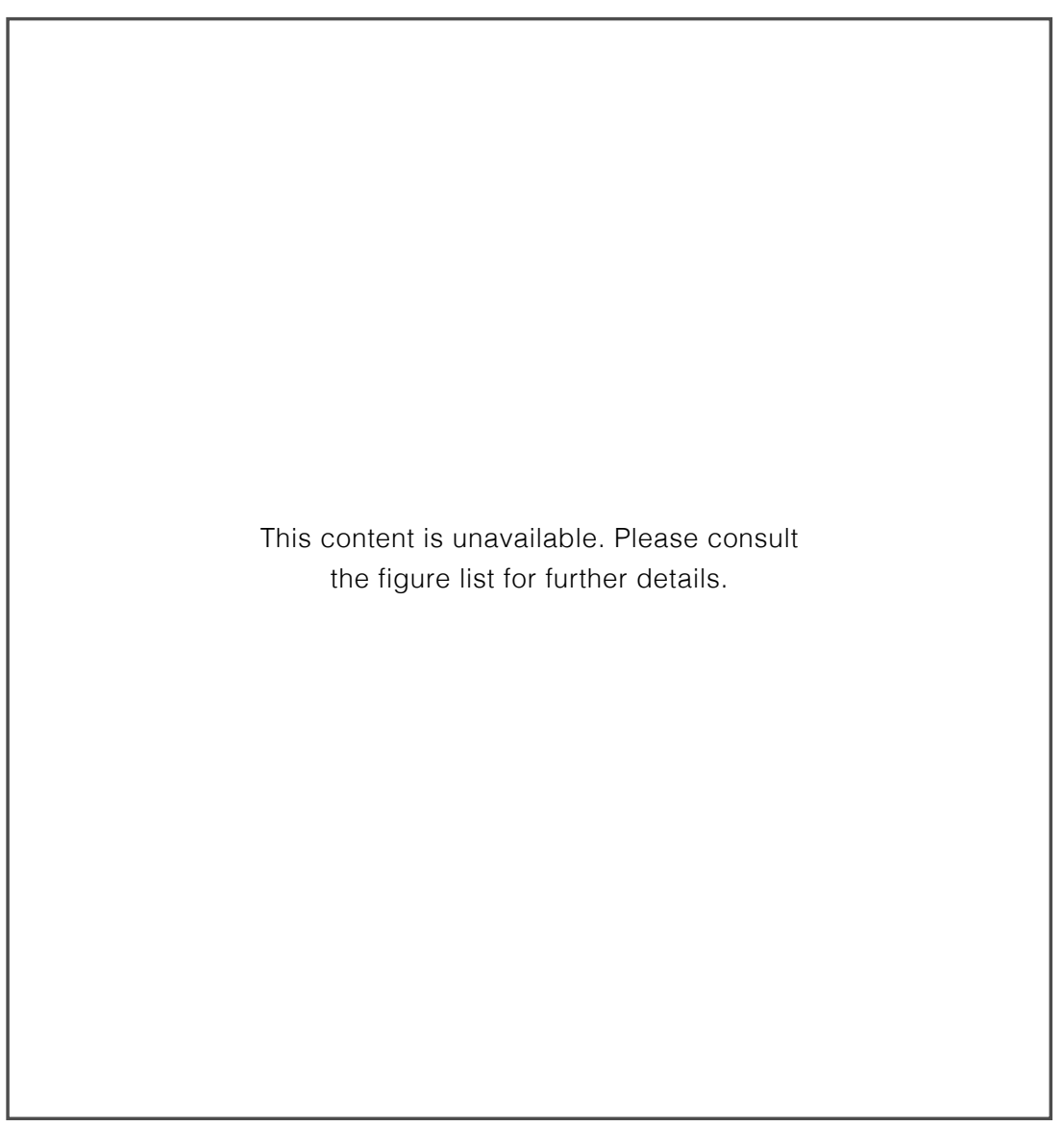

If we are to respond to climatic shifts in a way that considers all entities, we nc to start to conceptualise their autonomy, agency and capacity for change alongside our own. Affective methodology and assemblage theory have mobilised this research process by placing the articulation of these lives and processes at the core of design-led investigations. In this way, the design study can respond to the needs and migration of all forms of life around tidal realm through the design of a shared coastal walkway.
34. See glossary p38.

36. Linquist, Greg. "Socia Ecologies" Brooklyn Rail, 2015. 7. Britta Timm Knudsen and Affective Methodologies, 2015 38. Ibid. 
PROXEMICS AND AFFECT

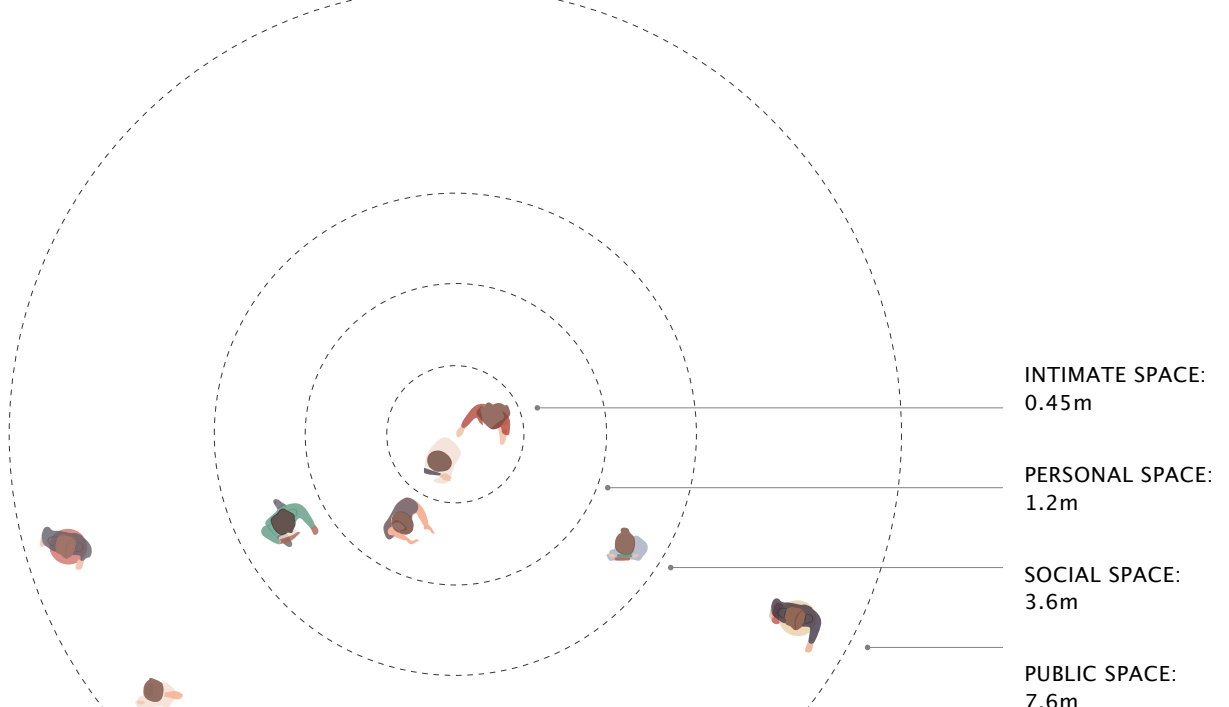

PUBLIC SPACE:
$7.6 \mathrm{~m}$

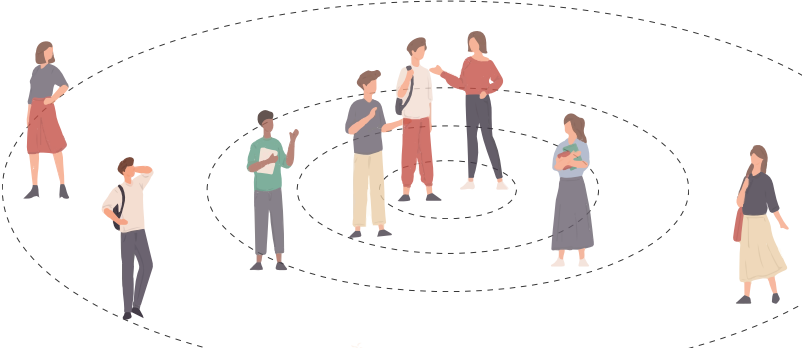

own adapted
from Edward $T$

The term Proxemics was coined by

anthropologist Edward T Hall in the 1960's

to describe the way people use physical

distance to communicate nonverbally ${ }_{30}$

By measuring distance between two

individuals, invisible social boundaries

or territories could be observed, with

close proximities reserved for intimate

relationships and wider distances kept

between acquaintances. If these distances were reduced, then discomfort was perceived. This research primarily revolved around the experiences of human beings other human beings and recorded the physical and psychological aspects of this discomfort or 'affect' with the idea that it could be applied in the design of architectural spaces and city planning. This research seeks to expand these principles beyond this anthropocentric vantage however to explore this concept could be applied in to more-thanhuman $_{40}$ relationships, and the design of shared public spaces. Here I consider

how the study of proxemics through the employment of affective methodology offers designers a set of physical

parameters that can be synthesised into the design of shared public spaces. This creates a framework to allow for co-

existence and observable proximity without discomfort.

In her thesis Synanthropic Suburbia ${ }_{41}$ Sarah Gynawan explores interspecies relationships of close proximity through the creation of mutually beneficial cohabitation designs, where species can coexist within the fabric of a building without making either party uncomfortable. Gynawan posits that the relationship between animal and human differs depending on perception and control - whether the animal is perceived as friendly or dangerous, and how much control the human has over the relationship of

coexistence. She gives the example of a bird: a wild bird is perceived of as friendly neighbour when it is outside the home, however it if it flies inside uninvited it is an intruder. A bird in a cage is a pet, but what is a bird that cohabits the fabric of the building independently? For Gynawan the conceptual limits of human and anima erritory are poorly defined." By breaking down the boundaries between nature

and culture and synthesising the needs

of different species, mutually beneficial

designs can be created.
Understanding where these invisible boundaries lie shows itself as key to designing spaces of coexistence. Research surrounding individual territorial thresholds and the needs of users beyond humans $_{42}$ instils an ethic of care towards other forms of life, both through the design process, and in the users upon design instillation. ${ }_{43}$ This research then explores how landscape architecture has the capacity to enhance the publics affective attunement to the site and its inhabitants through the creation of immersive environments and facilitation of the encounter through proximity. Greater knowledge and awareness through direct relational contact and interpersonal relationships has the potential to move people, thus a sense of responsibility is instilled.

39. "Proxemics." A Dictionary of Cultural Anthropology. Oxford University Press, 2018 40. Designing with and for non-humans see glossary p38. The use here applies relationships between humans and nonhumans. 41. Synanthrope is the name given to nonhuma animals that are neither wild nor domestic, but rather co-habitants of the suburban condition. Sarah Gunawan. Synanthropic Suburb 42. As explored in chapter five. 43. As design installation is beyond the scope of this research, this aspect can only be 
Aesthetics, materiality and phenological processes are pertinent to the discovery processes in this design investigation. Given the aim of generating an affective resonance of enchantment ${ }_{44}$ for those moving around the tidal realm here draw on literature to understand how the creation of immersive experiences. Changing people's perceptions of their place with in the environment ${ }_{45}$ requires introspection which leads me to ask, how can landscape architecture be a vehicle for prompting encounter and its attendant introspection.

Art and aesthetics have the power to frame people's vision and thus to a certain extent - the way people perceive things. Art is a political and social commentary about what is important to us: the artist, or humanity. The designer therefore has the capacity to encourage and shift patterns of behaviour through exposure and direct relational contact to subject material. To bring something to the forefront of a person's attention, through tactile engagement or visual framing, is to affectively attune someone to their environment, and encourage personal connection. This research takes up such a challenge.

Elizabeth Meyer argues that it will take more than ecologically regenerative designs for people to be sustainable. "What is needed are designed landscape that provoke those who experience them to be more aware of how their actions affect the environment". In her manifesto 'Sustaining Beauty' she suggests that the aesthetic experience of the landscape has the potential to alter how people relate to the environment and each other, creatin an emotional connection to the landscape and its inhabitants that transcends moral idealism.
Aesthetics in Meyer's understanding of the term thus extends beyond that which is immediately or visibly pleasing, but rather immersive experiences that cal into question assumptions we may hold. She describes this as an exchange "a perceptual entanglement between a sensing body and the world" - a series of connections and changing conditions within the environmental assemblage. This leads us to see and be attentive to how there is transformative phenomena, or affective force, existing in the landscape, prior to its 'being designed'. Here my inquiry labours to 'work with' the materiality of this 'affective force',

The embodied experience of moving through the landscape changes as processes alter the aesthetic qualities of the space. On any given day the sensory experience is likely to be different due to changes in weather, time of day and seasonal shifts. Kastner described experiencing the aesthetic qualities of performative art in nature as a "phenomenological synthesis of anticipation, perception and memory" ${ }_{47}$ Here the experience is imbibed with meaning depending on the viewers understanding and engagement with their surroundings. Thus, slow processes of immersion are necessary to capture the minds and hearts of the viewer. Through the act of moving along a line, or for tht matter a pathway, the landscape unfolds before the viewer.

Tilley ${ }_{48}$ described the act as symbolic, not only of the interconnectedness of all life, but movement through time, stating "The importance and significance of a place can only be appreciated as part of movement from and to it in relation to others"
The movement of Land Art was highly influential to the practice of landscape architecture as it placed the site at the centre of the aesthetic consciousness, working with land directly as an artistic medium. This work addressed a growing concern for environmental awareness Landscape architect, Elizabeth Meyer admired earthwork operations for their ability to engage with and record phenological processes across time, often through a change in physical state. By making processes of weathering visible, the works themselves were able to reveal the particular phenological qualities of a place to the viewer that may not be perceptible at first glance. This gives me clues to how to focus the materiality of the intertidal.

Early environmental art engaged with, and even celebrated processes of growth and decay; something which was radically different from the current discourse of landscape architecture at the time, which focused strongly on functional problem solving $_{4.9}$

One of the most influential pieces of work that exemplifies this is Robert Smithson's Spiral Jetty'. Working directly with the material makeup of the site, Smithson's etty emerges out from The Great Salt Lake in Utah. basalt rock. As in the landscape which shift and decay, Smithson wanted to imbue his art with the same entropy, association with time, and even potential dissolution as is natural within geological landscape processes. For years the Spiral Jetty was submerged from sight, under the water of the lake. Its re-emergence was only due to a series of prolonged droughts caused by global warming that dropped the water levels in the lake, causing the rocky jetty to reemerge cloaked in crystals.
Smithson's work interrogated the dualities between nature and culture by recording man's mark upon the landscape. He worked with natural processes of time materiality and weathering; celebrating ambiguity and change in his designs. Smithson successfully used his understanding of phenological processes to create a design that changed its form over time, enhancing the original work to create something new, in a form of sympoises.

What this review suggests is that working with and engaging with phenological

\section{processes through the use of material}

nvestigations, a range of possibilities for tactile engagement as part of an immersive design could be opened up. These

'transformative phenomena' can be utilised both physically and emotionally; through the provision of habitat in the erosion of the material (built in 'failure through erosion as cracks and crevices create shelter and new life), thus generating moments of encounter through the shared material substrate of the coastal path.

4. Refers to Jane Bennett's text. "The Enchantment of Modern Life : Attachments,
Crossings, and Ethics" 2001. Pp 3-16. - see 'Landscape in flux'.

45. Relinquishing the nature/culture dichotomy 46. Elizabeth Meyer. "Sustaining beauty. The Performance of Appearance: A Manifesto in Three Parts." Journal of landscape architecture,

Pattamon "A Study extracted from Selanon, Environmental Art to Landscape Architecture in the Context of the United Kingdom". ProQuest Kastner's words in "Land and Environmental Art" ondon. Phaidon, 1998. 48. Chistopher Tilley, "Place, paths and monuments - a phenomenology of landscape"

49 Selanon, Pattamon, 1998. Ibid. 

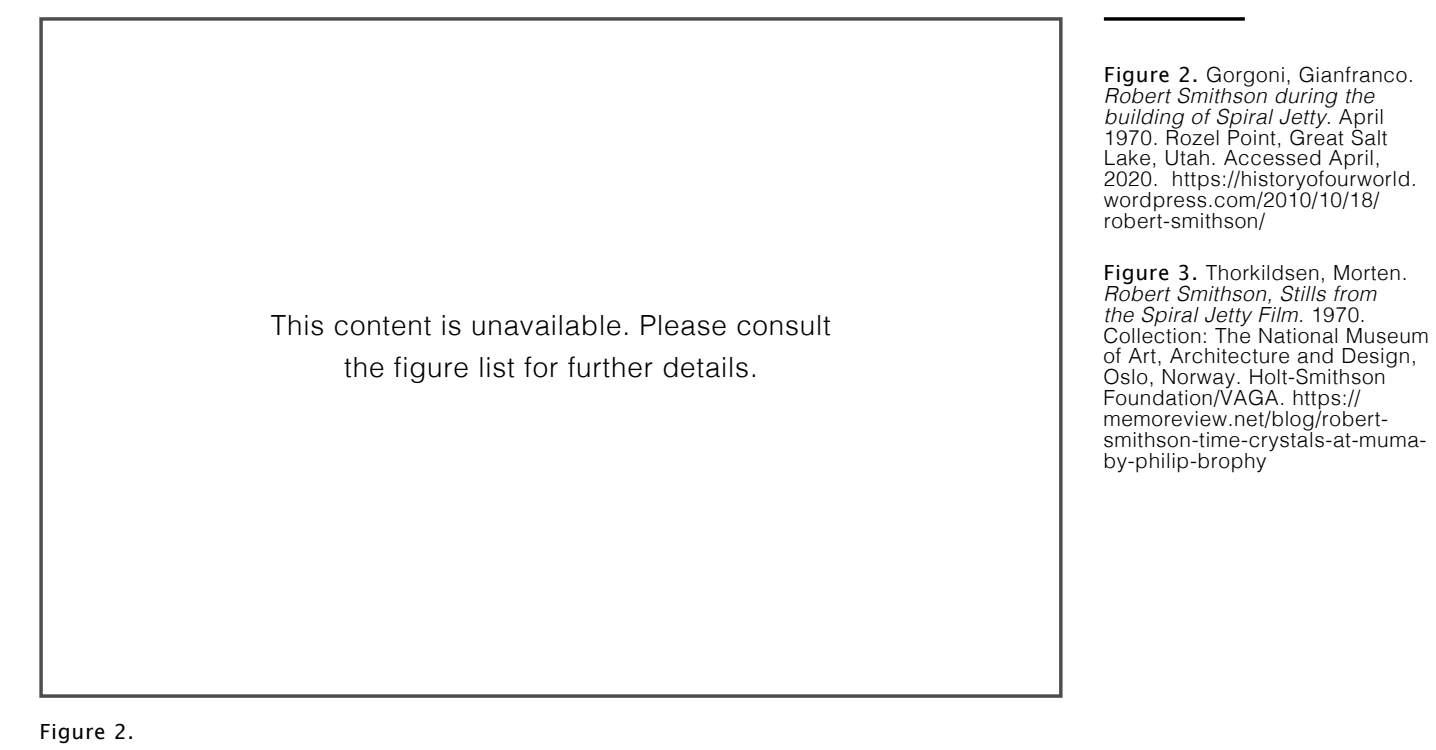

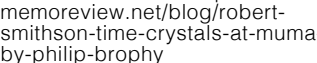

Figure 2

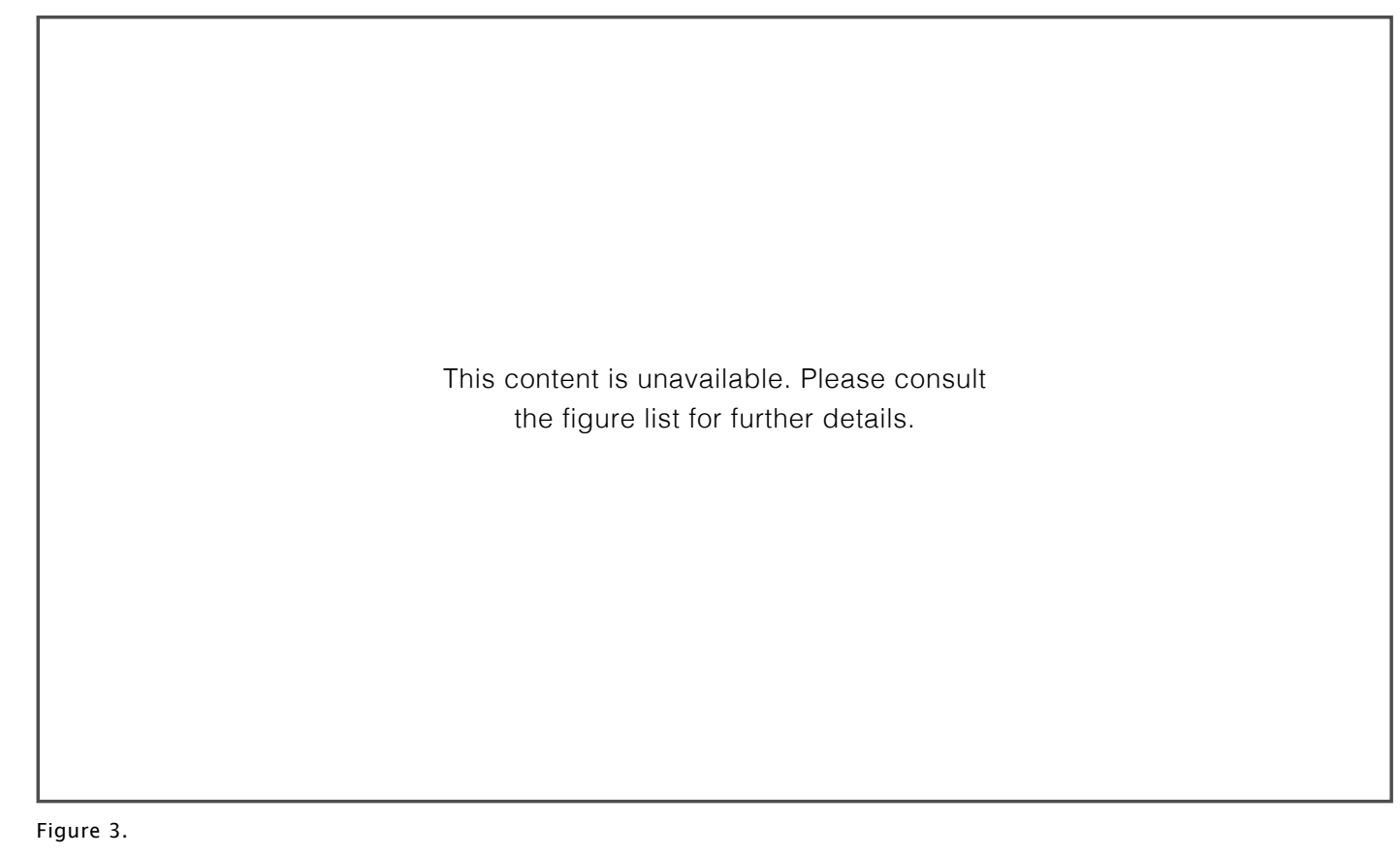

Chistopher Tilley, "Place, paths and

(

1994. 31

\section{REFLECTION ON LITERATURE REVIEW}

By engaging with new materialist thinking alongside the science of sea-level rise,

this research is given grounds to consider all forms of life in the design of adaptive responses systems. This contextual

literature review thus establishes

thinking and vocabulary not towards the stabilisation of rapid change solely for

humans, but towards the celebration of landscape processes themselves. The evaluative review opened a field of thought to work alongside the materiality of the tidal margin and its phenological processes orientating design practice in response to an uncertain future and shifting tidal edge. What can be called on-solutionist design thinking is mobilised through this approach.

The reimagining of a public (human and non-human) coastal realm is used to

catalyse enchantment within those moving around the tidal edge, enhancing their attunement to the biosphere and the beauty of all life within it. Here I discover how material studies can be medium to acilitate co-exist provide both habitat and a subst the much-needed landward migration the potential for encounter through shared proximity within the landscape is enabled. Drawing from Smithson, I also embrace processes of engineered decay within the design inquiry. What brings this approach together is the employment of affective methodology through design led research to further explore and expand on these concepts thought the process of design itself. 


\section{Glossary}

To work beyond prevailing discourse and innovate an approach to Sea Level Rise new language needs to be used as a way of speaking to this change. This glossary expands on the definition of terms used within the literature review.

Abiotic: abiotic conditions indicate heavily altered physical and spatial (non-living) components of an environment that affect the lives of organisms within that ecosystem.

Affect: to have an effect on something Affect is the innate pre-personal reaction to stimuli intensity, it exists separate and prior to conscious thought.

Affective method: as described by Mehrabi records "affective encounters and bodily responses as a crucial part of knowledge production; one that can formulate new questions, research agendas, and modes of data collection and analyses." See Mehrabi. "Affective Methodology" New Materialism: how matter comes to matter, (January 2018)

Agency: a core term in new materialist theory, though without singular meaning In its simplest form, agency refers to the notion of a living entity have the ability to freely and independently make their own choices. Most commonly in this text it refers to the abilities of non-humans to shape the world around them.

Anthropocene: term coined by Paul Crutzen to reference the latest geological epoch in which humans have significantly impacted the earth's geology and ecosystems

Biotic: biotic factors are living things within an ecosystem, that affect the lives of other organisms by altering or shaping the ecosystem.

Co-creation: input from users helps to design the product or place that they use - Symbiosis names prolonged associations between two or more dissimilar biological organisms that may or may not be mutually beneficial.

Coexistence: living entities existing at the same time, in the same place.

Natural ecology: Community of living an non-living organisms. Distinctive processe connect the components together into a complex ecological web.

Novel ecosystems: this term is used to distinguish the degree of impact that human alteration has had on an ecosystem. Novel ecosystems have been heavily altered by humans (with abiotic and biotic characteristics) to the extent where its natural systems (pre human) have been disrupted by climate change systems and other human induced issues (introduction of invasive species, altered nitrogen levels, the ability of the environment to sustain itself etc) and thus have the ability to 'manifest novel qualities without human management'

\section{New materialism: References a turn} away from dualisms in cultural theory, this movement shares an agenda with posthumanism by recognising both humans and nonhumans as 'actants' Non-solutionism: seeks to design with change, rather than working against the perceived problem

Open systems thinking: a system that connects to the infinite continuum of the world

Phenology: the study of cyclical seasonal patterns and natural phenomena

Phenomena: Plural of phenomenon: a fact, occurrence, or circumstance observed or observable.

Socialecology: A term developed by Murray Bookchin, argues that 'ecological problems arise from deep seated socia problems' in particular around hierarchy.
Spatiotemporalites: temporal existence in both space and time.

Sympoiesis - is defined by Donna Haraway as a collectively producing system, a "making with" in opposition to Autopoietic (self-organising) system.

Synanthropic species: defined by Sarah Gunawan as "animals who benefit from. Living in close proximity to humans yet, remain beyond their control"

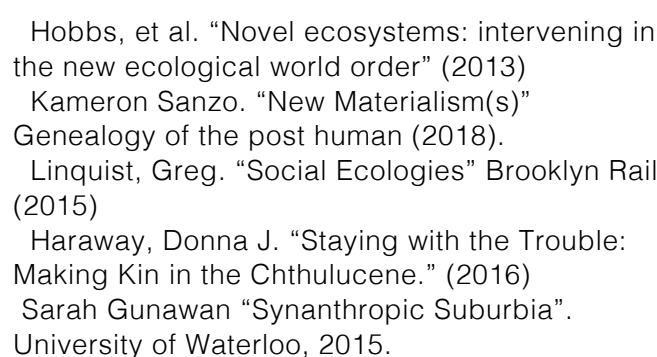
the new ecological world order" (2013) Genealogy of the post human (2018). Linquist, Greg. "Social Ecologies" Brooklyn Rail (2015) Haraway, Donna J. "Staying with the Trouble: Making Kin in the Chthulucene." (2016) University of Waterloo, 2015 


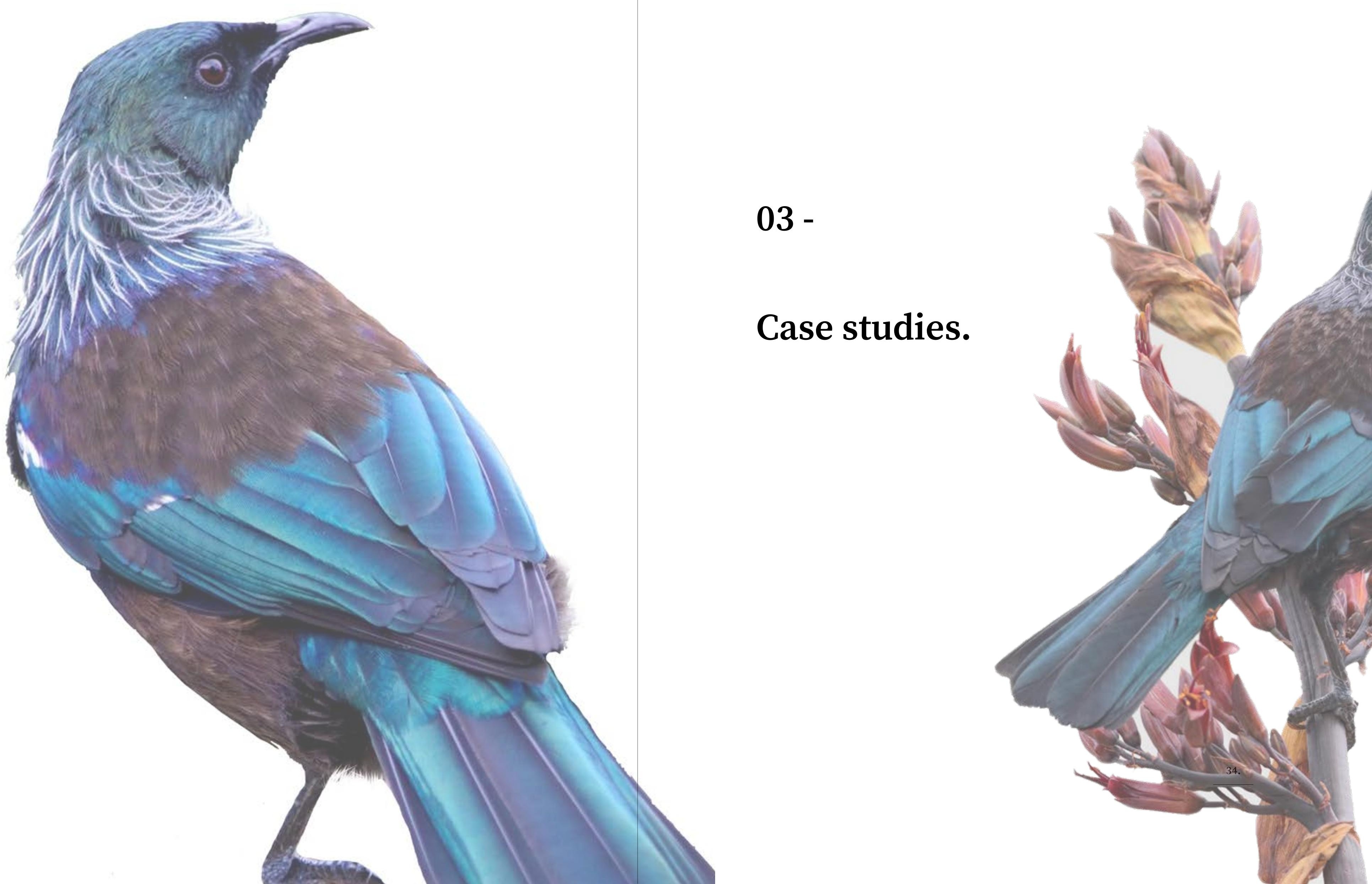




\section{Case studies: Coastal Pathways}

\section{INTRODUCTION}

This chapter investigates designs and approaches that address the tendencies within landscape architecture. By looking at examples of existing work, principles are drawn upon for design testing.

Two different areas are examined. The first considers the design of coastal pathways, both in New Zealand and abroad. Here I discover how pathways in the tidal realm are approached and extrapolate principles which might aid this research intent of designing a shared pathway. These studies are primarily assessed on their experientia qualities, i.e., how movement is propelled or slowed down by physical features in the landscape. Thus, I observe how existing topographical features, materials and view shafts are used to leverage different user affects, and alter peoples experience of the pathway as they move around the water's edge.

The second, looks at design that generates modes of encounter between different life forms, creatively, playfully and safely. Here I am discovering how to begin breaking down the perceived barriers between humans and non-humans and toward in which coexistence can generate meaningful interactions.

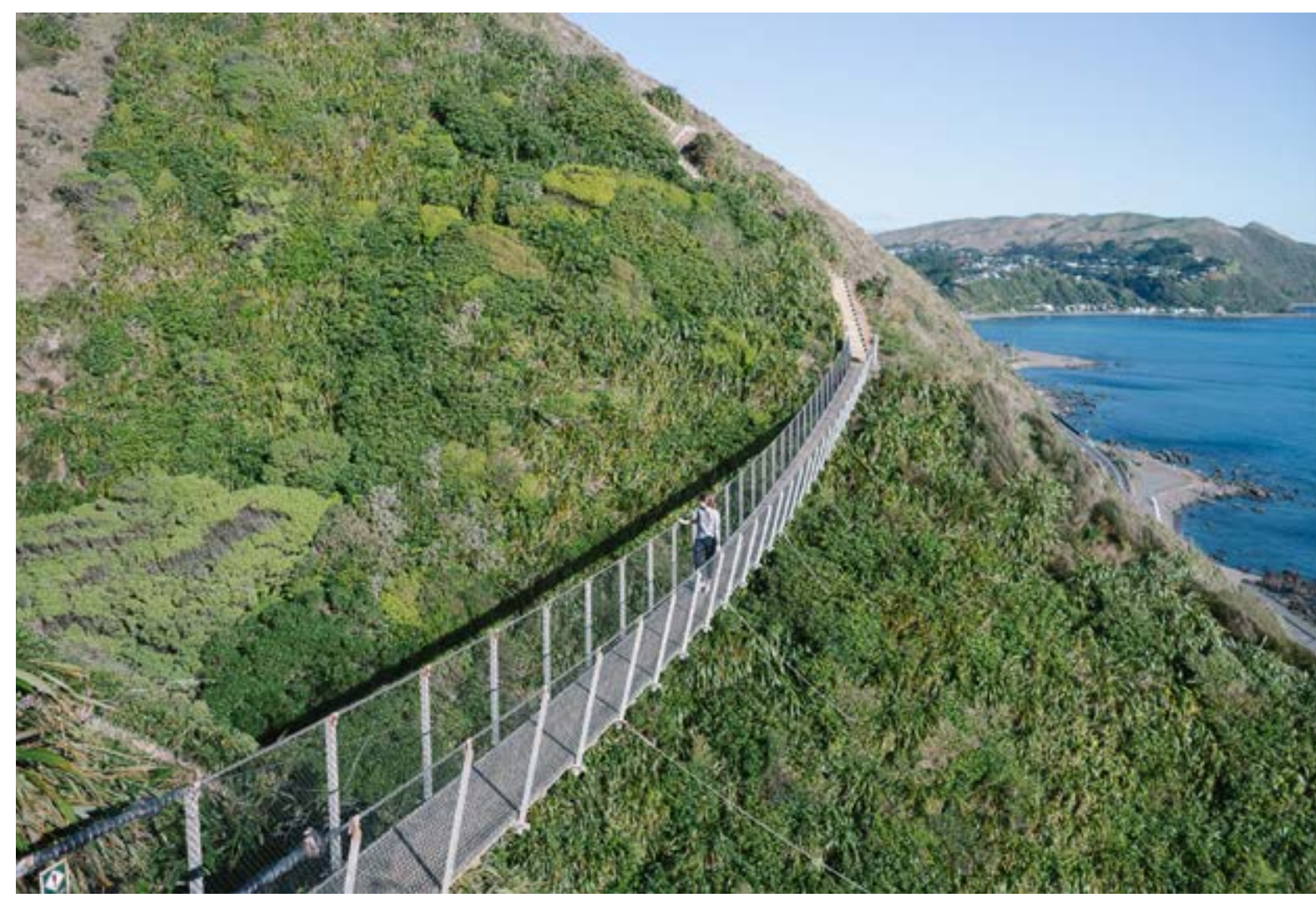

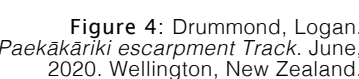




\section{CASE STUDY: PUNTA PITE TERESA MOLLER}

\section{OVERVIEW:}

Teresa Moller approaches landscape design with empathy and care. She works intuitively and spends many hours immersed in site conditions before a design starts to emerge. The project at Punta Pite, in Chile, was not designed via the convention of plan, but instead its form emerged on site. Moller uses rebar and string to visualise its spatial dimensions in situ.

The designed pathway is minimal and constructed out of the same stone

that surrounds it. We can consider it constructed like jigsaw pieces that fit neatly into their surroundings. There is beauty and poetry in the simplicity of the design. There are no superfluous elements and no one linear route. Instead the steps and pathways only provide access over previously inaccessible areas, otherwise

people are allowed to make their own route across the rocky shoreline. This approach to the ground condition invites people to engage directly with the qualities of the landscape and the elemental conditions of the site.

\section{KEY LEARNINGS}

There is beauty within any existing landscape and it is the job of the designer to draw these qualities out and make them obvious to those who move through the spaces we create. This relation disrupts habit by provoking attentiveness to the site.

Careful observation and time spent with the site is key to thoughtful design approaches.

Site specific designs cannot be replicated, though there are aspects that we can learn from them and apply elsewhere.

By omitting superfluous design elements and engaging directly with the sites material qualities, Moller's design allows people to get immersed within the environment and the embodied experience of moving thorough the wild landscape is heightened.
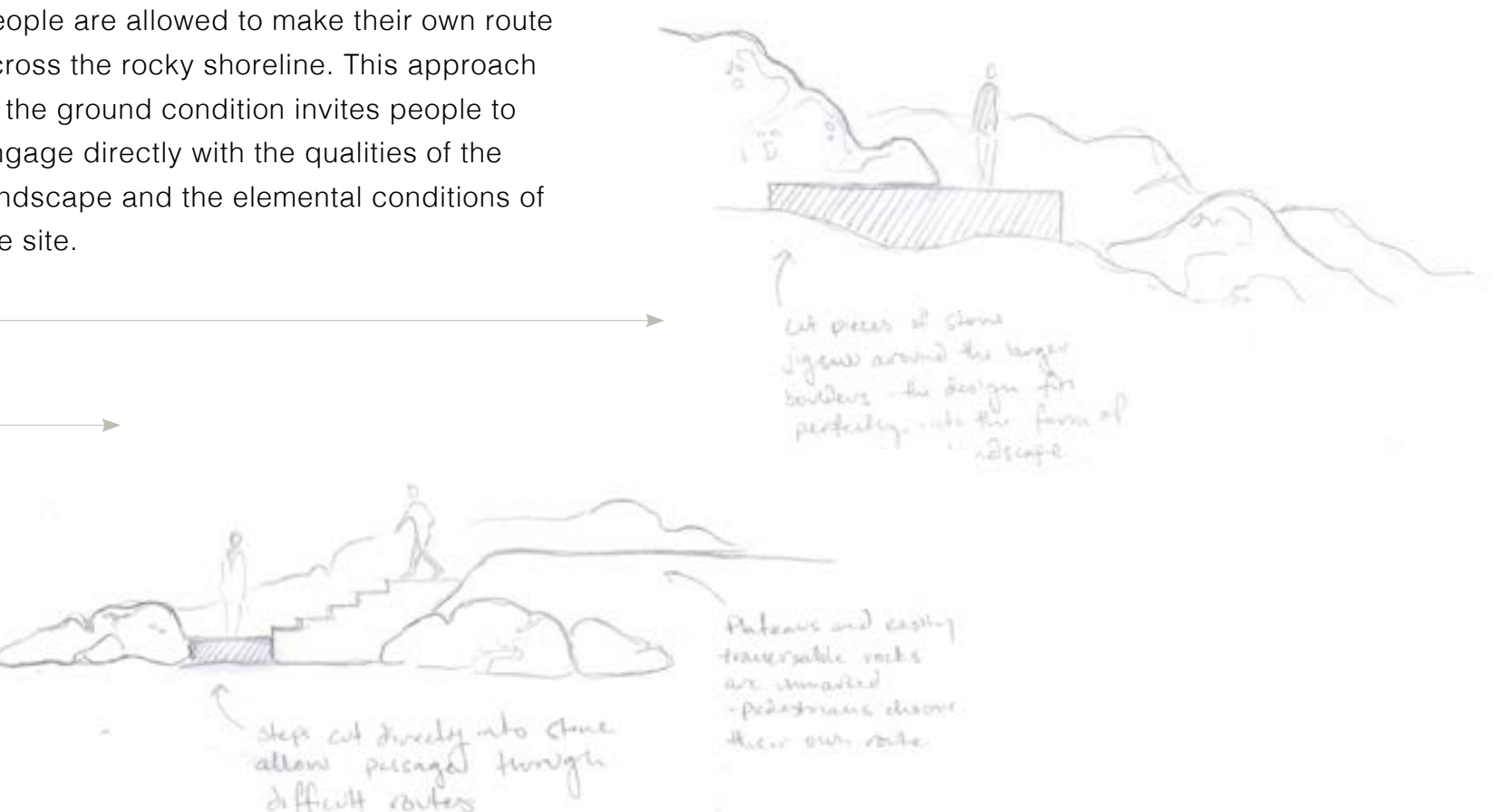

CASE STUDIES

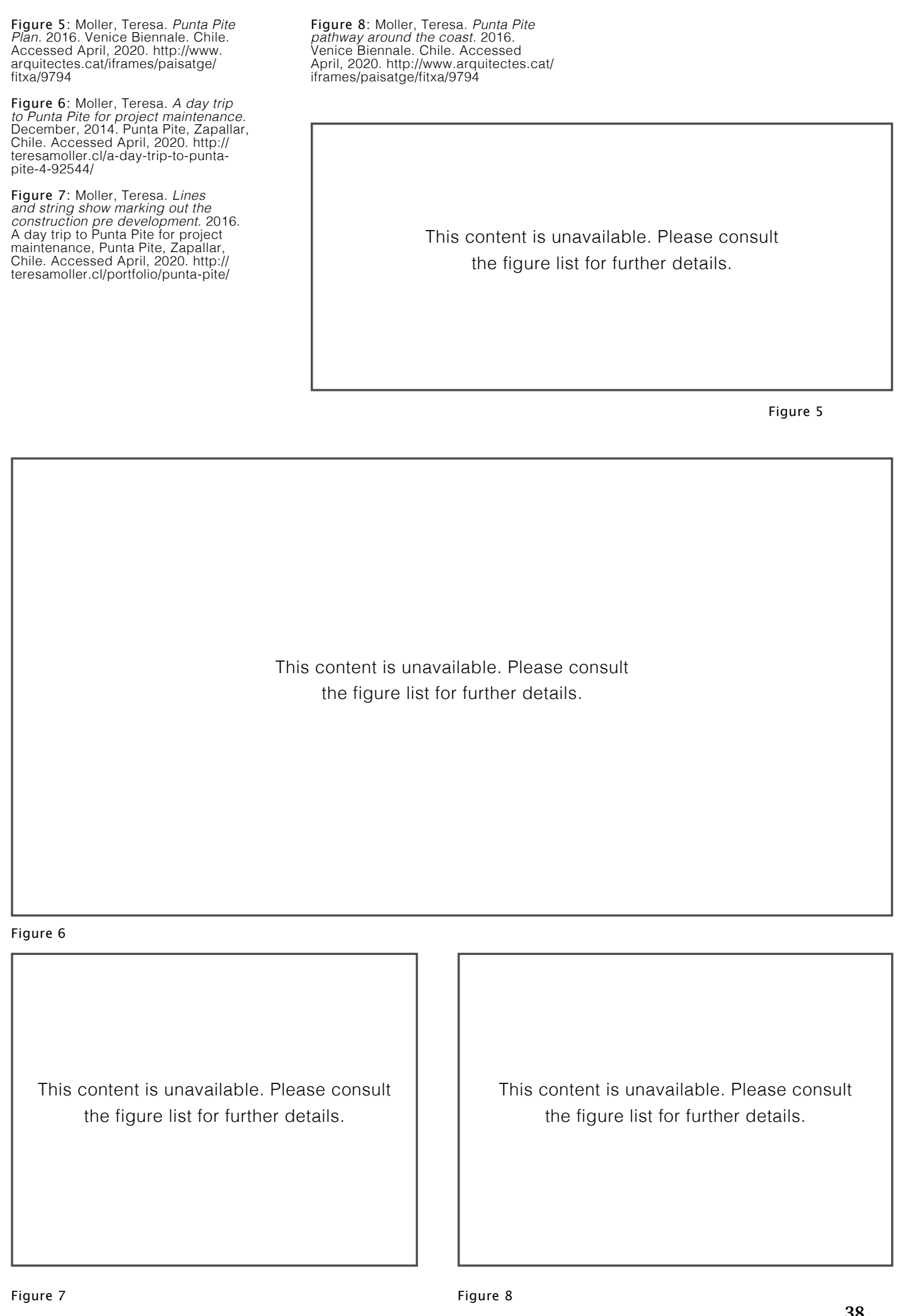




\section{CASE STUDY: ORIENTAL BAY - \\ ISTHMUS.}

\section{OVERVIEW:}

This public space waterfront project strikes a successful balance between the technical and aesthetic. Hardscape structures jut out into the harbour create wave breaks, act as groins. This creates space for beaches to take form on the

leeward side without being washed away. The design thus works with the sediment deposition of the area.

The simple custom concrete outcrops create different layers of engagement at the water edge, allowing people to sit or swim near deeper waters. They act as points of interest or recreational 'event' spaces, with multiple objectives and

heights. Breaking up the linearity of the

walkway, they draw people in and provide

spaces to rest and play.

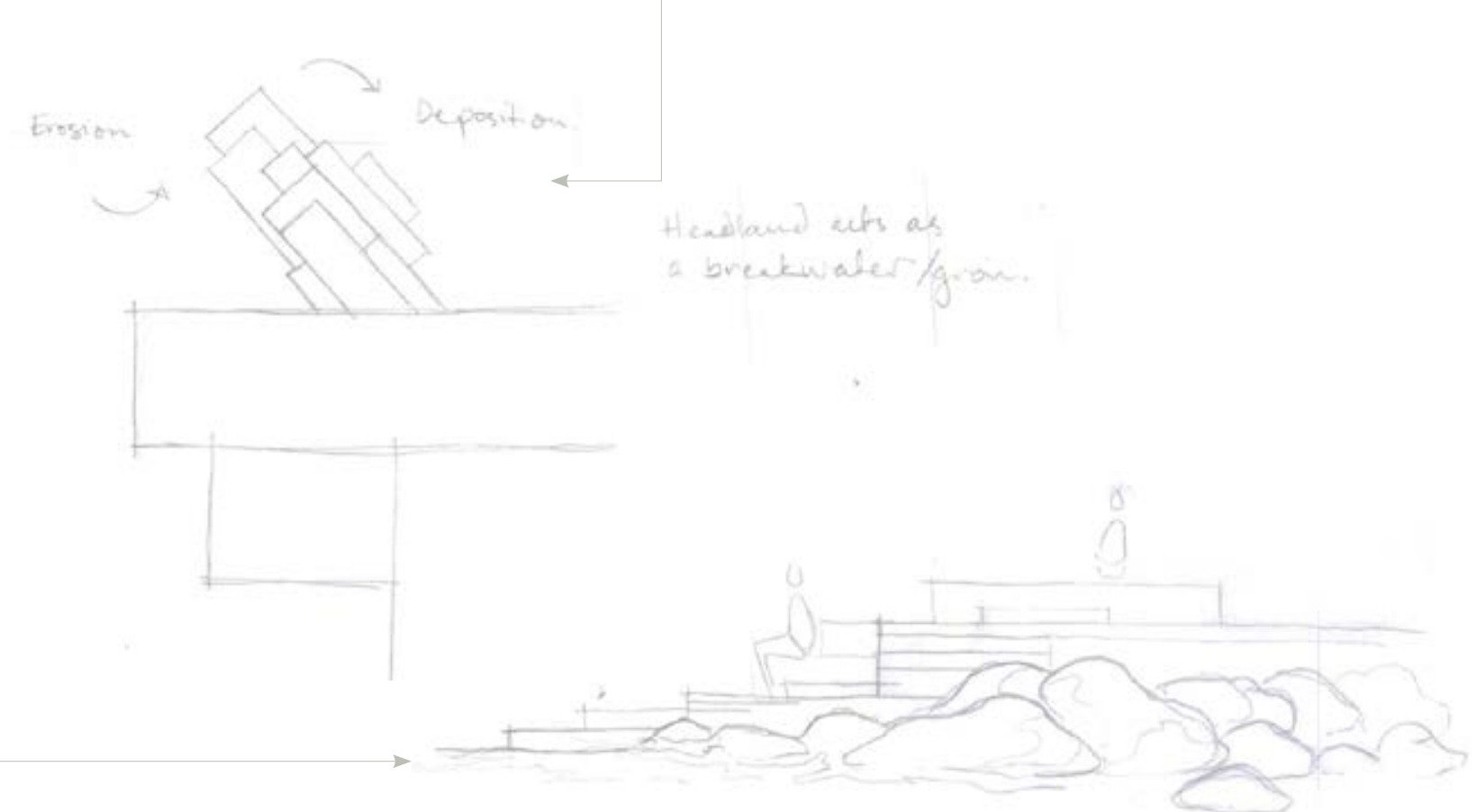

\section{KEY LEARNINGS:}

Generic engineered techniques and standard materials can be aesthetically pleasing and spatially dynamic if properly synthesised into the design rather than implemented for pure function.

A successful coastal edge design allows people to access the water in multiple immersive experiences, and perspectives and relationality.

The incorporation of 'event' spaces such as jetties and lookouts provide a range of different forms of interaction with the waters edge and create a more interesting/ dynamic water's edge. different ways affording them different

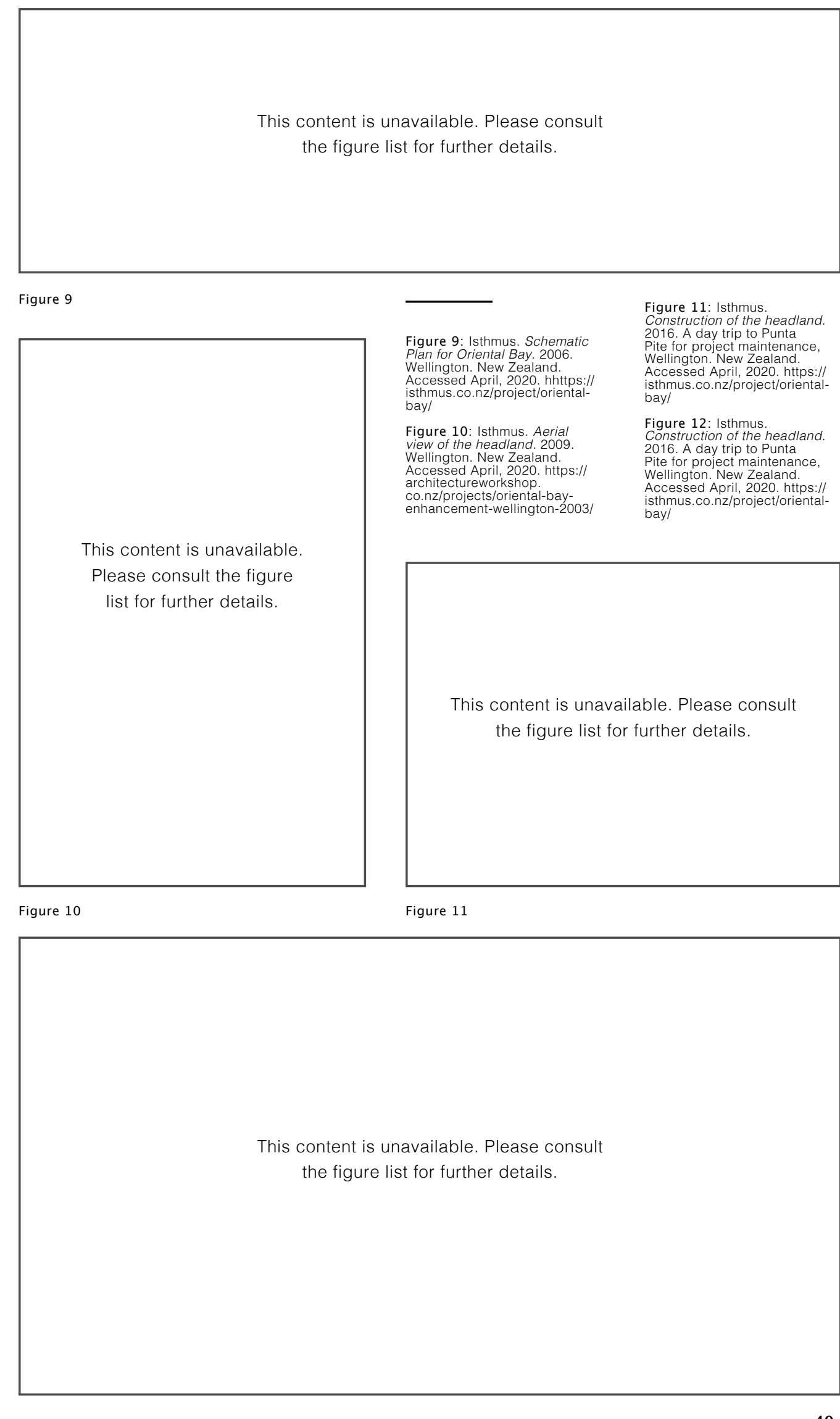

Figure 12 
CASE STUDY: ESCARPMENT TRACK PAEKAKARIKI.

\section{OVERVIEW:}

The escarpment track is a narrow pathway pathway along a the side of a very steep hill. It provides beautiful views along the coastline between Pukerua Bay and Paekakariki.

Positioning the walkway high above the motorway below creates a feeling of safety or 'extensive differentiation.' You are removed from the loud noises and chaos below, and thus the walkway allows the user to experience the beauty of the area without being exposed to the traffic below.

The pathway is largely through reclaimed farmland and thus is open and exposed to the elements. However there are pockets of dense kohekohe forest which provide protection and visual interest, breaking up the route and providing shelter as well as important habitat for wild life

The pathway includes the construction of a lizard habitat area, developed in conjunction with local schools and community this space is informative and playful, allowing the residents to interac with and support wildlife in their area.

\section{KEY LEARNINGS:}

By elevating the pathway away from the sea edge you can create dynamic views across the water. It also affords a seaside acted by changing and dynamic tides.

The experience of moving through a landscape is significantly more enjoyable if it feels as though you are being immersed mity to a motorway and the corresponding noise, speed and danger that comes with it reduces that feeling and makes the user feel uneasy.

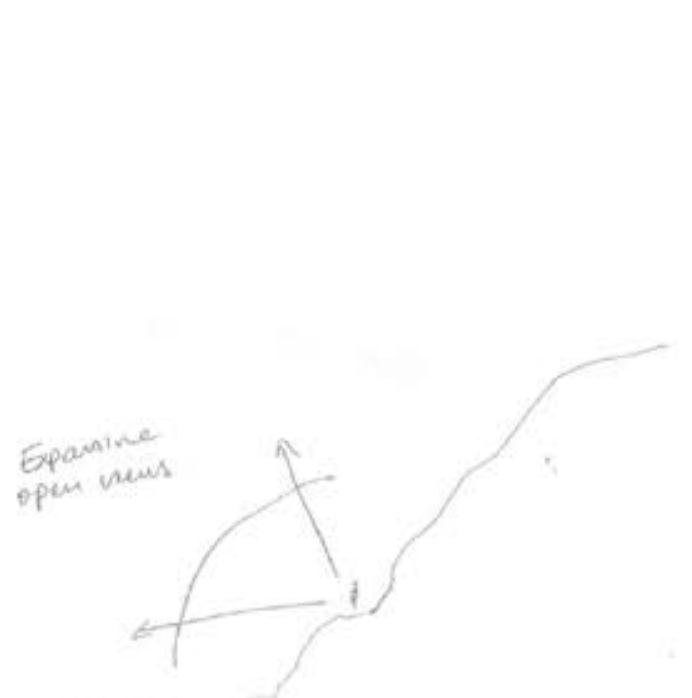

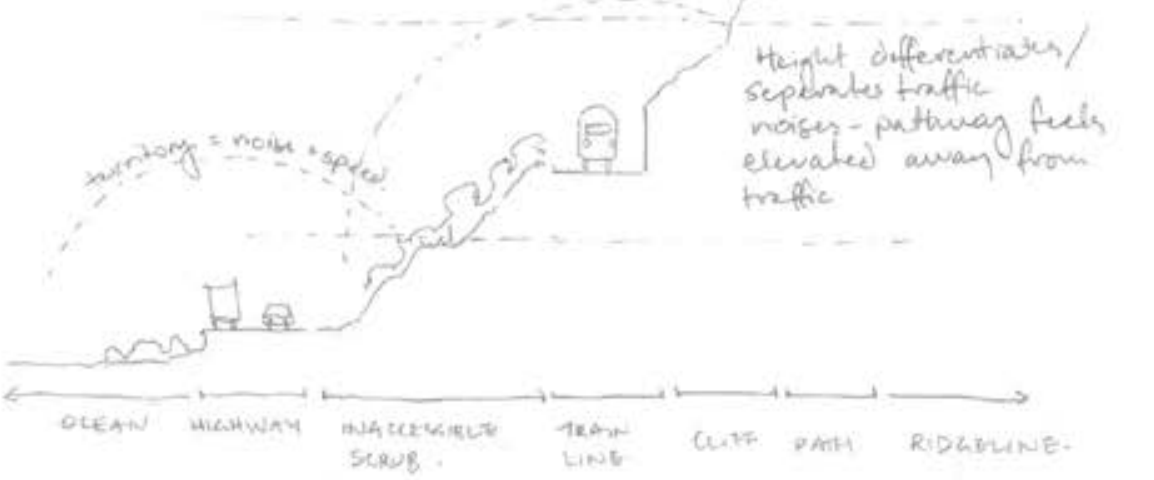
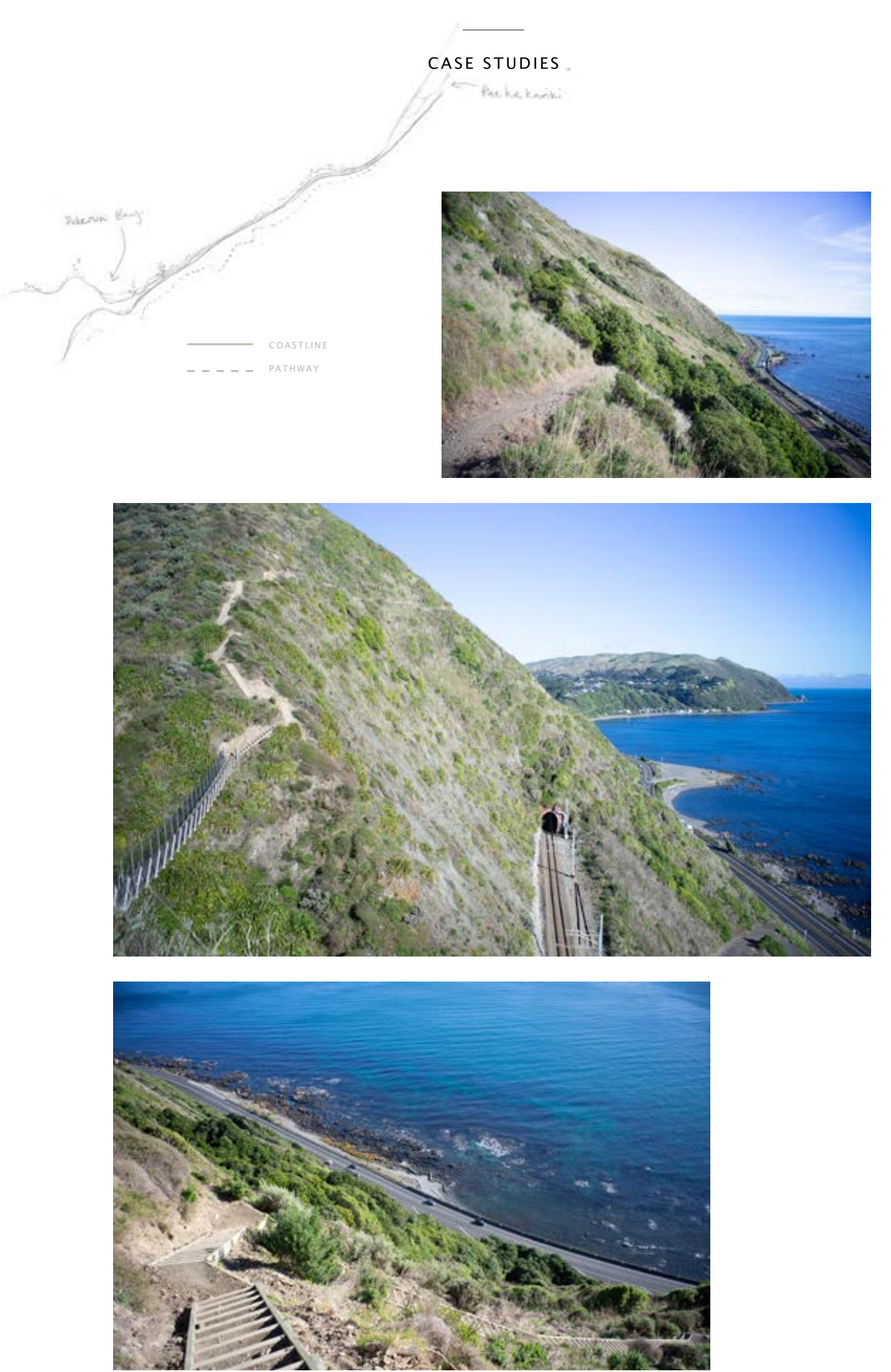


\section{CASE STUDY: HOBSONVILLE'S DISCOVERY TRAIL. HOMES FOR CREATURES \\ - HABITAT MARKERS}

\section{OVERVIEW:}

Located along hobsonville penninsula in Auckland, this design seeks to connect the community to the local ecology of the area in a playful and interactive way. Designed 'interruptions' along a linear pathway

create playful moments for children to

explore and encounter nature unique to that area. As part of this design 'habitat markers' have been installed - wooden posts with holes and hollows carved out of them for birds and insects to make their own homes in, in this way the markers become an evolving living sculpture.
KEY LEARNINGS:

The project uses kinaesthetic tactile engagement to get kids excited about the environment through play. This is form of hands-on learning is more likely to give children positive associations and is used as a tool to enchant.

Habitat markers placed around the landscape, entice people over and encourage them to observe and interac with the life they support, through this, the design strategy successfully facilitates interspecies encounter.
This content is unavailable. Please consult ther details.

Figure 13

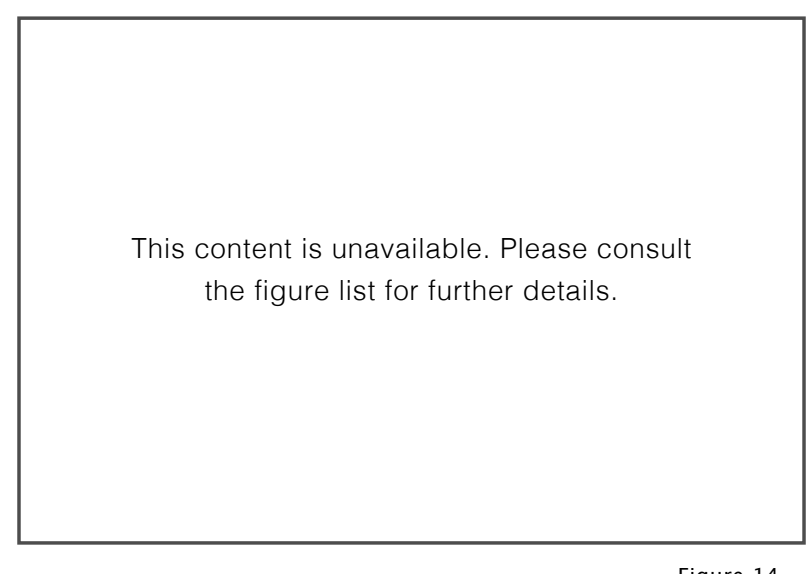

Figure 14

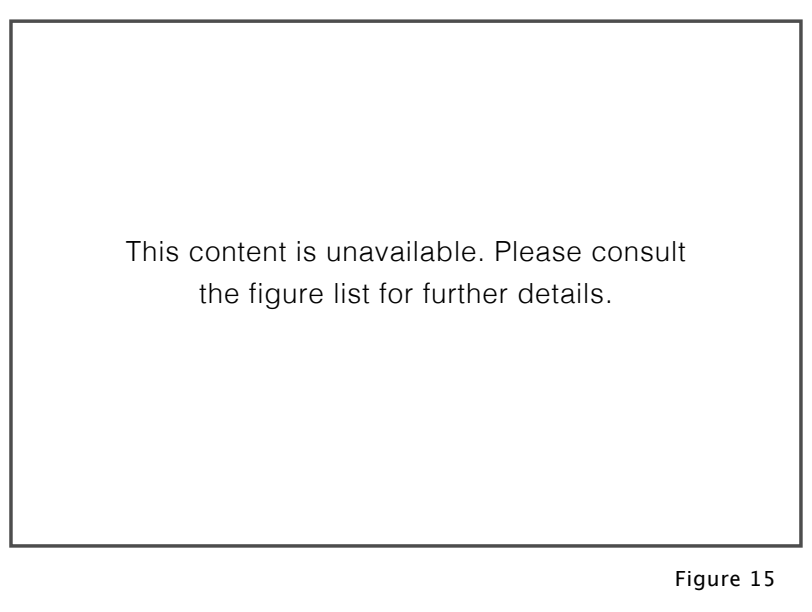

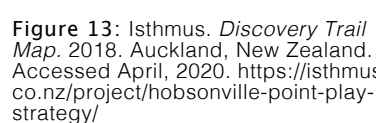

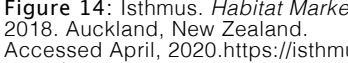

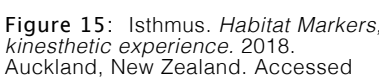

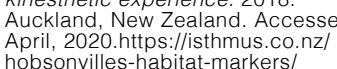




\section{CASE STUDY: TE WHAU PATHWAY, AUCKLAND}

\section{OVERVIEW:}

This design developed by Monk Mackenzie and Jasmax is still at concept stage, and yet its slick and stylish renders have captured people's attention, resulting in the design being shortlisted for several awards years before its construction. Focus is placed on aesthetic form and symbolism through the pattern embedded into the timber decking. Although aesthetically pleasing in conception, the design seems slightly restrictive in use. The narrow width does not allow much space for people to keep their distance from one another, coupled with its $12 \mathrm{~km}$ length and linearity of the single route, the design channels movement quickly; along without shelter, variation or multiple egress options (alternative routes).

\section{KEY LEARNINGS}

Strong focus on function (utility of movement) and form (aesthetics through symbolism) while seduced due to the homogeneity of geneity of the design.

Both the form and materiality of the pathway are homogenous offering very little variation in width or form across $12 \mathrm{~km}$.

The design leaves its users rather exposed, without alterative routes, distances or shelter, users may potentially feel unsafe or trapped without being able to deter away from the predetermined route.
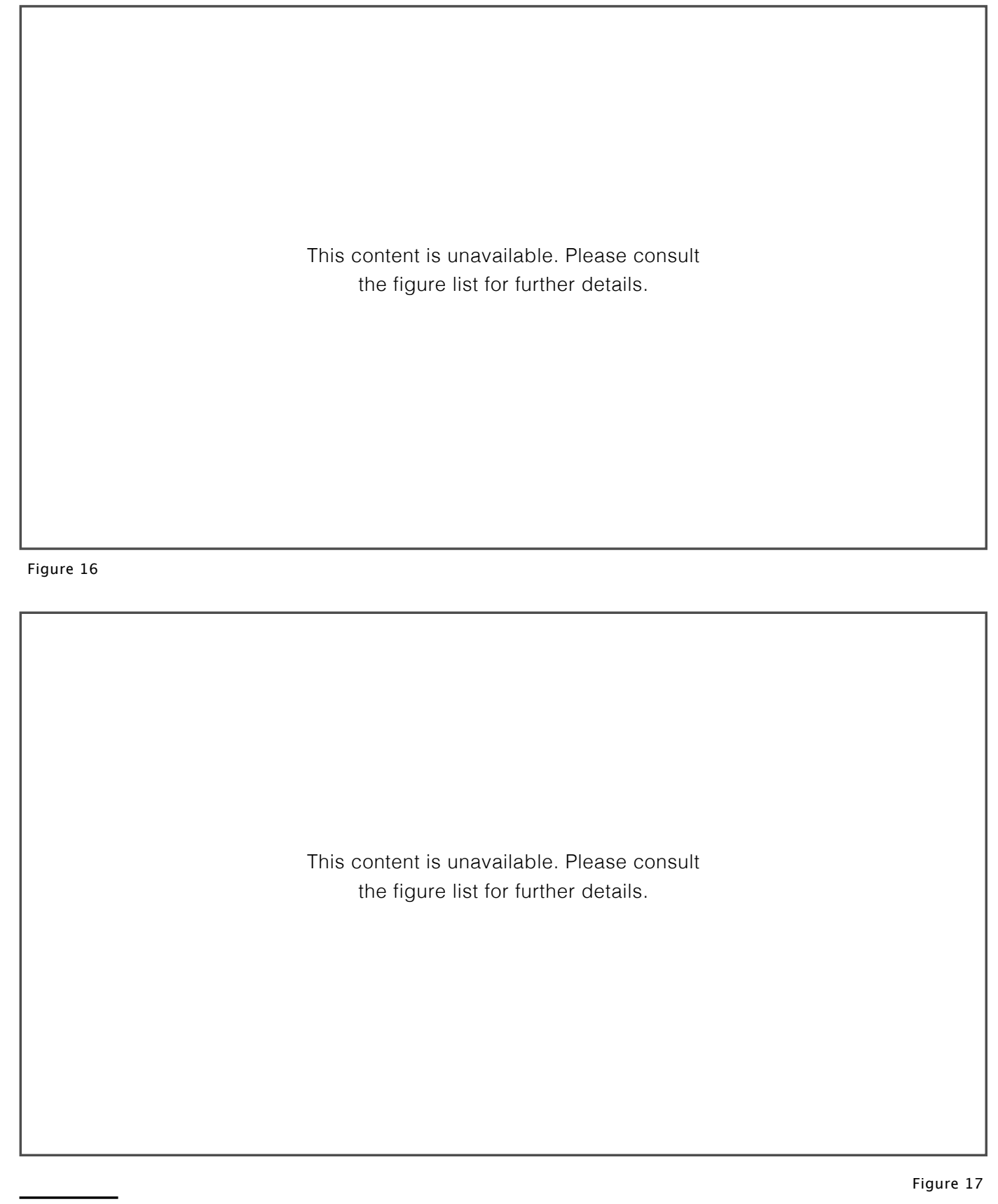


\section{Critical reflection:}

Although they all engage with very different landscapes, these case studies share similar principles that have supported $\mathrm{my}$ investigations into, yet beyond, the typological conditions of a coastal walkway. Focus is given to the experience of the users as they move through the space, each design takes the existing qualities that are unique about the site (topography, materiality, ecology) and heighten the experience of being within that terrain to eeling to create an immersive experience that allows people to connect emotionally o the site.

'Events' along the harbour create interest as you move along a route. They break up the journey. This could be a place of rest (seat/table/forest) outlook (peninsula/jetty) or a playful interactive space (habitat marker/bird hide/rock pools/park). These areas can create space where one can pause and appreciate the surroundings. This goes for both humans and wildlife.
It is within these moments of introspection/ reflection that the embodied feeling of exsiting in the landscape looks to be enhanced. It is within this moment that design opportunities for encounter can occur, decentreing the human and making space for all coastal life. 
04 -

Site investigation -

Pauathanaui Inlet.

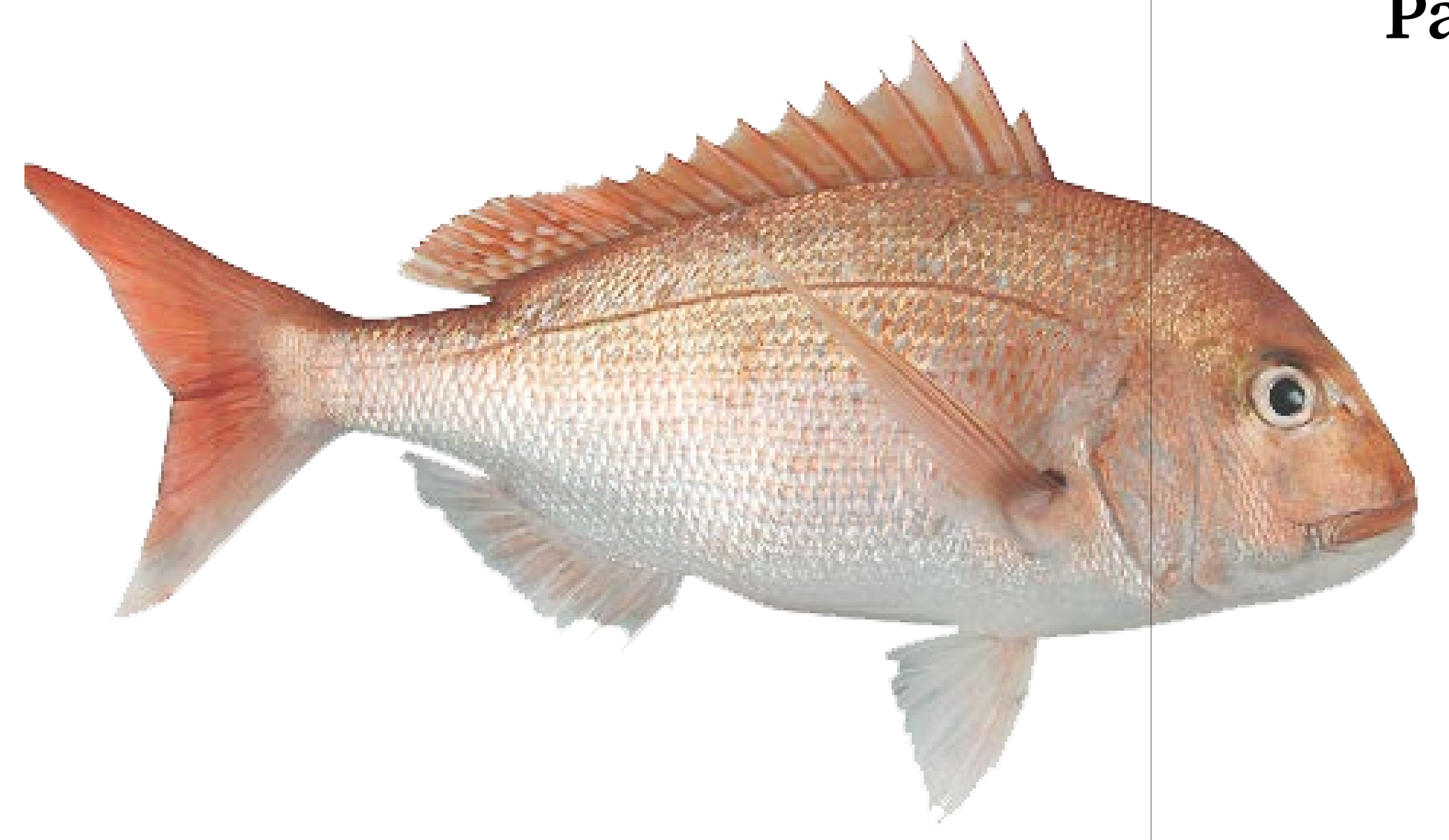


Site selection:

\section{Pauatahanui Inlet, Porirua.}

INTRODUCTION:

Te Awarua-o-Porirua Harbour is the largest estuarine ecosystem in the lower North

Island. The Harbour consists of two shallow

inlets which are connected to the ocean by

a single narrow channel. Pāuatahanui Inlet

is a nationally important site for migratory

shorebirds and wading species attracted

by the large, marine invertebrate-rich tidal

flats. Many of these species rely on the

vast intertidal mudflats to nest and feed.

The saltmarsh and seagrass meadows

are vital in supporting life within the inlet,

providing food, habitat and nesting sites

for wild life. Both ecological systems rely

on the shallow nature of the harbour and

stillness of the water column to thrive. 


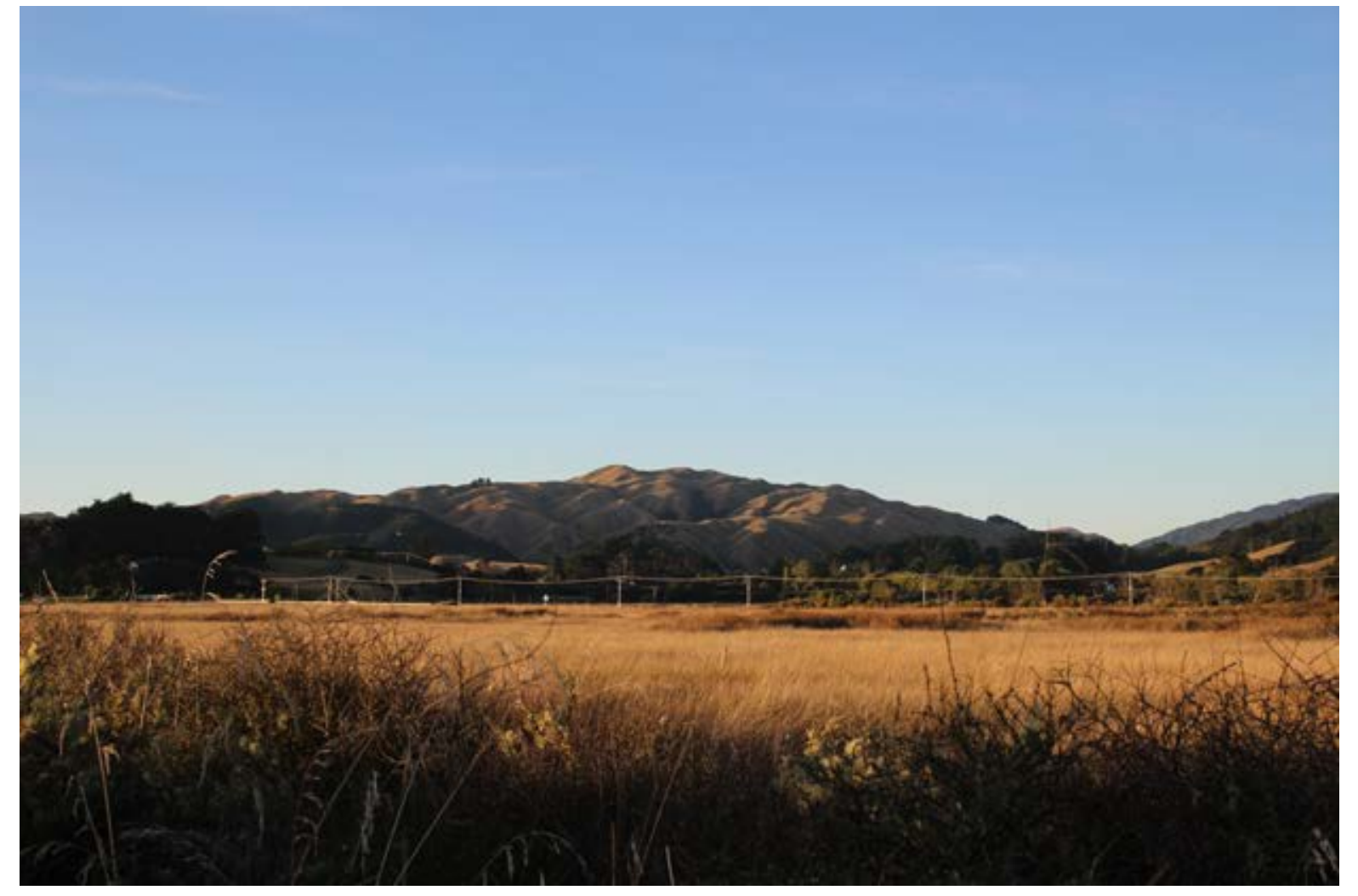

Pauatahanui inlet is arresting on arrival. It is an incredibly beautiful harbour enclosed by rolling hills. Despite its proximity to New Zealands capital, the inlet to feels rural and remote. The hills to the north are largely undeveloped pastureland and the historic township of Pauatahanui to the east is obscured from view by coastal forest. Carpets of amber oioi saltmarsh reeds fringe the coastline edge. Due to conservation efforts life within the inlet is flourishing, however future form of the coastal margin is uncertain as global climatic shifts begin to accelerate and demand for housing across the country increases.
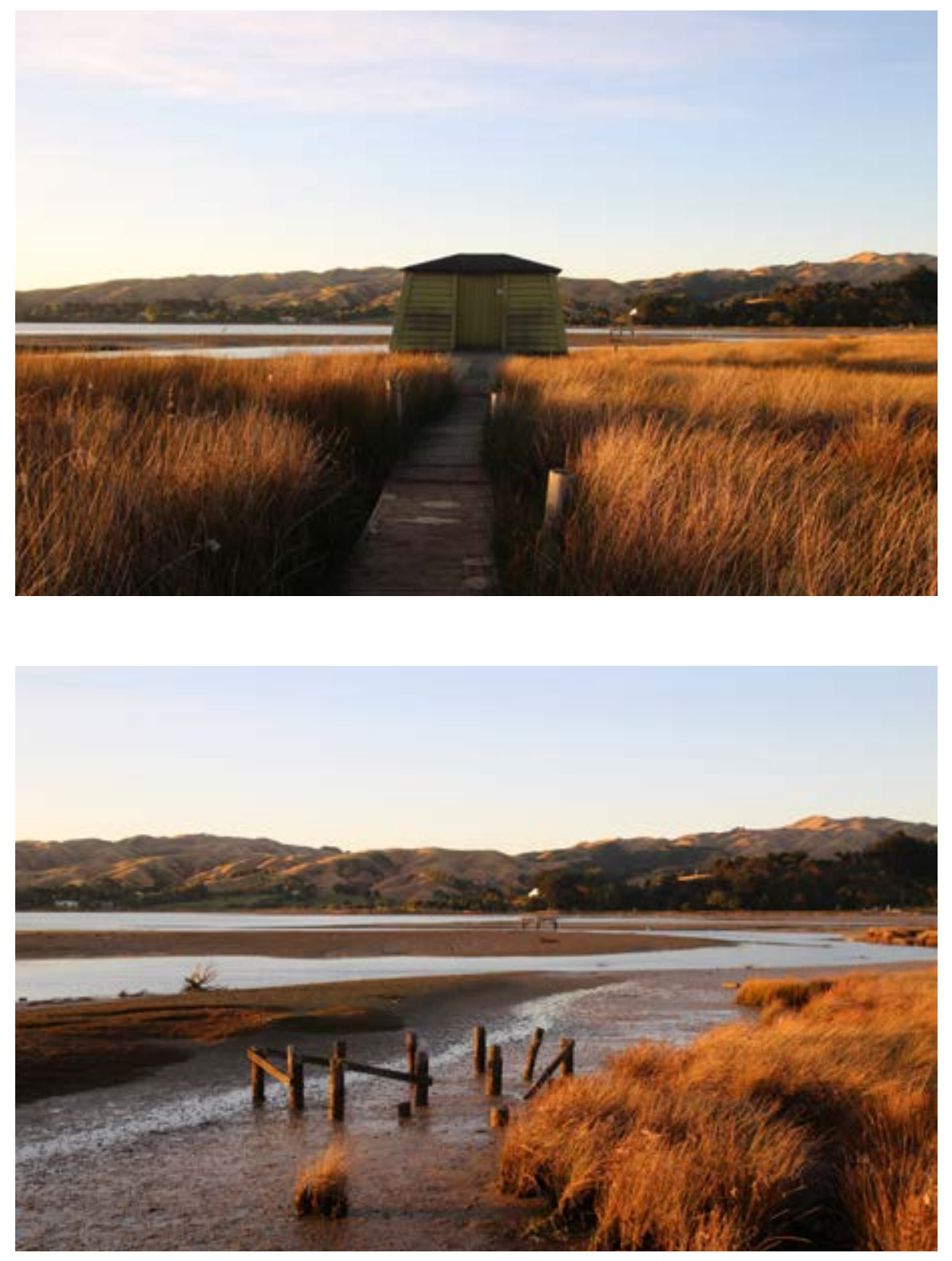

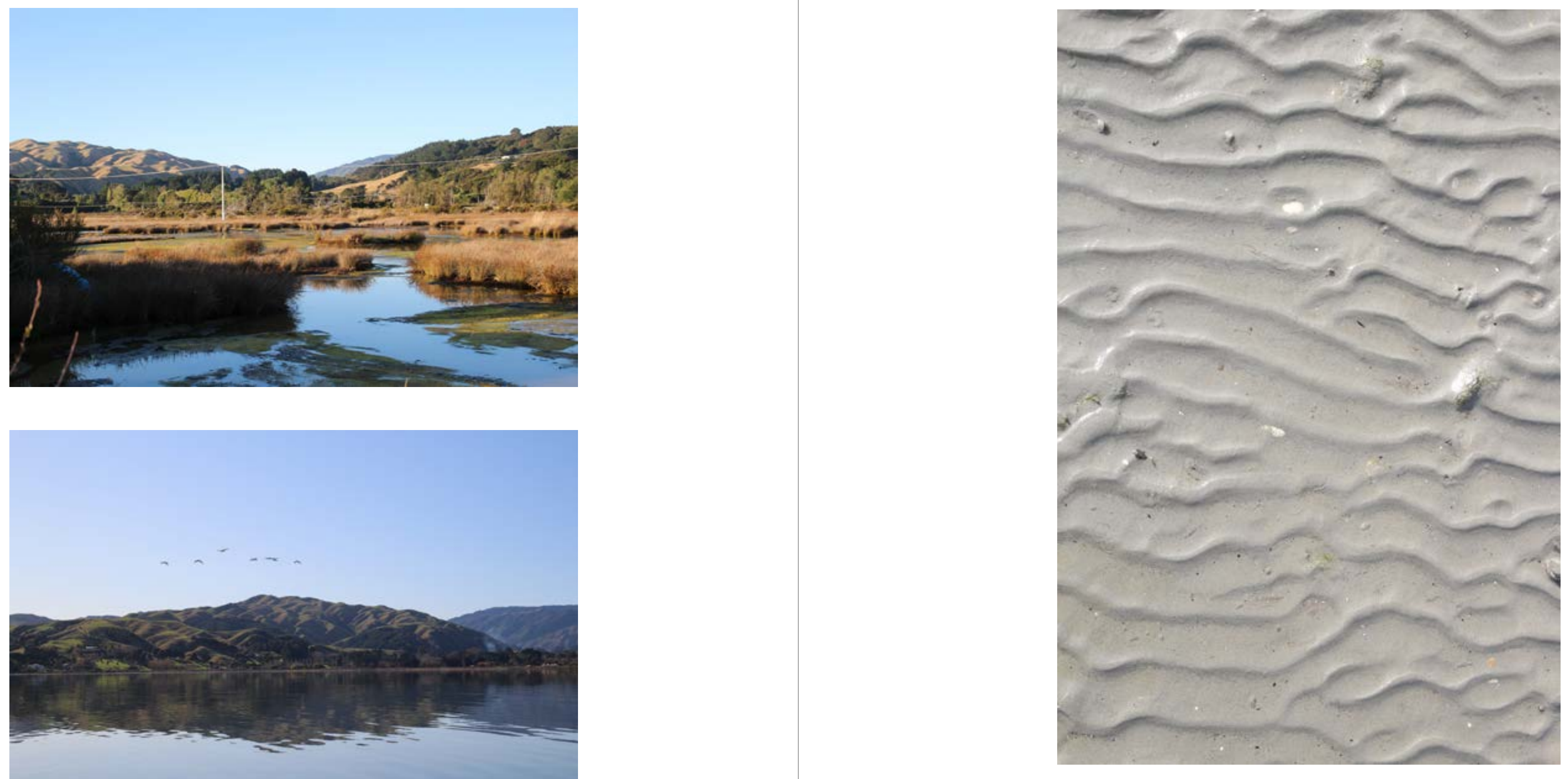

Fine scale landscape movement fine sedimentray patterns shifted

by tidal movement 


\section{An uncertain edge.}

\section{SEDIMENTATION}

By geological standards, Pauatahanui is characterised as an estuary in decline (nearing old age). As with all natural geological systems (and living things), estuaries have a natural life cycle. As they age they fill with sediment, developing intertidal flats slowly become more extensive as sediments accumulate. The length of time attributed to this process varies. Depending on the size of the catchments land area, the mouth of the inlet and the rate of sedimentation entering the harbour, the aging process can accelerate or slow down.

For Pauatahanui, this process has significantly accelerated since the arrival of humans in the area. The surrounding hills were deforested by fire when Maori first settled in the inlet and have continued to be farmed in pasture to this day This, along with urban earthworks on the southern hills, has caused the amount of sediment Projections estima loads entering the harbour continue at their current rate, that the inlet will be completely filled in as little as 145-195 years time

\section{VS. Sea level Rise}

At the same time, the impact of sea level rise poses a significant threat to the

ecological fabric of the inlet. Storm surge and flooding are expected to exacerbate areas already vulnerable to coastal

erosion. In around 100 years, the mean

tideline is expected to have increased by a metre, even as seemingly small a change

as this potentially could permanently

inundate low lying coastal areas with

floodwaters.

These two conflicting predictions allude to a dynamic and unstable coastline in the near future. If unsustainable human farming and urban development schemes continue to offload sediment into the harbour at their current rate, the most likely scenario is that the harbour will be filled, and intertidal wildlife habitat destroyed in the next two hundred years- a blip in the life of the inlet. However the future is difficult to predict, especially with global climatic shifts rapidly increasing. This research situates itself within this shifting and dynamic edge: between siltation and sea level rise. Attempting to create publicly accessible coastal edge that can weather any future outcome. This process begins by first understanding the complex network of relations and territories overlapping and intersecting within the inlet.
SEDIMENTATION

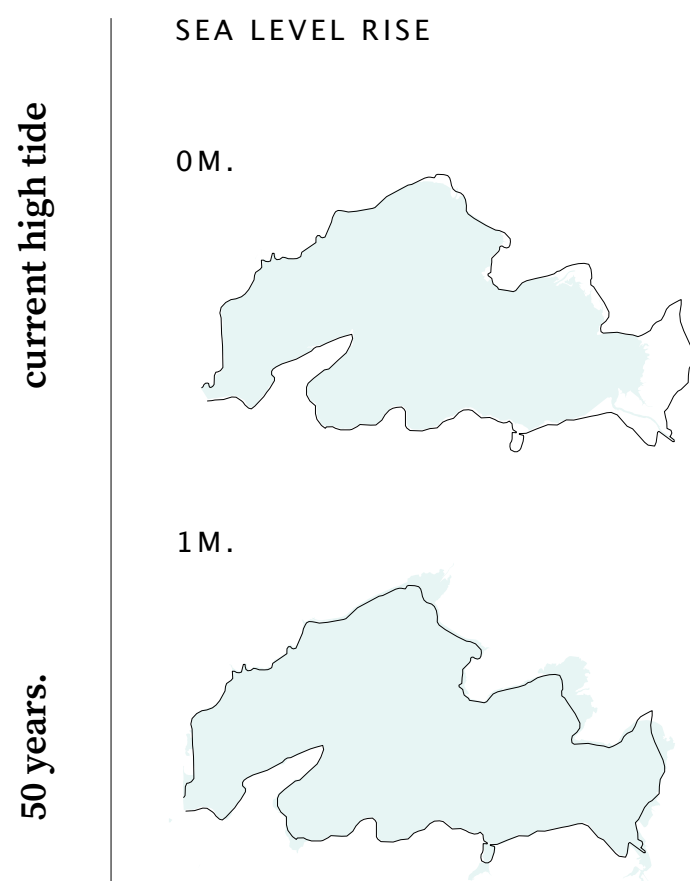

$3 \mathrm{M}$.
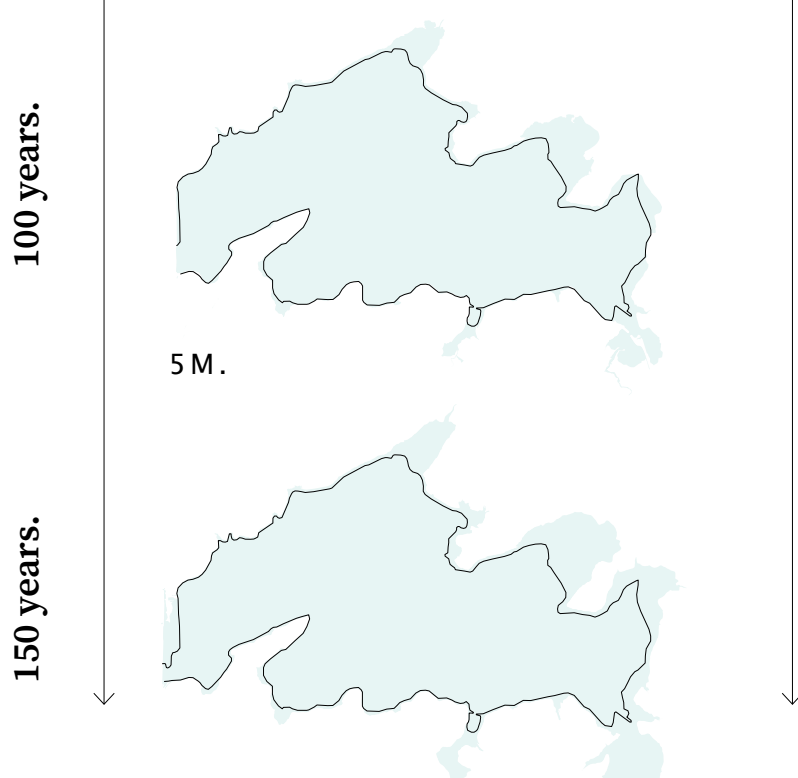
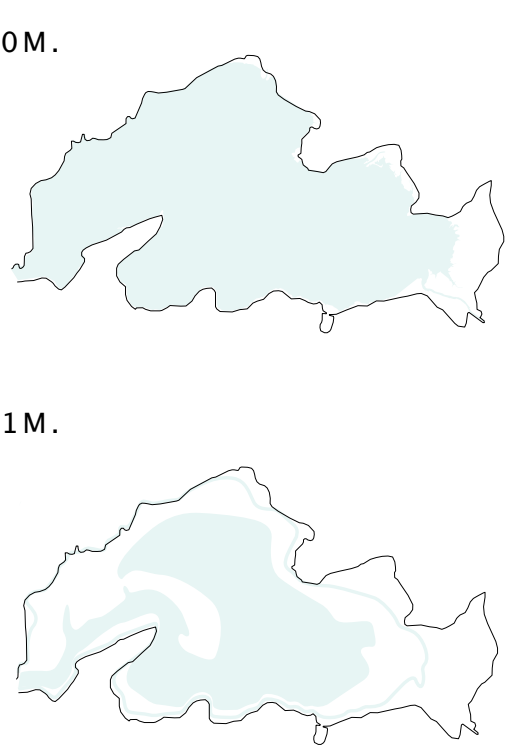

$2 \mathrm{M}$

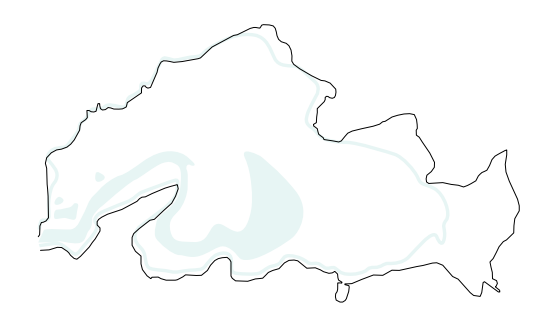

$3 \mathrm{M}$

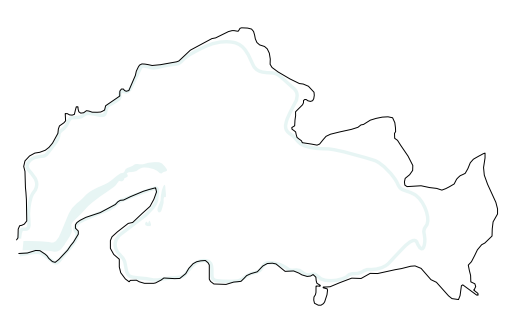




\section{Designing with fluidity.}

The complexity of the the landscape and

these two opposing preditctions render

traditional landscape design responses of

remediate and mitigate difficult.

The uncertainty of the future of this coasta

edge puts design responses into question

- how do you fix something when you cant predict what the problem is?

It is this question that mobilises this design

investigation. Instead of attempting to

predict, a study is developed that can

adapt to a changing tideline and still

acilitate movement.

This chapter investigates the qualities

of Pauatahanui's shifting form through

time, in order to better understand the

significance of its uncertain future, we

must first understand the the forces

that have shaped the landscape:

historical, geological, climactic and built

infrastructure. This undertaken both

through literature and extensive fieldwork.

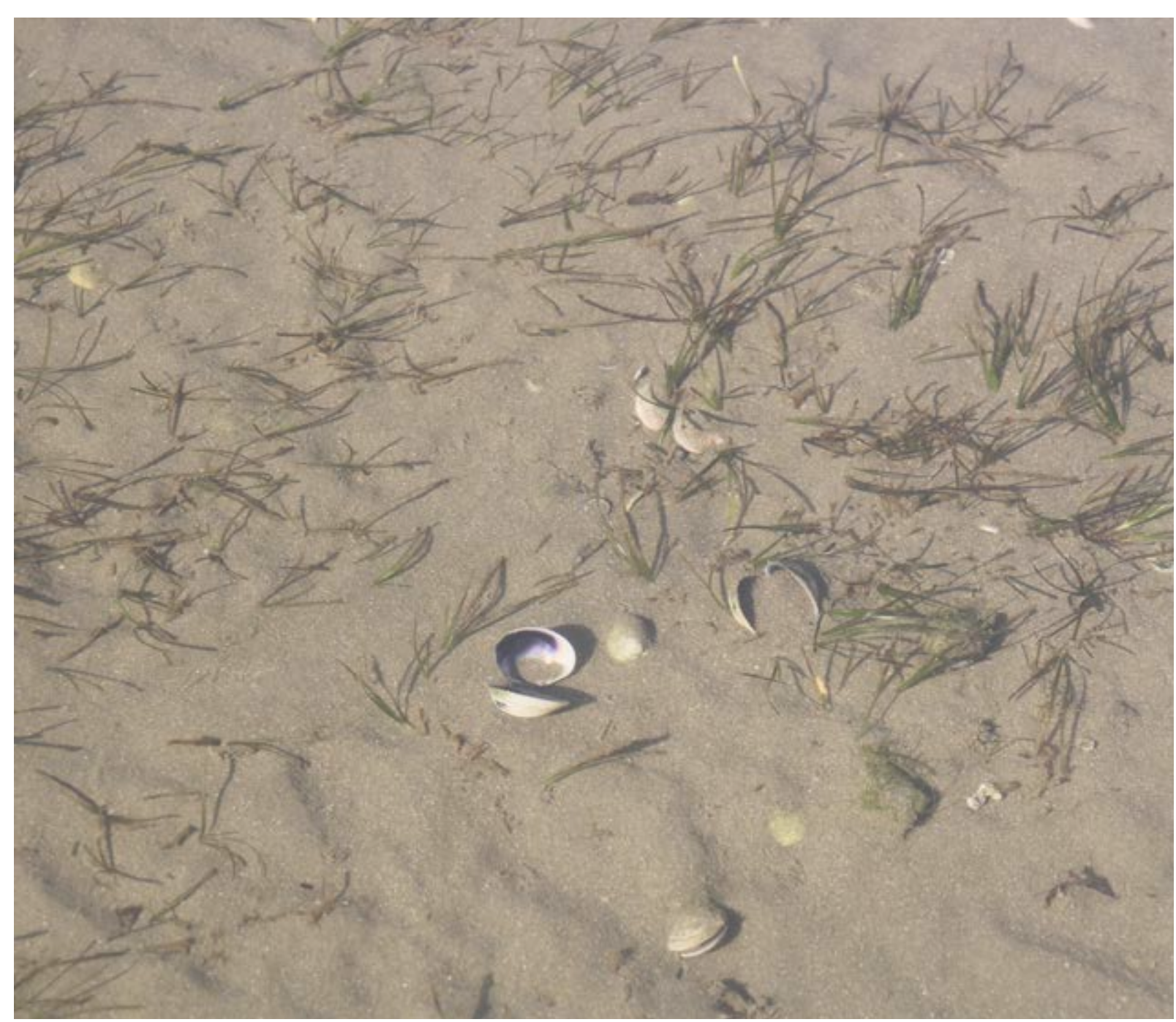

Seagrass floating on the tide. 


\section{HUMAN HISTORY OF PAUATAHANUI}

\section{INTRODUCTION}

Humans have heavily

influenced Pauatahanui's

ecosystem from their earliest

arrival in the 1

around preserving the

ecological significance of the harbour have shifted through the years. As public understanding

has grown around the impact

of development around the

harbour, so to has their desire

to see it preserved. However with the ever increasing demand for housing, the surrounding ills of Pauatahanui have been earmarked for development with kely very strong implications of the future of the tidal realm.
50. Healy, W. B. Pauatahanui Inlet: an Environmental Study Wellington, N.Z: Science Information Division, DSIR, 1980. P12-31. 51. Eiby, George, "Changes to Porirua Harbour in About 1855 : Historical Tradition and Geological Evidence." Journal of the Royal Society of New Zealand 20 ,
no. 2 (1990): $233-248$. I hanui Wildlife Reserve - The First 25 Years, 2010: 11

53. Bellingham, Neil. Pauatahanui Inlet a Living Resource Wellington, N.Z: Guardians of Pauatahanui Inlet, 1998. 4. 11

\section{$1100 . /$}

The first humans arrived in the inlet and cleared the surrounding forests.

\begin{tabular}{|l|}
\hline This content is unavailable. \\
Please consult the figure \\
list for further details. \\
\hline
\end{tabular}

"Porirua Road 1853- watercolour by Lt.
Col. W. A. McClevererty

Ngati-ira settled in the inlet. Two historic pa sites are known in Pauatahanui: Motukaraka pa at Ration Point and mouth of the stream. ${ }_{50}$

\section{1}

Te Rauparaha occupied the pa site at Motu-karaka briefly after invading the area in 182 Ngati Toa then became the

dominant iwi in the area. After he

fled in 1846 it became an army

barrack. ${ }_{51}$

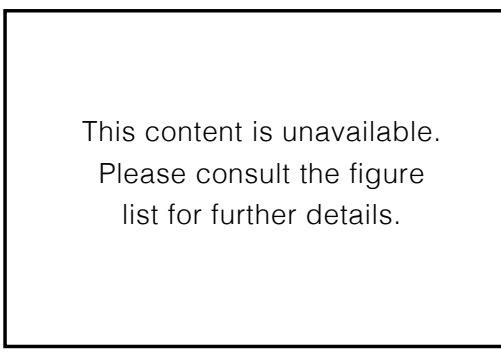

Pauatahanui Stockade, within the palisade

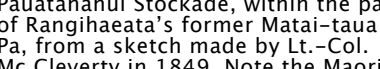

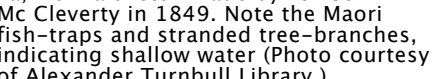

$1960 . /$

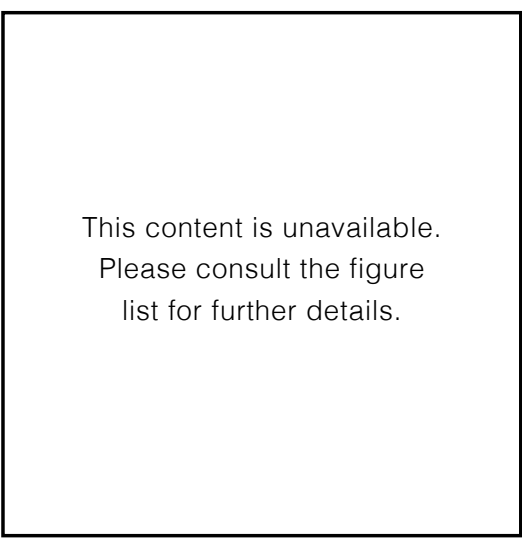

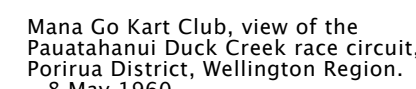

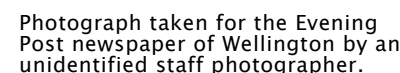

A large recreational park was developed on the eastern flats of the Harbour, in front of the small The land was a Public Domain and as such had facilities for These included a go kart track, a cricket pitch a tennis court and a BMX track. ${ }_{52}$ settlement town of Pauatahanui. various sporting activities on it.
1966. /

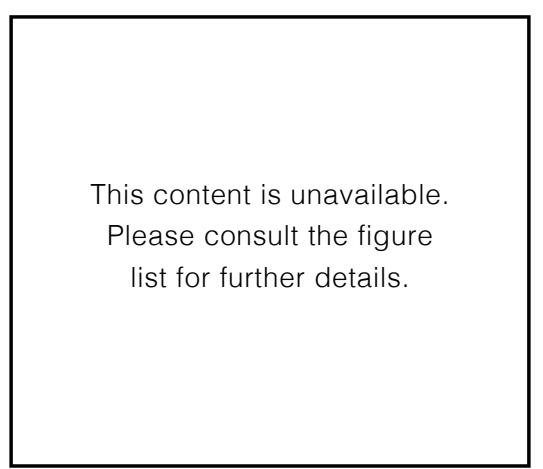

Wellington Regional Council: Pauatahanui,
a plan for the city. Regional Planning
Authority. August 1966

Pauatahanui city plan in 1966 was created by the council as development plan for the future of the inlet. A heavily modified edge, industrial design, very similar to the current form of Porirua today

After some persuasion from ecologists and environmentalists, regarding the importance of the saltmarshes national significance, the plan was dropped.

\section{$1980 . /$}

In 1980, the ornithological Society approached the Lands and survey Department to manage the land as a wildlife reserve.

The ponds, walkways and visitor centre were fundraised and constructed over the years.

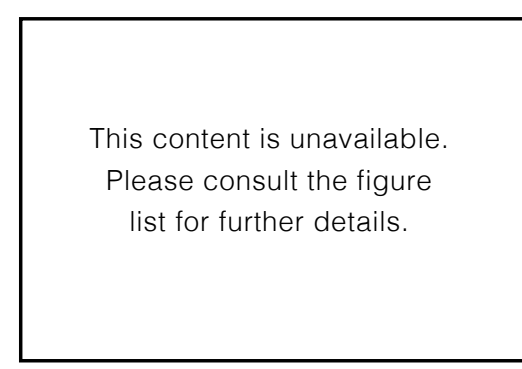
today, perched on still hal overlooking the wetland. This remains a promenent an the harbour.

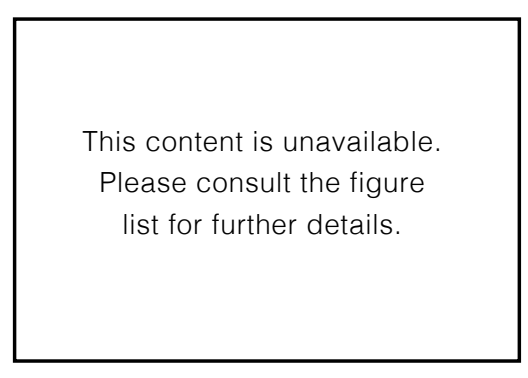

This content is unavailable. Please consult the figure list for further details.

Pauatahanui Wildlife reserve - the first 25
years. Track building in the $1980^{\circ}$ 's

Pauatahanui a living resource.

\section{2. /}

A survey was undertaken in 1992 by Guardians of Pauatahanui Inlet and volunteers to monitor number and size of cockles were recorded as the key indicator species. A trend in declining helth was noticed and the survey has since been

undertaken every three years.

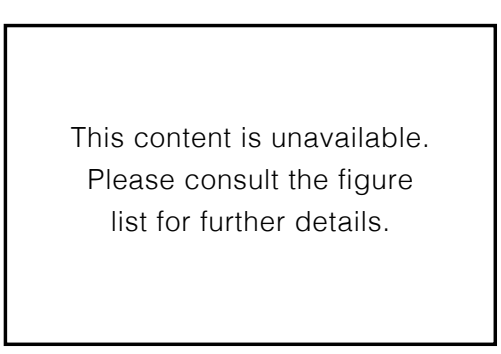




\section{Terrestrial sediment.}

Sediment loads within catchments have

he potential to increase significantly as

storms intensify and occur more frequently,

causing streams to swell and banks

to slip. ${ }_{54}$ The higher concentrations of

sediment turbidity within the water column

is likely to reduce the amount of ligh

filtering through to benthic creatures (such

as cockles) and eelgrass meadows; both

of which require relatively low turbidity and

high levels of sunlight.

Early settlers deforested the hills around

Pauatahanui, setting the land alight.

Historically thick forests cloaked the

catchments, consisting largely of Rimu,

Tawa and Rewarewa. Early records from

Buller remarked on the height and density

of the forests between Wellington and

Porirua. ${ }_{55}$ Once stripped of vegetation,

land is vulnerable to soil erosion during

heavy rainfall.
Currently, the largest sediment load ntering the harbour is from the deforested pastureland in the northern catchments, Horokiwi in particular. Without vegetation to stabilise the slopes, soft alluvia sediment from the surrounding hills enter the waterways, taking with it pesticides, herbicides and effluent from cattle.

54. RG Bell, TM Hume, DM Hicks. “Planning for Ministry for the Environment New Zealand, 2001. 55. Healy, W. B. "Pauatahanui Inlet : an Environmental Study" Wellington, N.Z: Science Information Division, DSIR, 1980

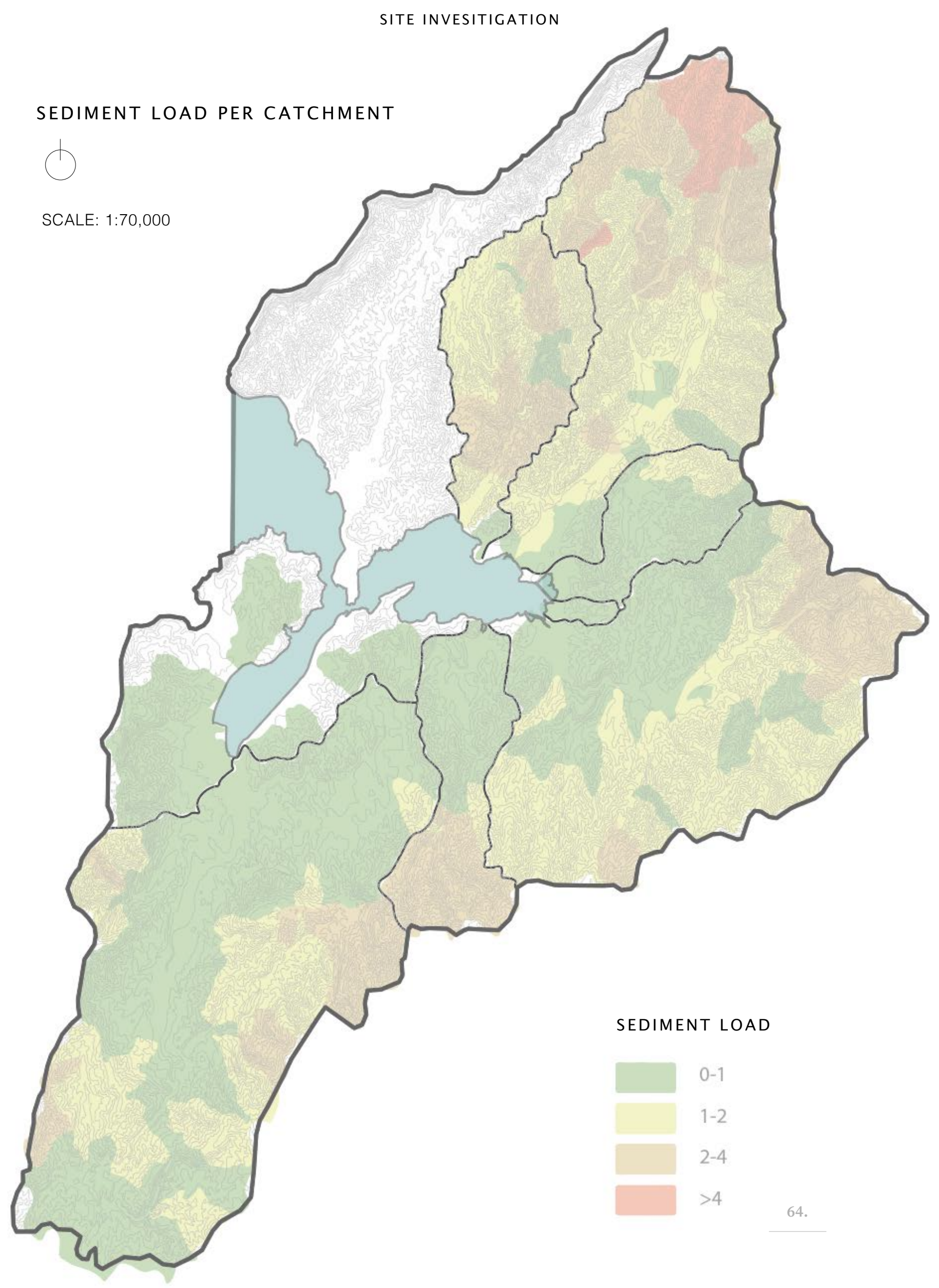


Sediment records indicating changes in Pauatahanui's environment.

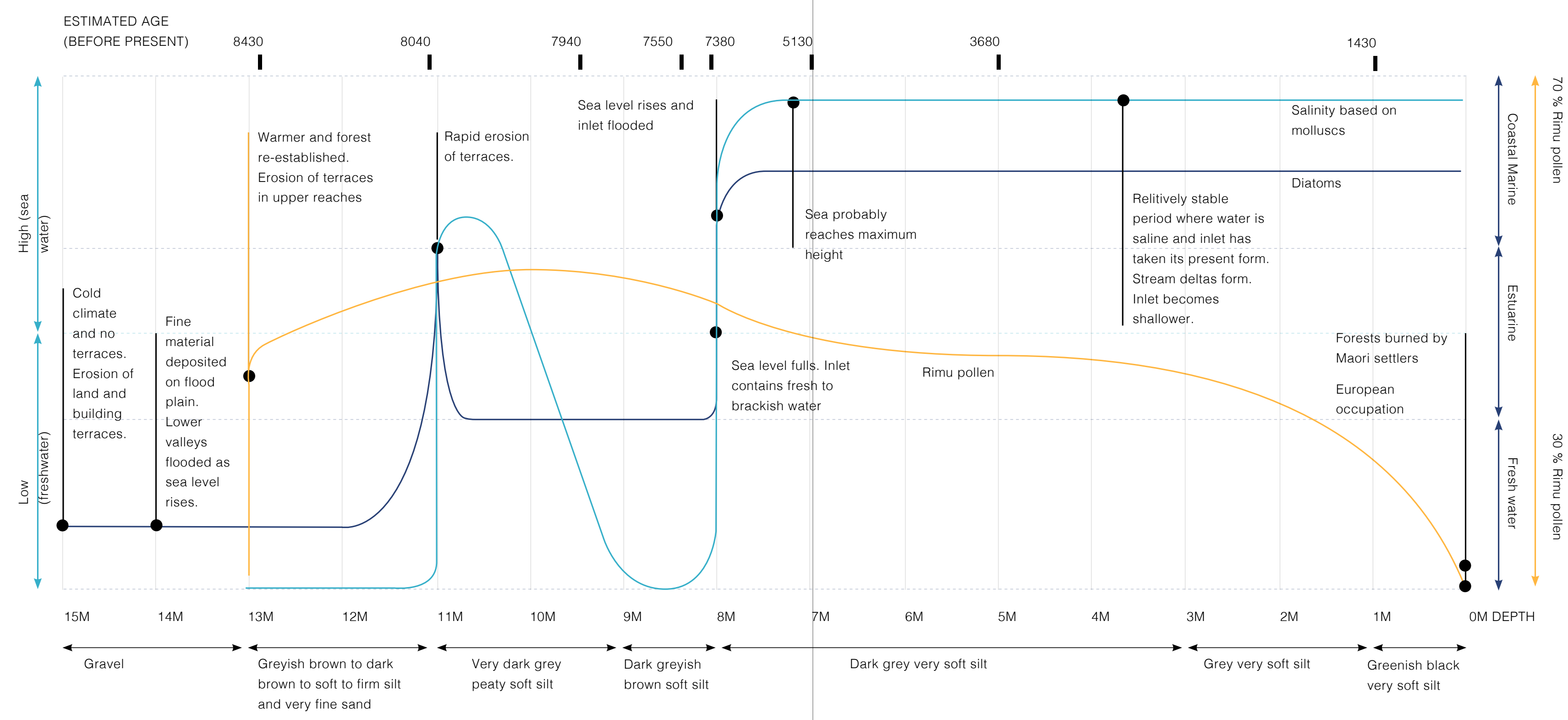




\section{Pauatahanui inlet short-core $\mathrm{x}$-radiographs of 2-cm thick slab.}

\section{Sediment cores taken from around the area show that that the \\ annual sediment load entering the harbour is several times higher since the deforestation of the catchment, and that the rate is steadily increasing. Land cover
changes and earthworks changes and earthwo
associated with \\ urbanisation such as the developments around and the harvesting \\ of exotic forest have the potential to furthe increase sediment loads to the inlet and smother eelgrass communities. These cores indicate that at the time of sampling sedimentation was entering the harbour at forest clearance rates were around $1 \mathrm{~mm} / \mathrm{yr}$ )}
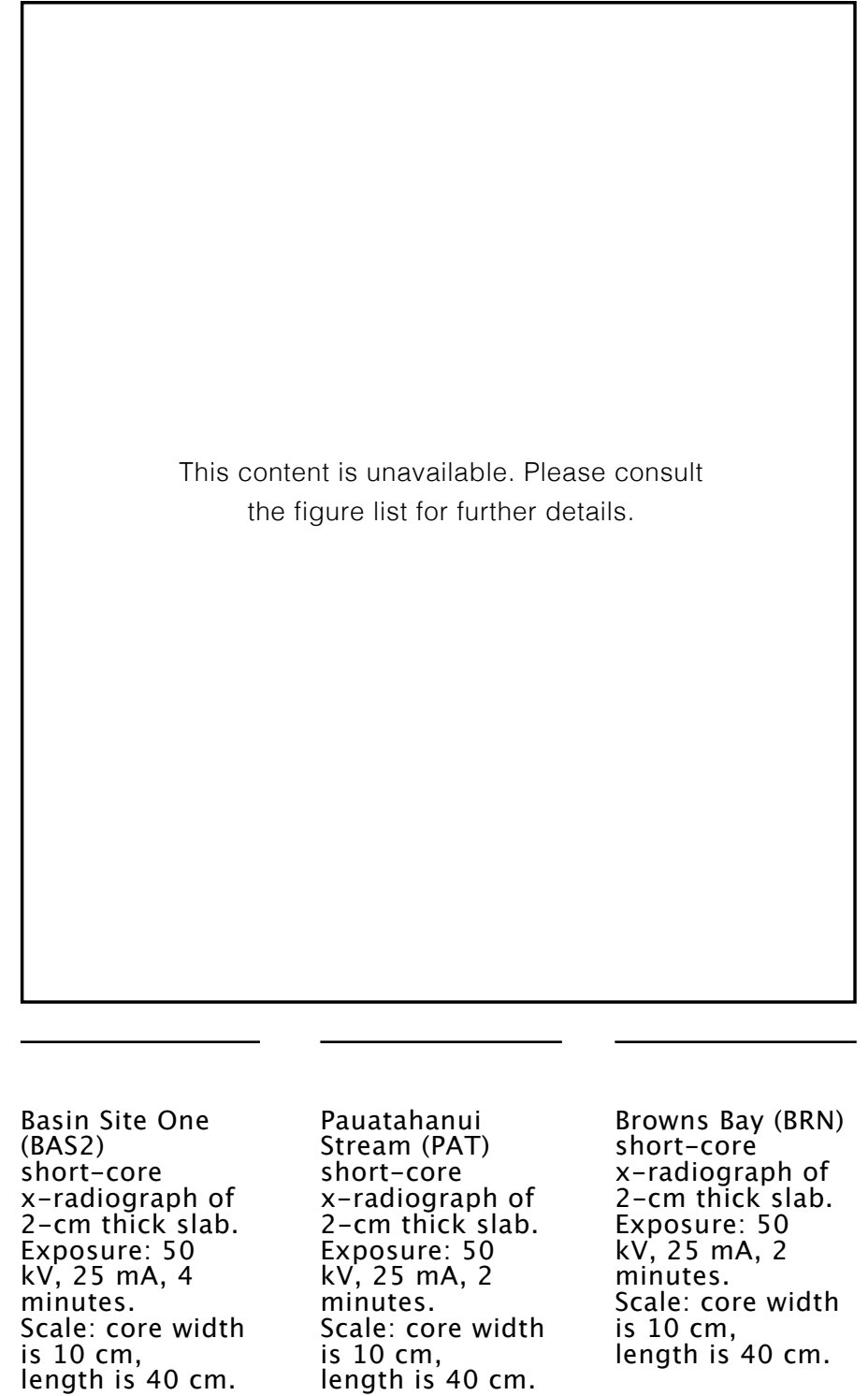

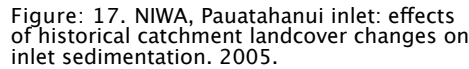

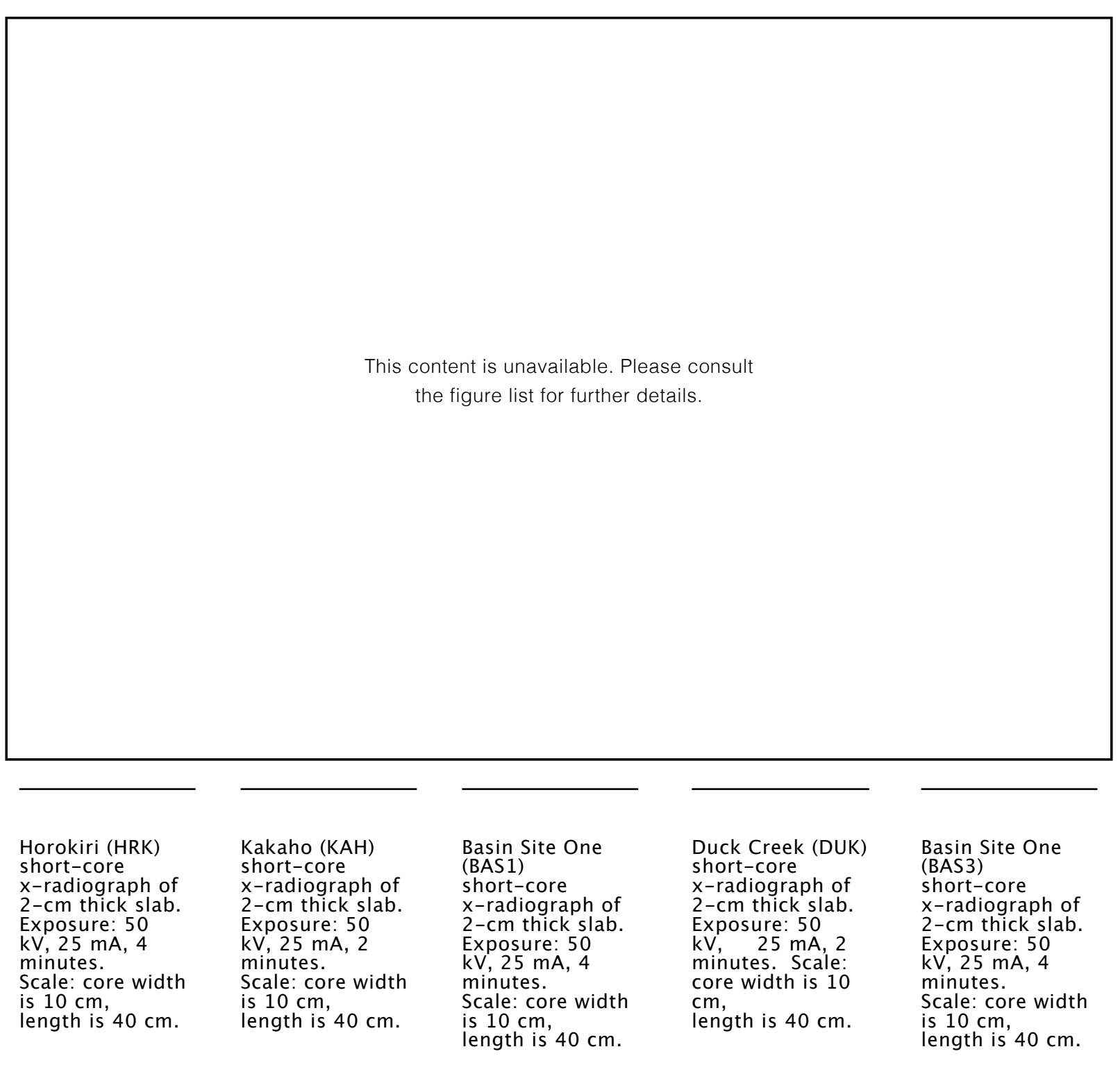




\section{CATCHMENT CONDITION}

Subcatchment Aea (sq $\mathrm{km})$ Relief $(\mathrm{m})$ Main channel length $(\mathrm{m})$ Average channel slope $(\mathrm{m} / \mathrm{km})$ Catchment cover

\begin{tabular}{|c|c|c|c|c|c|c|}
\hline (A.) & Pauatahanui & 43.4 & 431 & 9600 & 0.023 & $\begin{array}{l}\text { Pastoral pockets of scrub and bush. } \\
\text { Urban densification increasing. }\end{array}$ \\
\hline (B.) & Horokiwi & 32.9 & 530 & 12900 & 0.022 & Pastoral pockets of scrub and bush \\
\hline (C.) & Duck & 10.5 & 490 & 7200 & 0.034 & Urban \\
\hline (D.) & Kahao & 11.3 & 439 & 6000 & 0.037 & Pastoral pockets of scrub and bush \\
\hline (E.) & Ration & 6.13 & 260 & 4800 & 0.027 & Pastoral pockets of scrub \\
\hline (F.) & Browns & 1.23 & 157 & 1200 & 0.065 & Urban \\
\hline \multicolumn{2}{|c|}{ + Smaller catchments } & 3.1 & & & & \\
\hline
\end{tabular}

Total

105.5

Several catchments comprise the watershed. Large alluvial

catchments in the north

(Horokiwi and Kahao) carry

nutrient rich fine silt into

the harbour. This silt has

the potential to smother

marine life and suppress

the growth of eelgrass. The

catchments to the south

are similarly compromised

although the sedimentation

load is smaller there ar

higher concentrations of

heavy metals and other

urban developments. The

development of Whitby

has had a visibly negative impact on the health of Duck Creek, and the catchments to the east: Ration Creek and Pauatahanui are under threat from the developmen of Transmission Gully, a new state highway.

The streams within these catchments are either

bridged or

accommodate the road that

almost completely encircles the harbour edge.

The health and wellbeing of these streams (and therefore the wider catchment) are intrinsically linked to the health of the harbour and its inhabitants. Māori have always understood the need to consider the environment in its entirety through a concept referred to as ki uta ki tai (Tipa et al, 2016). This concept describes their holistic understanding of freshwater ecosystems and how the health and well-being of the people are intrinsically linked to the natural environment. Therefore we cannot consider the development of the coasta edge as separate from its contextual surroundings, they are interconnected through a complex web of interrelated systems.

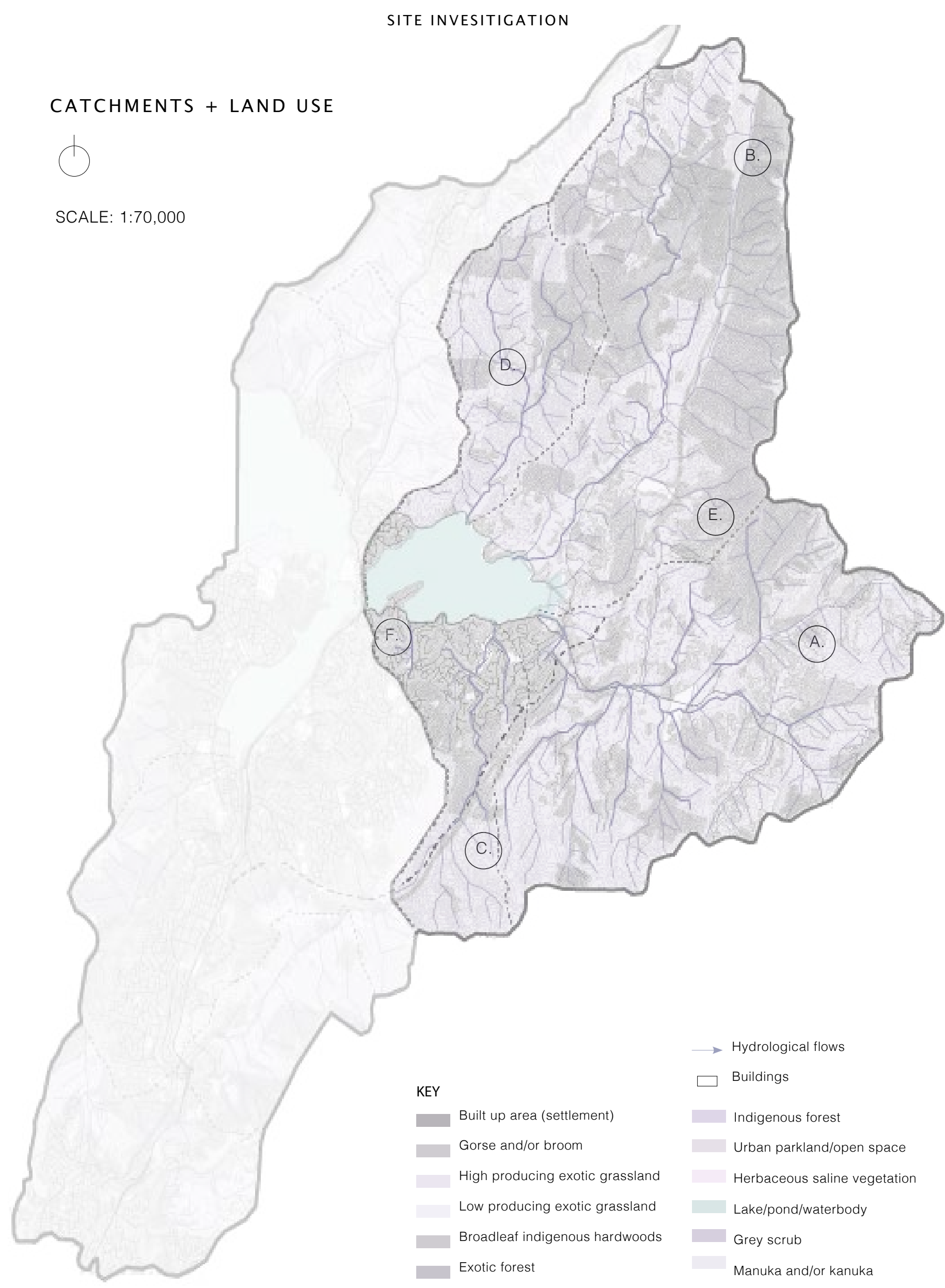




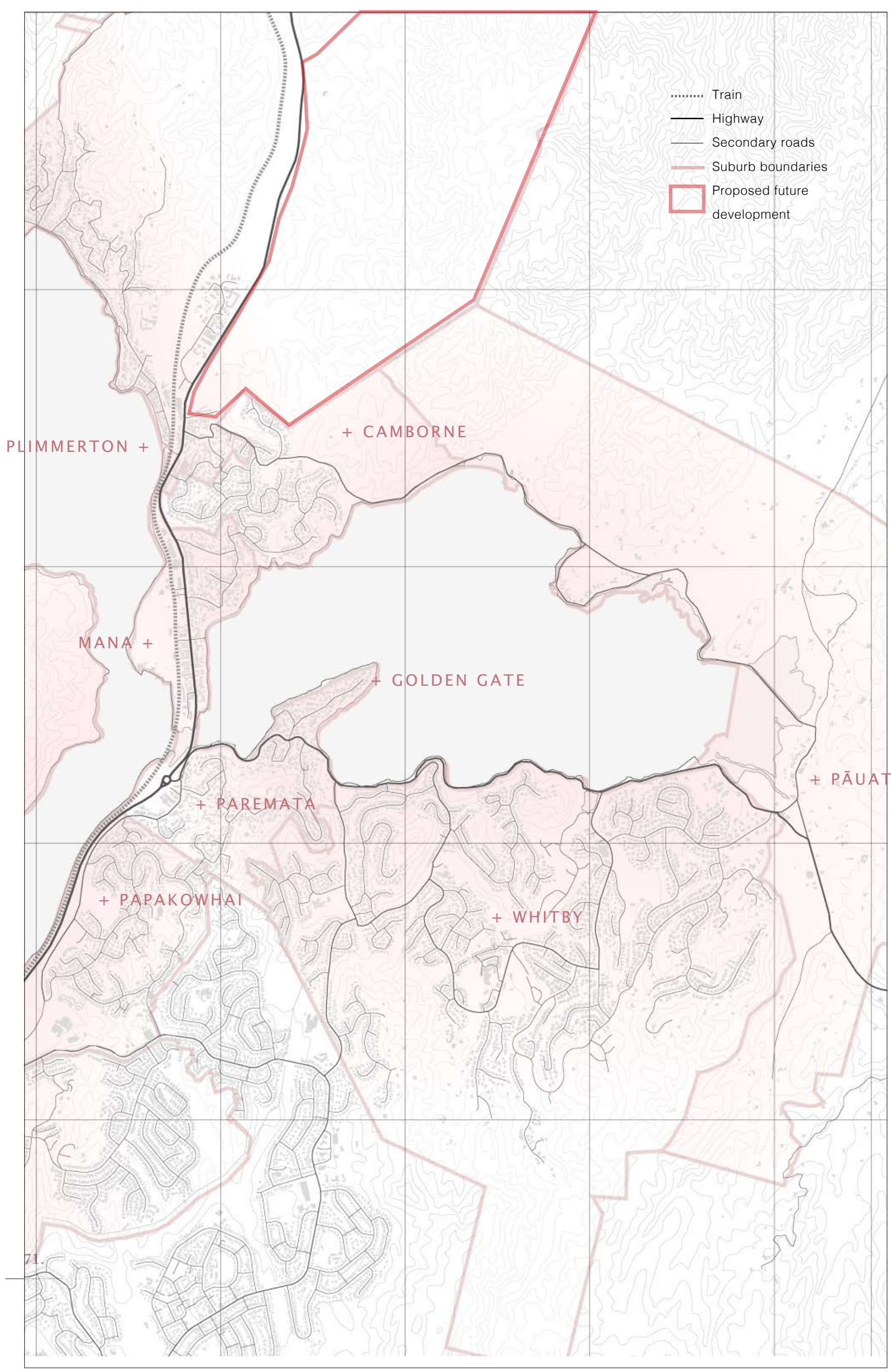

\section{URBAN FABRIC}

Suburban developments flank the steeper edges of the inlet, linked by state highway one; Camborne and Mana to the west, Paremata and Whitby to the south. The

historic settlement of Pauatahanui lies

to the east set back from the shoreline

behind the saltmarsh. The northern side is dominated by farmland and pasture.

With Wellingtons increasing housing demand and constrained footprint on which to build, portions of these hills have been earmarked for suburban housing developments to support this growth.

\section{KEY}

\section{Rooflines}

Predicted sedimentation fill line

\section{+ MANA}

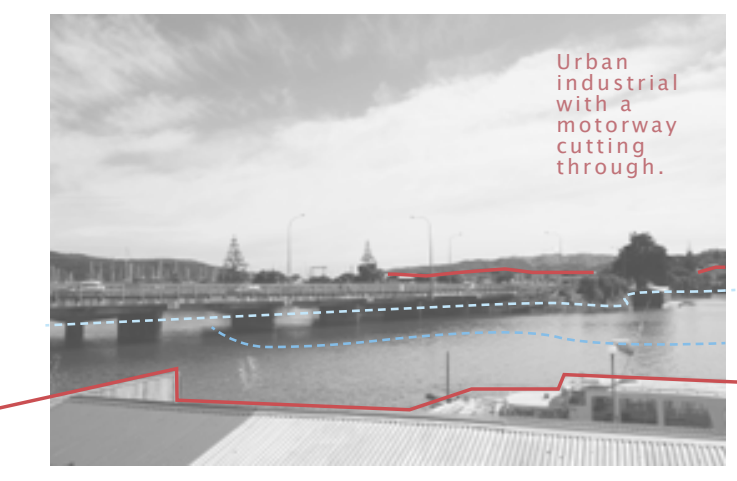

+ PAREMATA

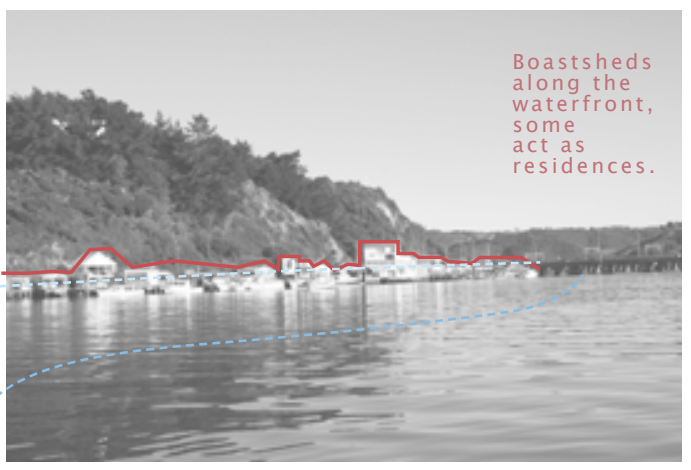

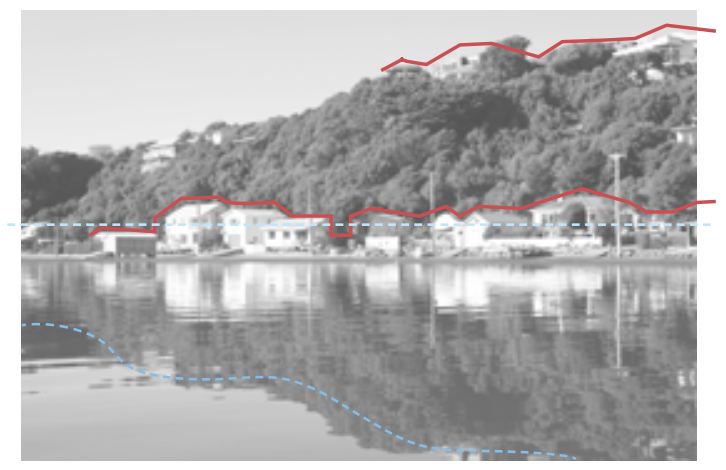

WHITBY

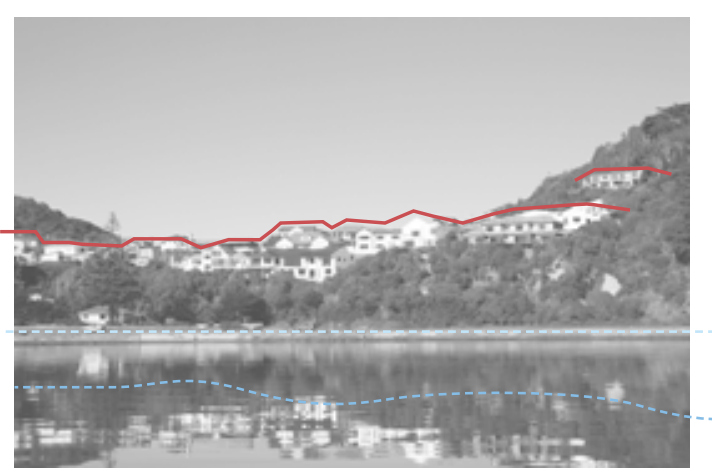

\section{Whitby is
andillside}

suburban
development
overlooking
the inlet. The houses
were all
bulith
and

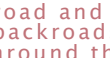

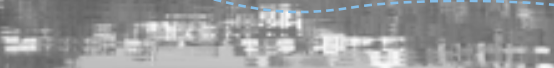

+ PĀUATAHANUI

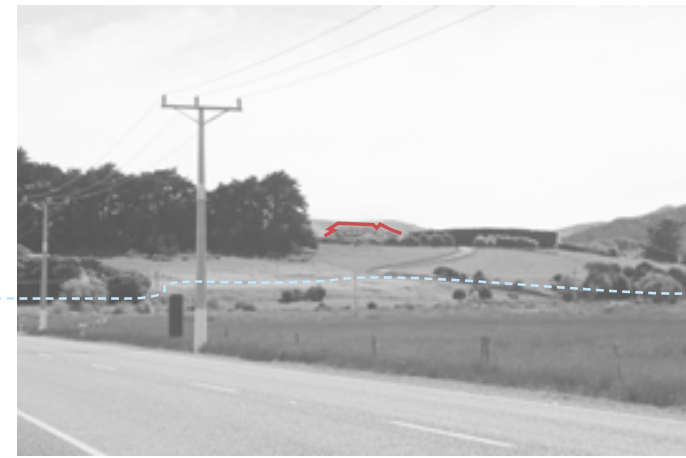

Small
village
tulced
behind
bush and
saltmars Surrounding
rolring
farmland

+ CAMBORN

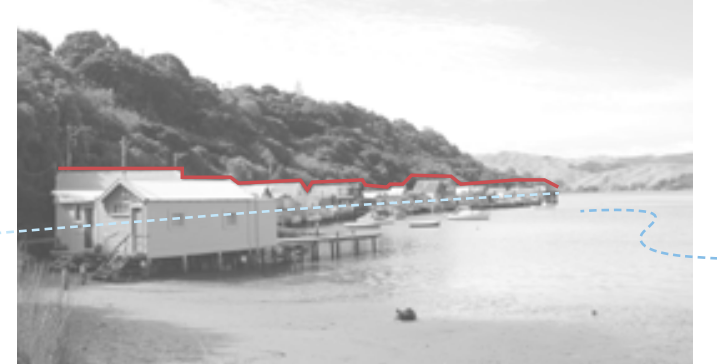

Boatsheds
along the
the Residential
housing 


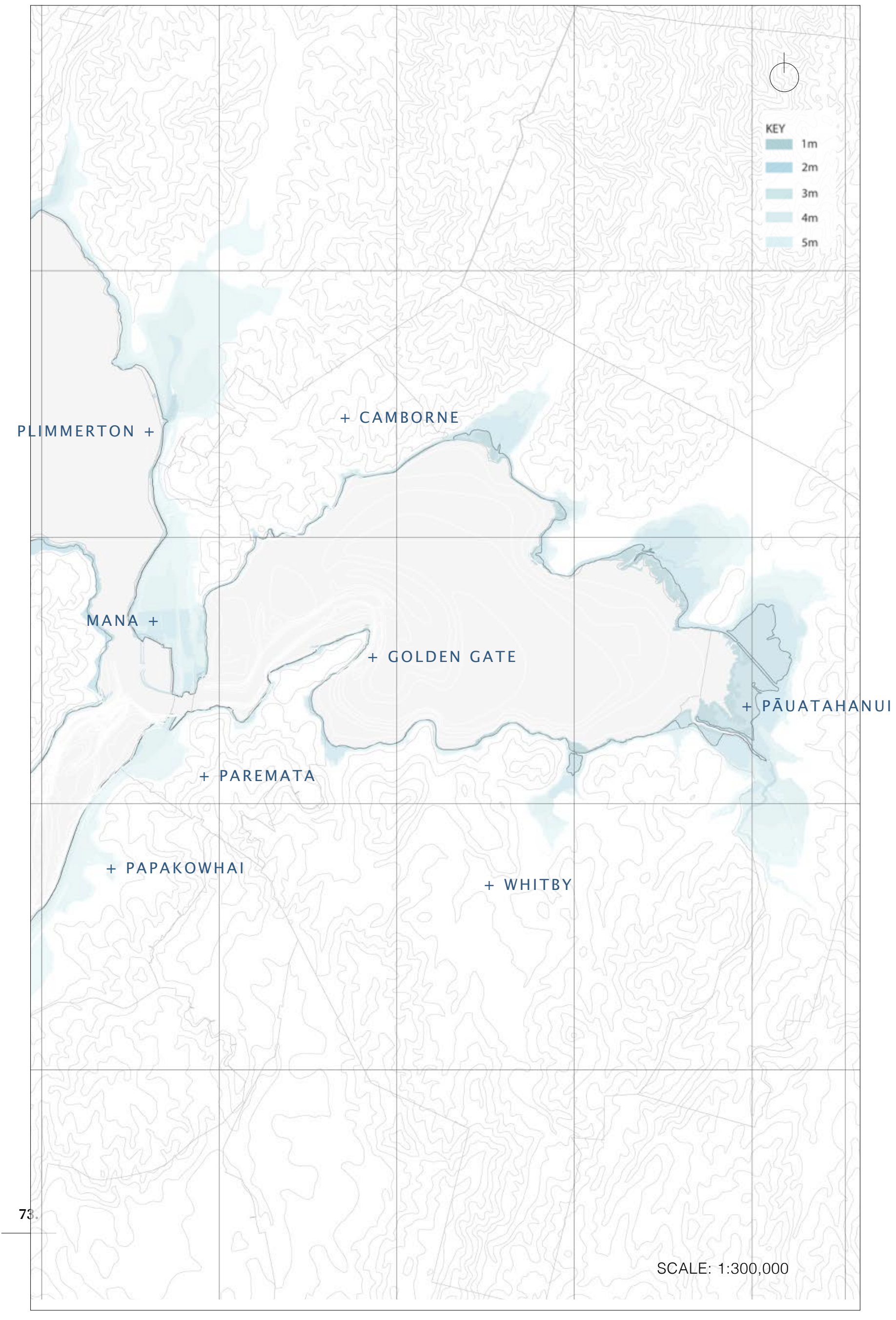

SITE INVESITIGATION

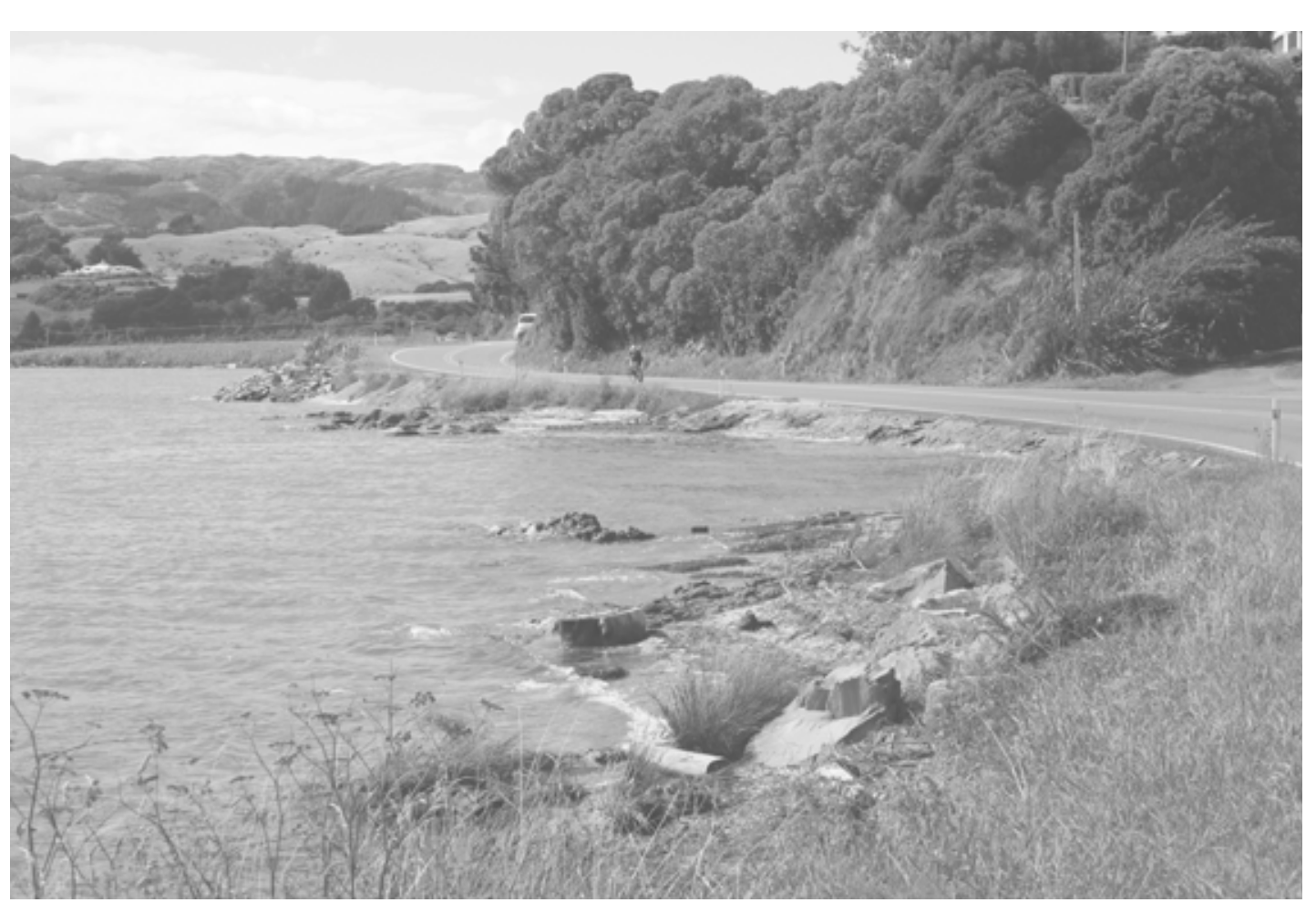

EDGE CONDITION AND THE

IMPACTS OF SEA LEVEL RISE:

A ring road encircles the harbours edge

fortified by sea walls and rip rap. The

coastline in some sections is completely

inaccessible for pedestrians; dominated by

roading infrastructure and vehicles moving

at high speed. This has constrained

and modified the large areas of the tidal

margin, creating a physical barrier in the

landscape, restricting movement between

the sea and land; thereby stopping plants

and animals from moving inland and

creating new habitat as the sea levels rise

and exacerbating the tidal squeeze. 


\section{Erosion and deposition.}

SCALE: 1:30,000
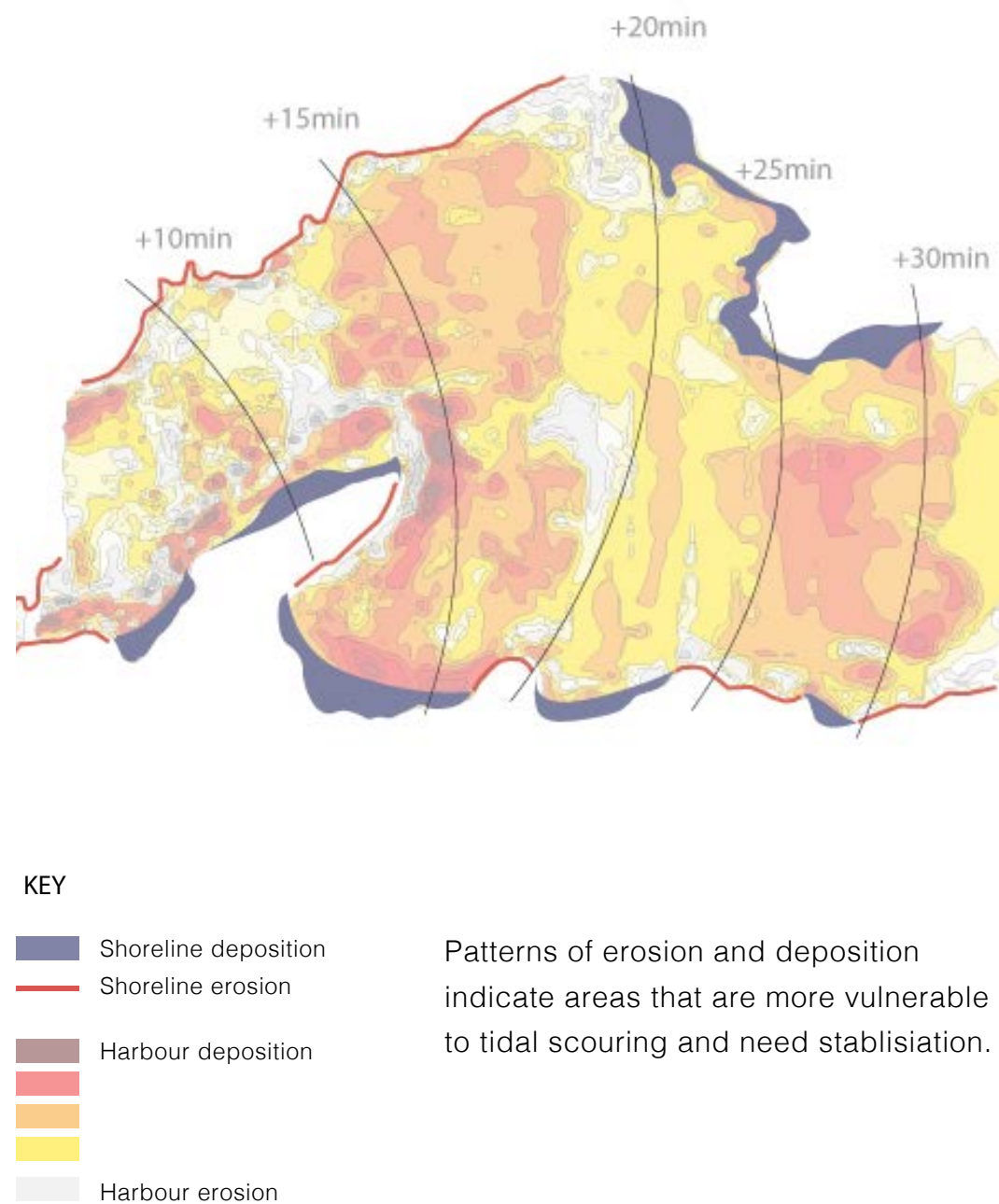

SOURCE: Data in this map has been pulled and reconstructed from: Porirua Harbour Patterns and Rates of
Sedimentation Report (Harbour erosion and deposition). Figure is authors own.
Areas prone to the highest level of erosion within the inlet appear to be steeper slopes such as the southern headlands and western forested edge as they jut un to sea and are therefore the path of higher wave action. Patterns of scouring and deposition alternate around the harbours edge with sediments collecting in coves and valleys

1. Flax roots bind together the shoreline.

2. Lace patterns formed by as an imprint once the flax

3. Mitigation techniques such as riprap and in small sections around the waters edge.

4. The coastal road that harbour is very close to the high water mark. the road, slowly eroding underneath the asphalt.
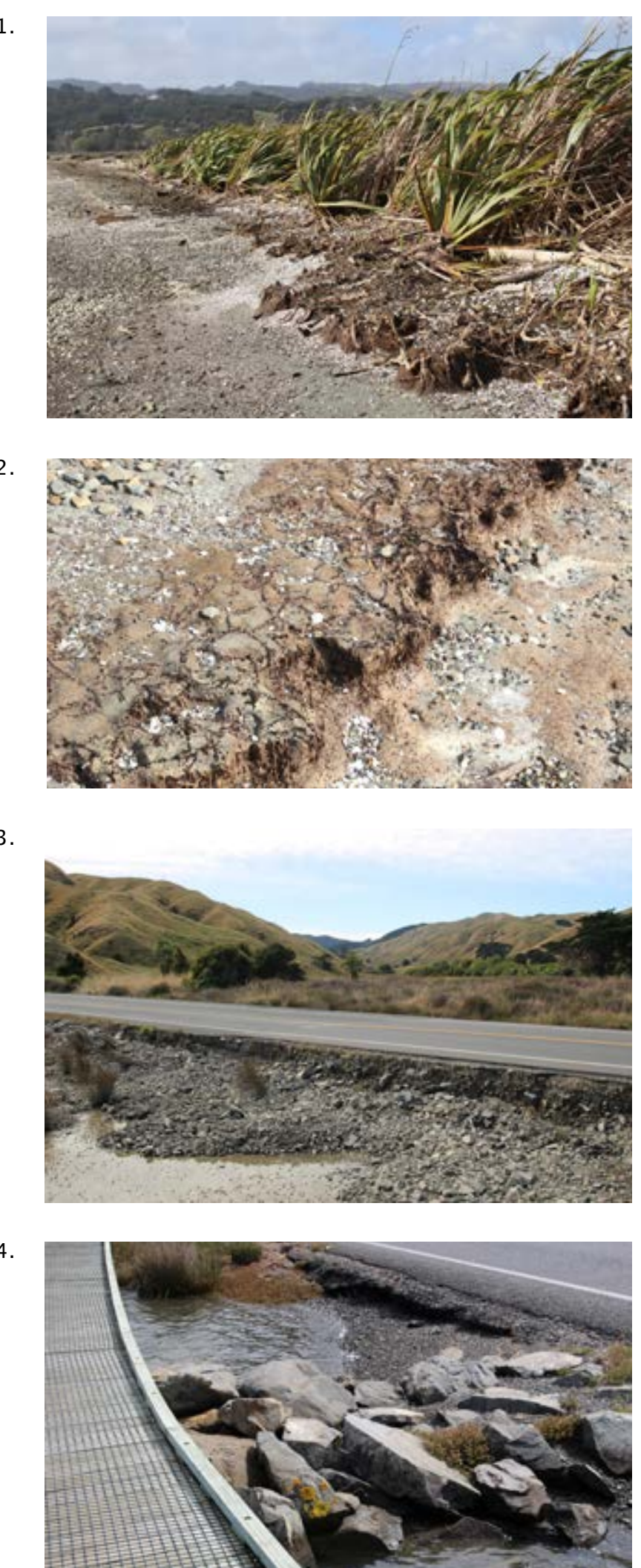


\section{Tidal sediments.}

SCALE: $1: 30,000$

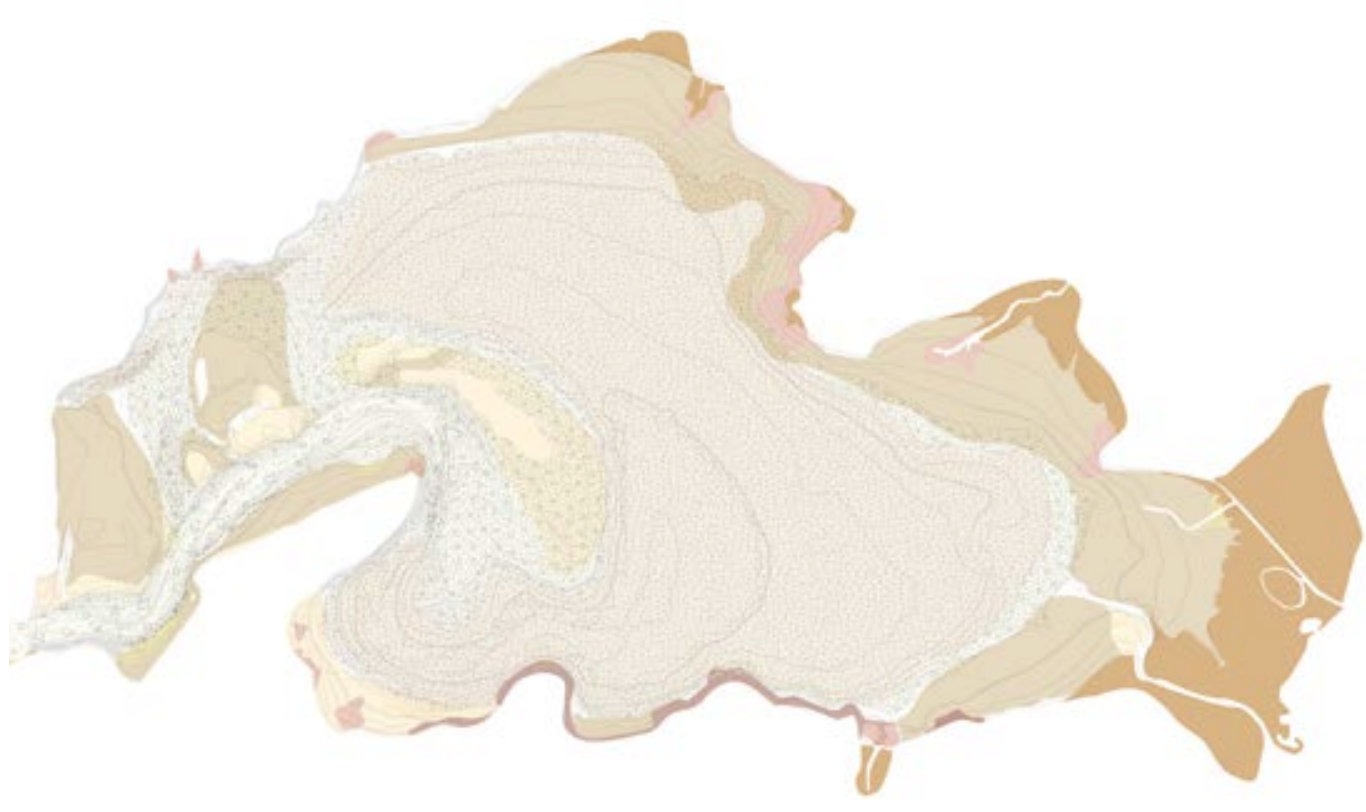

KEY

INTERTIDAL SEDIMENT TYPES BETHNIC SEDIMENT TYPES

$$
\begin{array}{ll}
\text { Shell bank } & \\
\text { Firm sand } & \text { Very soft mud } \\
\text { Firm muddy/sand } & \text { Soft muddy sand } \\
\text { Soft mud } & \text { Firm muddy sand } \\
\text { Rock field } & \text { Firm sand (shell) } \\
\text { Cobble field } & \\
\text { Gravel field } &
\end{array}
$$

SOURCE: Data in this map has been pulled and reconstructed from: Porirua Harbour Survey Report of Survey (Bethnic Contours)
- Survey prepared by Discovery Marine LLd. Porirua Broadscale Habitat Mapping (Intertidal sediments). Figure is authors own.
Sediments are not just terrestrial but also shifting within the harbour, moved by the tides.

Interestingly, saltmarsh wetlands have the ability to produce sediment through plant detritus, meaning they slowly grow higher over time. Historically this has increased level has matched the rate of the rising tide, decreasing the saltmarsh's vulnerability to tidal inundation. However climatic shifts causing an increase in storm surge events will overwhelm the tolerance of plants, necessitating inland retreat.

Silted sand ripples formed by the lapping tide.

Seagrass swaying under the waters surface.

Sediments floating on the
surface of the water, flush out to see from the surrounding catchements.

4. Amber tones of the saltmarsh sediment.

Eel grass and cockles exposed
at low tide.
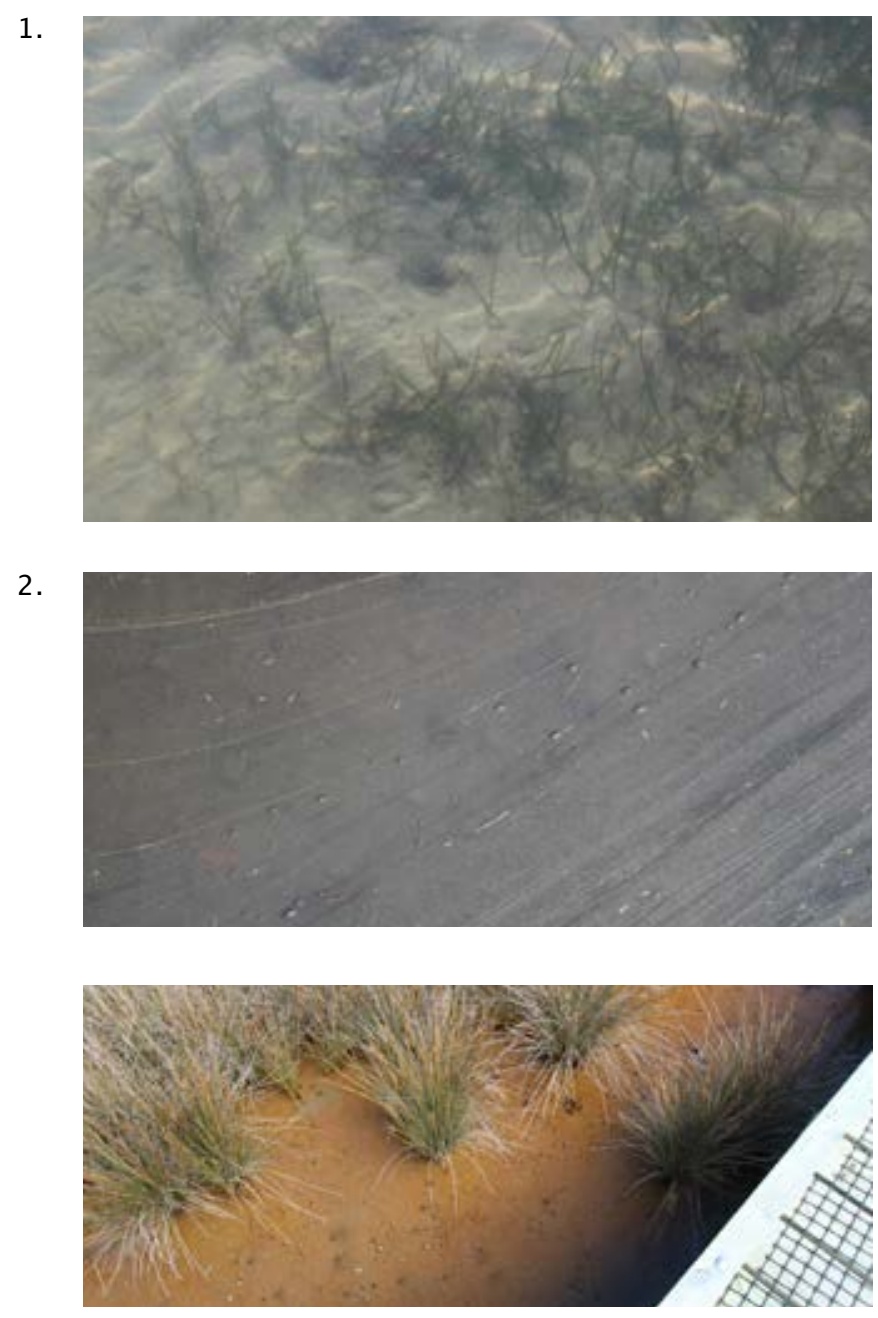

3.

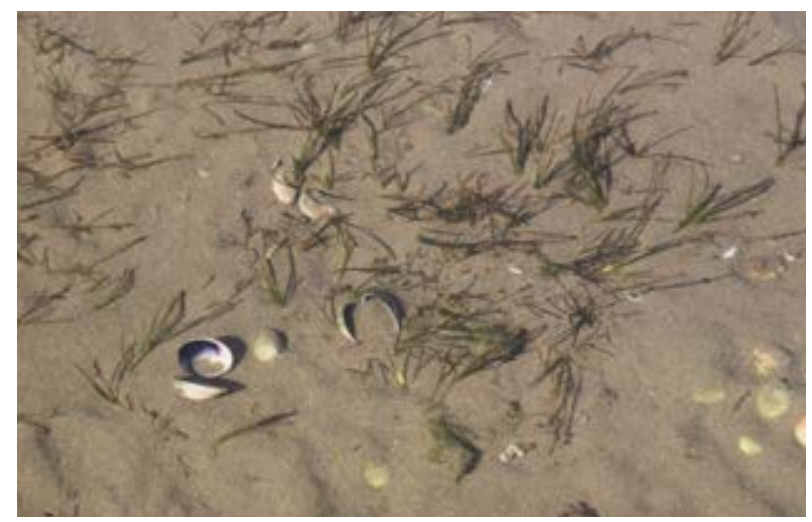


Mapping the current edge: Moving around the harbour

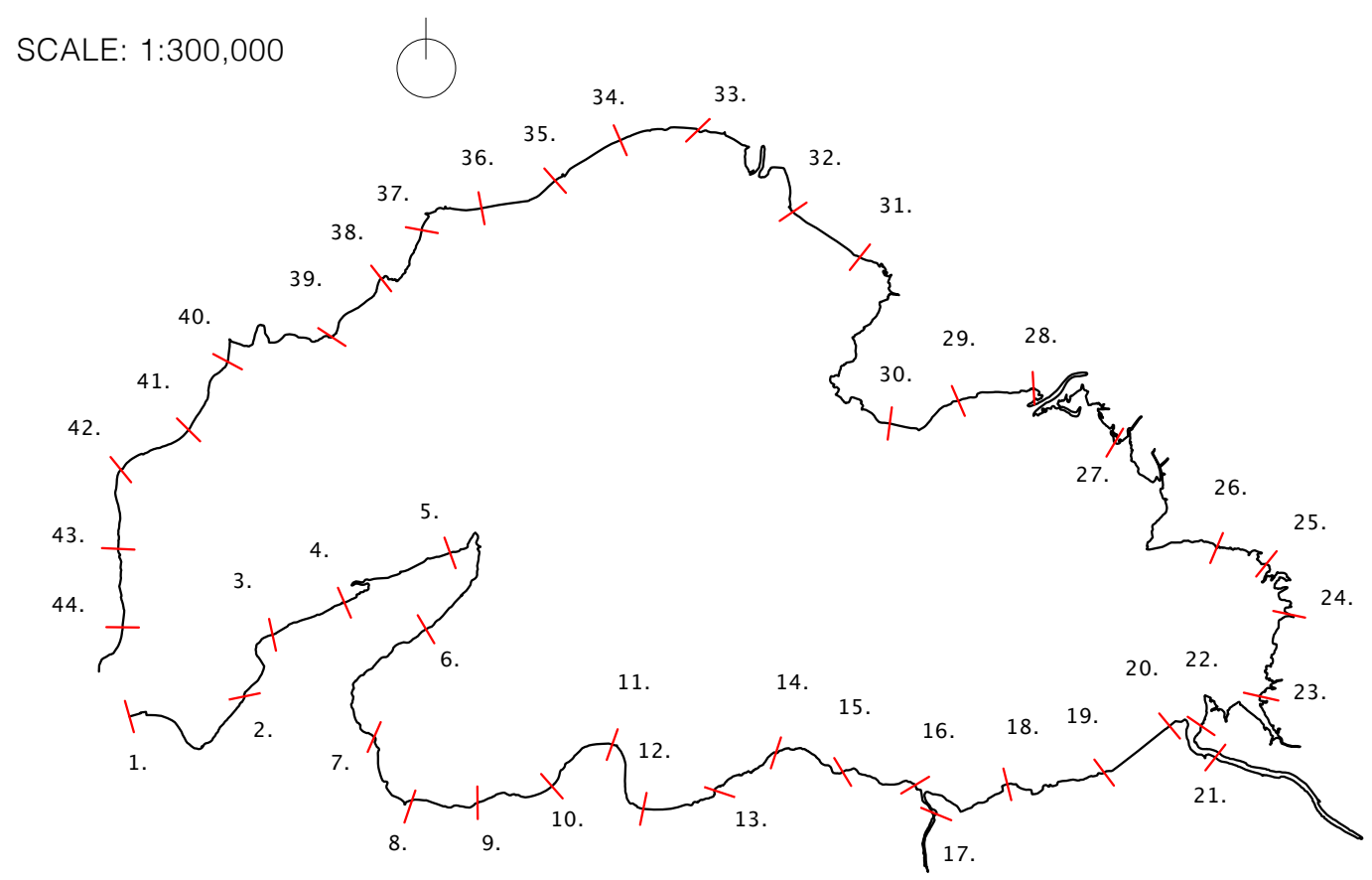

The coastal edge differs significantly as you move around the harbour. Currently large areas are inaccessible and

dominated by cars. Sections of this road are already being flooded by high tides, making them unsustainable even in the short term future.

This section analyses the existing edge condition as it is in 2020, and indicates possible design opportunities to encourag pedestrian movement around the harbour. This study is based off extensive fieldwork by foot, vehicle and boat. It records the topography, built infrastructure of the landscape and areas that are currently accessible for pedestrian movement.

The uncertainty surrounding the future water levels within the harbour, opens up the possibility to reclaim the edge condition for pedestrians and wildlife.
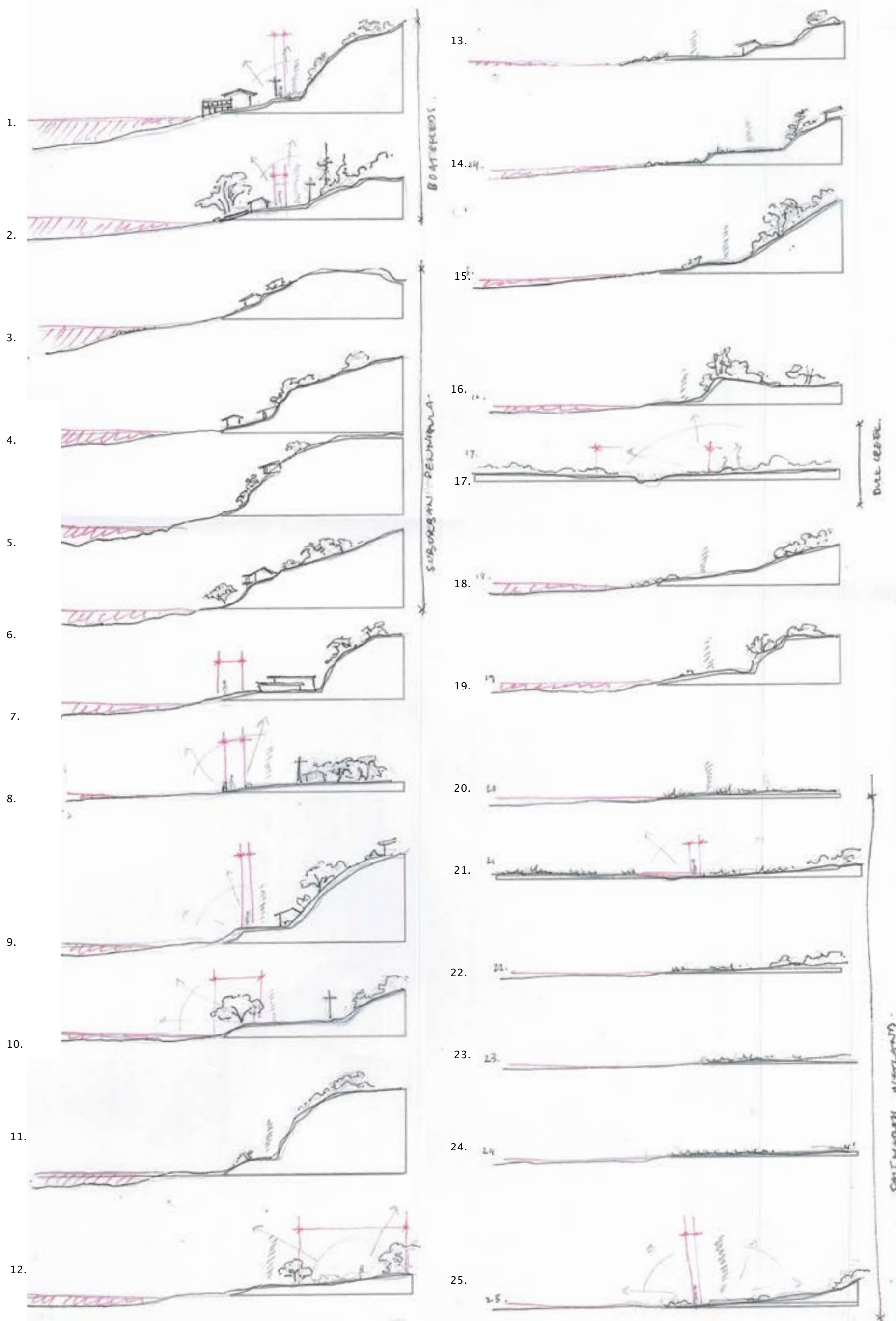
2

21

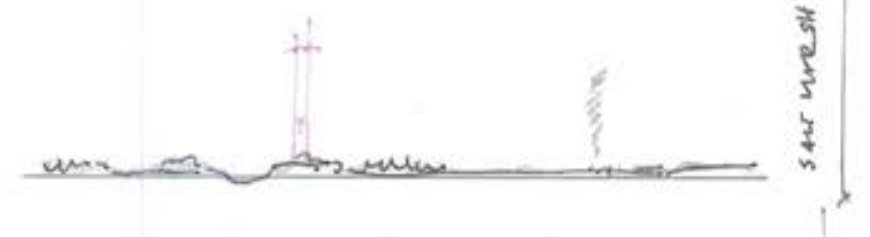

2x

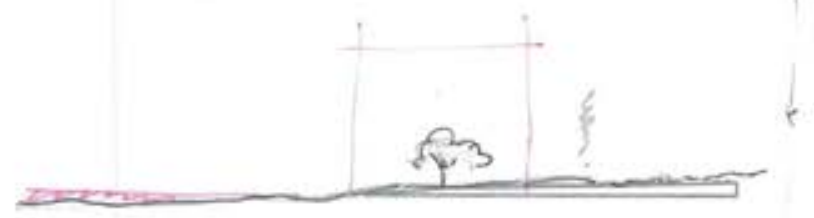

$\angle a$

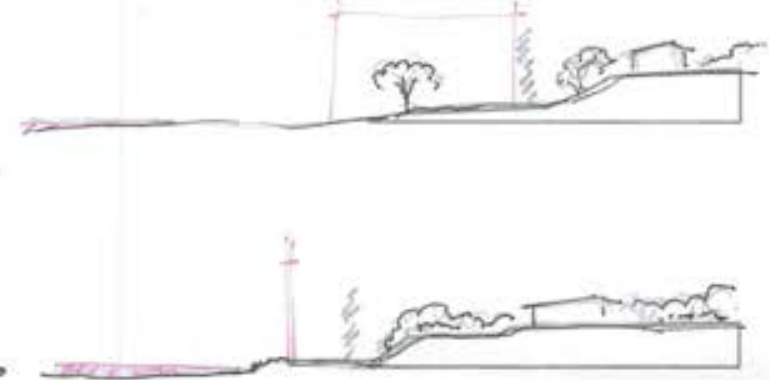

क
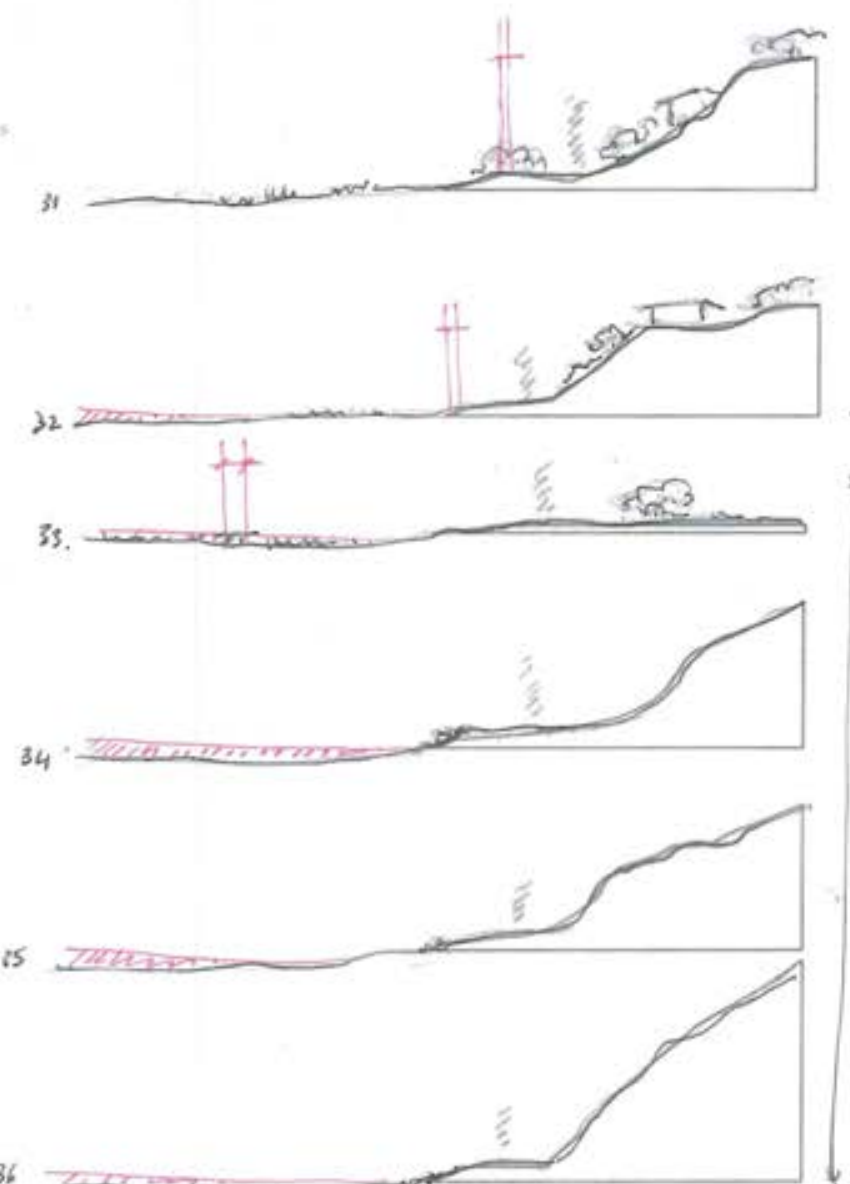

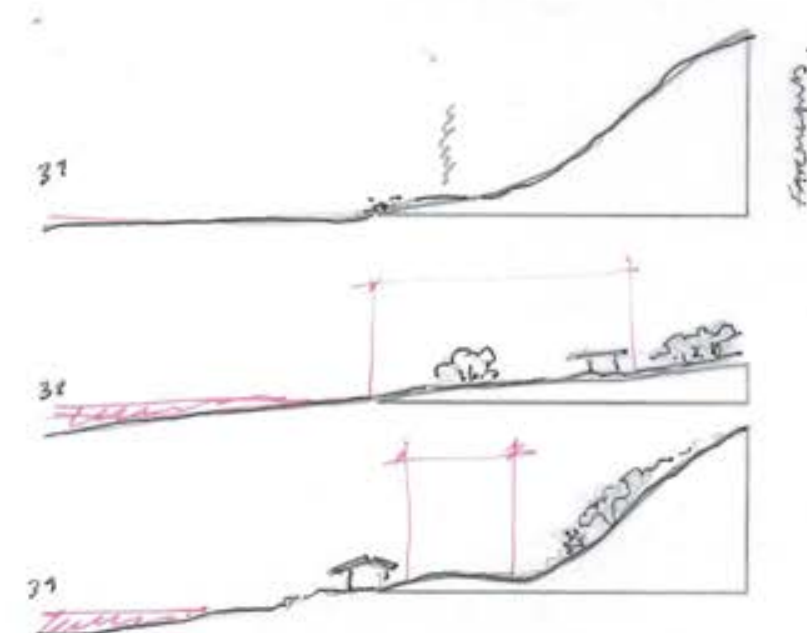

31

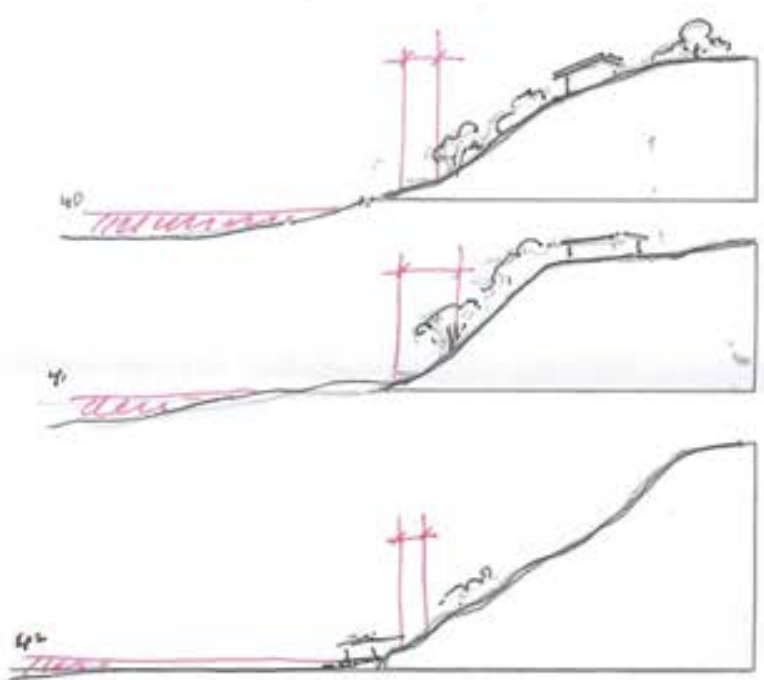

40

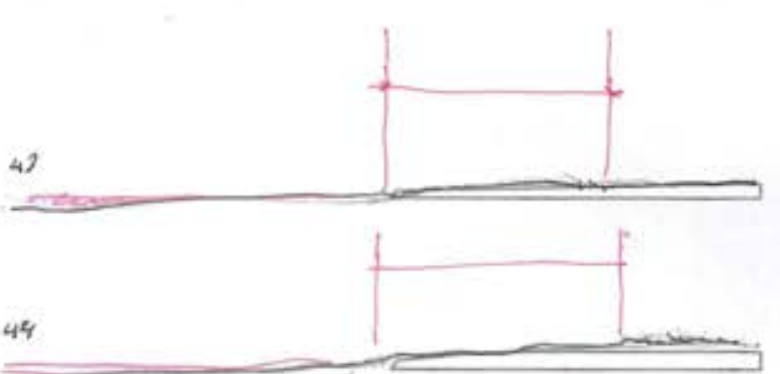

\section{SITE INVESITIGATION}

FINDINGS:

On the southern side of the harbour, due to the steep coastal edge along the water and the sheer cliff faces behind, there is not enough space for roading infrastructure and pedestrian pathways to coexist

alongside each other without undertaking significant earthworks.

The clay banks are steep and prone to erosion due to their soft clay soil.

To the east, there is lower chance of tidal inundation affecting the community of

Pauatahanui despite its low lying position, due to its setback from the water's edge and the protection of the saltmarsh in front. The clumping root systems of oioi, raupo

and harakeke plants weave together to stablise the coastal edge

On the northern side of the harbour a pathway has recently been built along the roadside called the 'Te Ara Piko.'

This pathway has been constructed in

order to allow pedestrian access from the wetland reserve to Camborne reserve on the western edge of the harbour. There is still a section of this pathway pending construction. This path is at risk of flooding as the sea levels rise.

To the west is Camborne and Mana. Camborne park in the northwest corner provides a boat launch site for jetskis and shallow hulled boats. A hillside walkway $(1.6 \mathrm{~km})$ runs along the shoreline, ending close to the mouth of the harbour, behind the Camborne boatsheds. Elevated from the tideline this track offers good views of the harbour with bushclad hills behind. Again, this existing pathway is removed from the road so feels calm and safe. 


\section{Key edge typologies}

PLIMMERTON SUBURBAN FOOTPATH

HIGHWAY ONE SOUTHERN SIDE

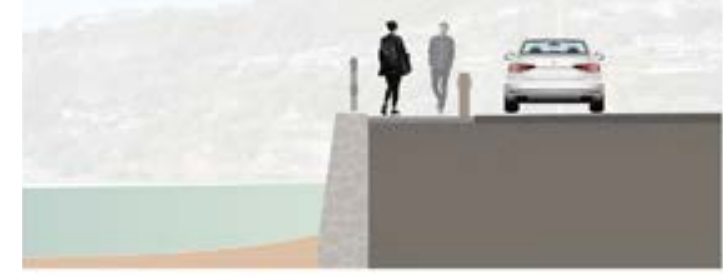

SECTION

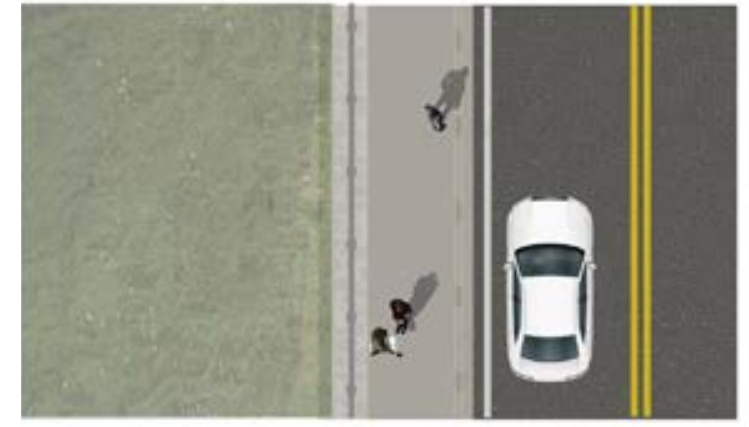

PLAN

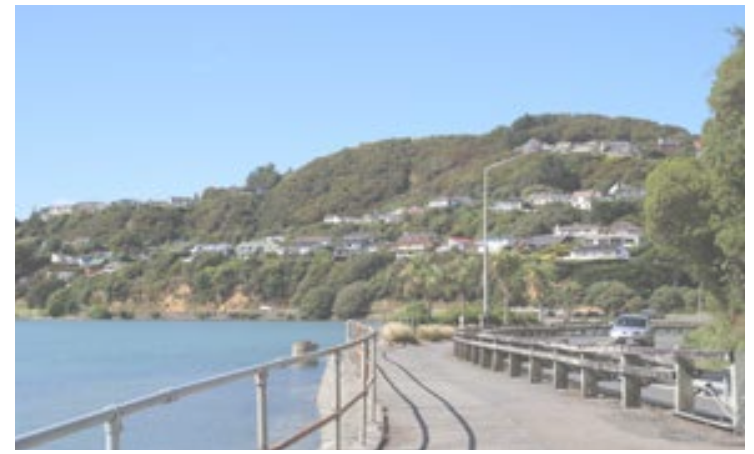

Suburban areas on the South eastern end of the bay by Paremata have constructed sea walls and allow enough room for narrow pedestrian footpaths along the side of the road.

SECTION

PLAN and the she

enough space tor roading intrastuch vehicles at speed.

SITE INVESITIGATION

NORTHERN SALTMARSH BOARDWALK
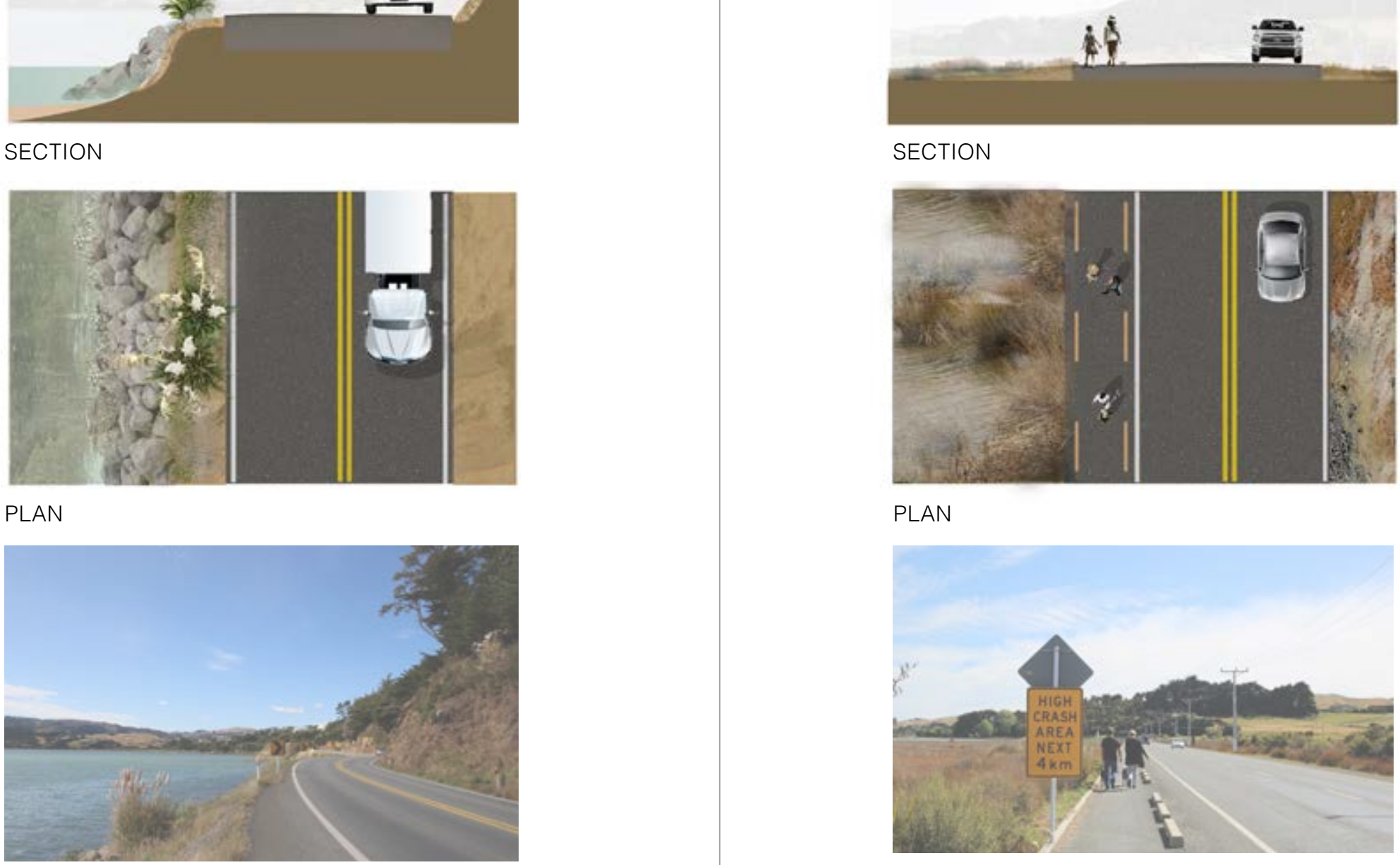

Along most of the southern side of the harbour, due to the steep coastal edge along the wate pedestrian pathways to coexist all, especially as the road is a highway and thus fused by heavy
The northern side of the harbour is low lying and prone to tidal inundation. Saltmarsh abuts the road and at high tide the water has been

known to innundate the road, eating away at the concrete.
WESTERN JETTY PATHWAY

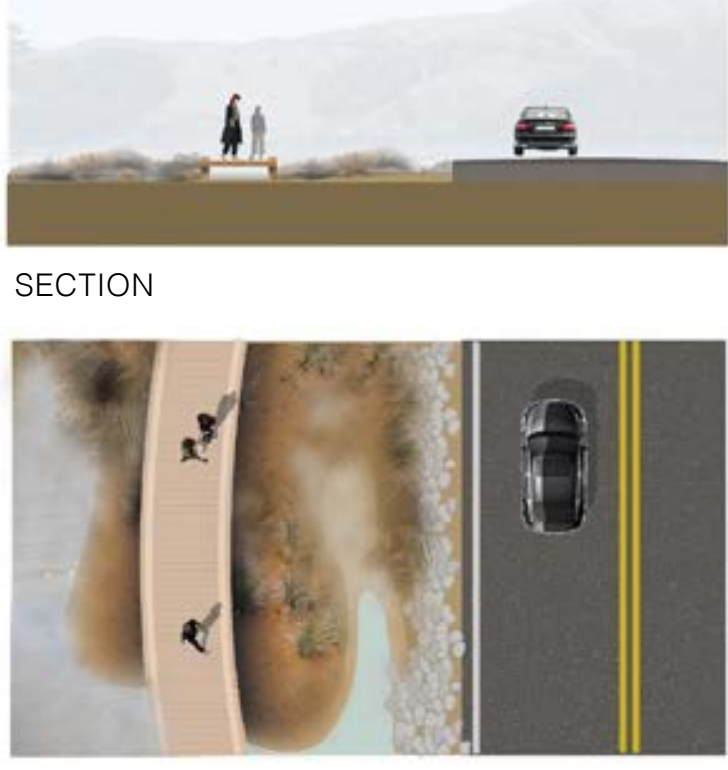

PLAN

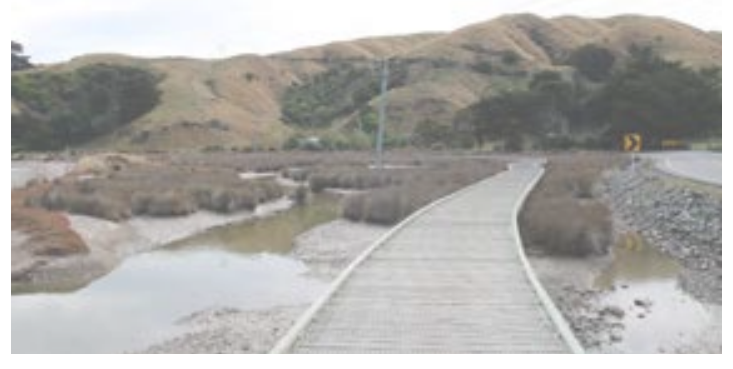

Te Ara Piko pathway. 


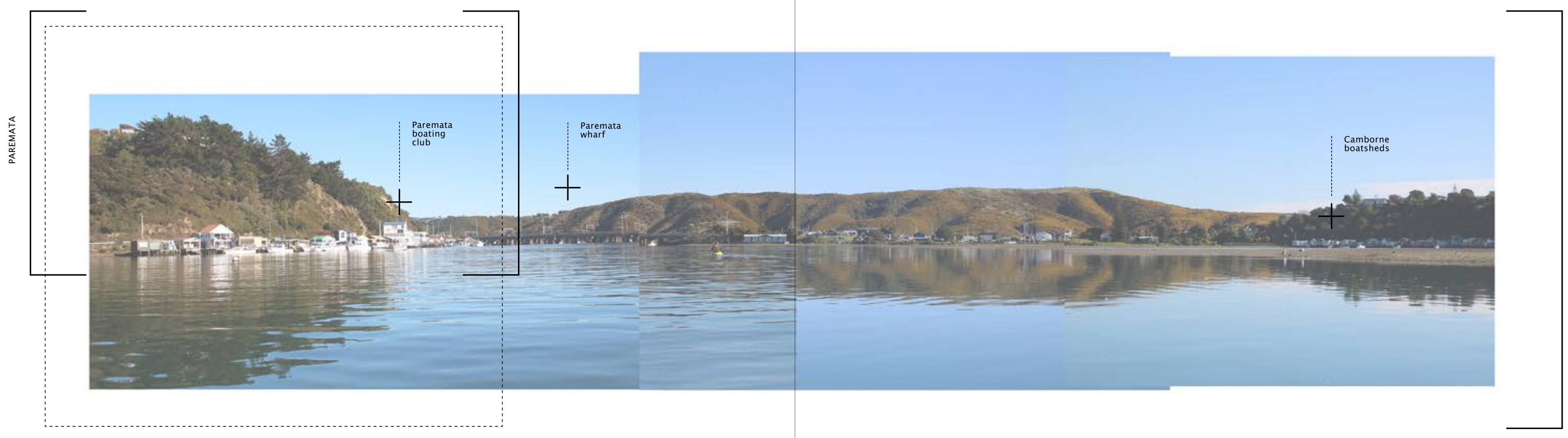

EASTERN SHORELINE

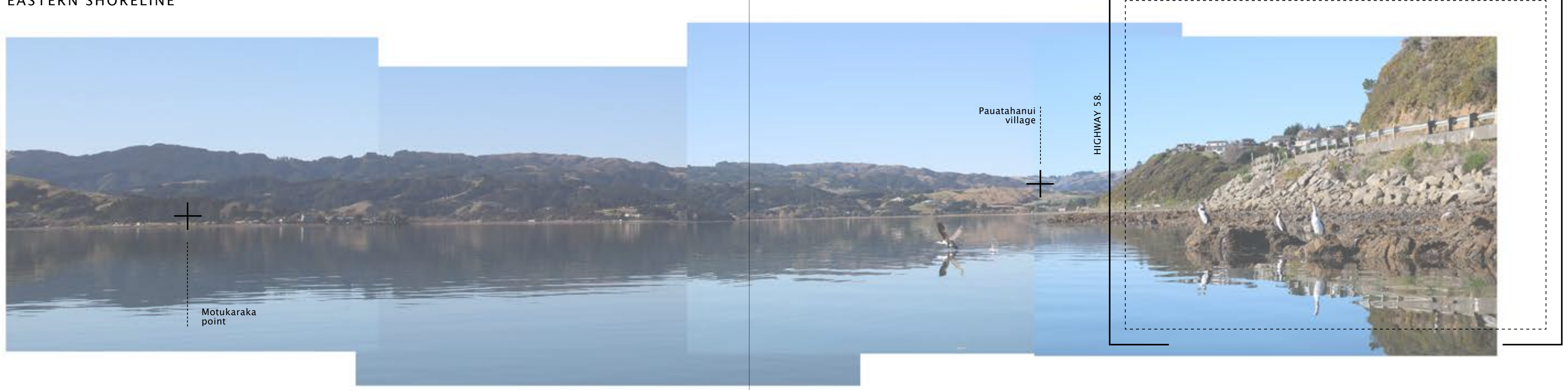



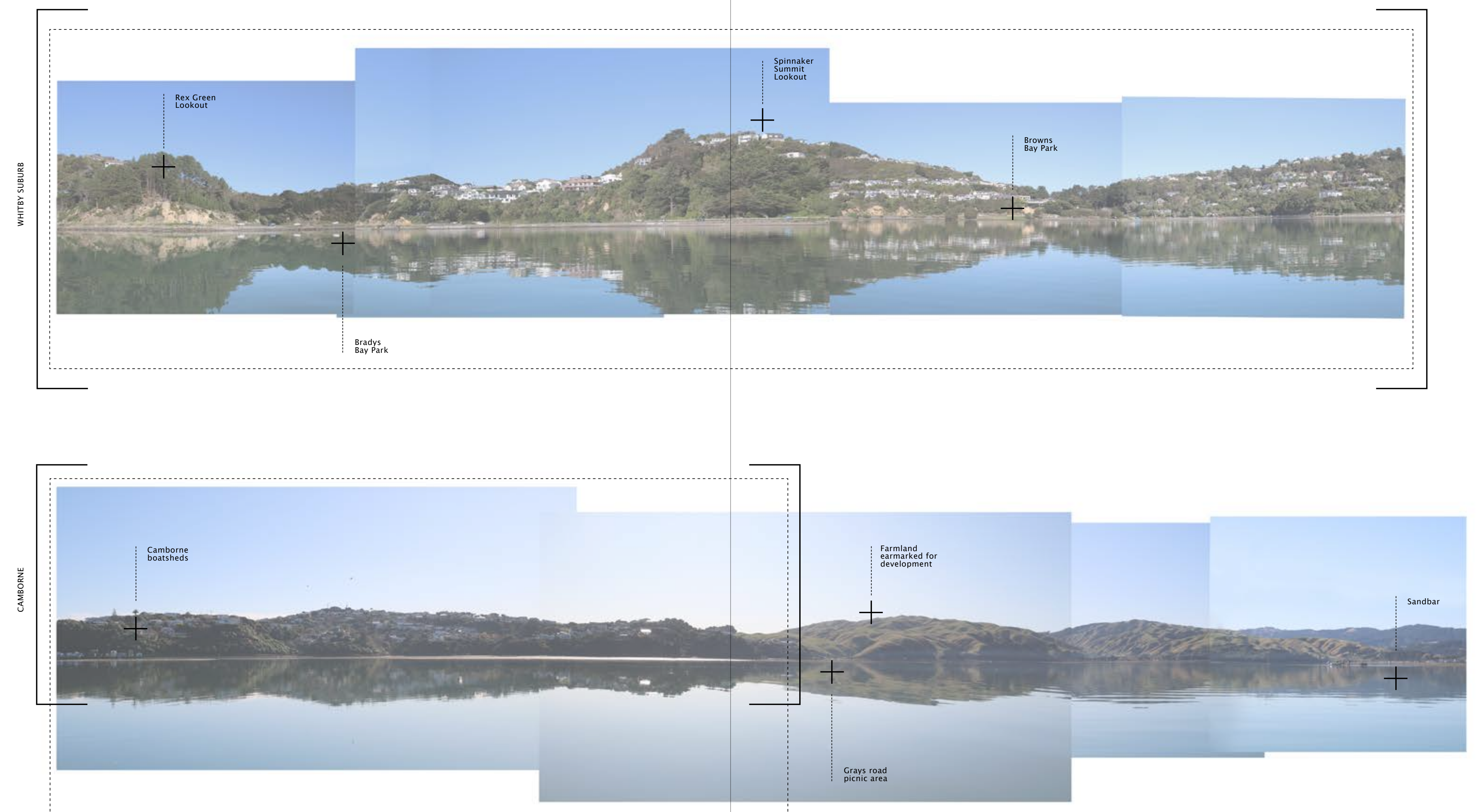


\section{Studies of the current edge condition of the inlet.}

\section{PLIMMERTON SUBURBAN FOOTPATH}

COASTAL PARK SPACE WITHIN AN

URBAN CATCHMENT

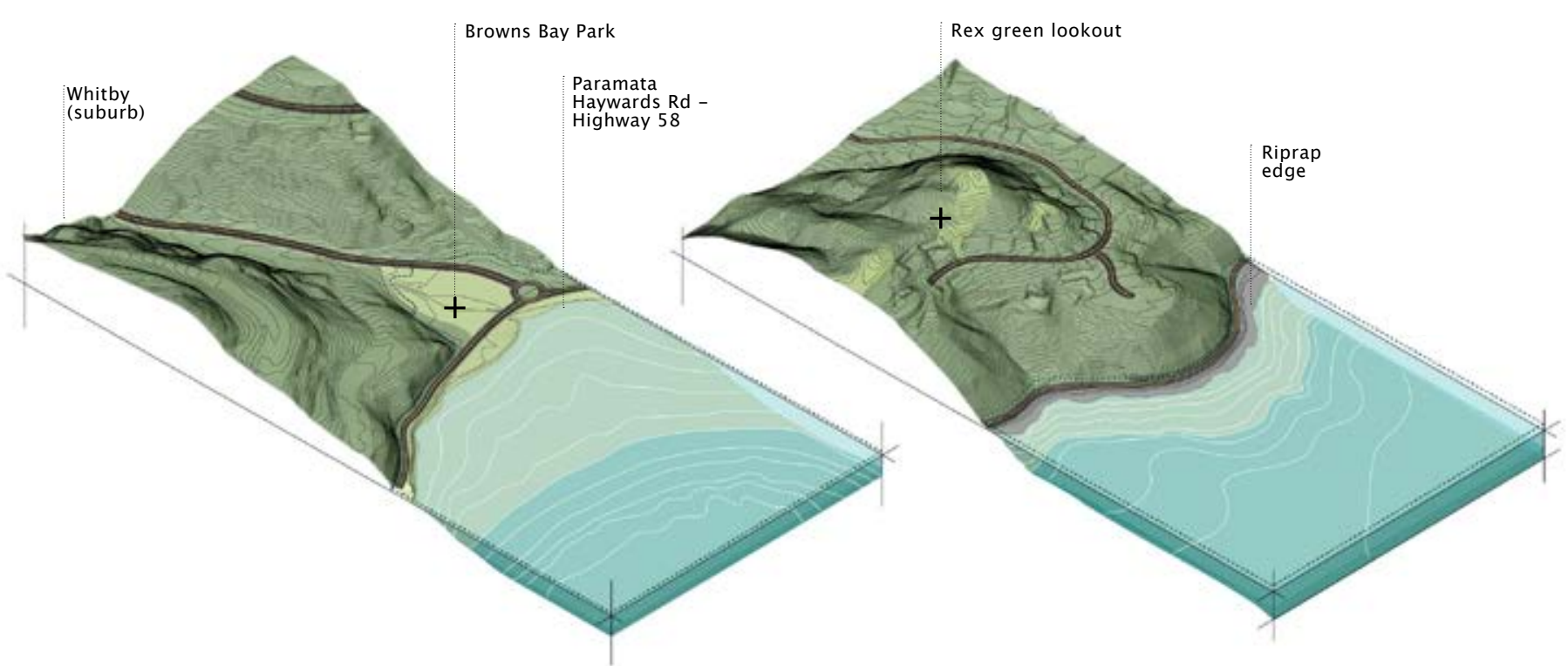

O EDGE CONDITION: RIPRAP

O ROOM TO RETREAT: MODERATE

O HABITAT: EEL GRASS

O STABILISATION RISK: MODERATE

O SEDIMENT RUNOFF: MODERATE
HIGHWAY ONE SOUTHERN SIDE

SUBURBAN DEVELOPMENTS ATOP COASTAL CLIFFS.

O EDGE CONDITION: RIPRAP/LOW SEA

O WALL

O ROOM TO RETREAT: LIMITED

HABITAT: EEL GRASS + SHELL BANKS STABILISATION RISK: HIGH

O SEDIMENT RUNOFF: LOW
NORTHERN SALTMARSH BOARDWALK

SALTMARSH WETLANDS/BIRD RESERVE

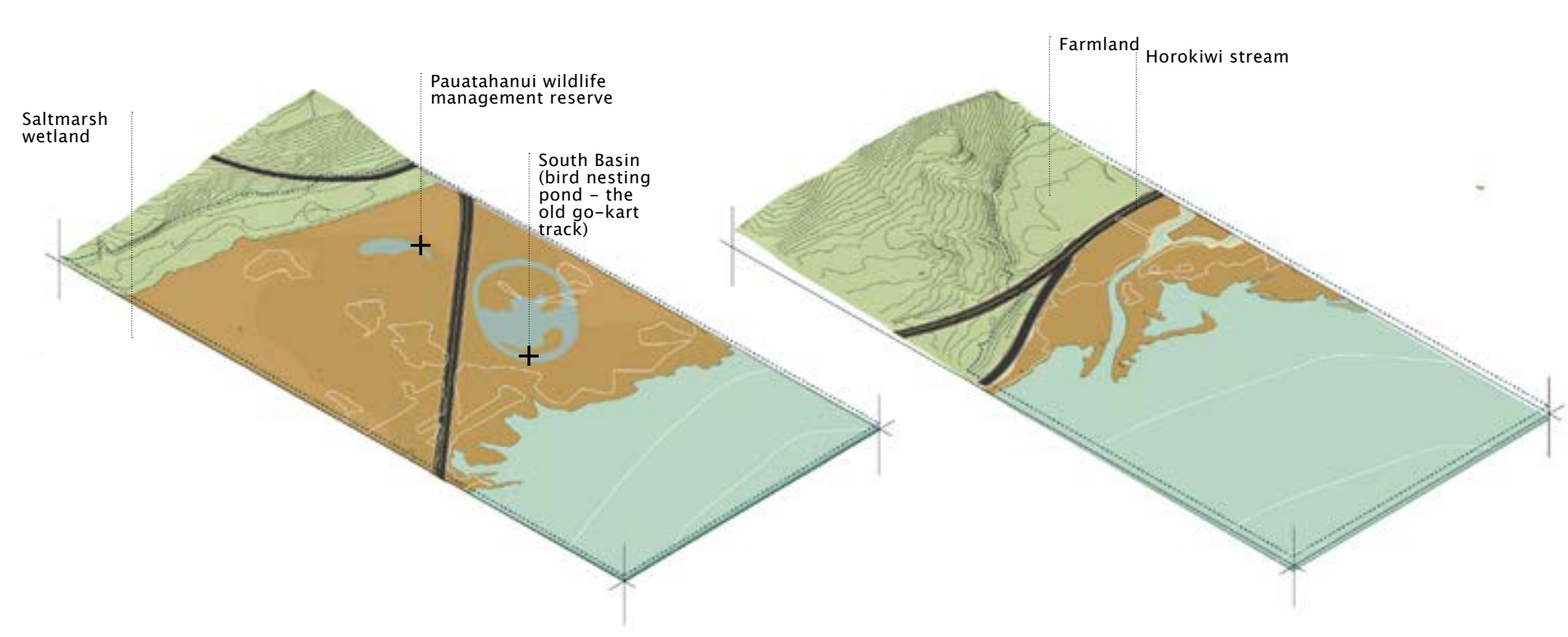

EDGE CONDITION: MARSHLAND BOUNDED BY ROAD

O ROOM TO RETREAT: MODERATE

HABITAT: SALTMARSH WETLAND +

EEL GRASS

O STABILISATION RISK: LOW

SEDiment RUNOFF: MOderate
WESTERN JETTY PATHWAY

FARMLAND STREAMS
EDGE CONDITION: MARSHLAND BOUNDED BY ROAD

ROOM TO RETREAT: ABUNDANT

HABITAT: SALTMARSH WETLAND EEL GRASS

O STABILISATION RISK: LOW

O SEDIMENT RUNOFF: HIGH 


\section{Projected tidal inundation on edge conditions.}

PLIMMERTON SUBURBAN FOOTPATH

COASTAL PARK SPACE WITHIN AN URBAN CATCHMENT.

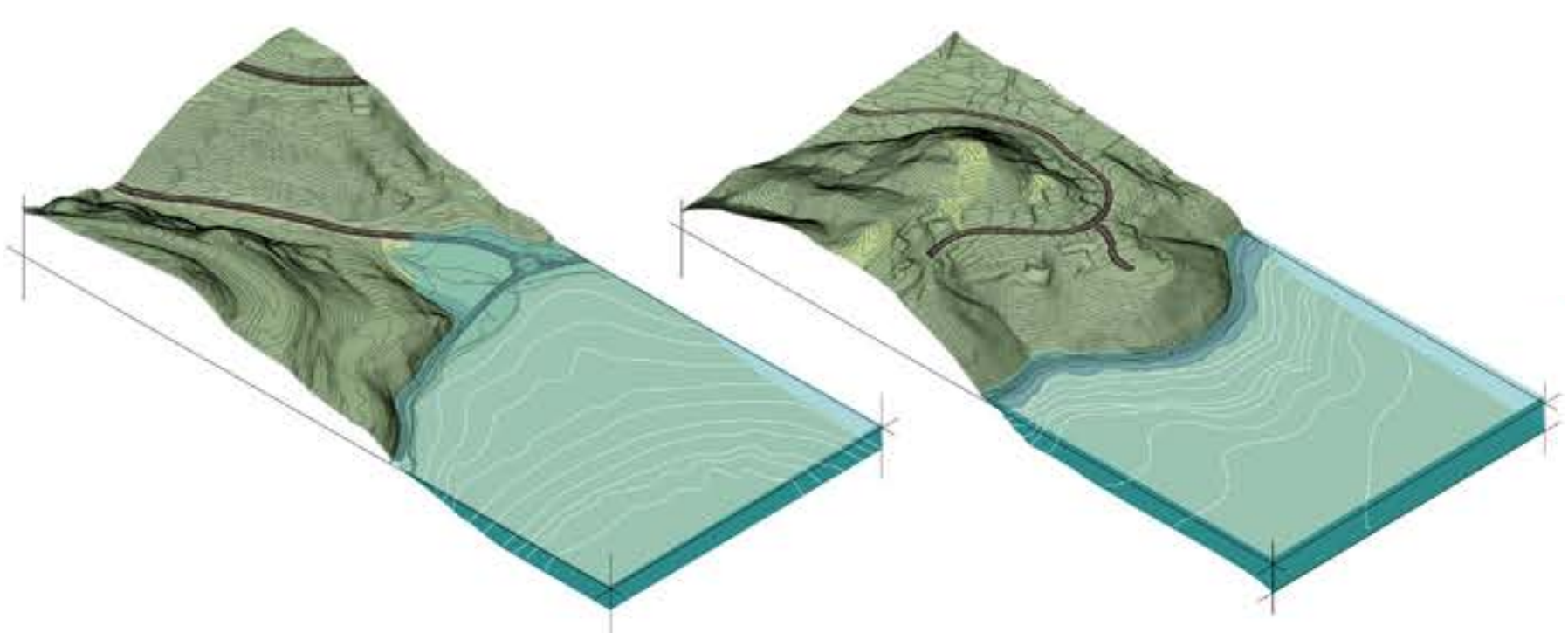

O APPROACH: ACCOMMODATE

OPPORTUNITIES:

+ SOME ROOM FOR RETREAT -

ALLOW WATER TO FLOOD LOW

LYING PARK SPACE TO CREATE A

WETLAND PUBLIC PARK
HIGHWAY ONE SOUTHERN SIDE

SUBURBAN DEVELOPMENTS ATOP COASTAL CLIFFS.

O APPROACH: PROTECT

OPPORTUNITIES:

+ RECLAIM EDGE FROM CARS AND CREATE A PUBLIC WALKWAY ALONG THE OLD ASPHALT SO AS NOT TO FURTHER ENCROACH ON THE TIDAL EDGE.

+ CONNECT PROPOSED PATHWAY TO EXISTING HILLTOP WALKWAYS
NORTHERN SALTMARSH BOARDWALK

SALTMARSH WETLANDS/BIRD RESERVE
WESTERN JETTY PATHWAY

FARMLAND STREAM

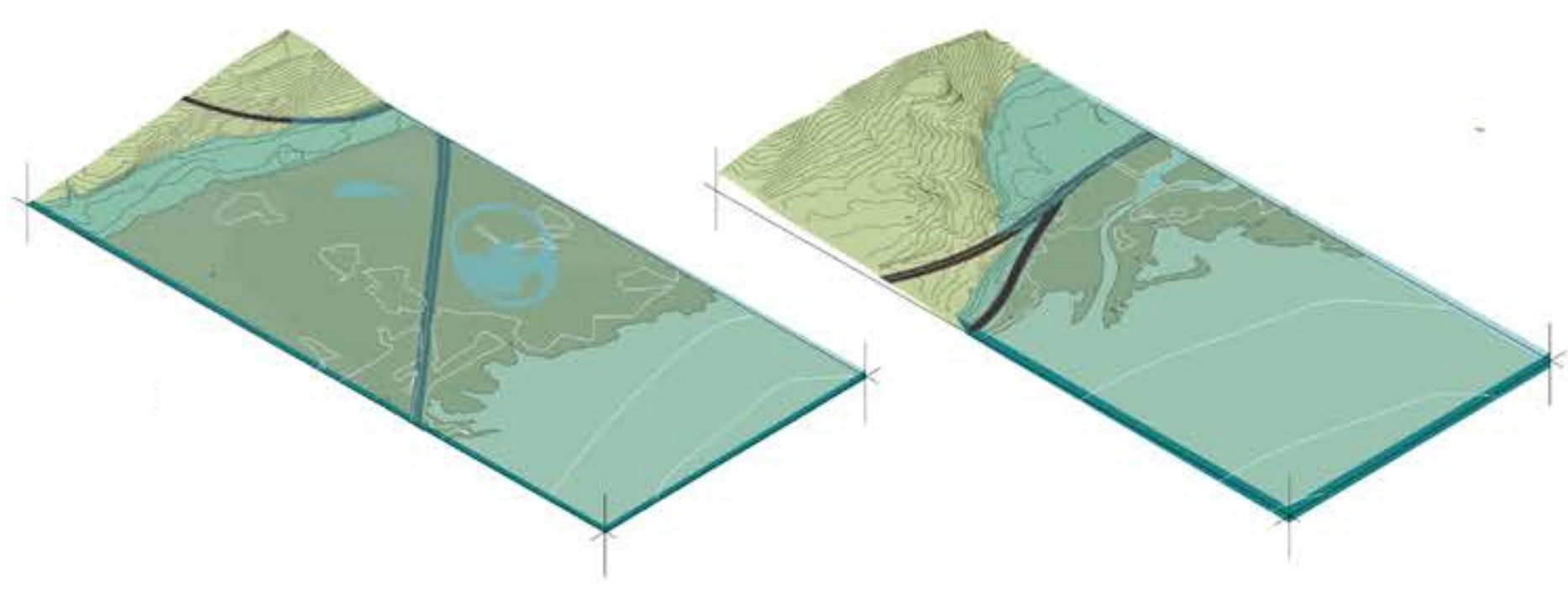

O APPROACH: RETREAT + PROTECT (SOFT INF.)

OPPORTUNITIES

+ LEARN FROM THE ECOLOGICALLY RICH HABITAT AND DRAW FROM

THESE SYSTEMS

+ CREATE ROOM FOR SALTMARSH TO RETREAT INLAND
APPROACH: RETREAT PROTECT (SOFT INF.)

OPPORTUNITIES

+ DEVELOP WETLANDS TO BUFFER ONCOMING TIDES AND ALLOW

SEDIMENT FROM STREAMS TO DROP BEFORE IT REACHES THE HARBOUR 


\section{Conclusions.}

The Northern and southern coastlines are the areas most likely to be affected by changes in the tideline and therefore have become the focus of this design-led study.

Low lying valleys in the north produce the largest amount of sediment runoff into the harbour and are also the most vulnerable to tidal inundation These valleys need soil stablisation through planting in order to support movement growth, and adaptabilty to climactic shifts.

Steep cliff faces along the south coast are protected from storm surge only by a narrow flat road along the coastal edge that restricts recreational use. By reclaiming this edge for

pedestrian access, measures can be taken that

slow the impact of potential sedimentation or sea

level rise effects without encroaching further into the water and thus disrupting the ecology.

The eastern and western edges already have well developed pathways and ecological buffers that should withstand any significant tidal changes.

These areas will be sythensised and connected to the proposed pathway. 


$$
05 \text { - }
$$

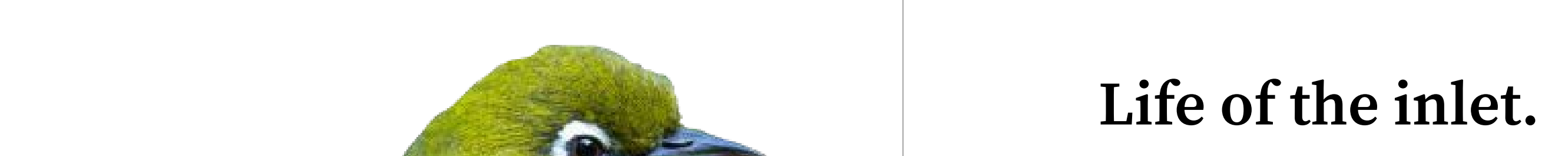




\section{Ecological Significance.}

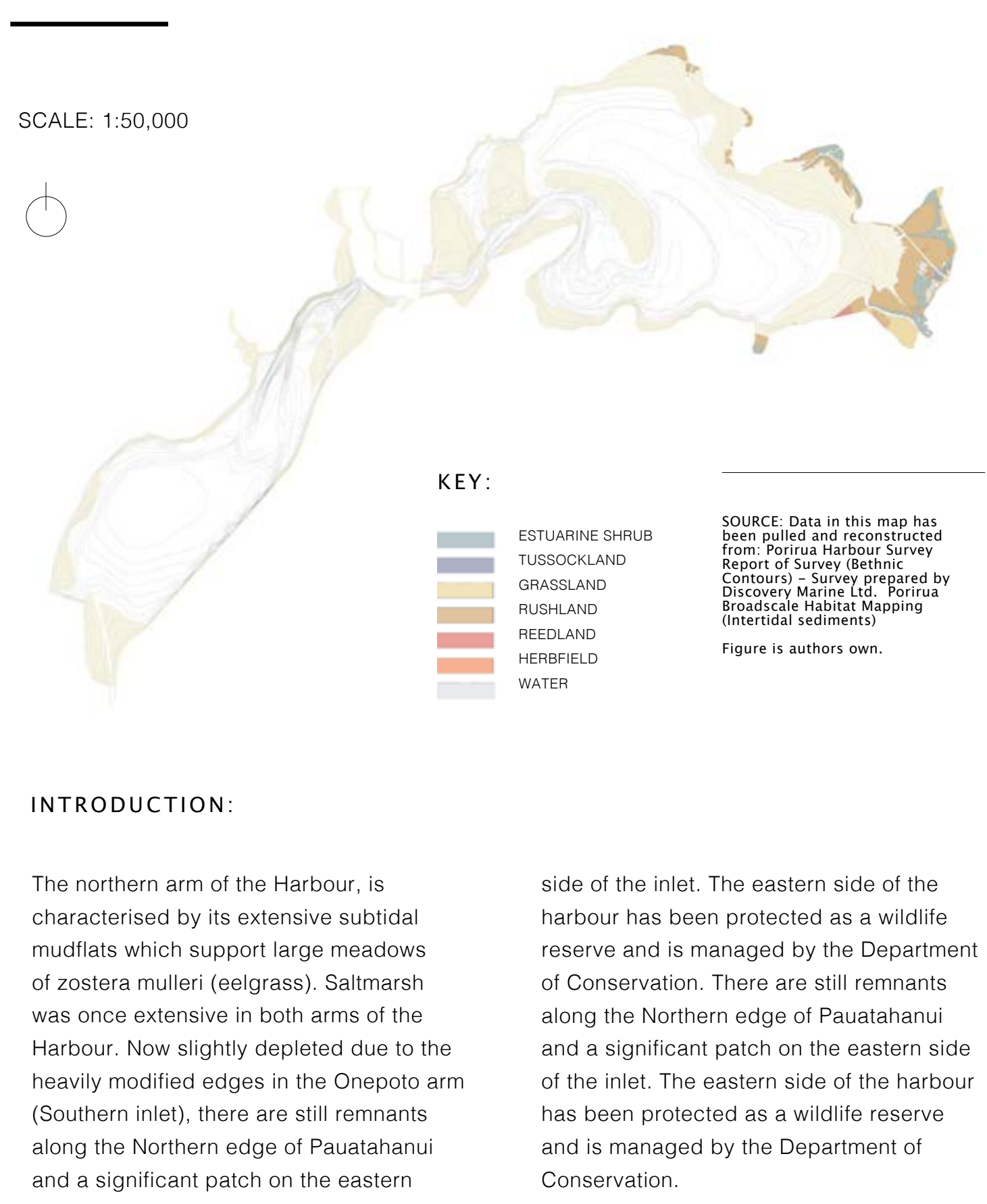

\section{Identifying species within Pauatahanui.}

\author{
INTRODUCTION:
}

This proposal recognises that landscapes cannot be considered as something to be acted upon but rather as a time-driven living process in flux. The interrelationships within ecosystems are multi-scalar, they change and adjust as processes through time.

In order to intervene within this complex environment, we must first begin to unrave the interrelationships that shape it and the needs of those who rely on it.

The deconstruction of these existing assemblages are unravelled through fieldwork (observation) and literature (species, habitat location and behaviour) to discover what forms of life exist within the harbour, how they interact and what their needs are. (Documented through isometrics 'deep' sections (transections) and behavioural mapping.)

Through this analysis we can begin to assess what safety requirements there may be around facilitating modes of encounter. How close can two species be without making either feel unsafe, what level of interaction can they tolerate (proxemics) and how can we facilitate an encounter between the two with room for genuine spontaneity. How can we get people to alter their behaviour, to cohabit and experience space in a way that is emotive? To get nuanced, poetic, beautiful encounters emerging

To do this, first we must first take record of the species living within the inlet, as well as their requirements, in order create spaces that consider and prioritise their comfort as much as humans. 


\section{Approach.}

To understand the nuances of these lives and the social ecology that makes up Pauatahanui, both quantitative and qualitative methods are employed. This allows a more complete picture to emerge of both the physical needs of the users (through literature and scientific records of) emotional or instinctive responses -by employing affective method. ${ }_{51}$ This method requires researchers to approach their research kinaesthetically. To do this I undertook hours of immersive fieldwork, moving around the harbour by foot, car and kayak, approaching wildlife and recording affective reactions when perceived (through proxemics studies) This analysis has been synthesised through a series of drawings which combine personal fieldwork research with scientific surveys to answer the following questions:
Who lives there?

Whereabouts are do they live/ what habita are they reliant on?

How do their lives cross over?

How close can inter-species get (in terms

of physical distance) before one party feels unsafe?

How do they move around the harbour?

51. Mehrabi stresses this point as it "because it highlights the reciprocal modes of doing science in which animals are not passive recipients but acive agents in bodied realities of doing science, moving away from the myth of absolute objectivity and disembodied science." Mehrabi, Tara. 2018. Being intimate with flies: on affective methodologies and laboratory work. Women, Gender Research. 27(1), 73-80.]

Who lives there?

The sheltered coastal beaches, mudflats and extensive saltmarsh within the inlet provide a stable and sheltered environment for a wide range of invertebrates, fish and birds to nest and feed. This section describes many of the animals living in the shallow subtidal and intertidal zones.

COMMON ANIMALS LIVING IN THE INTERTIDAL ZONE:
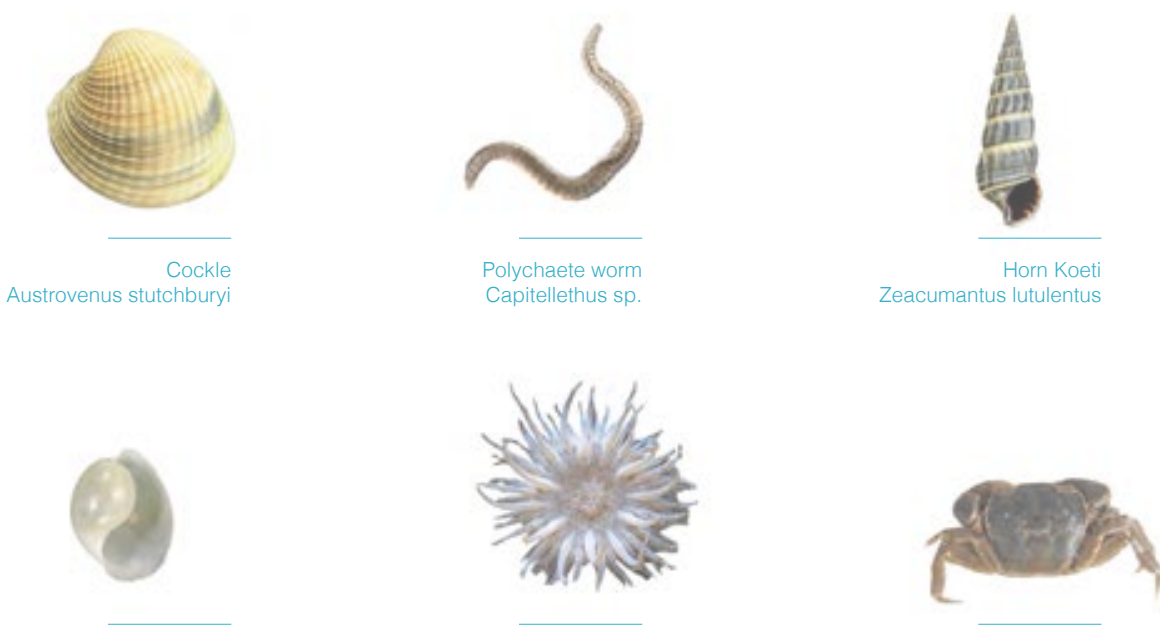

White buble shell
Haminoea zelandiae
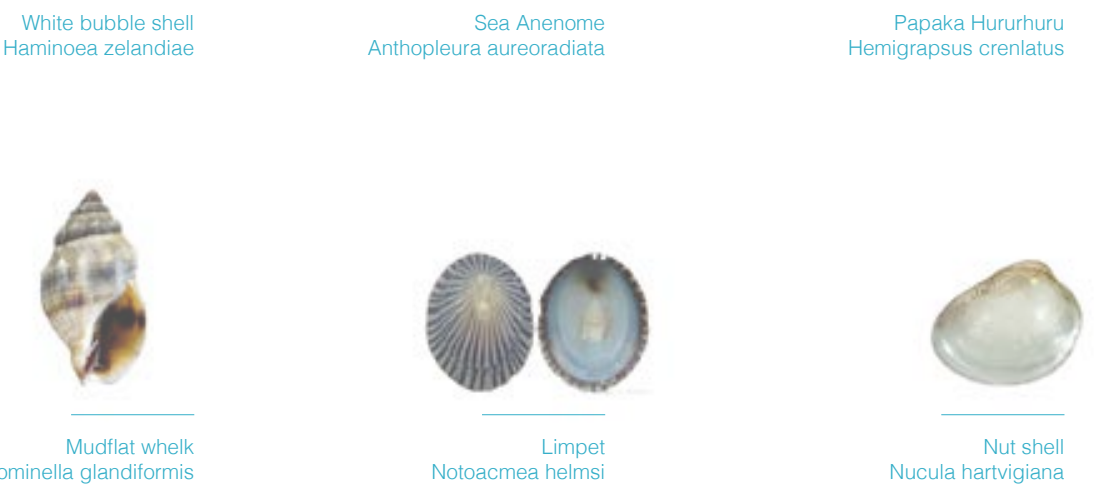


\section{Fish species.}

This diagram depicts the relative abundance of fish species found within the inlet. The data is complied from records by Healy (1980), Whitt (1983) and Hadfield \& Jones (2010).

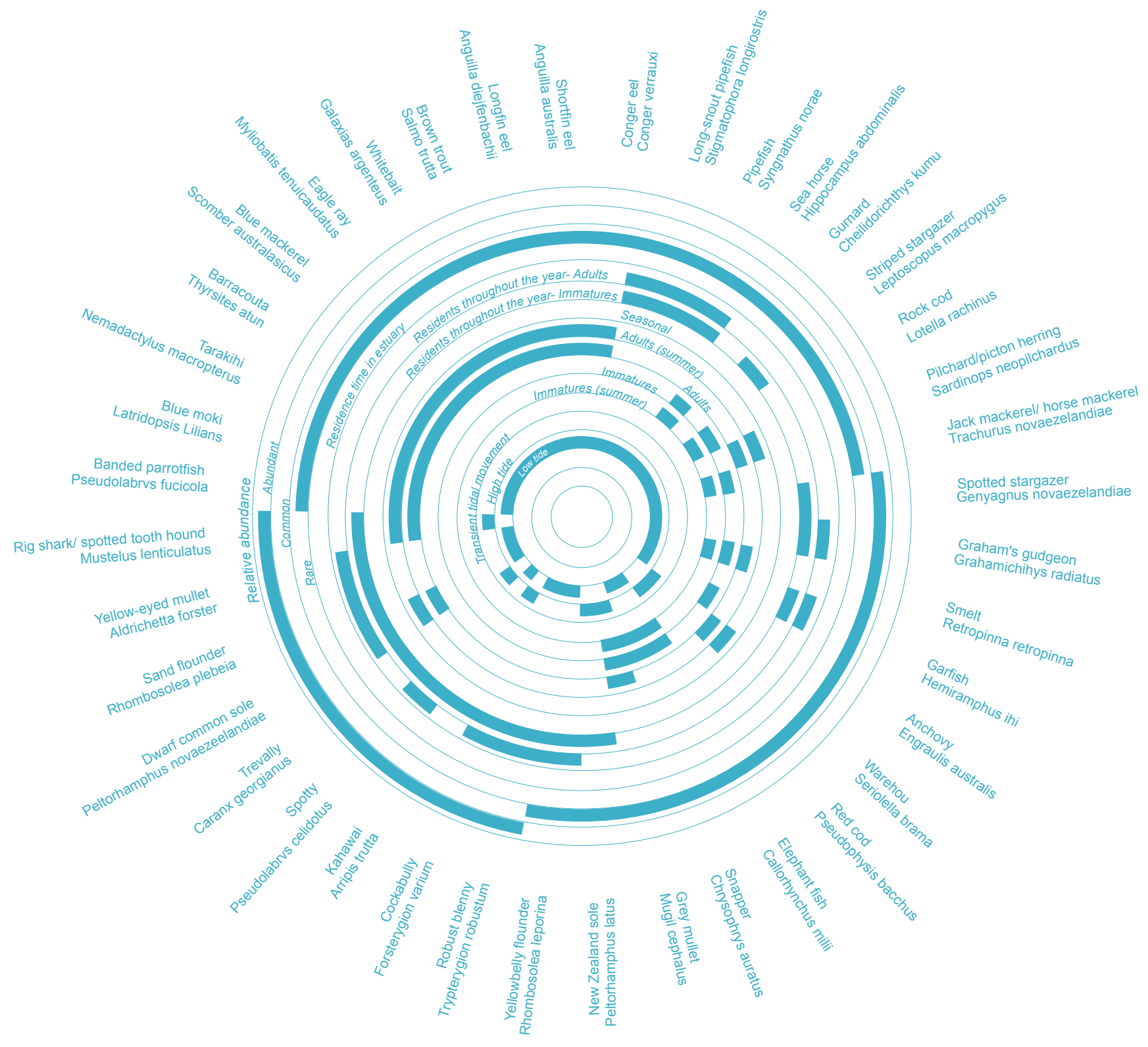

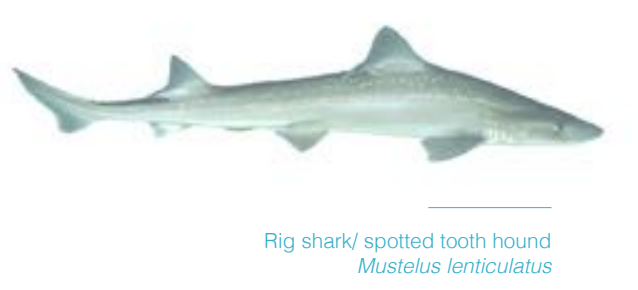
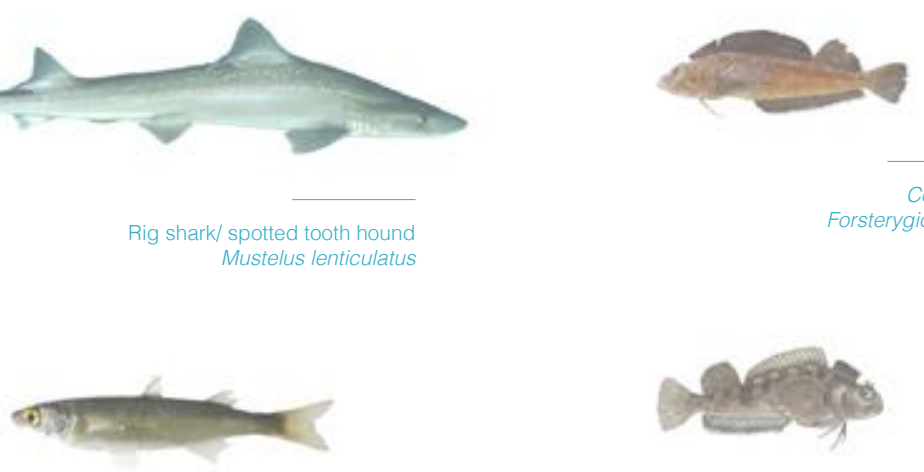

Yellow-eyed mullet
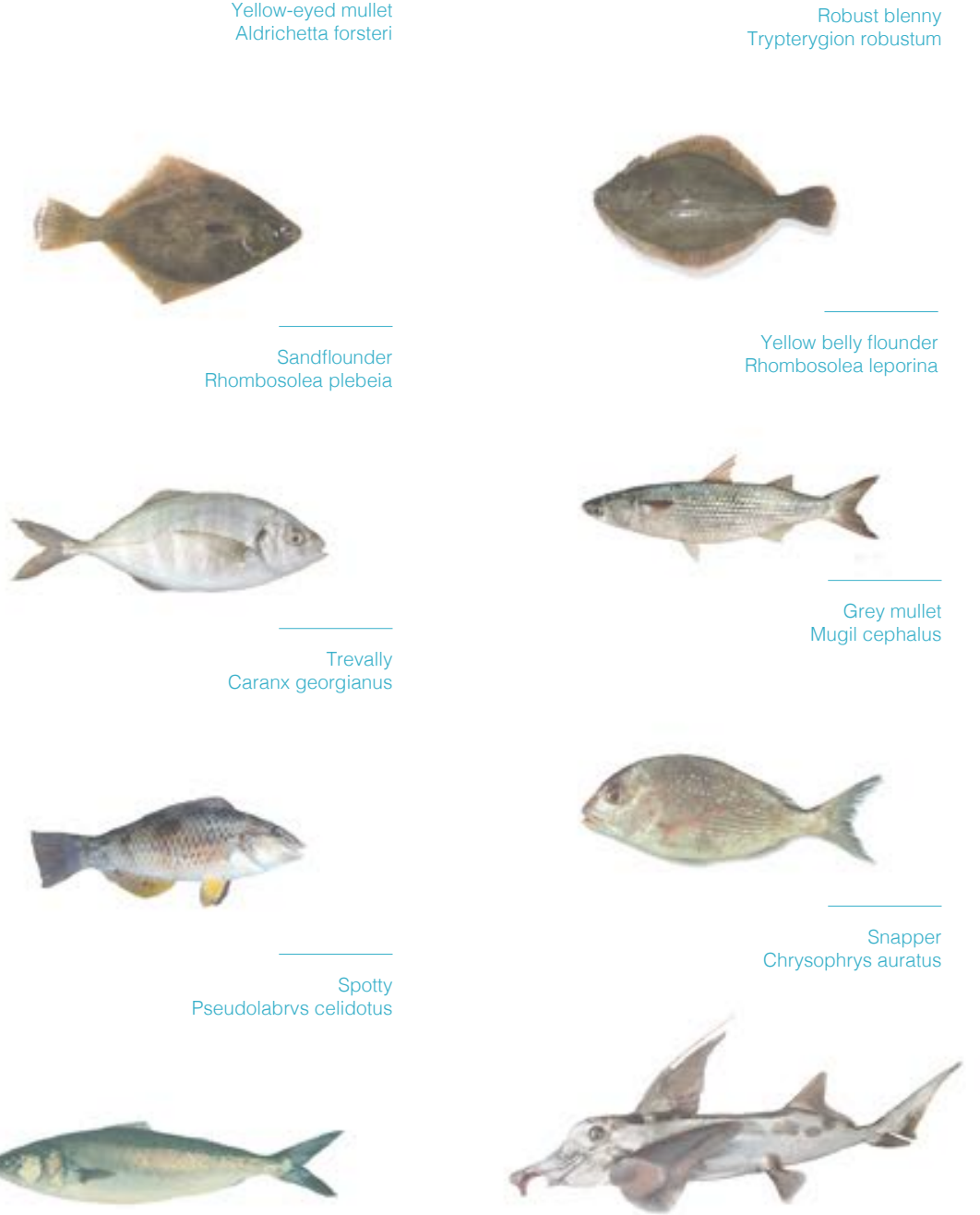

Grey mullet
Mugil cephalus

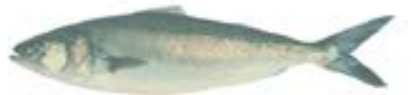

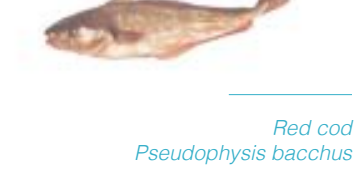
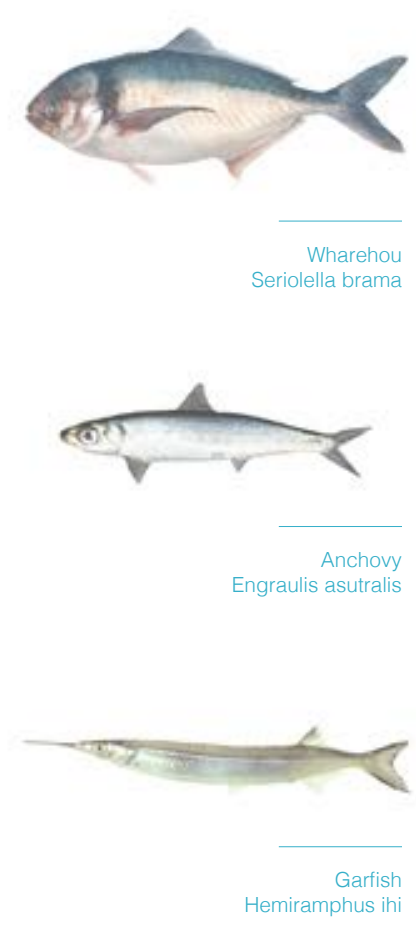

a.

$\overline{\substack{\text { Elephant tifh } \\ \text { callorinhonus milii }}}$

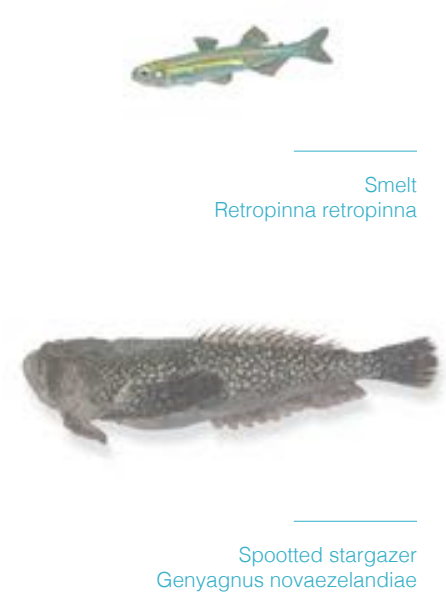




\section{Bird species.}

Similarities begin to emerge when you group species by their habitat preference. Nesting types, movement and distance

(from humans) all appear to be very similar depending on

where the bird might be found in the harbour. The saltmarsh

and farmland birds also appear to be the most common

nesters within the inlet, therefore more at risk of disturbance

when laying.

This data is complied from records by Healy (1980), Whitt (1983) and Hadfield \& Jones (2010).
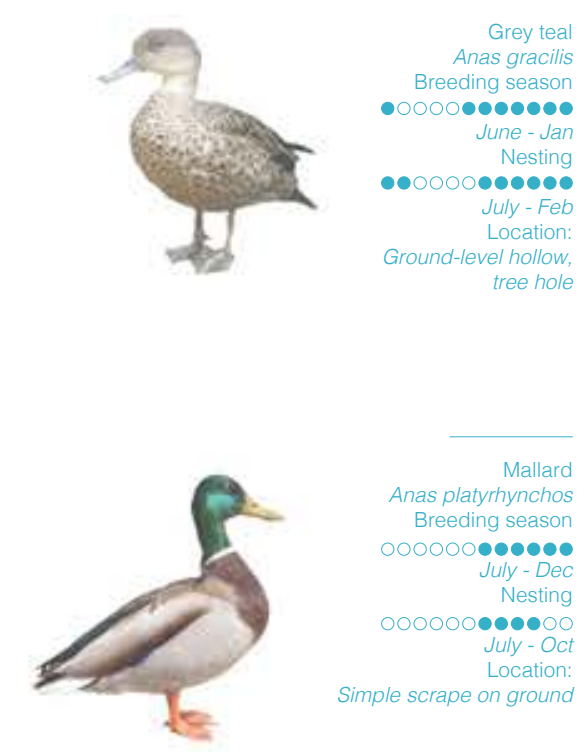

SALTMARSH + FARMLAND
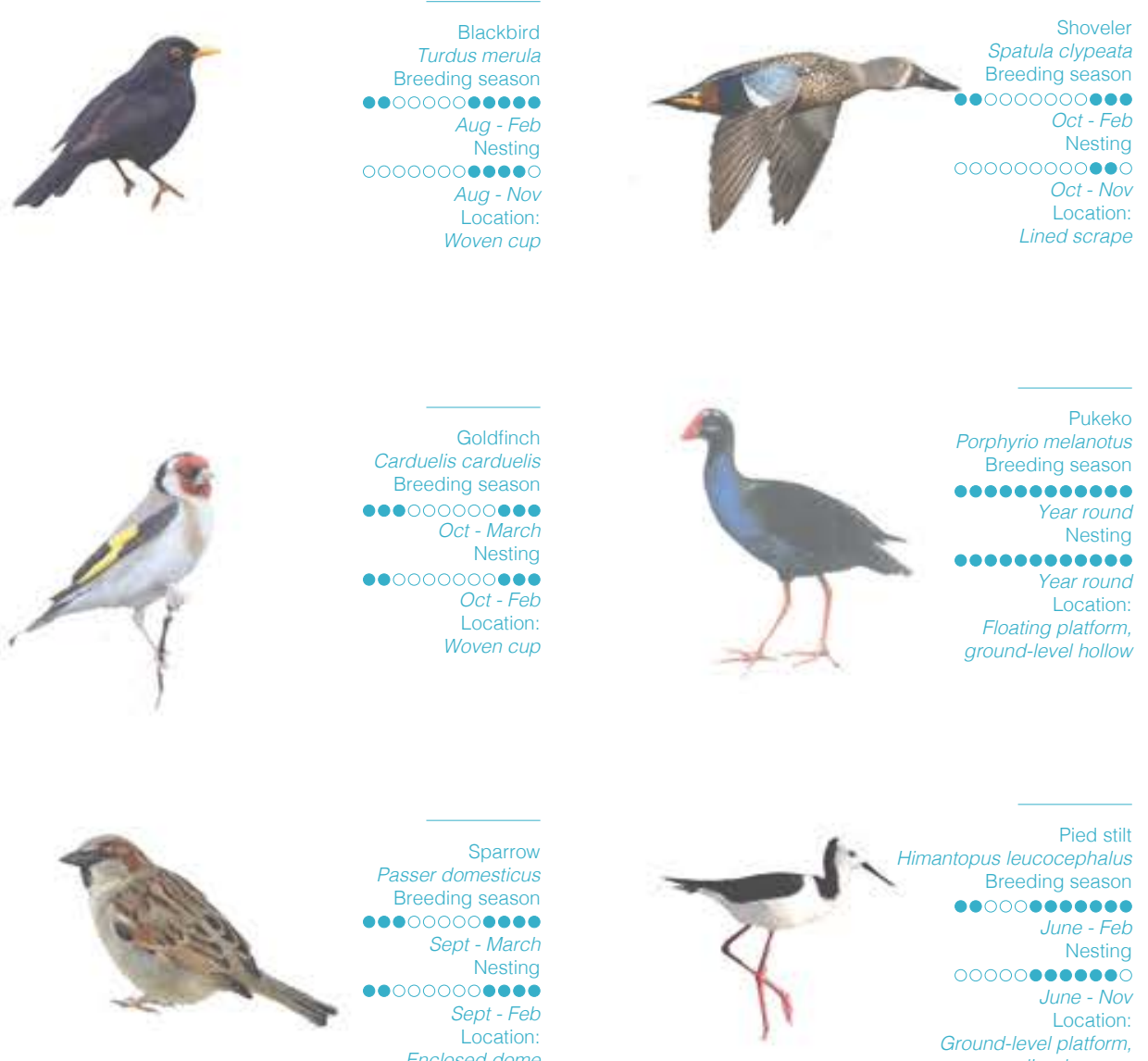

ROCK COASTLINE + SHELL BANKS
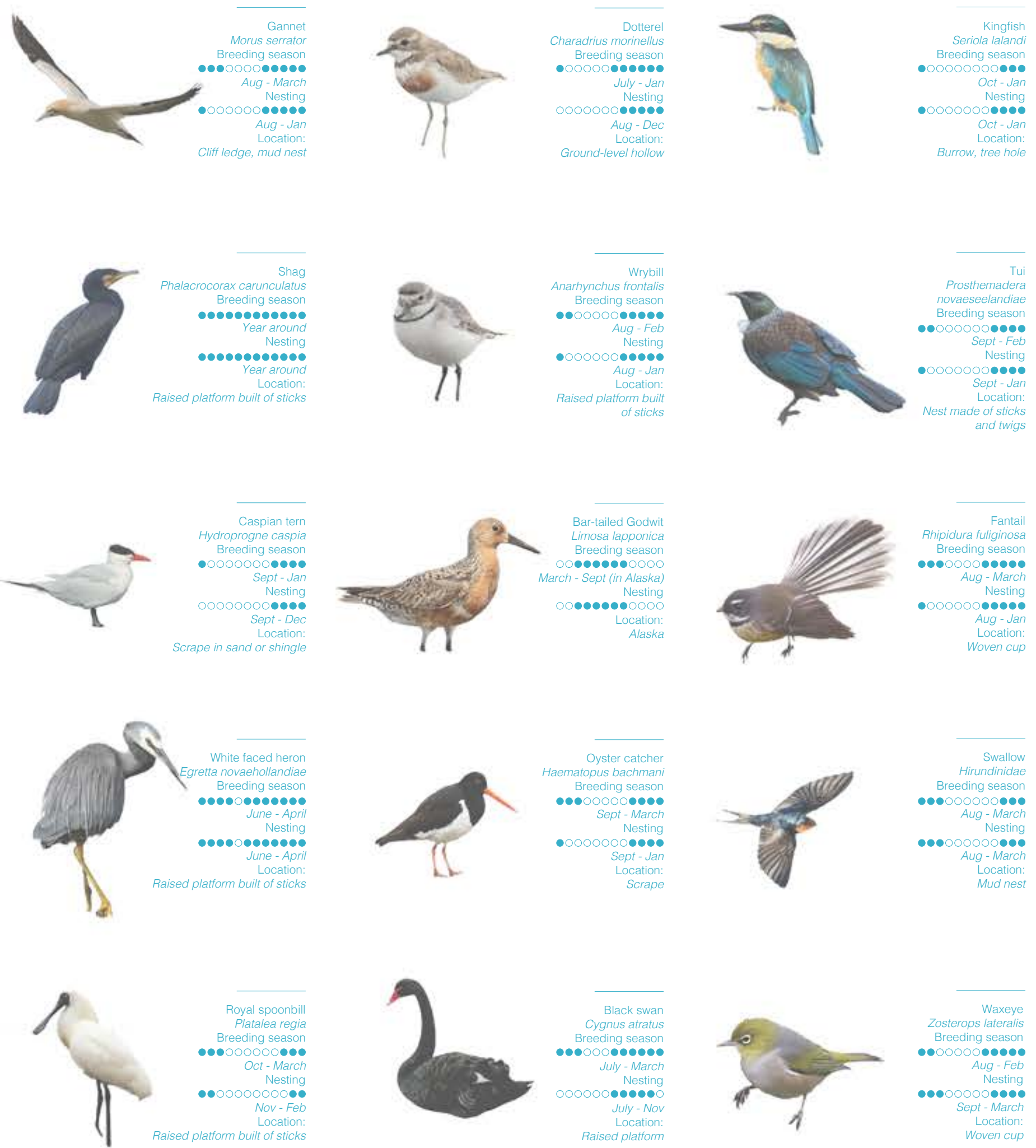


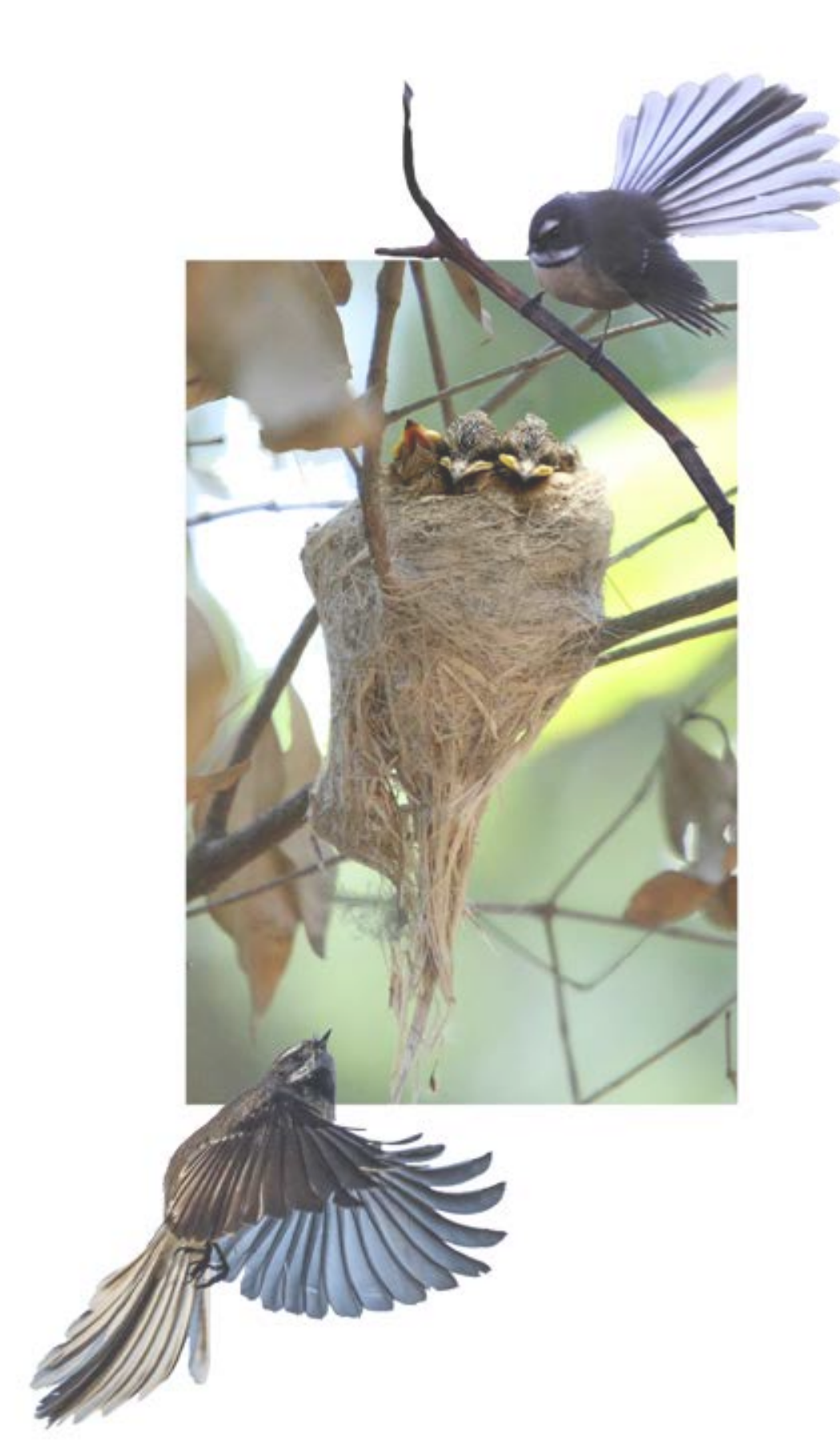

\section{Where can} they be found?

There are five key habitat types identified during my fieldwork:

1. Saltmarsh wetlands

2. Shell banks

3. Rocky coastal edges

4. Coastal bush

5. Farmland streambeds

These habitats had the largest number of species co-existing together in close proximity and it was clear from observation that they $\mathrm{p} \neq$ rovided

significant food and shelter to those living within the inlet. These habitats were all present at several locations around the site and tended to be visited by the same species at each site, indicating common trends in inhabitants and their needs.

A variety of nests around the harbour were also noted, indicating the type of bird species were present at each site.

\section{BIRD HABITAT}

$\begin{array}{lll}\ddot{u} & \text { A. } & \text { ENCLOSED DOME } \\ \stackrel{u}{0} & \text { B. } & \text { WOVEN CUP } \\ \grave{z} & \text { C. } & \text { STICK NEST } \\ \llcorner & \text { D. } & \text { TREE HOLLOW } \\ \ddot{u} & \text { S. } & \text { SCRAPE } \\ & \text { E. } & \text { MUD NEST } \\ & \text { G. } & \text { RAISED PLATFORM MADE OF STICKS }\end{array}$
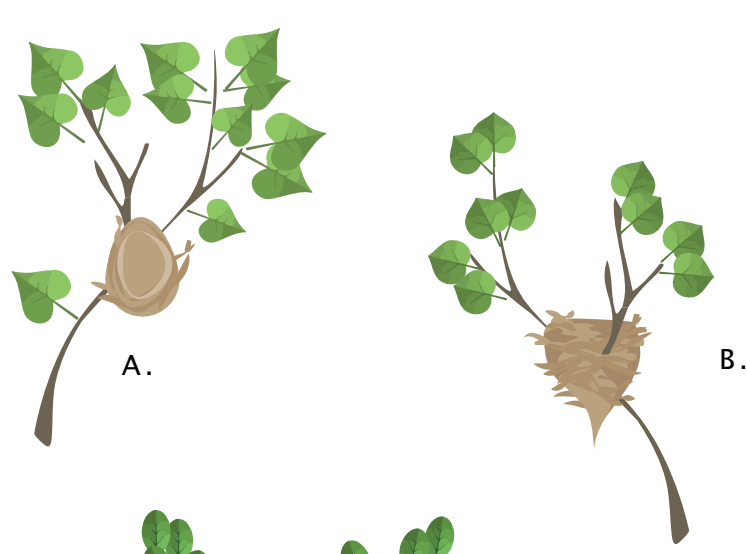

NESTING SITES
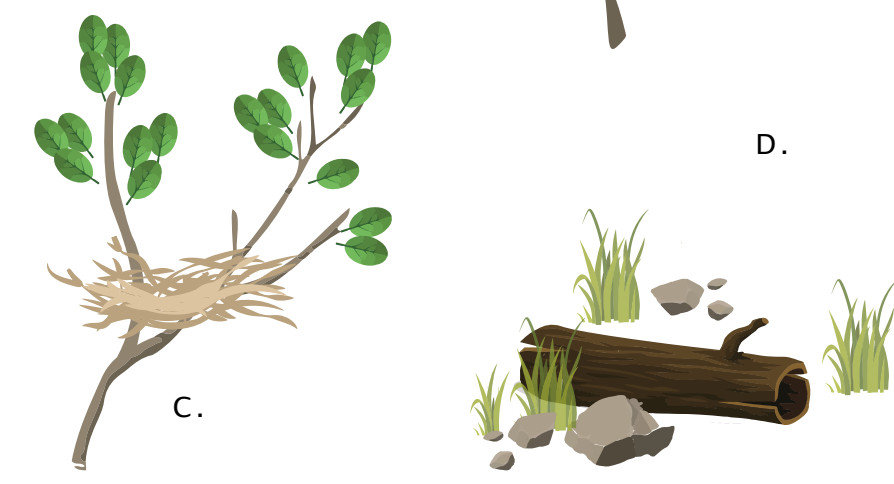

COASTAL FARMLAND SALTMARSH
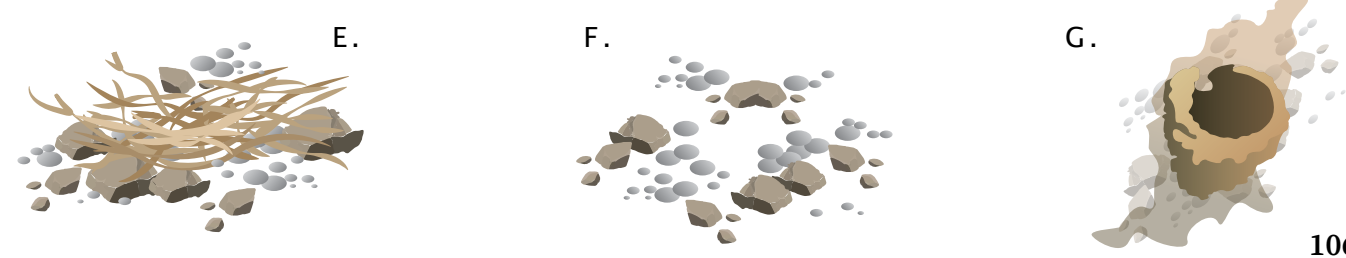


\section{SALTMARSH WETLAND}
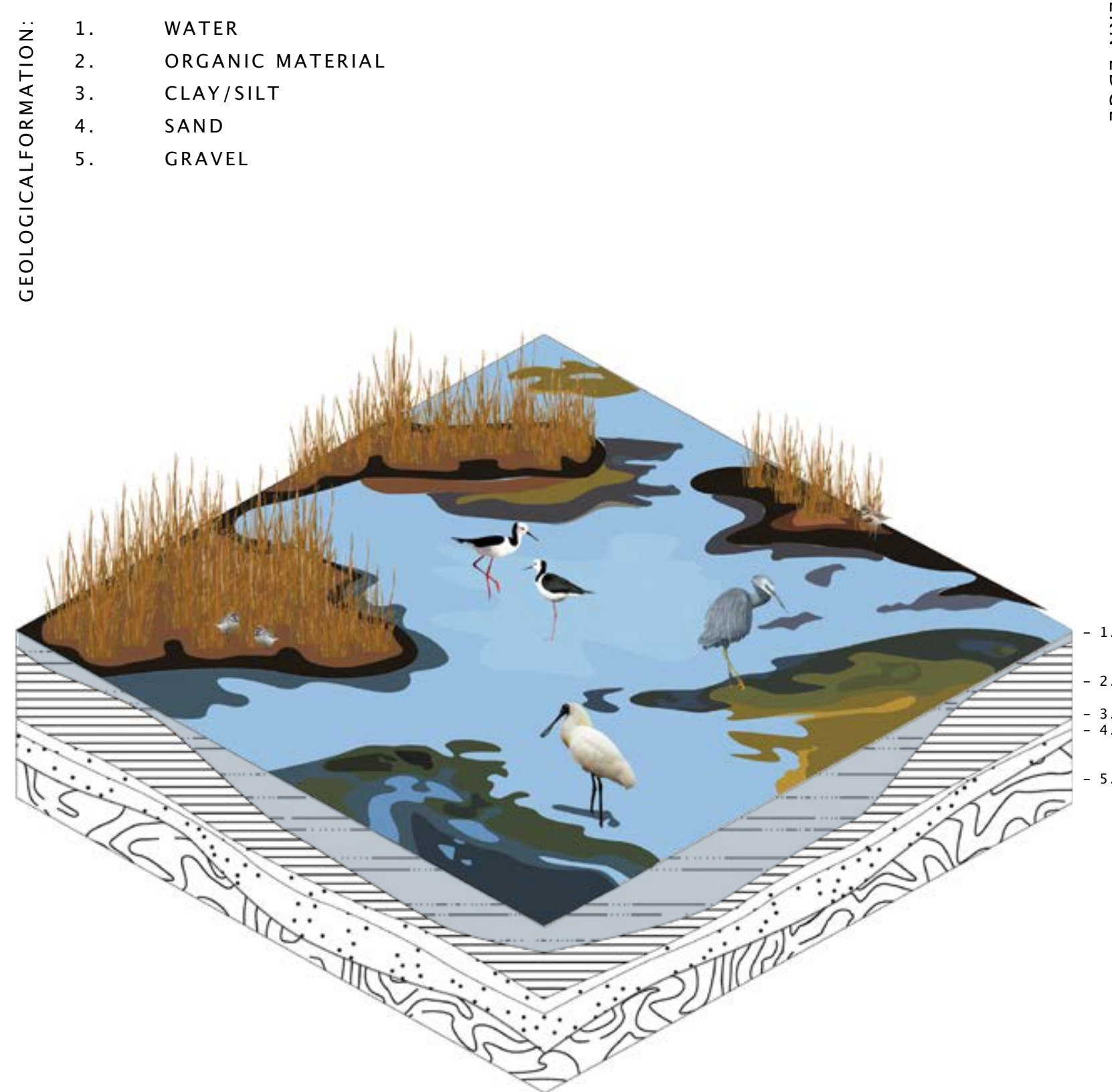

Wrybill
Anarhynchus frontalls

Bar-tailed Godwit
Limosa lapponica

Royal spoonbill
Platalea regia

White faced heron
Egretta novaehollane

Oyster catcher
Haematopus bach
Pied st
Himantio

$$
\begin{aligned}
& \text { Black swan } \\
& \text { Cygnus atratus }
\end{aligned}
$$$$
\text { Shag }
$$

Eagle Ray

Pukkeko
Porphyrio melanotus

Shoveler
Spatula clypeata
Mallard
Anas platyrhynchos

Grey teal
Anas gracilis

Sandiflounder
Rhombosolea plebei

Cominella glandiformis

Horn shell
Zeacumantus lutuentus

Earth worm
Phylum anelida

Polychaete worm
Phylum anelida

\section{FARMLAND STREAM}

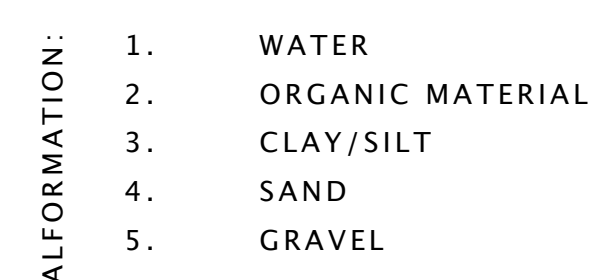

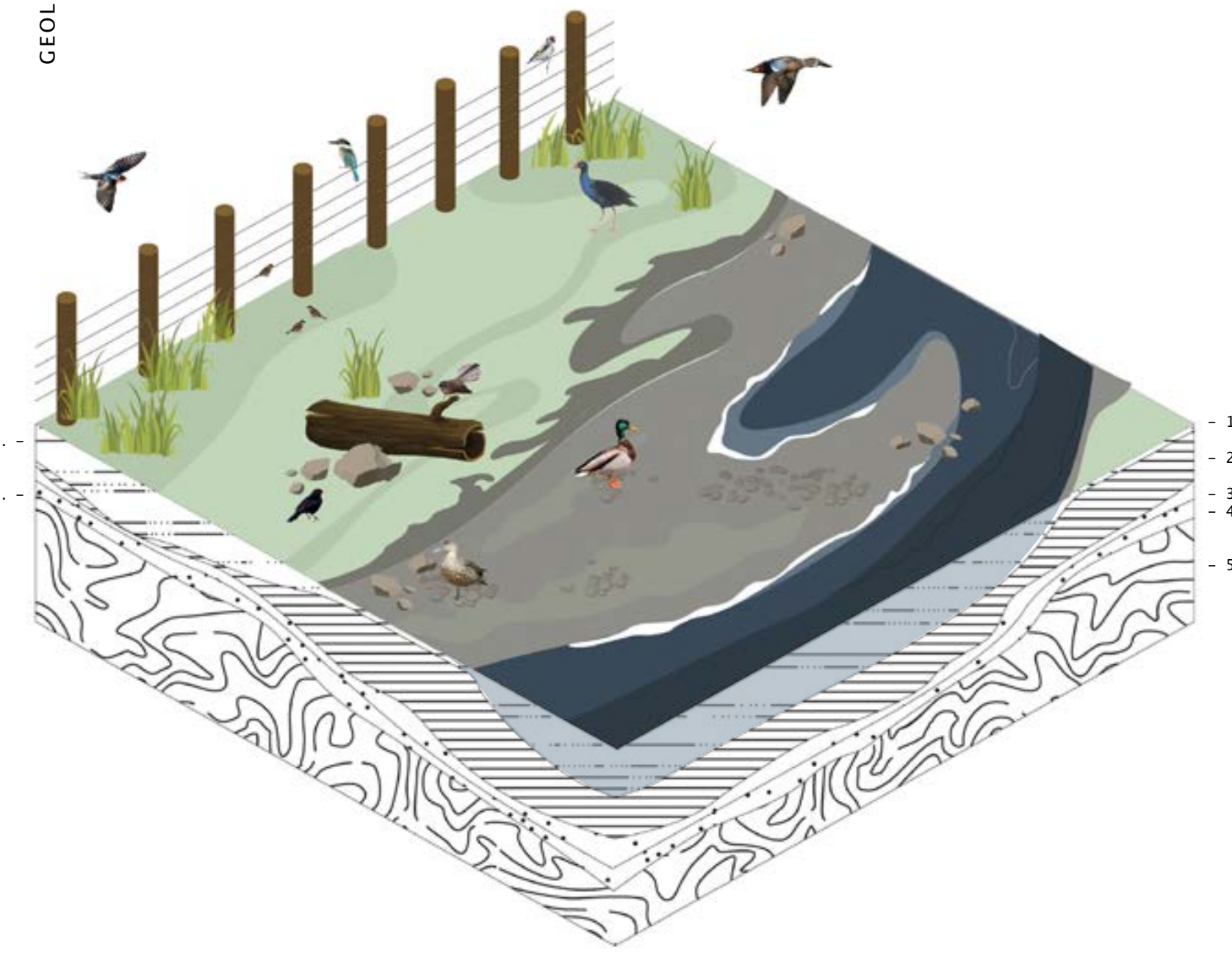

\begin{tabular}{|c|c|}
\hline $\begin{array}{l}\text { Backboird } \\
\text { Turdus merula }\end{array}$ & $\begin{array}{l}\text { Fantail } \\
\text { Rhipidura tuliginosa }\end{array}$ \\
\hline $\begin{array}{l}\text { Tuisthemadera } \\
\text { rovaeselandiae }\end{array}$ & $\begin{array}{l}\text { Pukkek } \\
\text { Porphyrio melanotus }\end{array}$ \\
\hline $\begin{array}{l}\text { Waxeye } \\
\text { Zosterops Iateralis }\end{array}$ & $\begin{array}{l}\text { Shoveler } \\
\text { Spatula alypeata }\end{array}$ \\
\hline $\begin{array}{l}\text { Golddinch } \\
\text { Carduelis carduelis }\end{array}$ & $\begin{array}{l}\text { Mallard } \\
\text { Anas platyrhynchos }\end{array}$ \\
\hline $\begin{array}{l}\text { Sparrow } \\
\text { Passer domesticus }\end{array}$ & $\begin{array}{l}\text { Grey teal } \\
\text { Anas gracilis }\end{array}$ \\
\hline
\end{tabular}

Swallow
Hirundinidae 


\section{ROCKY COASTAL EDGE}

\begin{tabular}{|c|c|c|}
\hline & \multirow{8}{*}{$\begin{array}{l}5 . \\
6 . \\
7 . \\
8 .\end{array}$} & WATER \\
\hline & & MUD/ORGANIC MATERIAL \\
\hline & & GRAVEL/MIXED \\
\hline & & MUDSTONE \\
\hline & & SILTSTONE \\
\hline & & LIMESTONE \\
\hline & & SANDSTONE \\
\hline & & CONGLOMERATE BASE \\
\hline
\end{tabular}

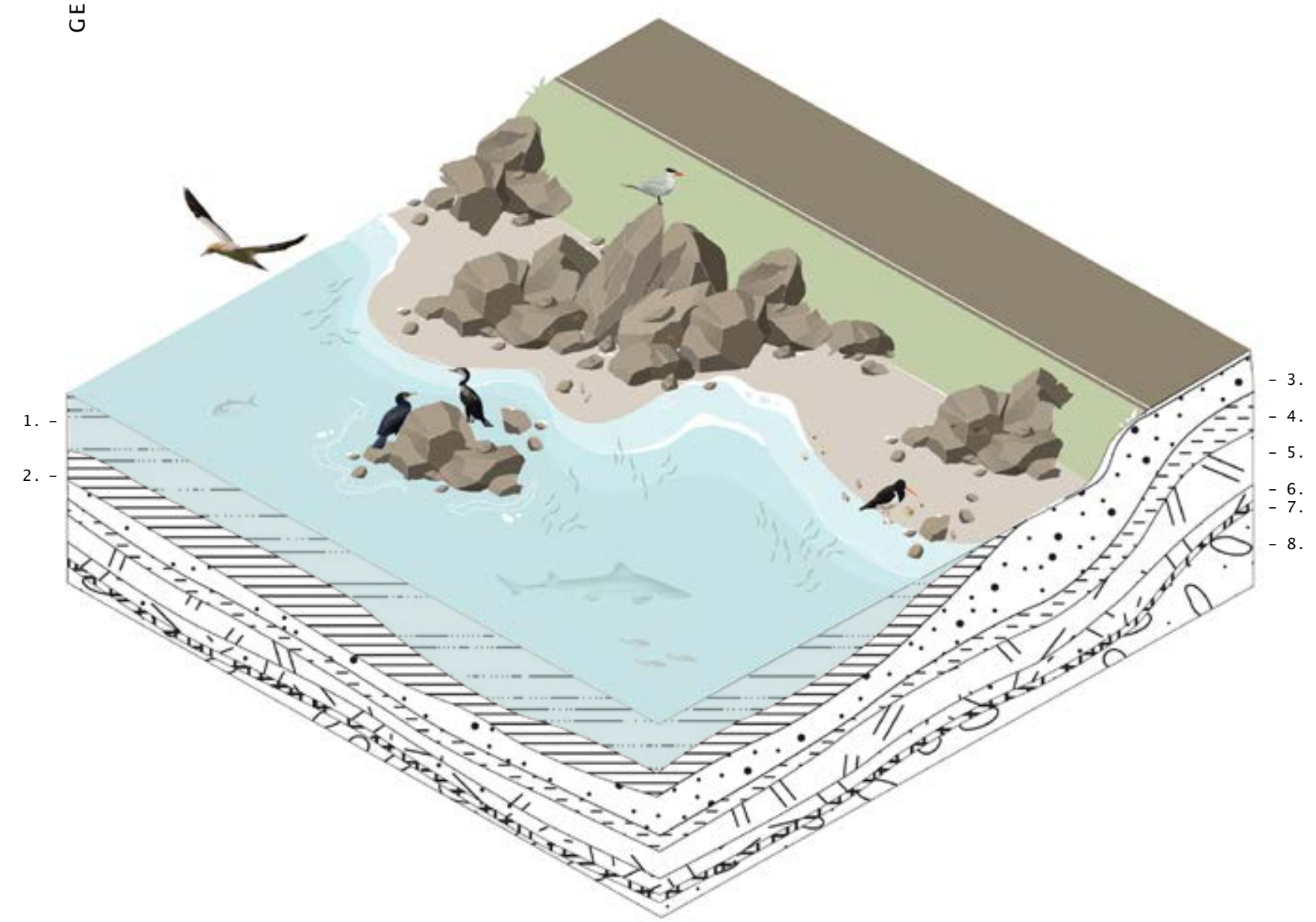

\begin{tabular}{|c|c|c|c|}
\hline $\begin{array}{l}\text { Caspian tern } \\
\text { Hydroprogne caspia }\end{array}$ & $\begin{array}{l}\text { Spotty } \\
\text { Pseudolabrus celidotus }\end{array}$ & $\begin{array}{l}\text { Elephant fish } \\
\text { Callorhinchus militi }\end{array}$ & $\begin{array}{l}\text { Nutsell } \\
\text { Nucula hartivigana }\end{array}$ \\
\hline $\begin{array}{l}\text { Gannet } \\
\text { Morus serrator }\end{array}$ & $\begin{array}{l}\text { Kahawai } \\
\text { Arripis trutta }\end{array}$ & $\begin{array}{l}\text { Red cod } \\
\text { Pseudophysis bacchus }\end{array}$ & $\begin{array}{l}\text { Mud whelk } \\
\text { Cominella glandiformis }\end{array}$ \\
\hline $\begin{array}{l}\text { Kingfish } \\
\text { Seriolal lalandi }\end{array}$ & $\begin{array}{l}\text { Cockabully } \\
\text { Forsterygion varium }\end{array}$ & $\begin{array}{l}\text { Wharehou } \\
\text { Seriolella brama }\end{array}$ & $\begin{array}{l}\text { Horn shell } \\
\text { Zeacumantus Iutulentus }\end{array}$ \\
\hline $\begin{array}{l}\text { Rig shark/ spotted tooth hound } \\
\text { Mustelus enticulatus }\end{array}$ & $\begin{array}{l}\text { Robust blenny } \\
\text { Trypterygion robustum }\end{array}$ & $\begin{array}{l}\text { Anchovy } \\
\text { Engraulis asutralis }\end{array}$ & $\begin{array}{l}\text { Eel grass } \\
\text { Zostera muelleri }\end{array}$ \\
\hline $\begin{array}{l}\text { Yellow-eyed mullet } \\
\text { Aldrichetta forsteri }\end{array}$ & $\begin{array}{l}\text { Grey mulet } \\
\text { Mugiic cephalus }\end{array}$ & $\begin{array}{l}\text { Garfish } \\
\text { Hemiramphus ihi }\end{array}$ & \\
\hline $\begin{array}{l}\text { Trevally } \\
\text { Caranx georgianus }\end{array}$ & $\begin{array}{l}\text { Snapper } \\
\text { Chrysophrys auratus }\end{array}$ & $\begin{array}{l}\text { Smelt } \\
\text { Retropinna retropinna }\end{array}$ & \\
\hline
\end{tabular}

\section{SHELL BANKS}

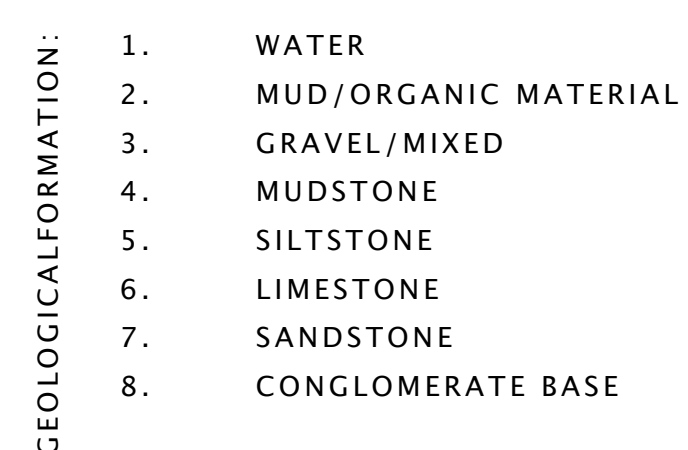

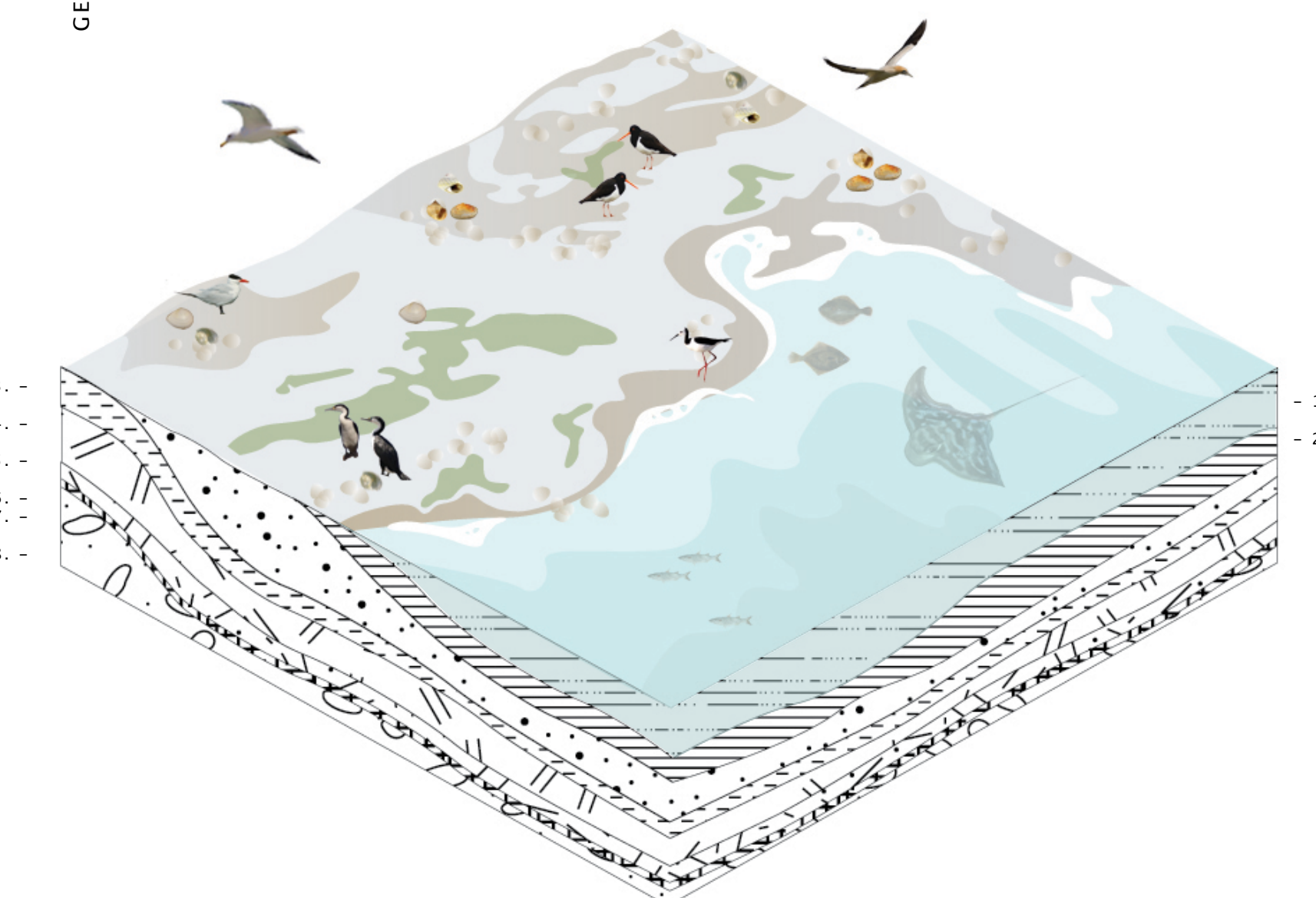

\begin{tabular}{|c|c|c|c|}
\hline $\begin{array}{l}\text { Dotterel } \\
\text { Charadrius morinellus }\end{array}$ & $\begin{array}{l}\text { Pied stitt } \\
\text { Himantopus leucocephalus }\end{array}$ & $\begin{array}{l}\text { Trevally } \\
\text { Caranx georgianus }\end{array}$ & $\begin{array}{l}\text { Smelt } \\
\text { Retropinna retropinna }\end{array}$ \\
\hline $\begin{array}{l}\text { Wrybill } \\
\text { Anarhynchus frontalis }\end{array}$ & $\begin{array}{l}\text { Shoveler } \\
\text { Spatula clypeata }\end{array}$ & $\begin{array}{l}\text { Cockabully } \\
\text { Forsterygion varium }\end{array}$ & $\begin{array}{l}\text { Nutsell } \\
\text { Nucula hartivigana }\end{array}$ \\
\hline $\begin{array}{l}\text { Bartailed Godwit } \\
\text { Limosa lapponica }\end{array}$ & $\begin{array}{l}\text { Grey teal } \\
\text { Anas gracilis }\end{array}$ & $\begin{array}{l}\text { Robust bienny } \\
\text { Tyypterygion robustum }\end{array}$ & $\begin{array}{l}\text { Mud whelk } \\
\text { Cominella glandiformis }\end{array}$ \\
\hline $\begin{array}{l}\text { Caspian tern } \\
\text { Hydroprogne caspia }\end{array}$ & $\begin{array}{l}\text { Sandfliounder } \\
\text { Rhombosolea plebeia }\end{array}$ & $\begin{array}{l}\text { Eagle Ray } \\
\text { Myliobatis tenuicaudatus }\end{array}$ & $\begin{array}{l}\text { Horn shell } \\
\text { Zeacumantus Itutuentus }\end{array}$ \\
\hline $\begin{array}{l}\text { Gannet } \\
\text { Morus serrator }\end{array}$ & $\begin{array}{l}\text { Yellow belly flounder } \\
\text { Rhombosolea leporina }\end{array}$ & $\begin{array}{l}\text { Anchovy } \\
\text { Engraulis asutralis }\end{array}$ & $\begin{array}{l}\text { Eel grass } \\
\text { Zostera muelleri }\end{array}$ \\
\hline $\begin{array}{l}\text { Oyster catcher } \\
\text { Haematopus bachmani }\end{array}$ & $\begin{array}{l}\text { Yellow-eyed mullet } \\
\text { Aldrichetta forsteri }\end{array}$ & $\begin{array}{l}\text { Garrish } \\
\text { Hemiramonus ini }\end{array}$ & 110. \\
\hline
\end{tabular}




\section{COASTAL BUSH}
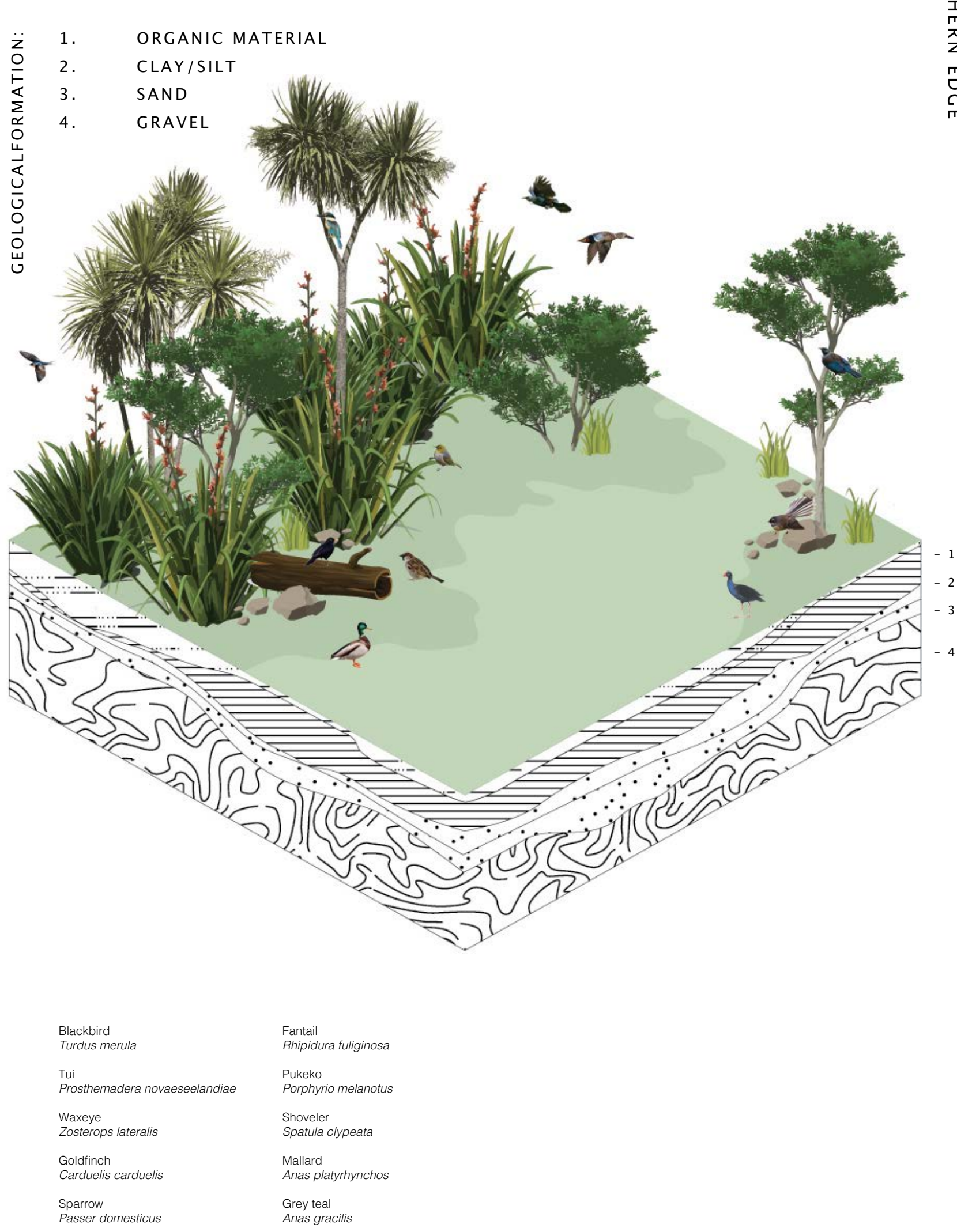

\section{KEY FINDINGS:}

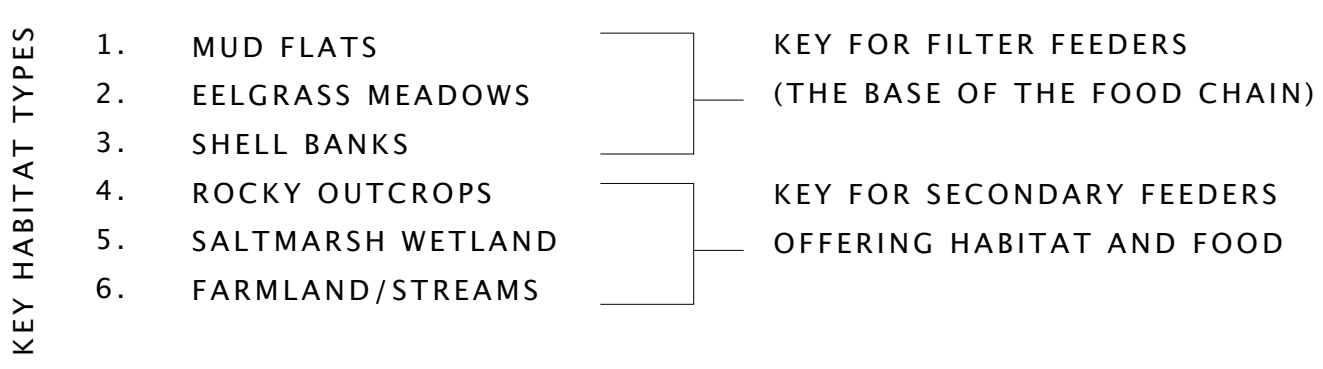

\section{COHABITATION DEPENDENCIES:}

Existing wild life is dependent on the habitat afforded by the shallow water depth and the saltmarsh for protection.

The food chain is based around plant detritus which comes in three forms:

$$
\begin{aligned}
& \text { - Eel grass } \\
& \text { - Salt marsh } \\
& \text { - Coastal bush }
\end{aligned}
$$

This detritus supports benthic creatures which in turn are fed on by the carnivorous birds and fish, thus feeding the nutrient cycle. This is an oversimplification of the ecological web that makes Pauatahanui what it is, however it emphasises the

interdependence of species living together and the cross links that can be made visible when relationships are traced. 


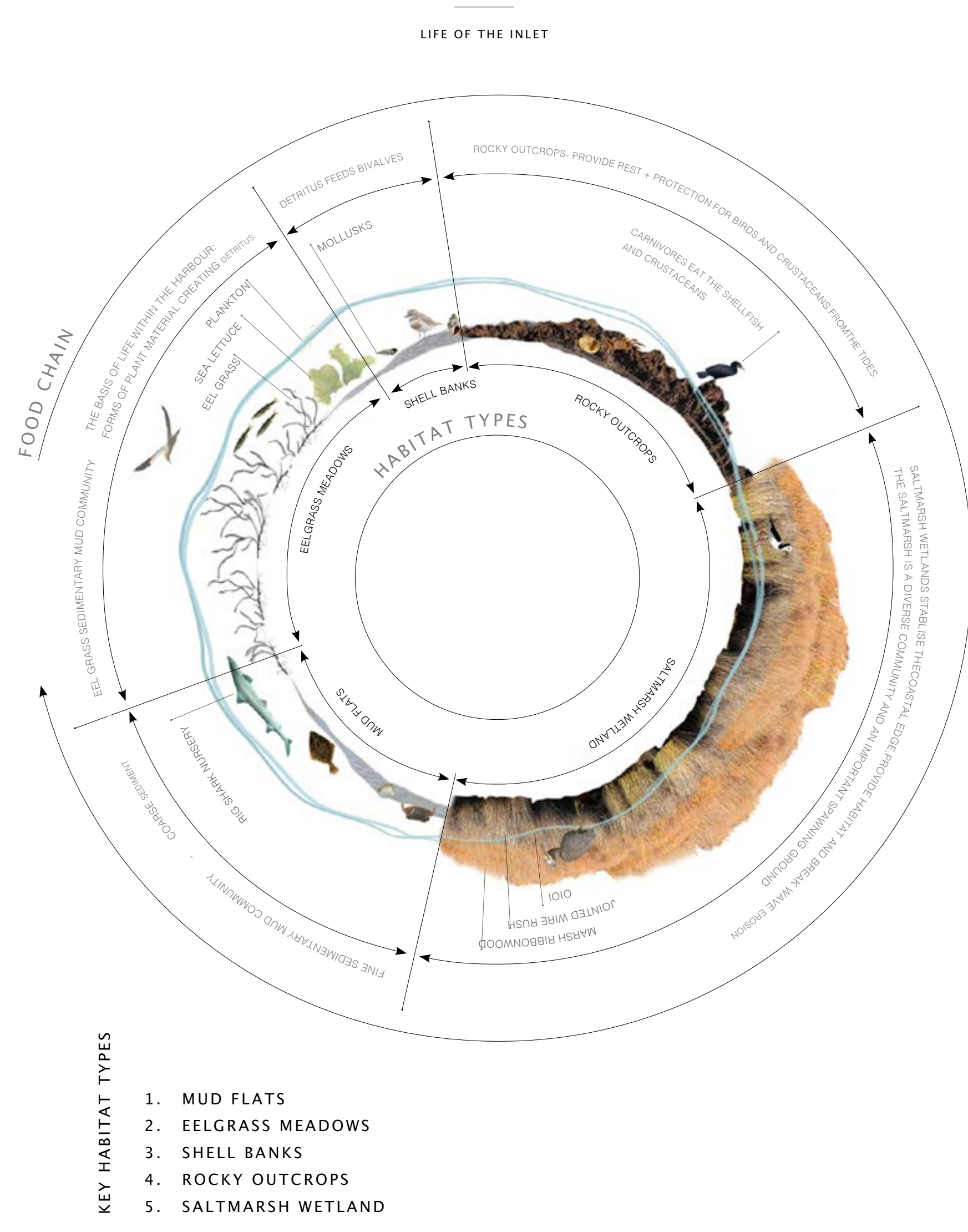

\section{How do their lives overlap?}

\author{
What are the spatial \\ and temporal \\ relationships?
}

What symbiotic relationships exist and how are they interdependent?
"When we physically encounter a landscape, what we see and sense is just a snapshot in a string of historic and future transformations, all unfolding at varied cadences. To gain real traction, we need to know how the assembly has arrived at its present state -”

- Milligan 


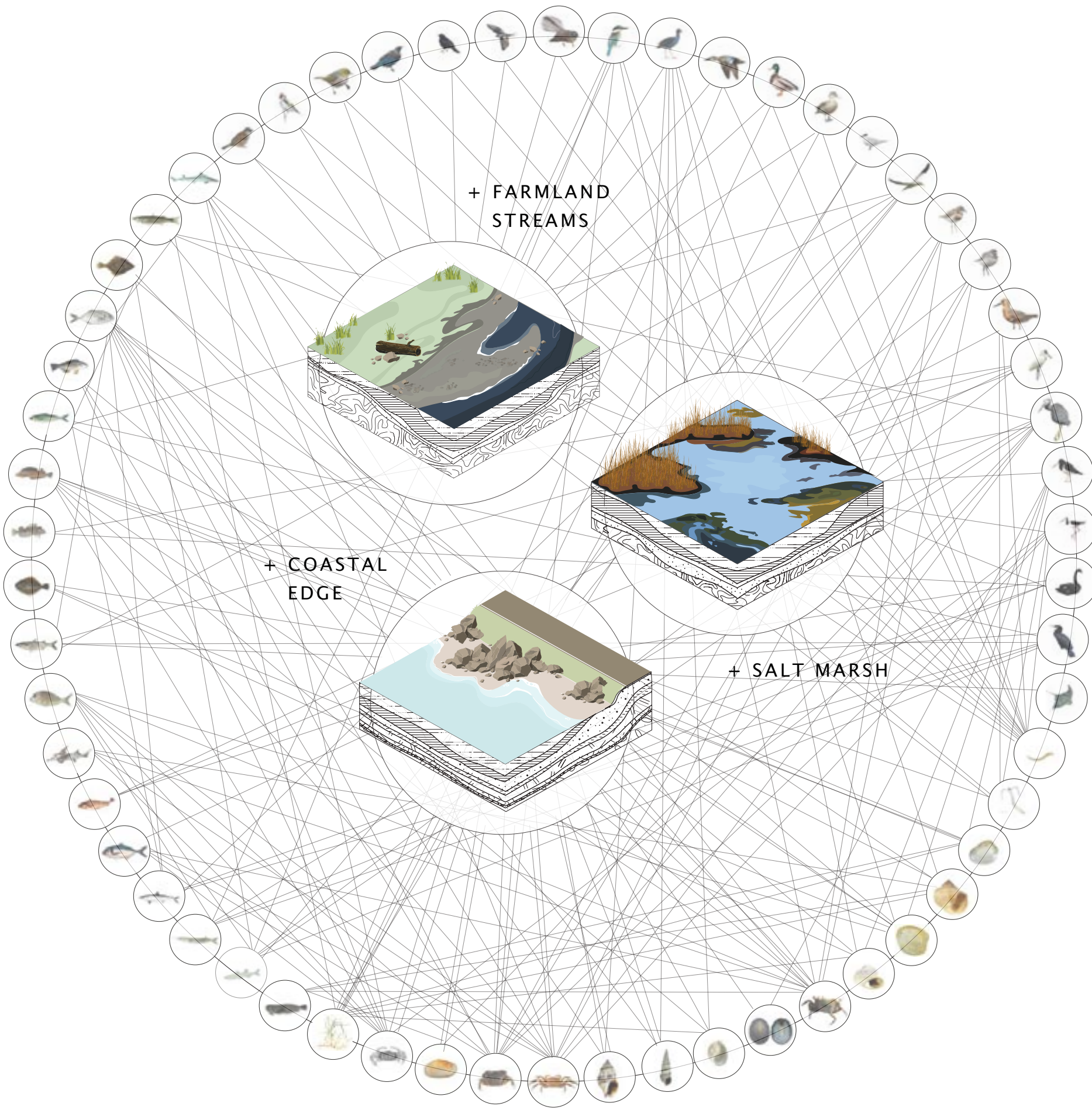

\section{Co-existence of species/ Life overlapping}

\author{
A landscape is a complex and dynamic \\ system in a state of endless movement. \\ By unravelling the threads that compose \\ the environment (or assemblage) we can \\ start to understand the lives that coexis \\ and the inter dependencies that are \\ created between creatures. This diagram \\ (left) alludes to the complex symbiotic \\ interrelationships within the harbour. \\ by pulling together the quantitative \\ data collected around each species \\ habitat and diet and creating links in the \\ ecological web. However this is study \\ only really begins to scratch the surface \\ of these relationships, and their reliance \\ on the habitat Pauatahanui affords them. \\ Interactions between species are temporal \\ and exsist fleetingly in space. \\ To create a resilient future, designers need \\ to provide and accommodate for all forms \\ of life to coexist - not just as secondary \\ users but equal participants. What might \\ this look like when applied to something as \\ foundational (and banal?) to the practice \\ of landscape architecture as a coastal \\ walkway?
}

What might a pathway look like for all forms of life?

There are a wide range of species in Pauatahanui, they all have diverse needs in terms of habitat/refuge, means of movement, spans they can travel and exposure to salt water they can tolerate. Thus a journey around the harbours edge looks different for everyone. Facilitating modes of encounter through experientially driven engagement can help inform the communities understanding of everyone else who relies on the surrounding landscape. 
LIFE WITHIN THE HARBOUR
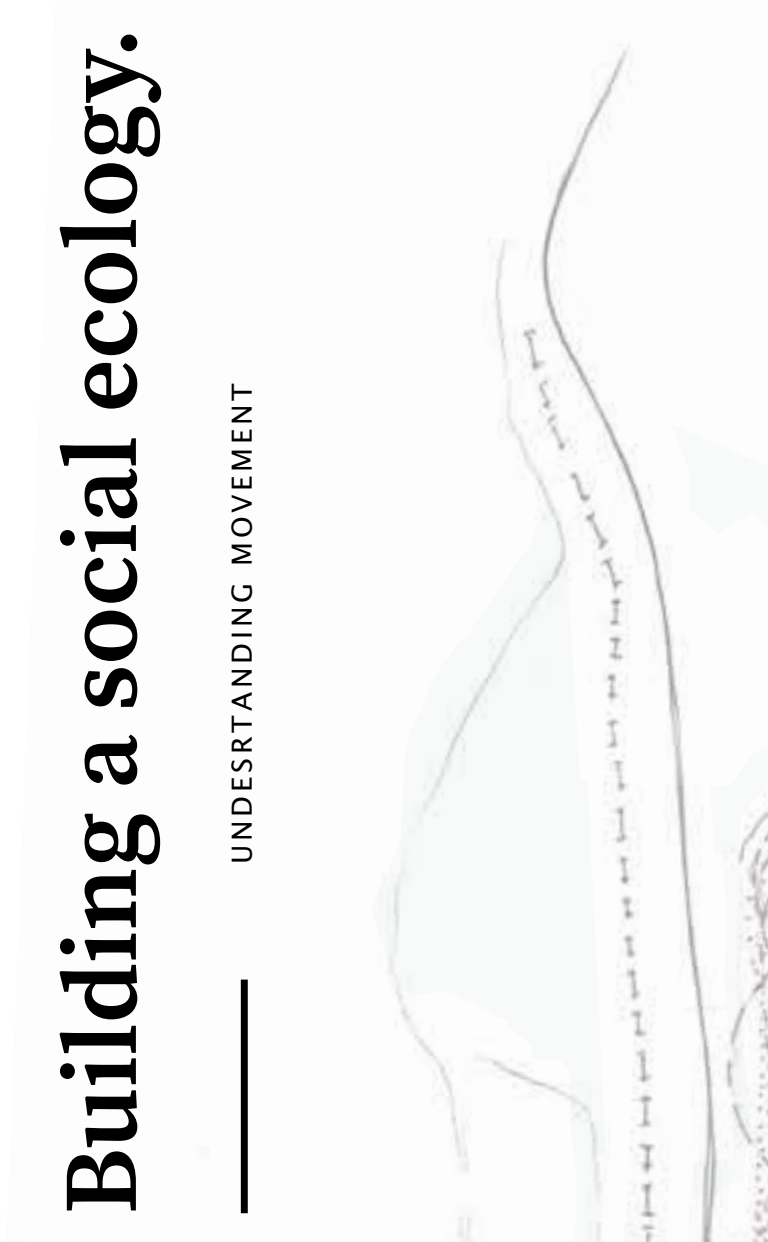

This fieldwork map starts to trace the spatial and temporal nature of lives overlapping within the harbour: in doing so a sort of social ecology begins to emerge.
-

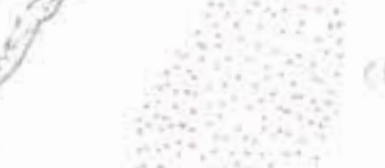

EAC

Territories of wildlife and human pathways are outlined, overtop of which a personal journey around the harbour is dem with short lines indicating points of tension: steep cliffs a structure this landscape speeds up movement through pressure, propelling users away at speed. The reclaimation of this edge (the southern motorway) pedestrians will change the experience of the whole harbour and slow down movement to allow space for introspection.

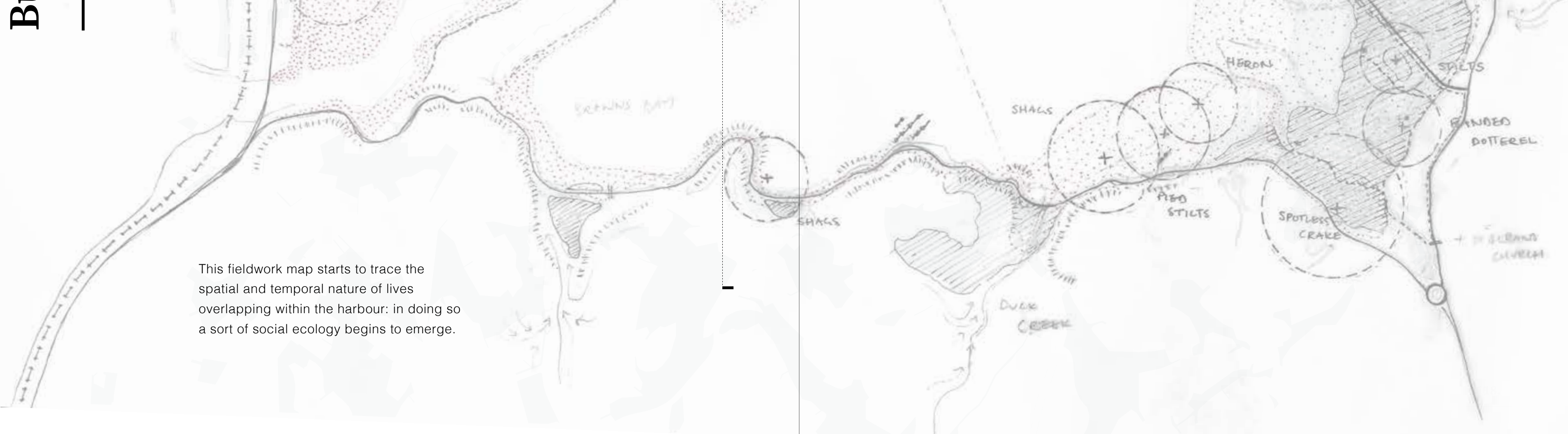



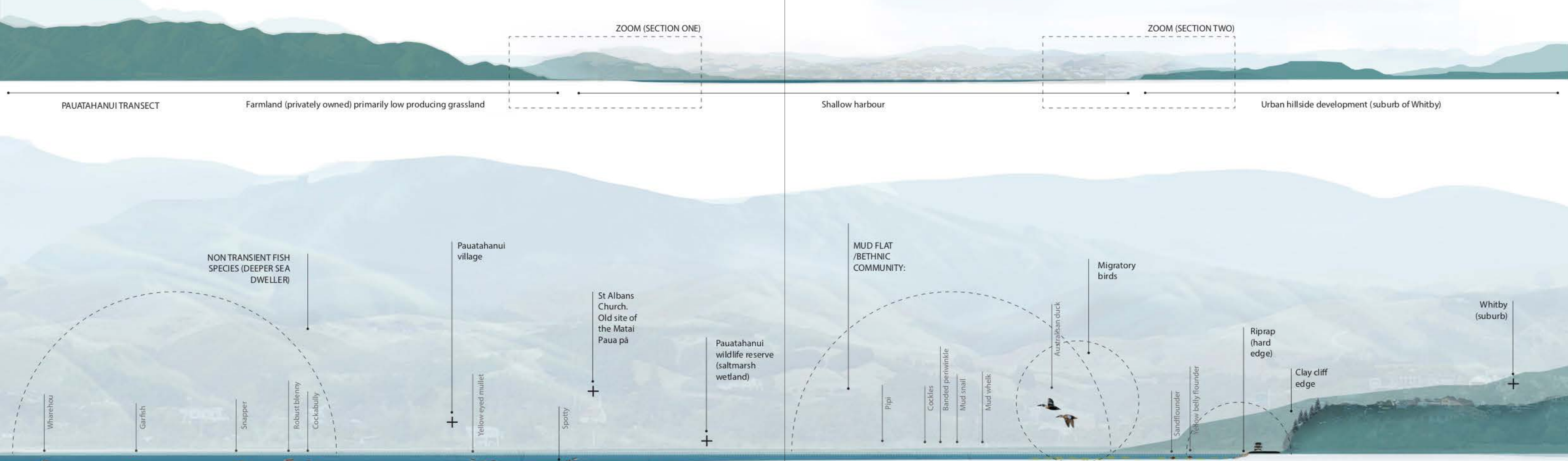

ZOOM (SECTION ONE

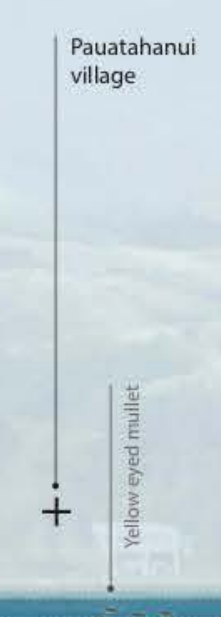

Pauatahanui
Village

NON TRANSIENT FISH
SPECIES (DEEPER SEA

DWELE
D FLAT

FHANC

Mgator

bird

管

날

Mudflat

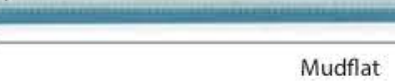

.

Eel grass meadows

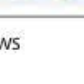

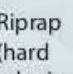

Clay cifif

$\longrightarrow$

Urban hillside suburbs
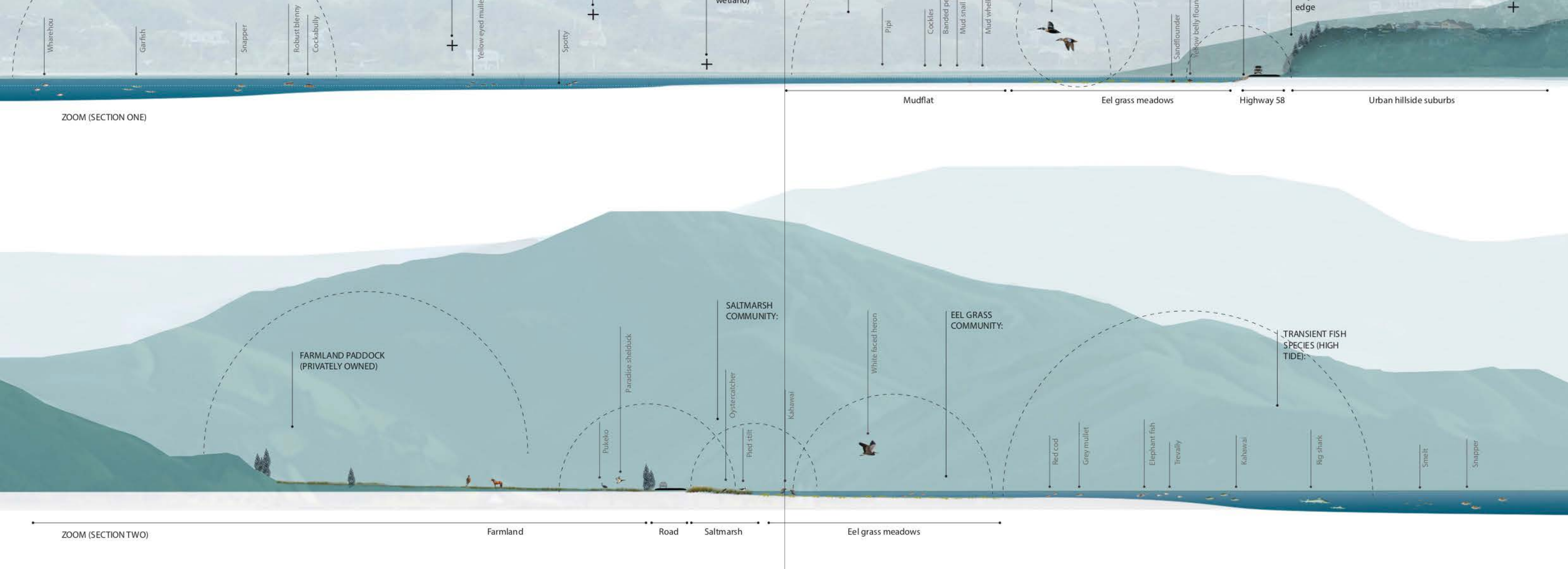


\title{
Facilitating movement:
}

\author{
To develop a shared sense of ownership \\ of the coastal edge as a public realm for \\ all life forms, the coastal pathway must \\ expand beyond pedestrian modes of \\ movement and incorporate the needs of \\ other users in its design. \\ To do this we must first understand the \\ current modes of movement, and their \\ tolerance toward sharing space (as \\ undertaken through a proxemics study) \\ along the pathway. \\ Therefore this section investigates the
}

How do they currently

following questions:

move around the

Harbour?

How close can interspecies get (in terms

of physical distance)

before one party feels unsafe? 


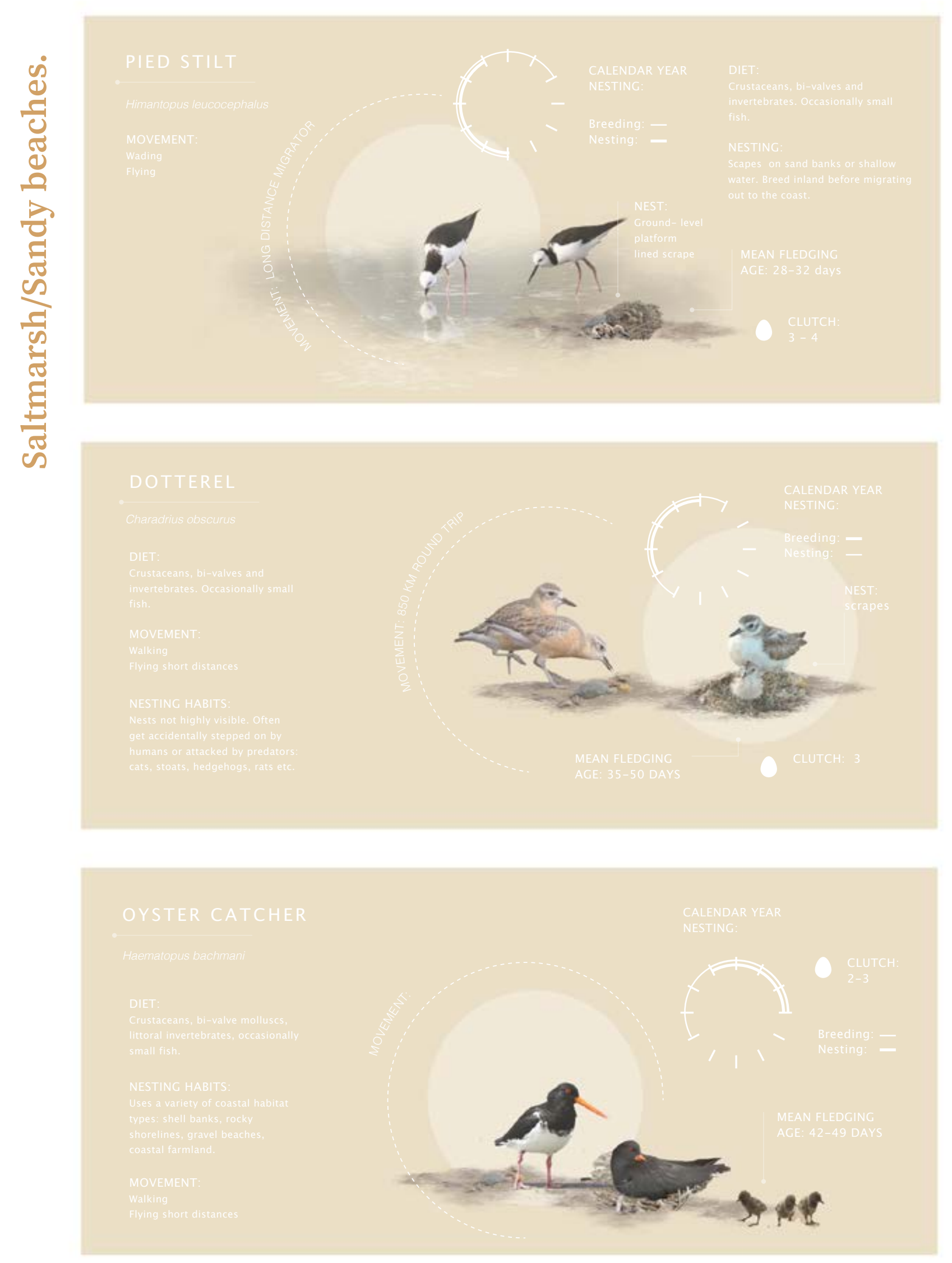

Citation:
Pied stitt - Adams, R. 2013 [updated 2017]. Pied stilt. In Miskelly, C.M. (ed.) New Zealand Birds Online. www.nzbirdsonline.org.nz Dotterel - Dowding, J.E. 2013 [updated 2017]. New Zealand dotterel. In Miskelly, C.M. (ed.) New Zealand Birds Online. Www.nzbirdsonline.org.nz
Oyster catcher - Dowding, J.E. 2013 [updated 2017]. Variable oystercatcher. In Miskelly, C.M. (ed.) New Zealand Birds Online. www.nzbirdsonline.org.nz
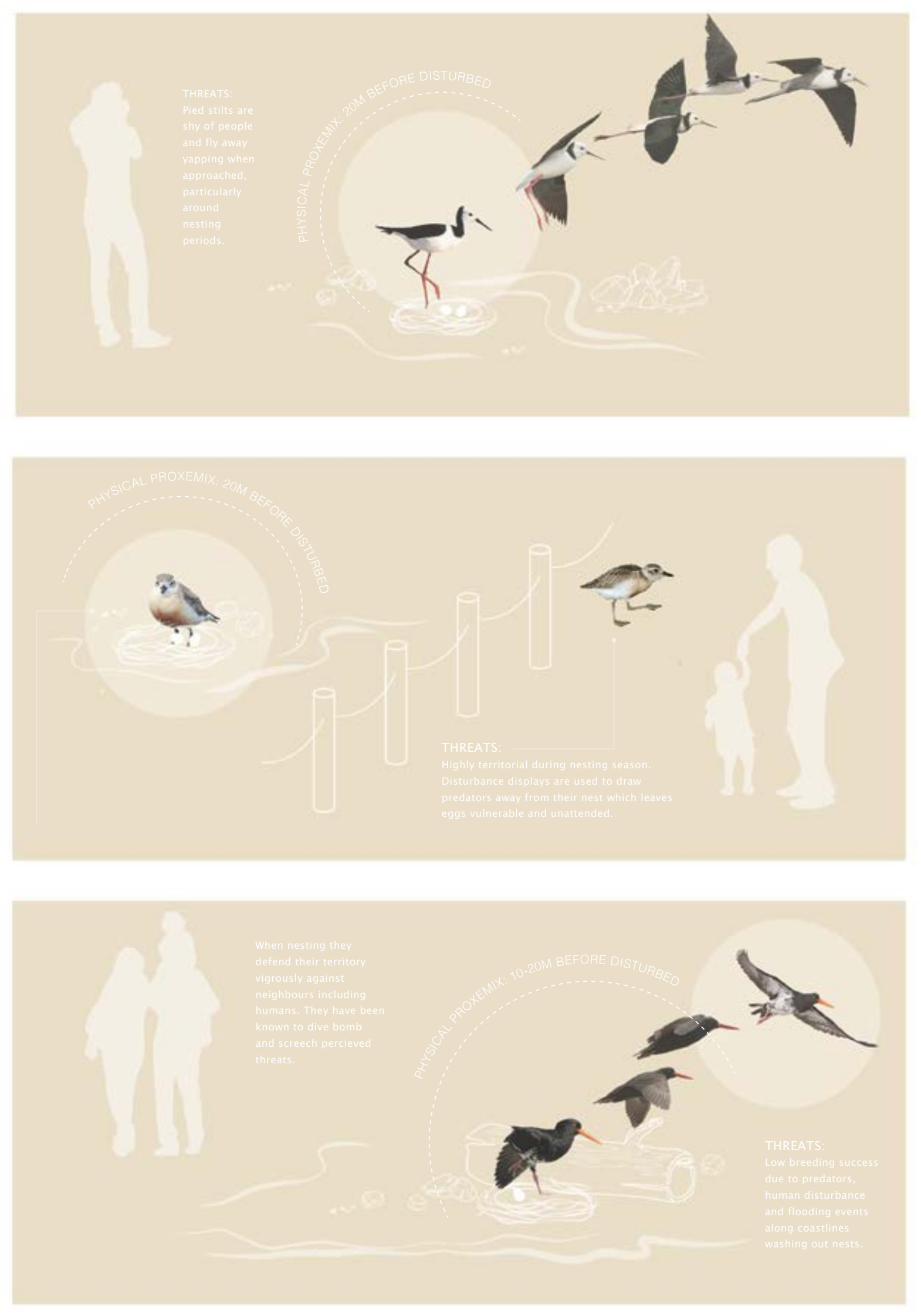

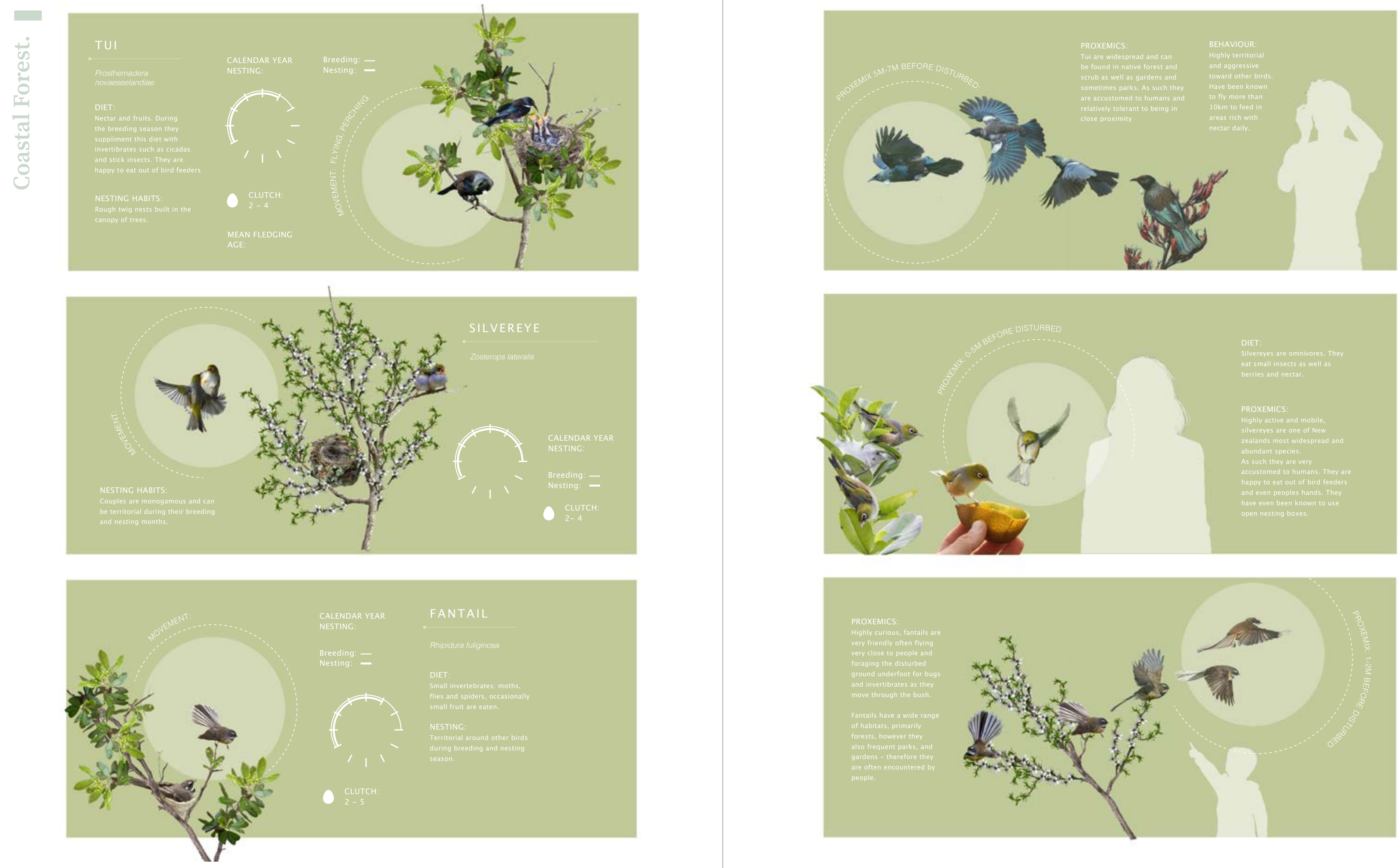


\section{Findings.}

\section{LESSONS IN AFFECT/PROXEMICS FROM FIELDWORK:}

The most territorial birds, and therefore the most likely to be disturbed, are those that live along sandy shorelines and saltmarsh ponds such as dotterels, oyster catchers and pied stilts. They nest on the ground in very inconspicous scrapes, making their nests difficult to see and therefore vulnerable to threats. They also tend to have high fidelity to both their mate and their nesting site, making it unlikely that they will relocate their nests even under stress.

Birds that nest along rocky coastlines tolerate a greater degree of human proximity as tend to rest in places with good surveillence and can retreat to rocky perches or treetops for safety easily.

Farmland and coastal forest species tolerate the highest degree of interaction. Often very accustomed to human neighbours, some species such as fantails and silvereyes are particularly friendly and will often come very close to humans to

forage or feed.

Possible causes of alarm or stress for birds: - too close

- too loud

- too fast

All of which can create feeling of danger

These aspects can also be applied to the human experience moving around the site. The proxemity of cars/ trucks moving at high speed past pedestrians creates a
CONCLUSIONS:

Saltmarsh and sandy beach sites around attention in terms of design proxem to allow inhabitants to feel safe while still sharing space.

Reducing the vehicular presence around the inlet will reduce stress caused by

speed, sound and danger from cars.

APPLICATION THROUGH DESIGN PRINCIPLES:

Space: allowing enough room for individuals to pass each other without feeling uncomfortable. For birds this could be as far as 20 meters for people it may only be 1 .

Also creating more room between individuals and cars moving at speed.

Sound: barriers such as vegetation or built structures can be used to reduce disturbance between parties.

Speed: lowering the speed limit of the surrounding roads and reducing car access to the site will help pedestrians feel safer.

People moving about on the saltmarsh (key nesting sites) should be obscured from sight behind so as not to disturb birds and put them under stress especially during nesting season.

Barriers allow for closer proximity without the feeling of danger - if there is no physical barrier - there needs to be more space given.

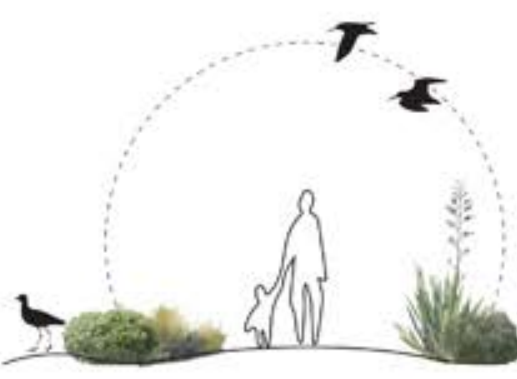

VEGETATION TUNNELS AS SCREENS

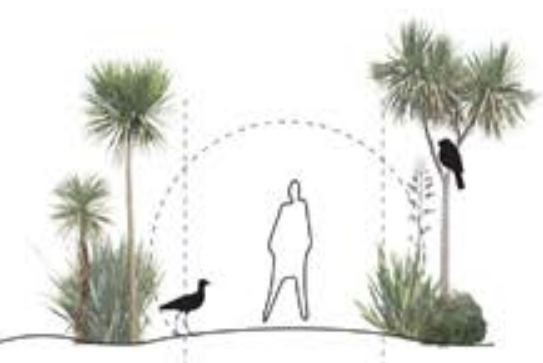

VEGETATION TUNNEL S SCREENS

Plants can be used as screens or 'walls' to

obscure peoples movement from the view of birds on the saltmarsh flats.

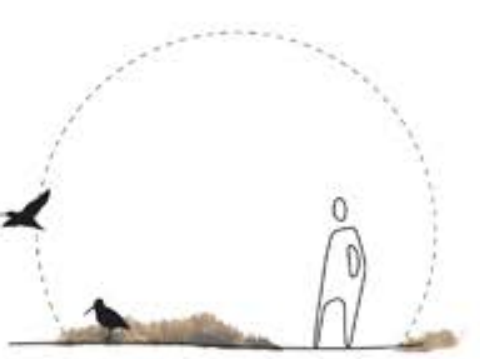

BUILDINGS WITH SMALL SLITS AS SCREENS

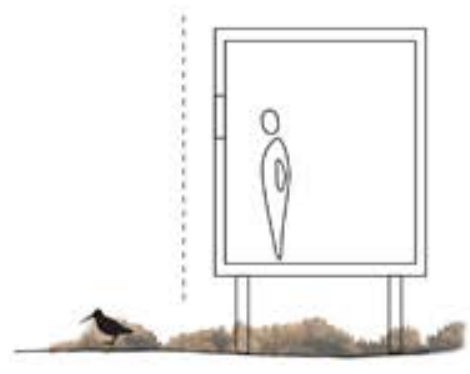

BUILDINGS WITH SMAL SLITS AS SCREENS

Physical buildings care highly effective at screening people from view. They also afford a good view

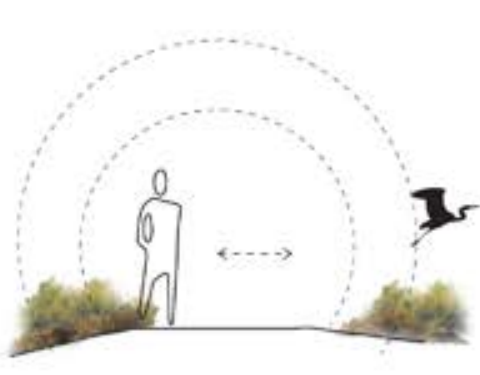

WIDER PATHWAYS

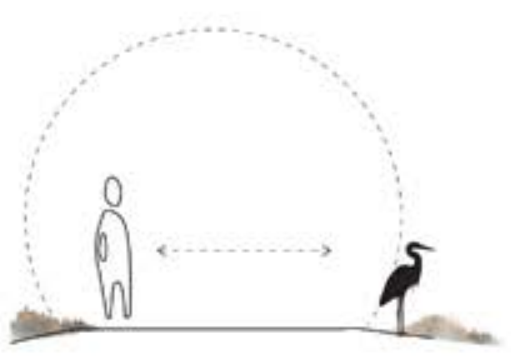

WIDER PATHWAYS

Wider pathways allow for individuals to give each other a wider berth where barriers cannot be created. 
KEY HABITATS AS MOVEMENT

\section{Existing habitat corridors}

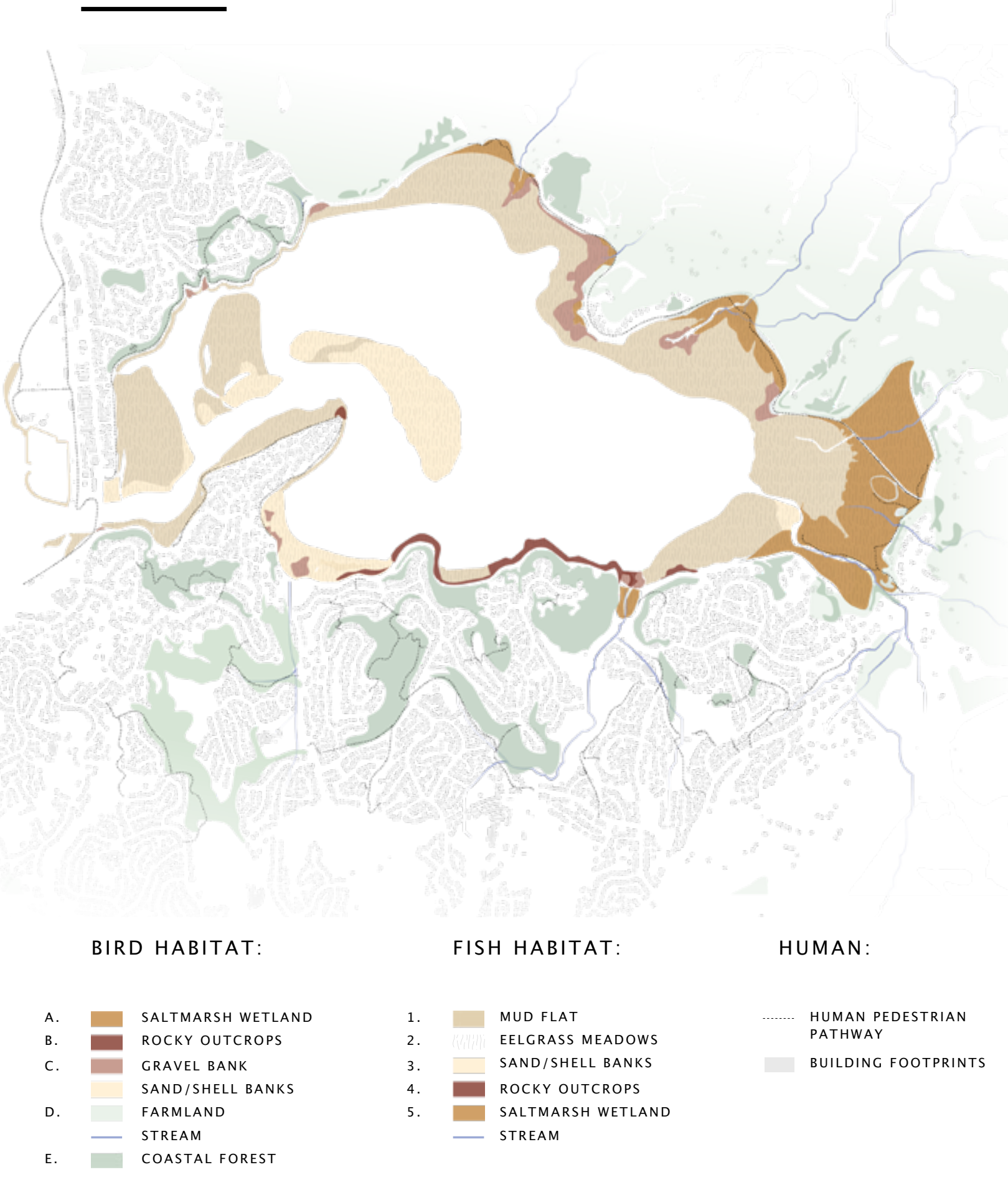

The avian movement study showed that there were correlations between the birds habitat needs, their movement characteristics, and their tolerance to being in close proximity to other species (such as humans) before feeling unsafe and taking flight.

As similar needs need to be met for the species reliant in each key habitat type (saltmarsh, riprap etc) the cohabitation aspect of the pathway design will change according to their tolerance for interactivity and cohabitation. Distances between each type or habilat will allow for their easy traversal around the harbour creating a series of overlapping habitat corridors.

B. RIPRAP COASTAL EDGE

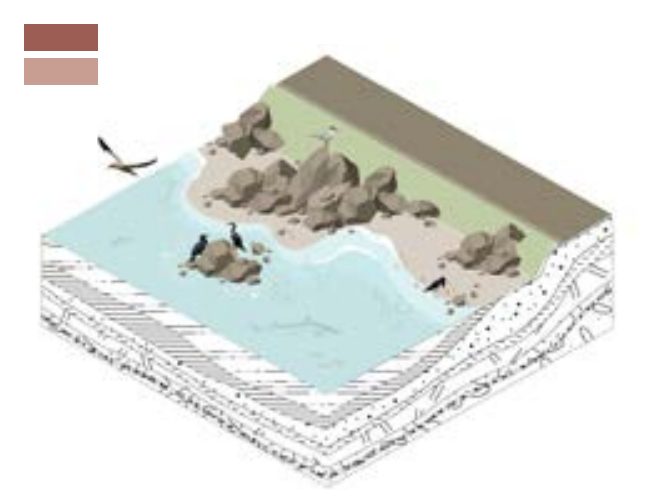

Key movement types:

- Longer distance flight spans

- Tena to fly rather than run away

Perch in places with good surveillance

of surroundings

D. FARMLAND STREAM

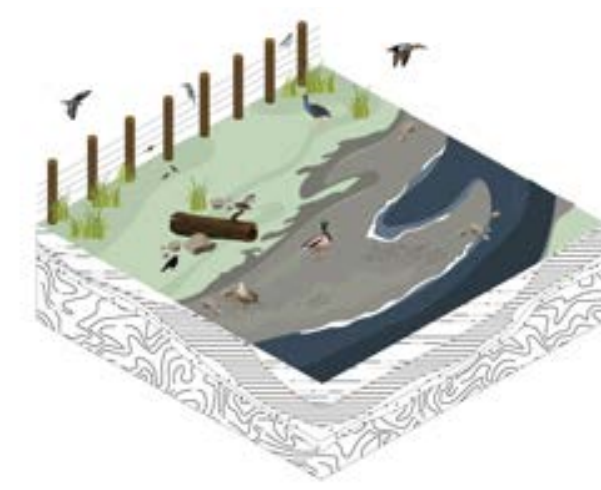

Key movement types:

- Walk away when approached, fly when

disturbed

-Fairly tolerant to interactivity
A. SALTMARSH WETLAND

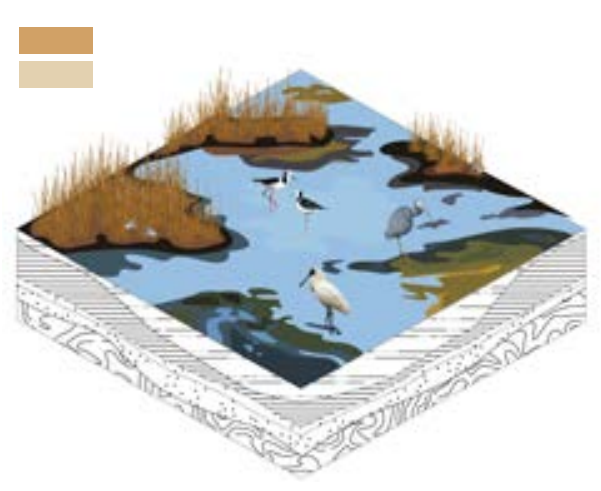

Key movement types:

- Medium distance flight spans

Tend to fly rather than run away

C. SHELL BANKS

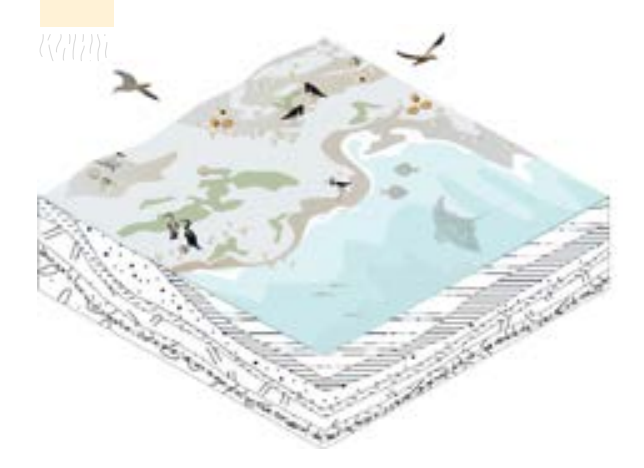

Key movement types:

Shorter distance flight span

- Birds run or walk

-Tend to rest sitting on the ground

Territorial behaviour

E. CoAstal bush

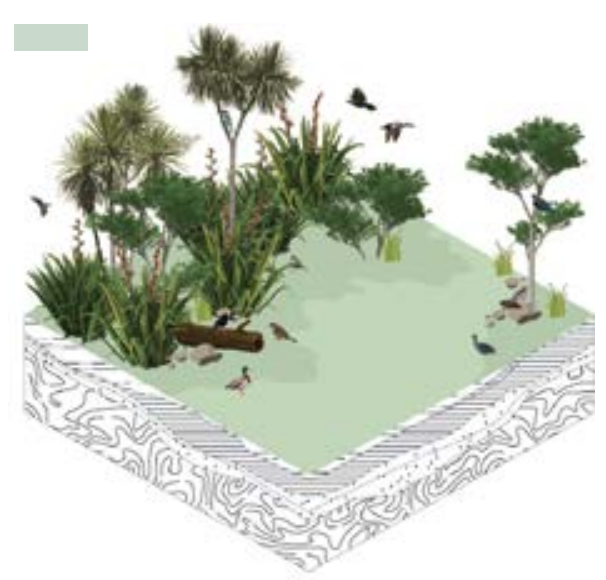

Key movement types:

- Medium distance flight spans

- Tend to fly rather than run away

- Fairly tolerant to interactivity 


\section{Humans.}

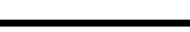

The key stakeholders in the development and maintainance of Pauatahanui are:

Greater wellington regional Council

Porirua City Council

Rūnanga O Toa Rangatira.

\section{Other parties with invested interest are}

Porirua Harbour and Catchment

Community Trust (PHACCT)

Guardians of Pauatahanui Inlet (GOPI)

Pauatahanui Inlet Community Trust (PICT)

Pauatahanui Residents Associations

QEII National Trust

Fish and Game New Zealand

New Zealand Transport Agency (NZTA)

Forest and Bird

Department of Conservation

Regional Public Health

Ministry of Fisheries.

Guardians of Pauatahanui Inlet are a highly active group of residents in the community who were concerned about the ecological health of the inlet and the impact of human activities within the area. They manage a coastal clean up and run the annual cockle survey in partnership with the department of conservation
Other ecological enthusiasts who visit the inlet are:

Bird watchers

Students (educational programmes)

Recreational users: cyclists, runners, dog

walkers, kyakers, paddle boarders, shallow hulled boats.

Surrounding residents/community

members

Many of whom have an invested interest in maintaining the harbours health and wellbeing

The inlet offers many recreational activities

for people to enjoy, by tracing these

activities patterns of movement begin

to emerge around the inlet. Areas of

disconnect such as the broken pedestrian

link on the southern coastline, and

opportunities such as boating networks,

present areas to consider when designing.

\section{Existing human movement.}
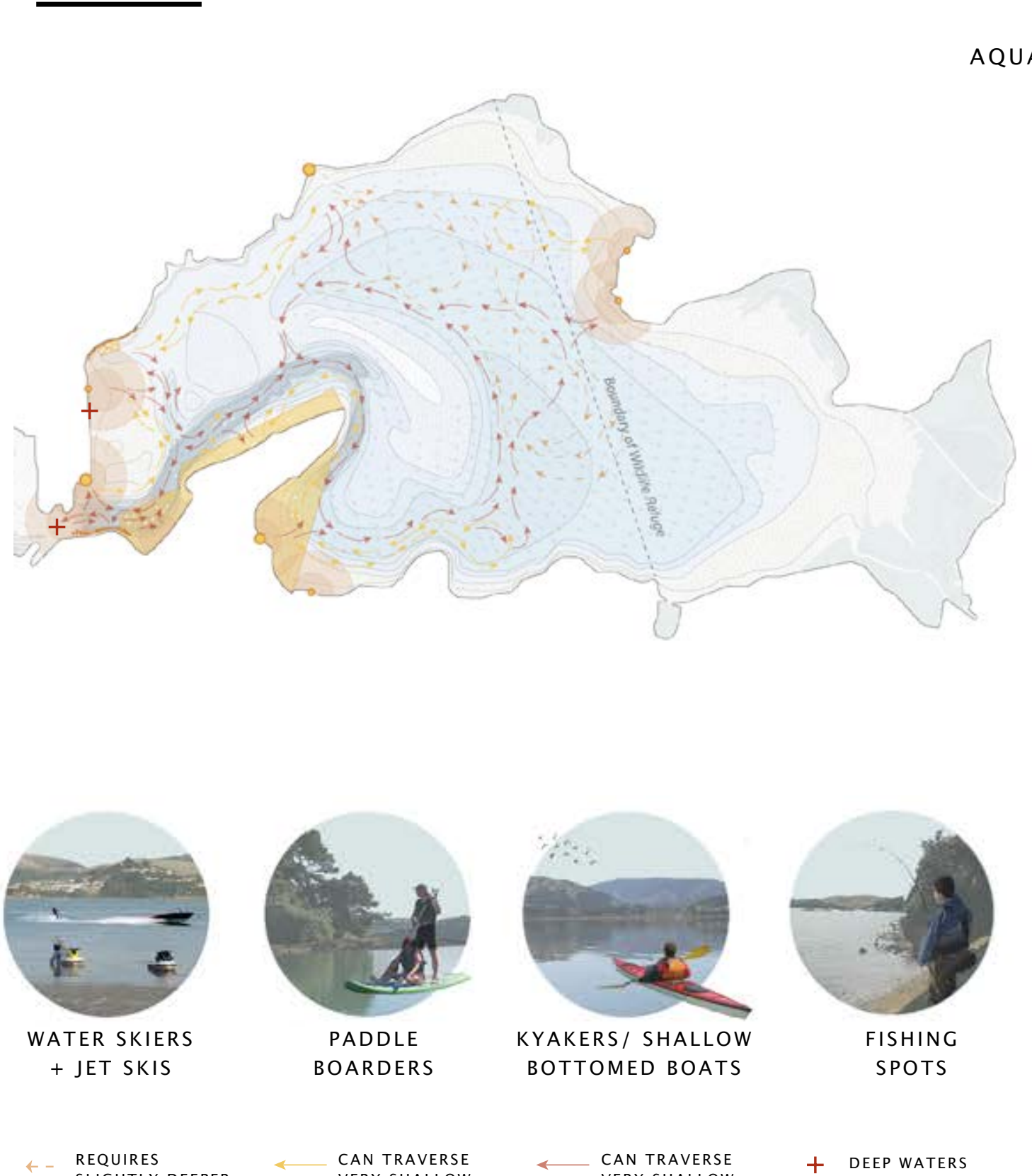

REQUIRES
SLLGHTLY DEEPER
AREAS OF WATER

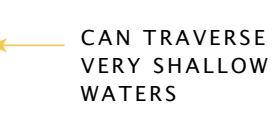

BOTTOMED BOATS

- BOAT ACCESS
CAN TRAVERS
VERY SHALLW
WATERS
WATERS
$+\begin{gathered}\text { DeEp WATERs } \\ \text { OUTSIDE OF }\end{gathered}$
THE RESERVE
FISHING SPOTS
BOAT RAMPS

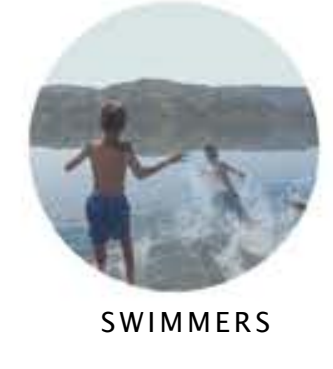

SANDY SHORES +
WHARF JUMPING AT PAREMATA 

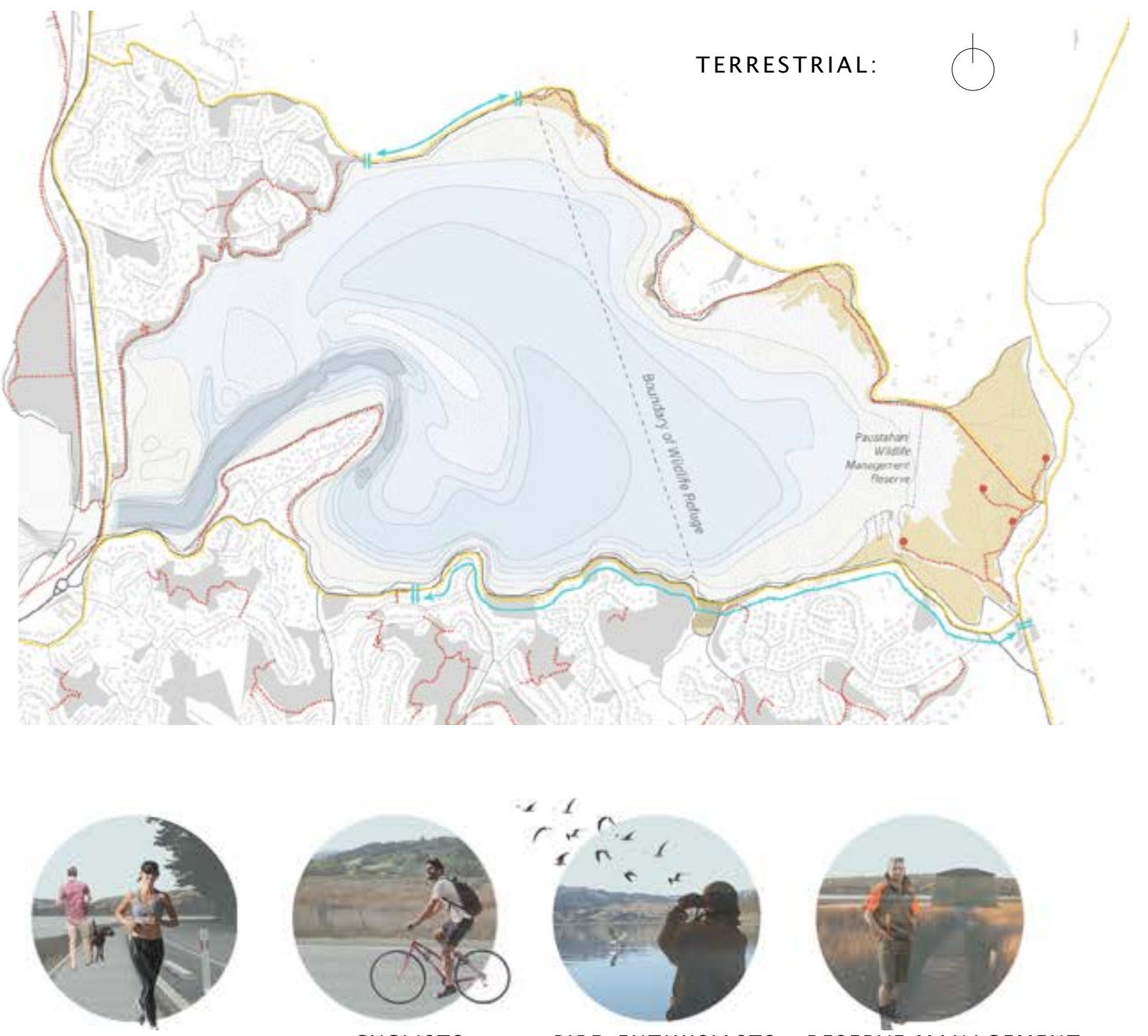

CYCLISTS

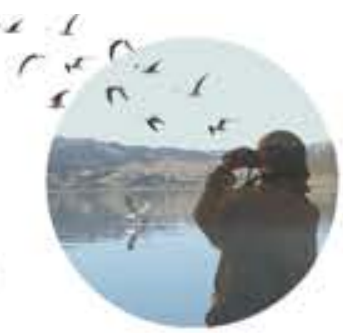

BIRD ENTHUSIASTS

/ SIGHTSEERS

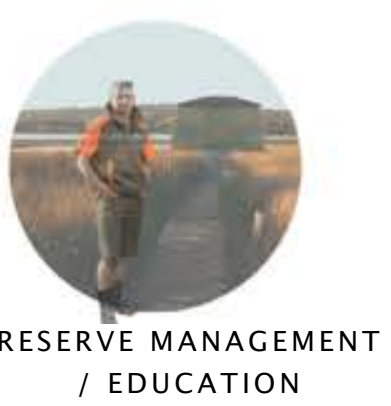

KEY: $\quad$........... PATHWAY ACCESS BIKE ACCESSIBLE
NO CYCLE LANE

- BIRD HIDES

$\underset{\text { DOC WILDLIFE }}{\text { RESERVE }}$
PUbLIC PARKSPACE

CURRENT MODES OF ENCOUNTER ON SITE BETWEEN HUMANS AND WILDLIFE:

WILDLIFE RESERVE:

Designated pathways keep people off the vegetation and at a safe distance from nesting sites.

Bird hide buildings are used to obscure people from birds but give vantage points across the saltmarsh.

the hides work well but are low to the ground despite being on stilts - this could place them at risk of future flooding.

They are also somewhat prone to

vandalesim and tagging - this is important to note in design development.

PATHWAYS AROUND THE HARBOUR EDGE:

Narrow footpaths or boardwalks often in close proximity to fast moving trucks and cars. "Te Ara Piko" boardwalk along the northern edge of the inlet is a new and nice addition, however it is at risk of storm surge in future. This area of road alongside the path is already prone to flooding at high tide - if the tideline moves much higher it is likely parts of this pathway will get damaged and be submerged at high tide.
Pathways around the harbour are broken -it is not possible to walk around the circumference of the harbour, particularly on the southern edge which is completely inaccessible to pedestrians. Existing pathways outside of the saltmarsh reserve are not close enough to the birds to bother them but are also not close enough to properly engage with them.

COUNCIL AND DOC EDUCATION NITIATIVES.

The Department of conservation along with the guardians of Pauatahanui Inlet conduc annual cockle survey's. Cockles are used as an indicator species to assess the health of the harbour. Anyone is welcome to apply to help and this is a great way to engage younger people to get up close and personal with intertidal wildlife. School trips and guided trips are sometimes organised to get people engaged with the harbour in a hands on way. 


\section{Conclusion / reflection:}

There is already a strong foundational

understanding between the residents

of Pauatahanui and the importance of

ecological systems. This design led

research seeks to build on that to develop

a stronger sense of cohabitation and

reclaim the tidal edge as a shared space.

Rather than prioritising human needs, the pathway seeks to facilitate movement for all forms of life. Rest spots, outlooks and areas of respite from the weather and

incorporated for humans, birds and other

animals 


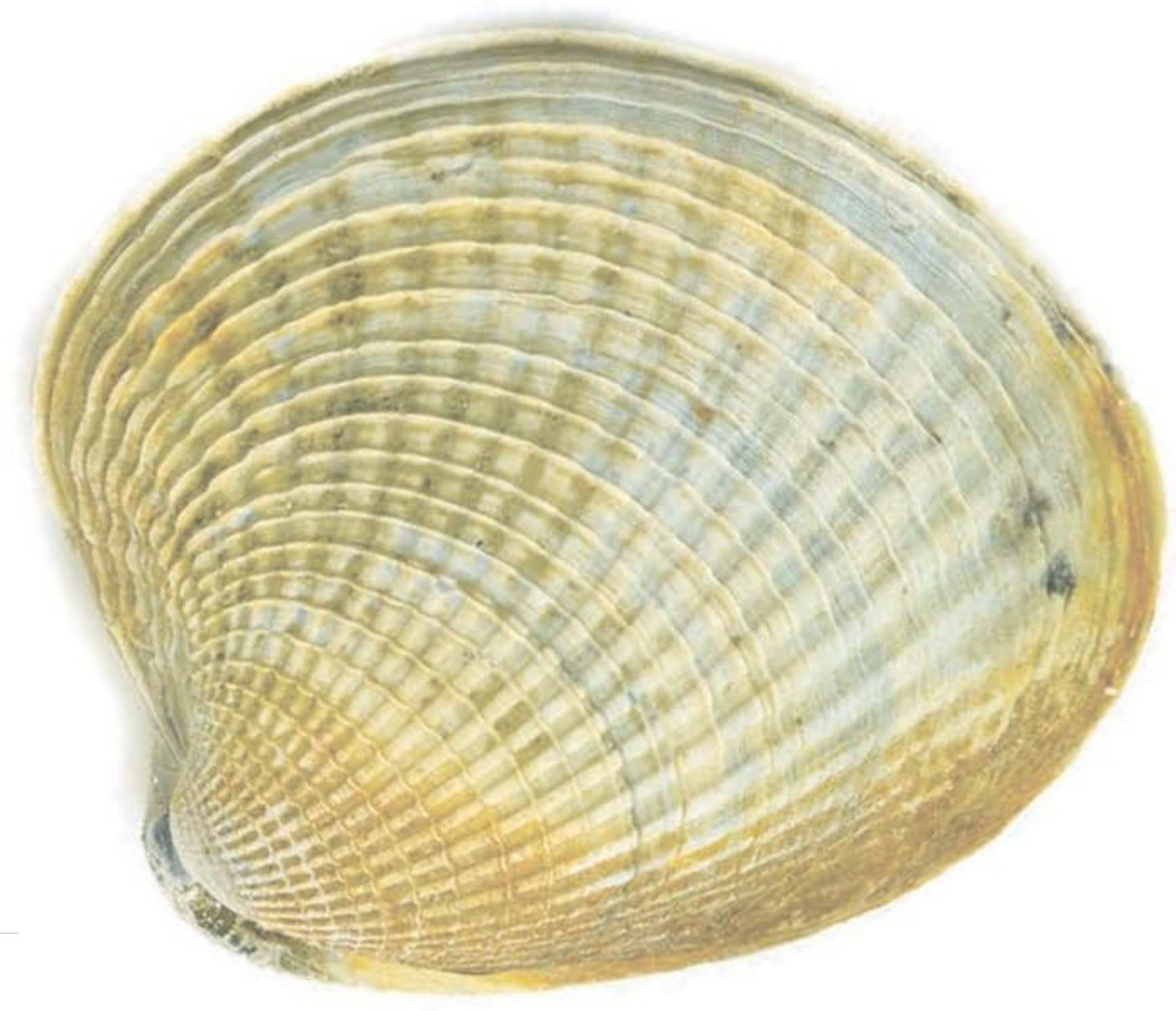

06 -

Design phase one: Material investigations 


\section{Material investigation.}

\section{INTRODUCTION}

This chapter explores how materiality can respond to change through time, facilitating movement, adaptation and habitat; synthesised into the fabric of a coastal pathway for all forms of life to raverse

Typical coastal pathways take the form of a timber boardwalk or asphalt strip that best enables human pedestrians to traverse easily across the landscape.

If we are to rethink the idea of what a pathway could be, then materiality is central to this.

For birds and fish, flying or swimming is unlikely to be impeded in such a contex There are no skyscrapers to dodge or obstacles under the surface of the water. Instead their needs to be met in the facilitation of movement take the form of an ecological corridor - places to eat and rest at intervals along a route.

In synthesising the needs for each form of movement, what if the materiality of the substrate that humans require - a flat elevated pathway - also provided shelter, food and protection for fish, birds and insects, so that they can also traverse easily around the harbour, cohabiting the tidal edge.

This chapter explores that hunch by using materials typical of built infrastructure: timber, concrete and clay; building in 'failure' by removing treatments which extend their lifespan - and using this decay to create nooks and cervices where animals and plants can take refuge appropriating the man made structures for their own use.

\section{APPROACH}

This study seeks to engage directly with the landscape in a tactile way, as in

alignment with affective method.

To do this the material interventions must first emerge from the site - shells, clay and timber are sourced, processed and placed back in situ. Observation records phenological patterns as they etch into the material studies. As the timespan given or this observation period is so short (due to the constraints of conducting a thesis) the rest of this study is speculative envisioning a future in which the substrate supports plants and animals, thus facilitating moments of encounter through cohabitation of the same space.

Their material prototypes are very simple in form, allowing them to be used in a multitude of ways and places - making them adaptable to any area or future scenario.

\section{Process.}

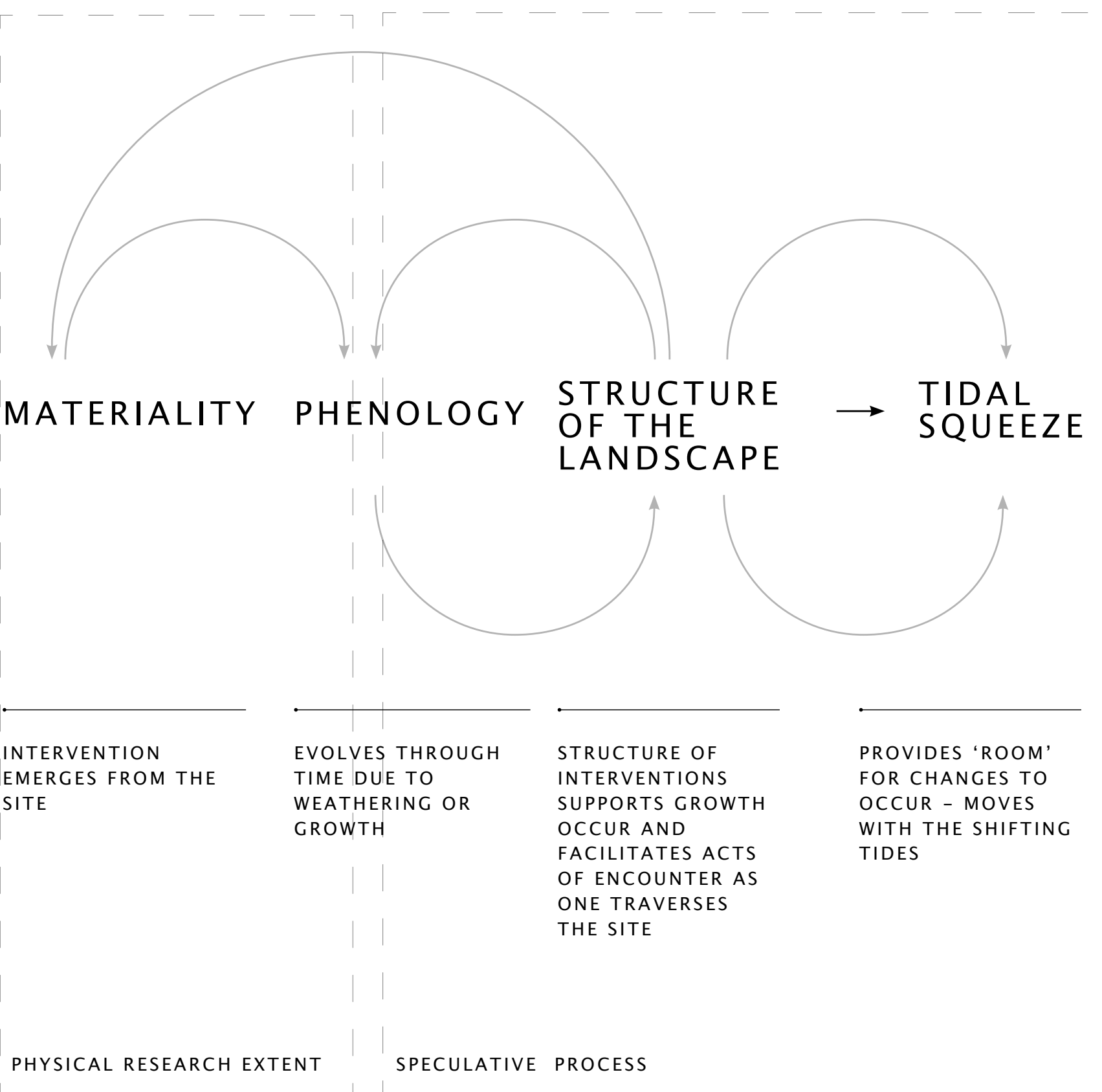


LIFE CYLE OF A MATERIAL:

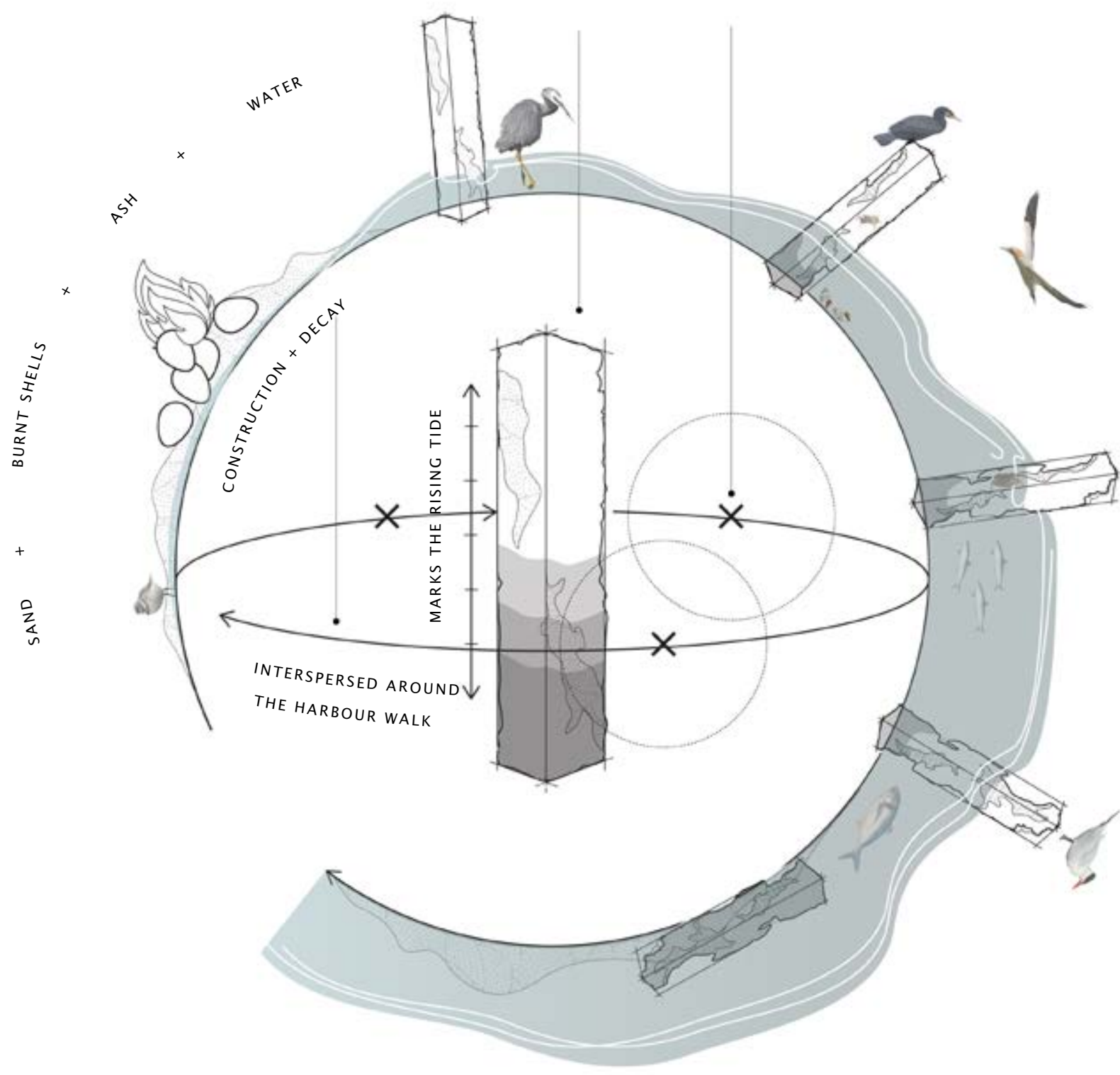

\section{Markers within the landscape.}

These material studies act as habitat markers within the landscape, providing hollows, high points and refuges for species.

These investigations draw directly from to connect people to the beauty of the surrounding environment and its phonological processes. They provide a substrate to facilitate growth(plants), movement (organic and inorganic), and habitat (perches, artificial reefs, barricades which build dune systems or saltmarsh). While also acting as a marker or visual indicator to highlight phenological processes: tidelines, weathering, seasona growth/use (plant or animal) as they occur. The role that they fill differs depending on their location within the harbour, and thus they are versatile and with programmatic indeterminacy to show the nuances of the inlet's environment, specific to each locality.
These material markers nod to land art through their sympathetic approach to the landscape (the very medium from which they emerge), their engagement with time and decay (Smithson's Sprial Jetty), and their experience driven form of encounter a constant state of weathering while providing habitat - and thus moments in which spontaenous movement could occur)

They exist both in isolation as an art piece or habitat pole - or as a material swatch - a test sample for construction materials.

These studies have been placed in situ and will be periodically filmed over the course of several months to understand patterns of life and decay around the harbours edge. They have been placed in three key habitat locations: coastal forest, shell banks and saltmarsh wetlands.

(These tests record and analyse the life occurring in and around them, what sort of uses and events can they create/enable? How do the create experiences and are experienced? Can their presence as a sculptural form entice people to move around the harbours edge from point to point?) 


\section{Material study.}

01 .

CONCRETE

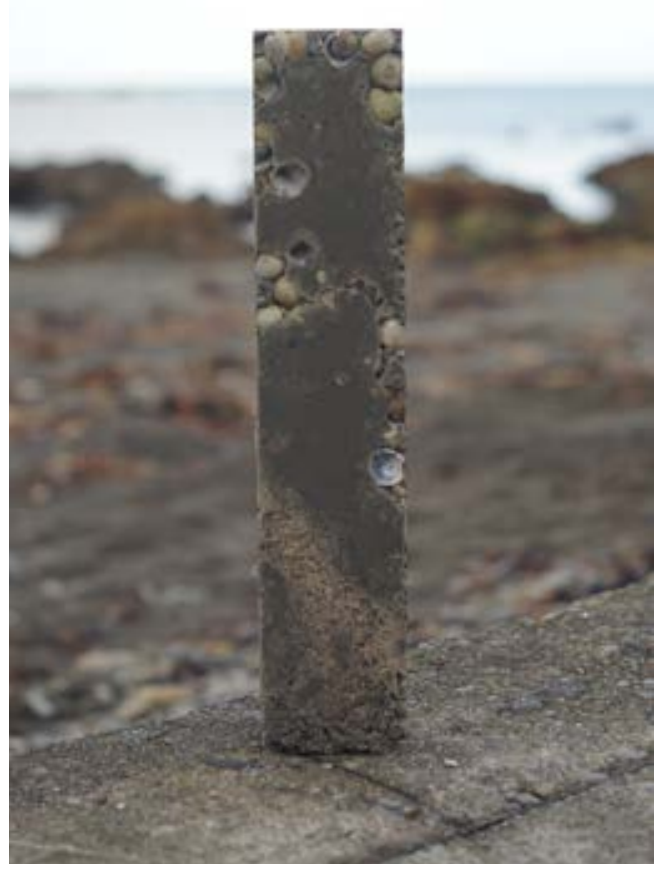

Cracks and crevices provide shelter for limpets, molluscs and crustaceans. Holes and hollows create space for birds and fish to hide and nest.

02.

CLAY/CERAMICS

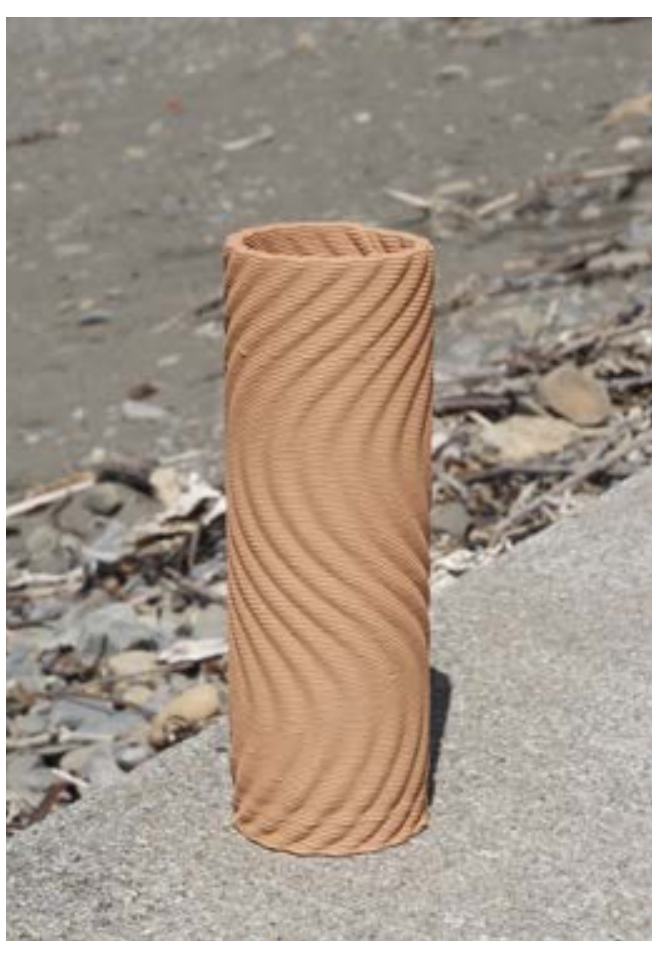

Ridged texture creates perforated substrate for mosses, algae and lichens to adhere to. Clay breathes and allows the moisture to move through it.
03.

TIMBER

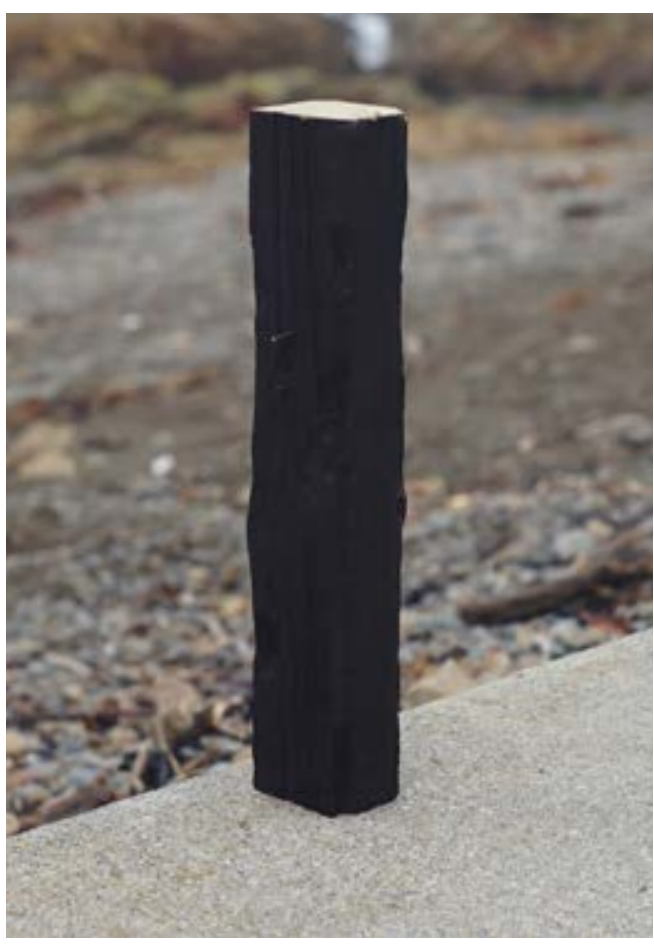

Textures and soil deposits: spaces for epiphytic plants and climbers to take root. Roosts for birds. 


\section{Fabrication: concrete.}

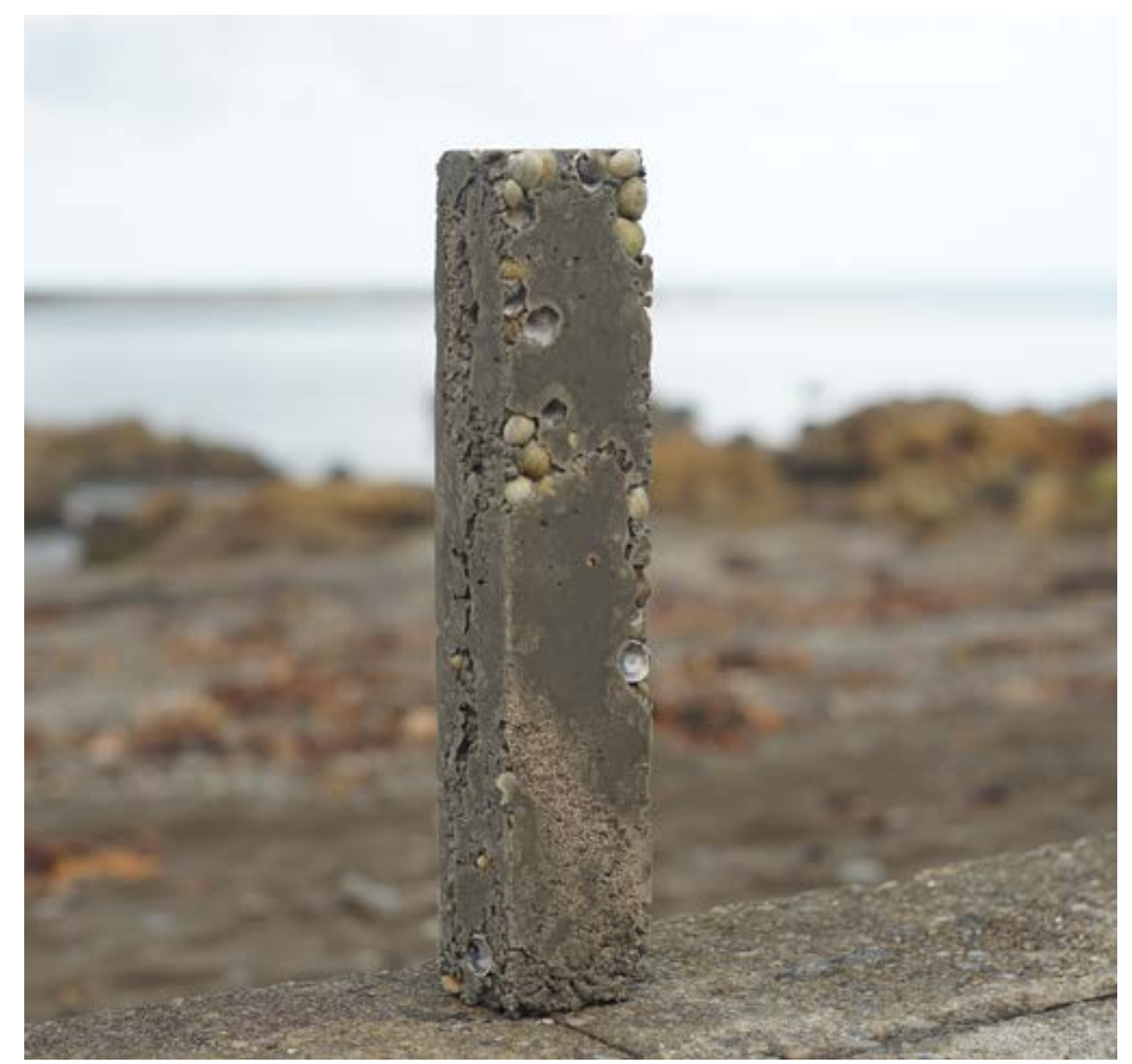

Tabby is a type of concrete thought to have been invented sometime around the 16 th century using a mixture of mortar and lime to create a mud like wall1. Quick lime was created by burning shells or excavating middens, this was then slaked, combined with shells, sand and water then

poured into mould like structures. By generating lime this way, the materiality of this concrete can directly reference the coastal atmosphere of where it is placed. Tabby is also prone to erosion by water revealing beautiful slated shells and creating cracks and crevices for limpets to attach.
STEPS

1. Moulds fabricated out of timber coated in melamine.

2. The concrete tabby mix is constructed ou of burnt/ground shell (which creates lime), sand, and ash. Due to time and material constrictions this also contained a portion of concrete mix to make sure the model set, rather than relying on highly accurate ratios to create successfu binding chemical reaction.

3. Varying porosities of concrete are made by adding larger portion of sand, shells and stones to portions of concrete - this will erode at a different rate from other areas.

4. The concrete is left to set before the melamine mould is removed.

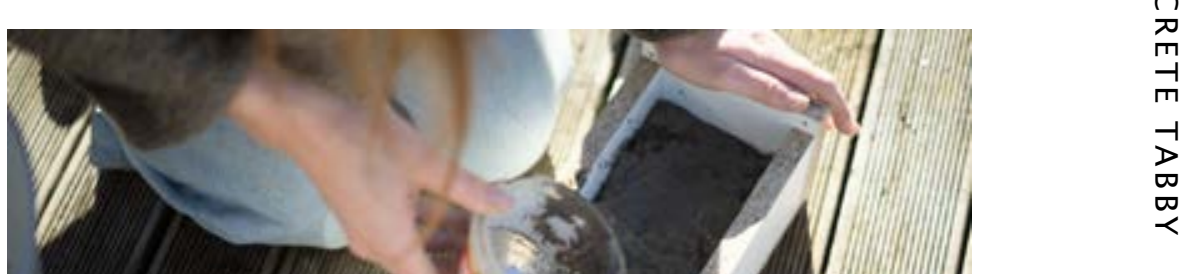
1. Tabby is highly durable, though somewhat prone to water damage. As result stucco was often
applied to the outside to preserve the walls from water. Some concrete tabby structures have 


\section{Predicted erosion.}

MATERIAL STUDY
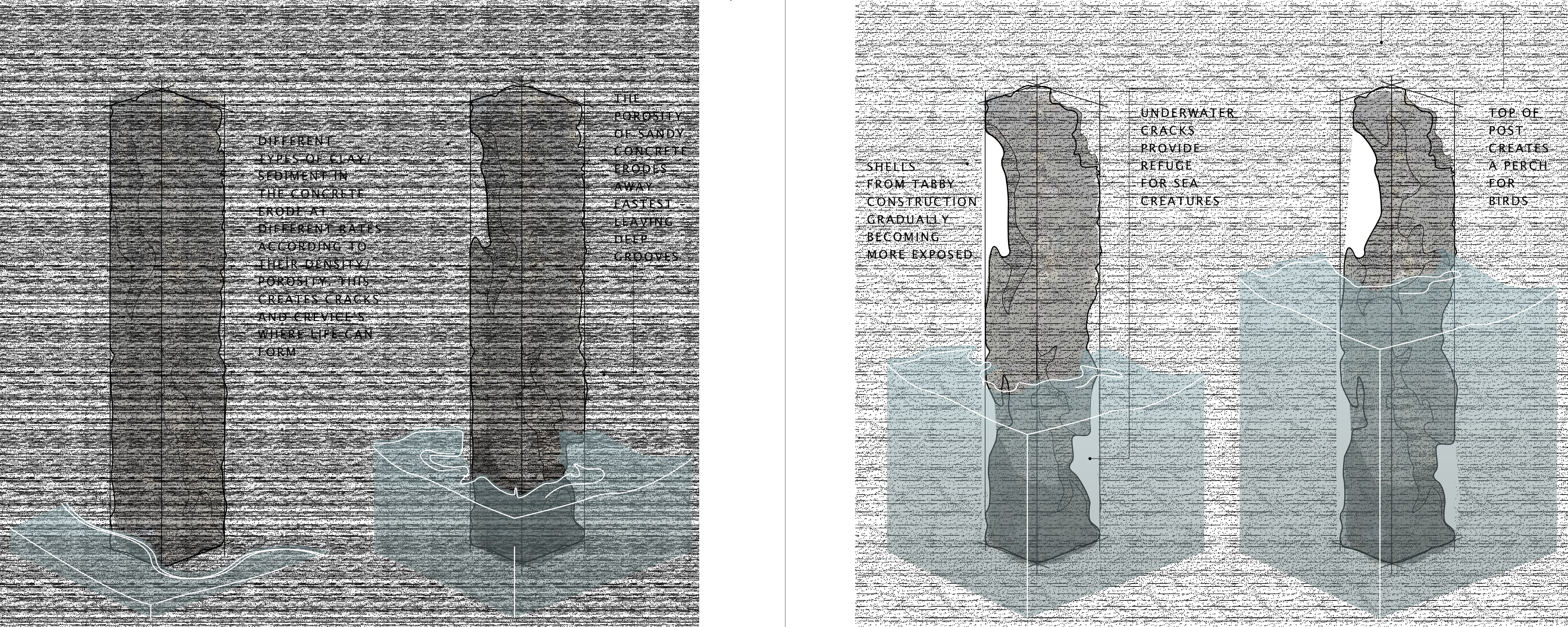

TIME SCALE - SEA LEVEL RISE 


\section{Fabrication: timber.}

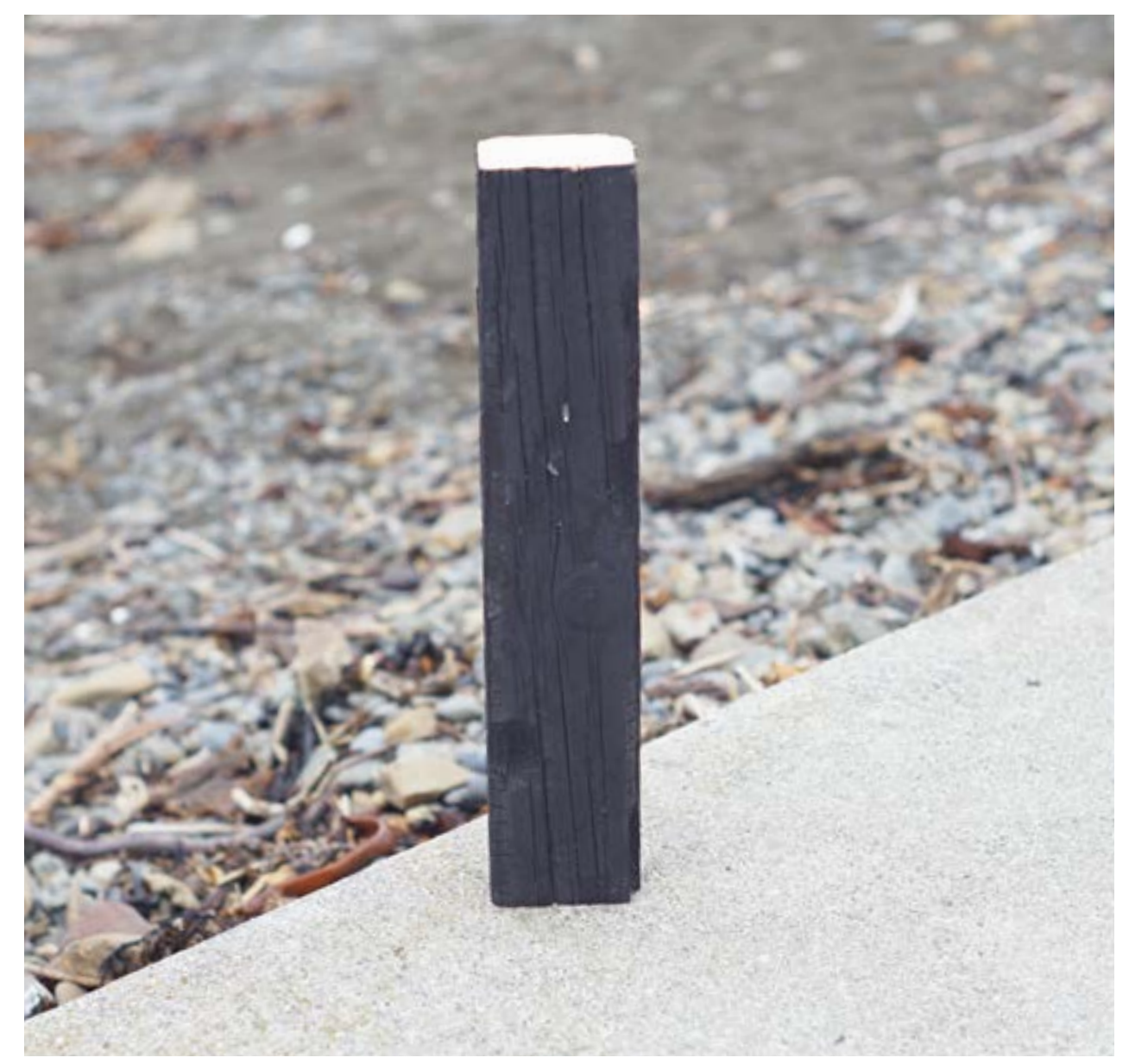

Shou sugi ban is a method that can be used to preserve timber without using chemicals - which could potentially leach into the surrounding environment. Although charring the timber does extend the life of the timber - it is not as resilient as chemical treatments, especially

when exposed to salt water. Oiling the timber will extend its lifespan by giving it a light seal. The combination of carbon and oil makes the wood esistant to water and mould. Shou sugi ban when looked after properly can last for more than 80 years.
STEPS:

1. Timber must be properly dried before burning.

2. A fire is lit, with supporting brick blocks on each side to keep the timber elevated above the fire and remain in control of the heat intensity and distribution.

3. The timber is slowly pulled along on top of the flame to char the outer surface of the log evenly. Care is taken to not burn the timber too deeply so as not to damage the structural integrity of the timber.

4. Charred timber is left to cool then washed and scrubbed to take off any soot then oiled. The

oil improves both the longevity and appearance of the

1. Shou sugi ban is an ancient Japanese method of preserve wood outside. It should be oiled to years to maintain its condition and extend its life.
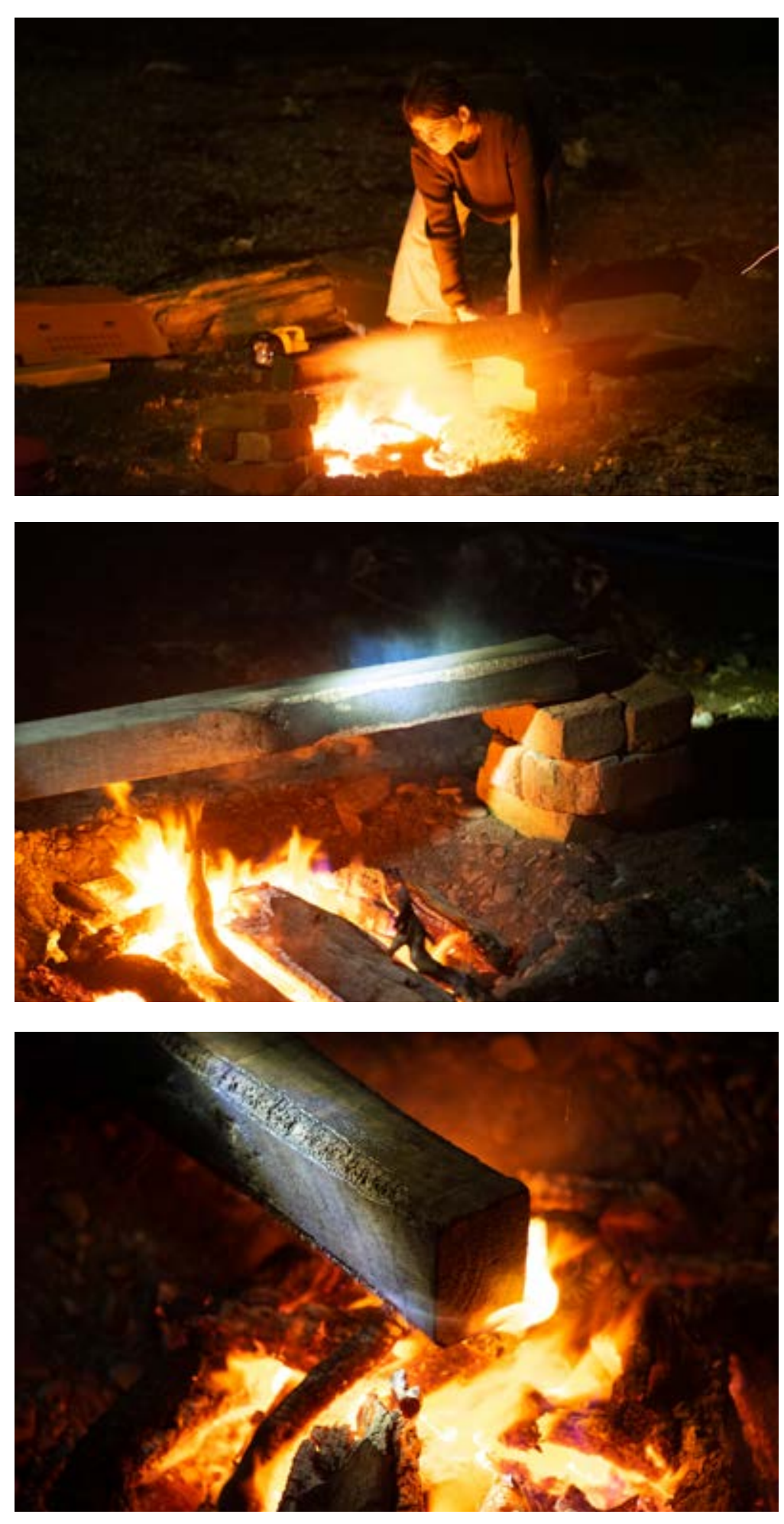


\section{Predicted erosion.}

MATERIAL STUDY
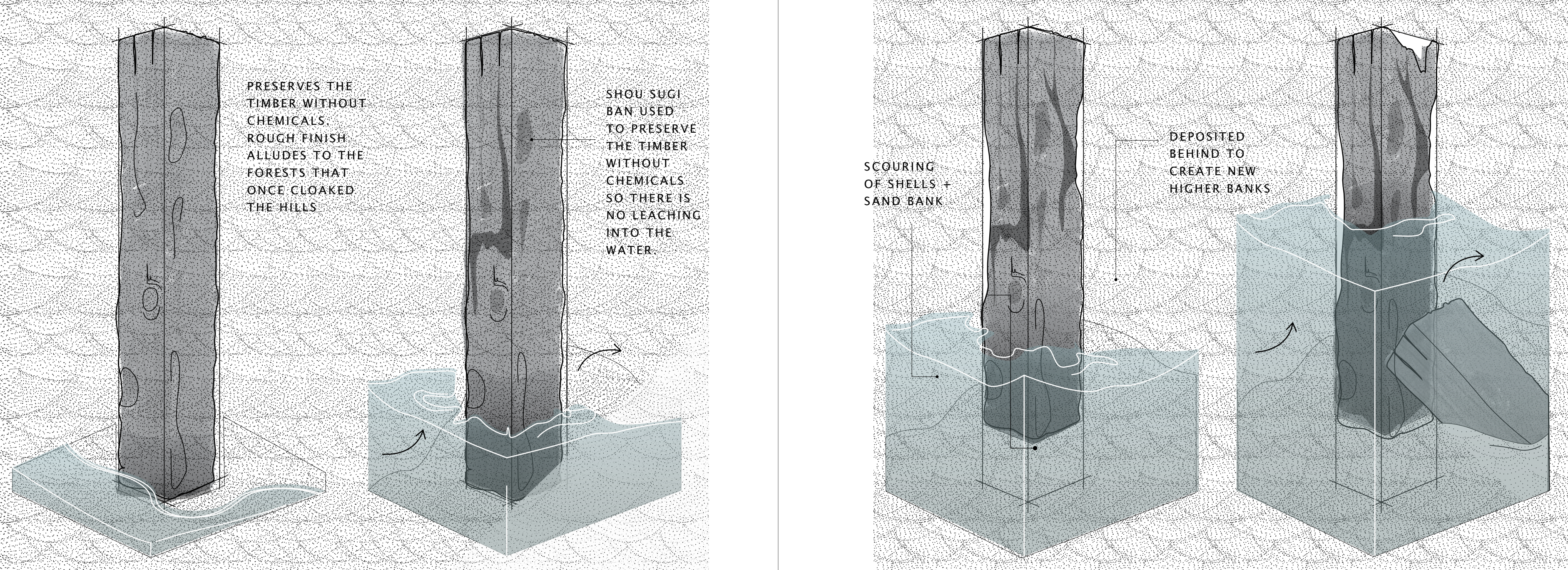

TIME SCALE - SEA LEVEL RISE 


\section{Fabrication: clay.}

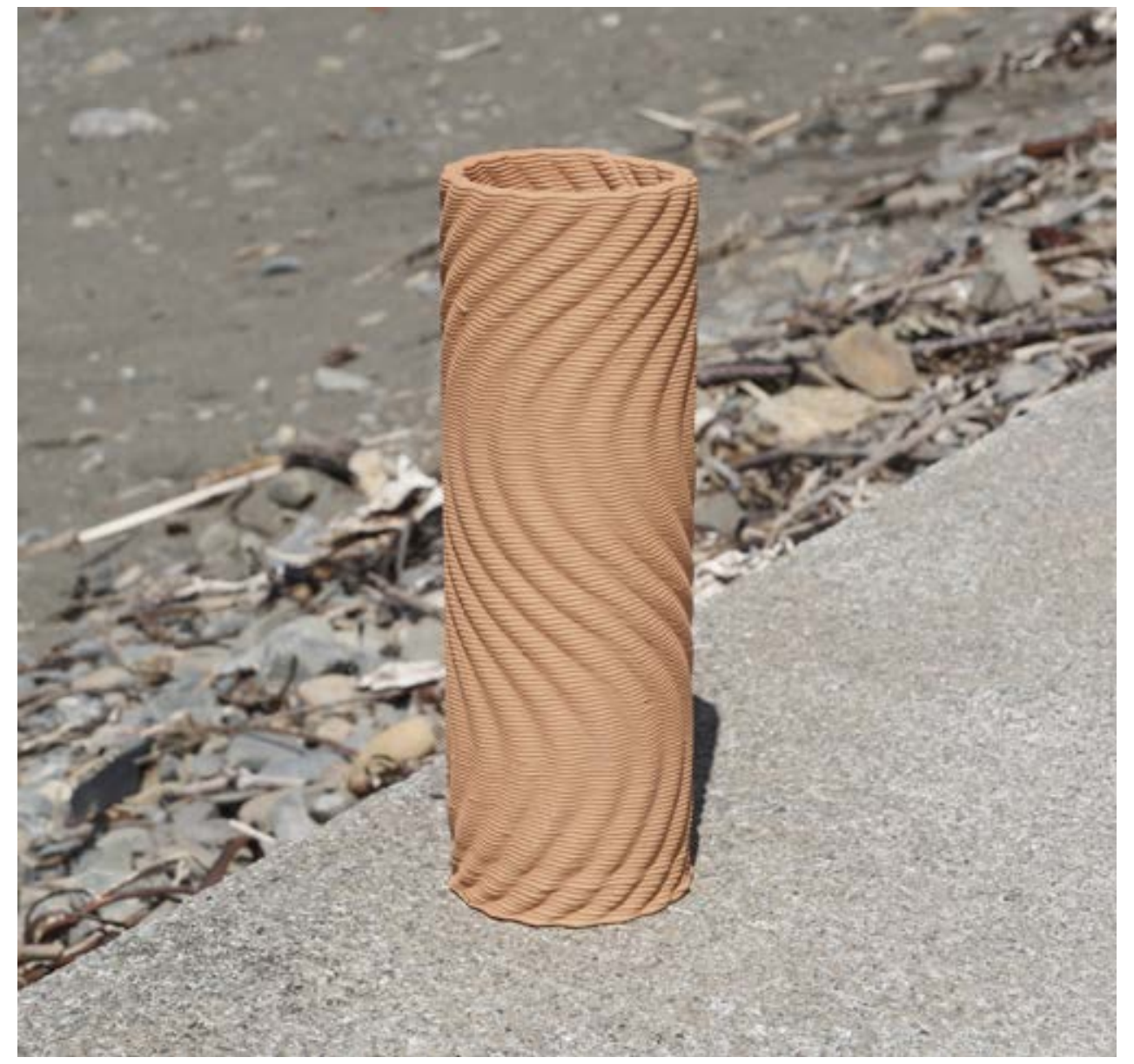

Ceramic 3D printing opens up a whole range of possibilities when it comes to creating textured substrates for wildlife to cling to or emerge from within. Beautiful and ecologically sound, the bisque fired terracotta will break down and become part of the earth once again at the end of its life.

The modelling is achieved through using grasshopper software plugged into rhino. The base formula for this particular model was adapted from a piece of code available online and altered to create a prototypical material test to explore the potential of this medium.

1. The orginal grasshopper code was made publicly availble for adaption by XU Yangyi as part of a teaching Programme at Zhejiang University in 2018.

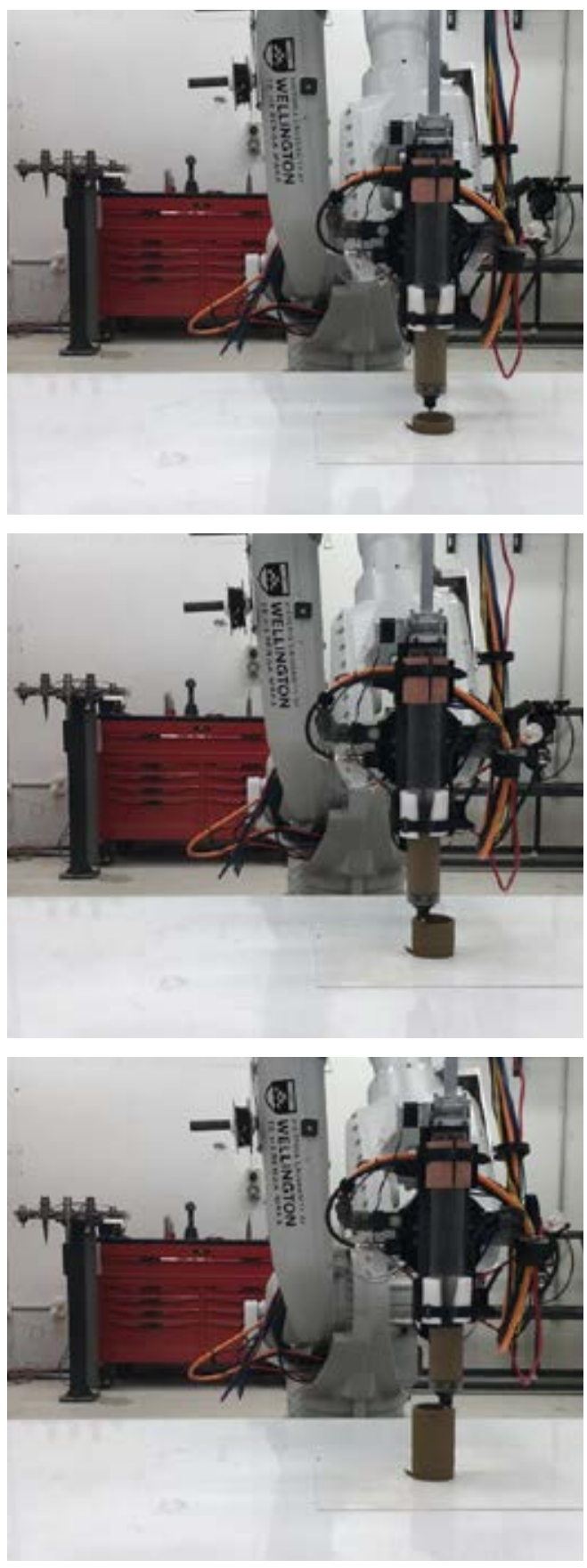

STEPS:

1. Clay is mixed with water and squeezed through a fine sieve to create the right consistency for extrusion.

2. The 'potter bot' is loaded with clay, taking care not to create any air pockets in the tube as you pack it. The screws are all tightened and the 'Potter bot' syringe is attached to the robot arm and set for extrusion.

3. Once extruded, the clay cylinder is left to dry for several days.

4. The cylinder is fired in a kiln to achieve a bisque fired terracotta cylinder-porous and breathable allowing water to move through the structure. 


\section{Predictions: Clay.}

These material prototypes are

designed with the intention that they could be placed at different points along the pathway and still provide substrate for new growth to occur.

Degradation occurs differently

depending on each location, so too does its use as habitat.

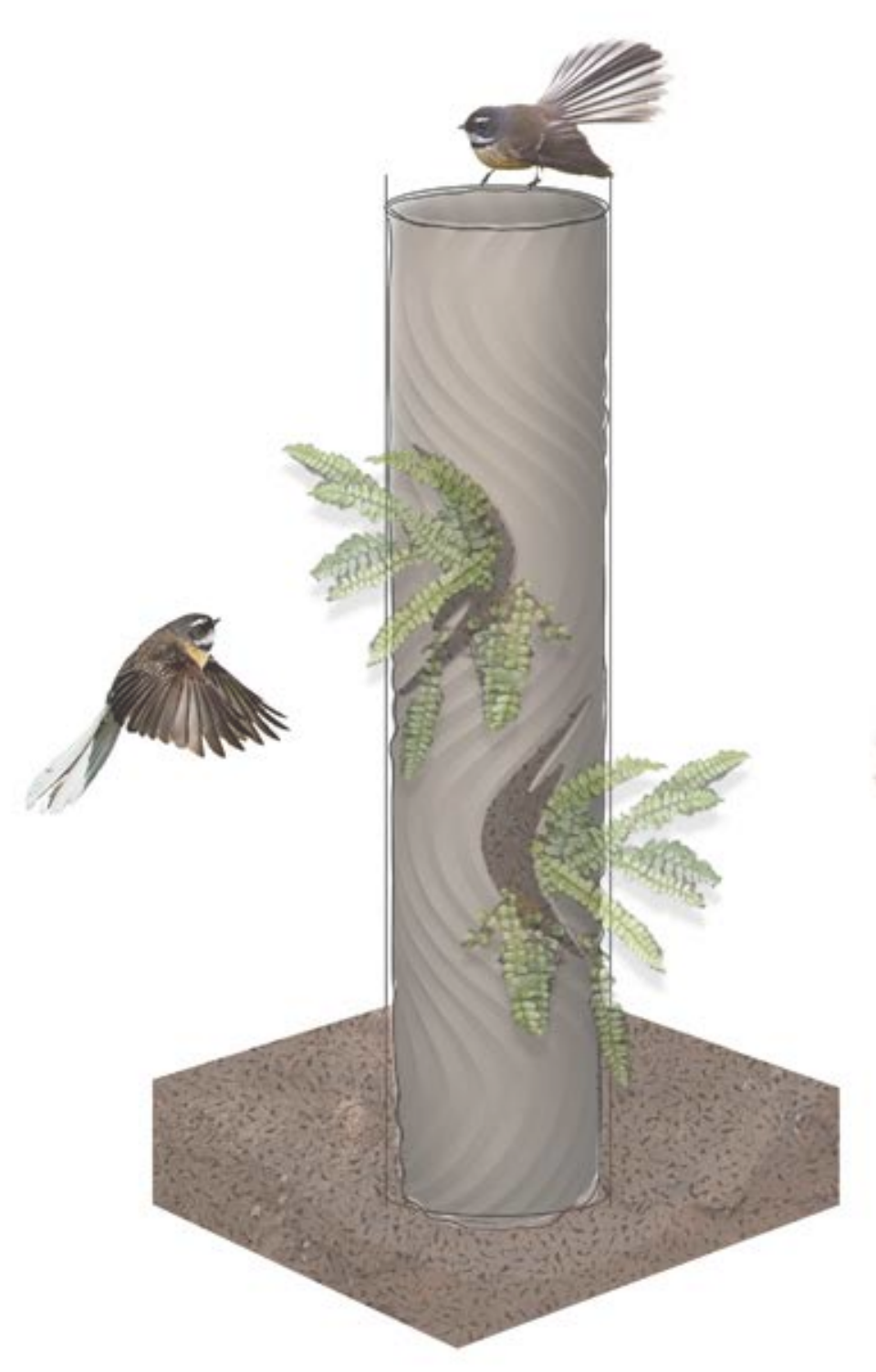

FOREST MARKER / PLANTER

MATERIAL STUDY

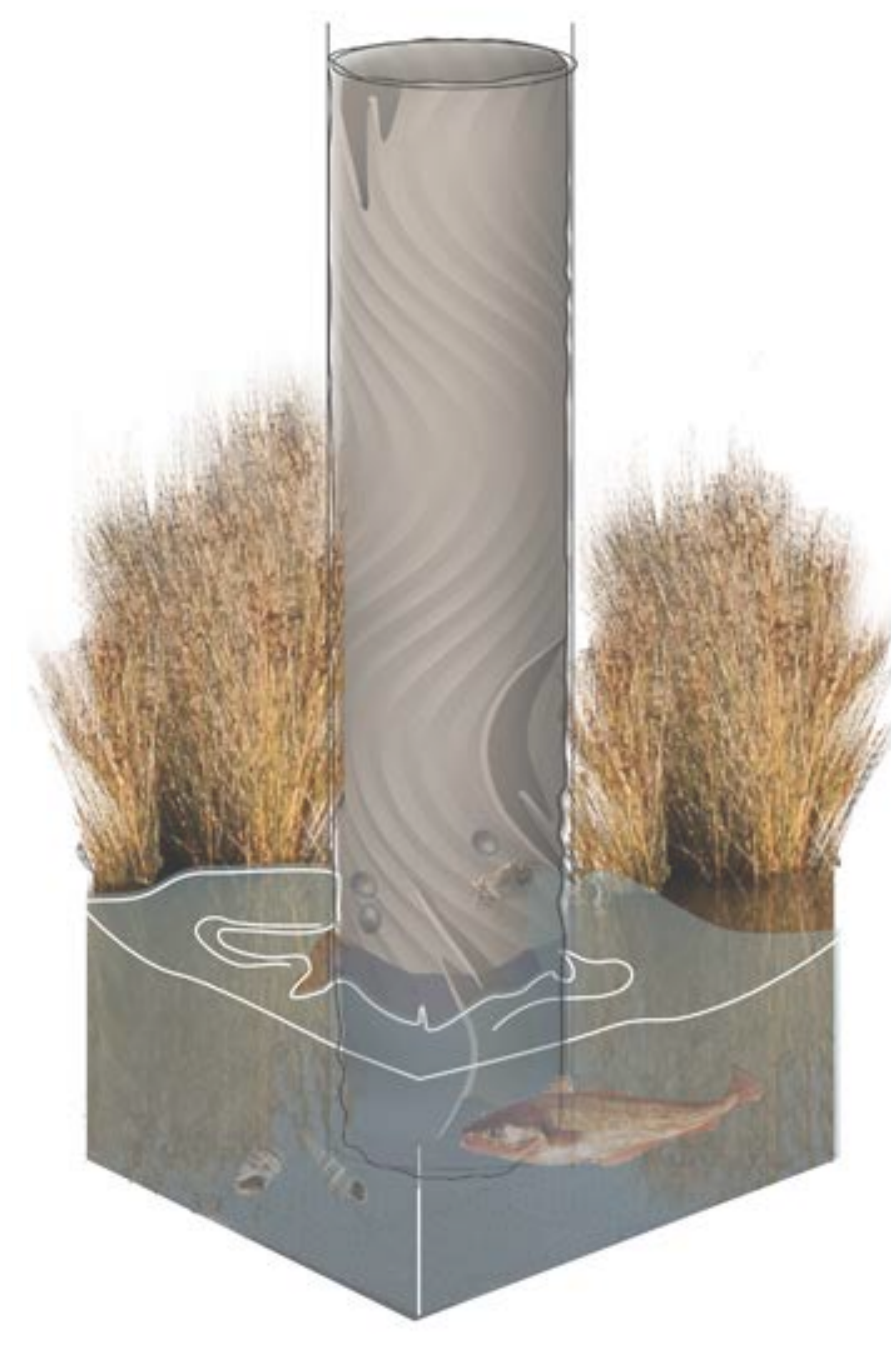

SALTMARSH / REEF

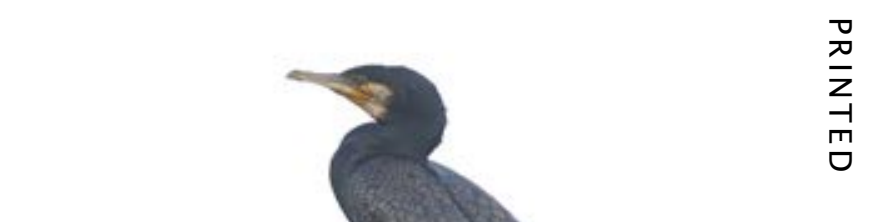

CONSTRUCTED REEF 


\section{Concrete in situ.}
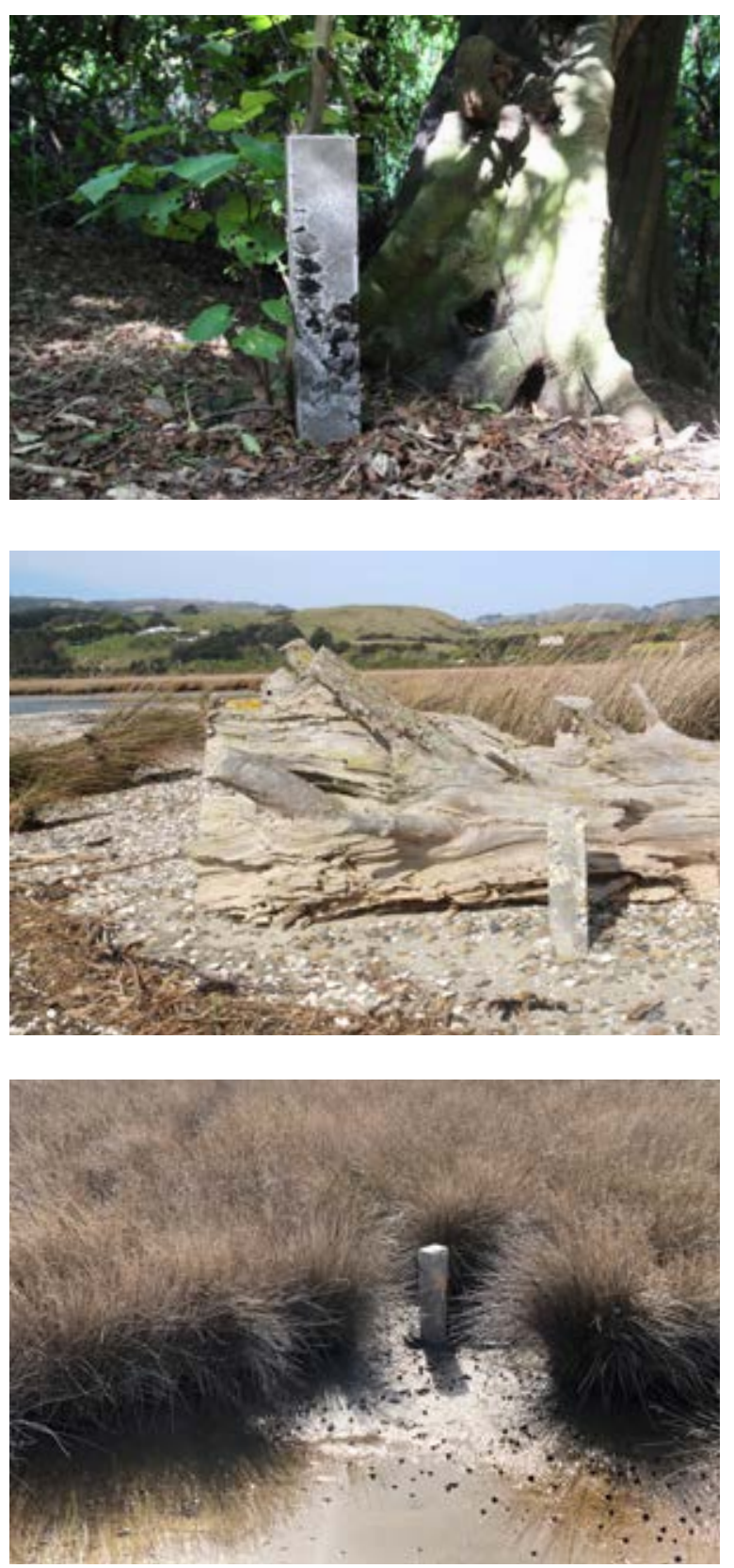

PREDICTIONS:

-Weaker concrete sections

erode and create homes for invertebrates.

- Substrate for lichen and

mosses to grow.

OBSERVATIONS:

Curious fantails flying around. - Dappled light highlights bug trails and spider webs

PREDICTIONS:

- Shelter for nesting birds to

build behind.

Cracks and crevices for

impets and mollusks to hide/

OBSERVATIONS:

- Salt crystals solidifying on the concrete along with watermarks

- The most secure of all the materials when exposed to coastal weather

PREDICTIONS:

- Weaker concrete sections erode and create homes for crustaceans and invertebrates.

OBSERVATIONS:

Tide marks

- Pattern of scouring and

deposition of the surroundings sediment

\section{Timber in situ.}

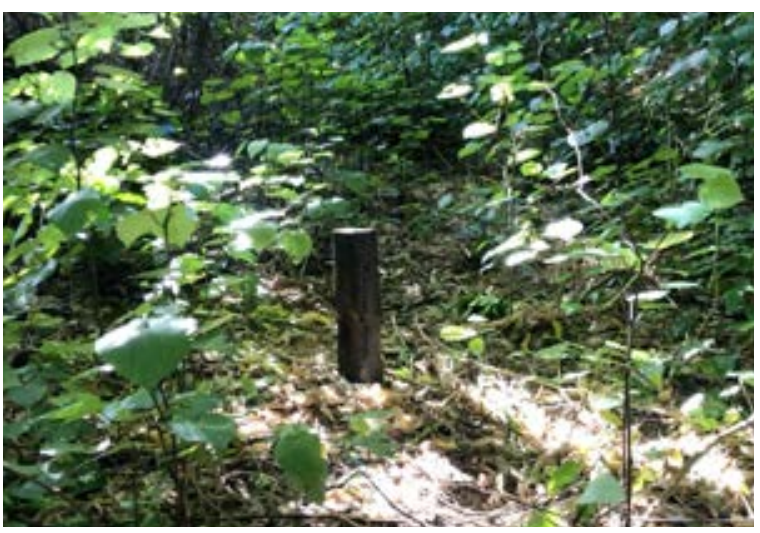

PREDICTIONS

Substrate for insects to hide underneath

Substrate for lichen and

mosses to grow in the cracks and crevices.

OBSERVATIONS

Curious fantails flying around.

- Dappled light highlights bug

trails and spider webs

PREDICTIONS

Perching spot for birds

OBSERVATIONS:

- Traces of the shifting water

noticeable on the timber from

slight salt stain.

First model lost to the sea after

only two weeks as it was the

lightest material.

$\underset{\substack{u \\ \infty}}{u}$

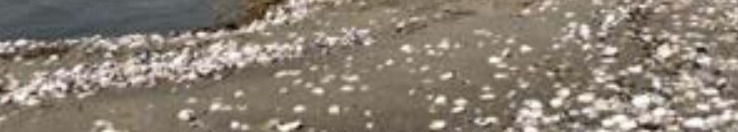

PREDICTIONS:

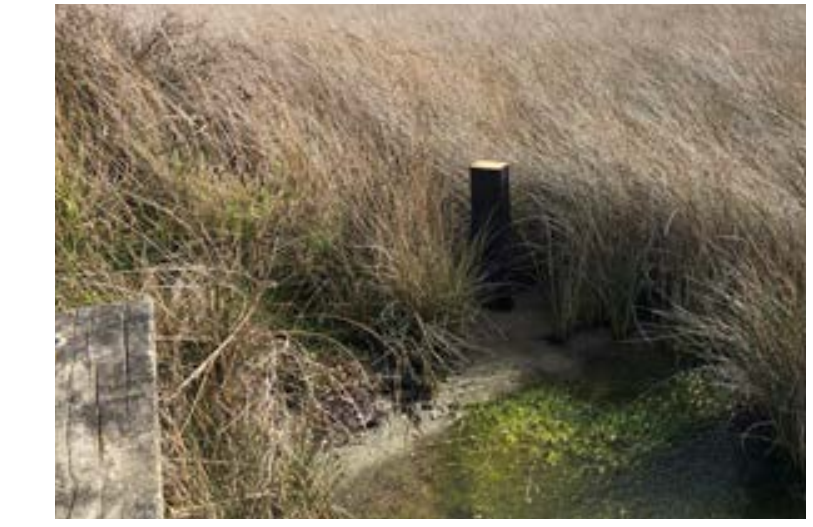

Cracks and crevices allow

underwater plants and mollusks to adhere.

Pattern of scouring and

deposition of the surroundings sediment

OBSERVATIONS:

- Tide marks evident

- Timber washed away after two weeks. 


\section{Clay in situ.}
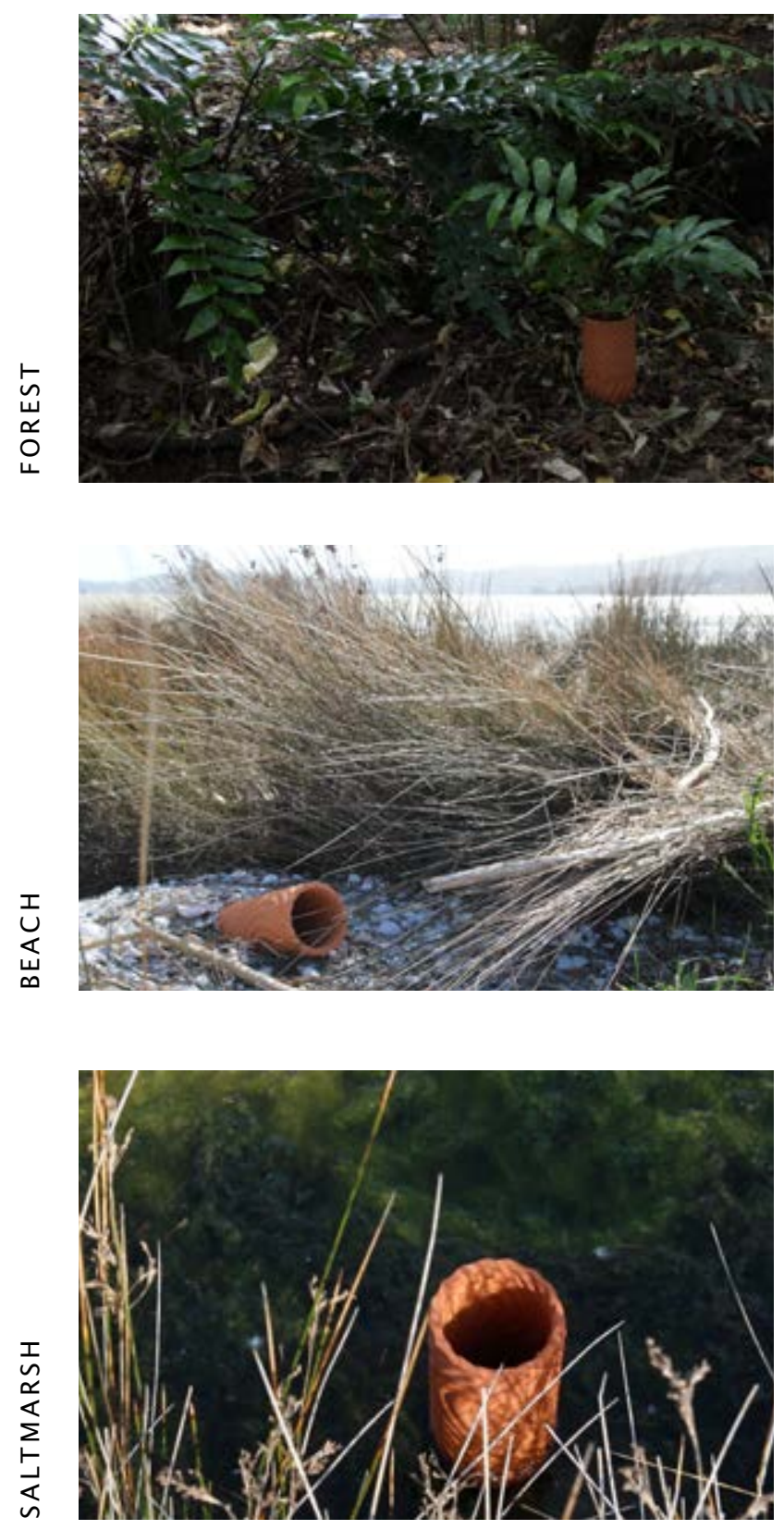

PREDICTIONS:

Insect hotel: home for spiders, weta and other invertebrates.

Substrate for lichen and mosses to grow.

OBSERVATIONS

- Curious fantails flying around.

- Terracotta cylinders make

good planting pots for ferns and undergrowth species.

PREDICTIONS:

- Shelter for nesting birds - Refuge for spiders bugs and other invertibrates.

OBSERVATIONS:

Moved around by the tides - Waterlines slowly etched into the clay

\section{PREDICTIONS:}

Substrate for underwater plants and mollusks to cling to.

- Potential to become an

underwater reef or fish nursery

if toppled over.

OBSERVATIONS:

- Water marks left behind by the undulating tide. Algal line.

\section{Critical reflections.}

Originally these material studies had been intended as sculptural markers within the landscape that would show whereabouts in the harbour certain animals could be found. However after observing the models over a period of time - they have instead become more like prototypical samples - not just existing on their own but synthesised into the fabric of the pathway itself. There were several limitations to this obseravtional study with must be acknowledged too: the objects are too small to hold weight as scultptures and were lost in the landscape, the period of time to observe too short to see any real change and several sculptures were lost to the sea and light handed opportunists having not been adhered to the ground. Thus the obserational records cannot be considered as 'fair tests' as such.

However this was still a very useful excerise as it allowed me to think more broadly about the pathway and its users. As well, being able to engage with the landscape in such a tactile way - gathering materials from the site, processing them and watching them change brought life to this design-led research in a project that is otherwise purely speculative.
The length of time that the models were placed in situ is not long enough to establish any solid growth or habitat to form. As they disintegrate, they slowly become more and more a part of the fabric around them. There is potential for these materials to integrated into the form of the pathway, sythenesising the needs of humans and wildlife into the same substrate.

The next section looks at how the materials explored in the previous study can be used in the fabrication of larger components in the pathway around the harbour: Sho sugi ban timber as boardwalks or slatting. Concrete tabby as coastal walls. Clay planting beds. 


\section{Integrating materiality into design:} concrete.

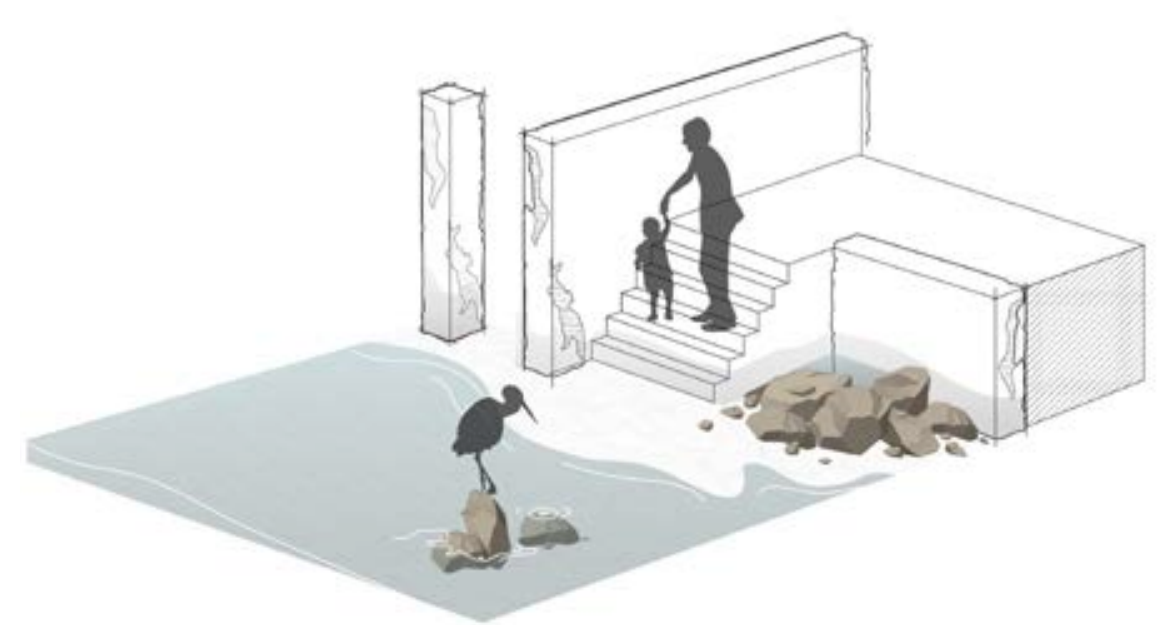

INTERACTIONS AFFORDED:

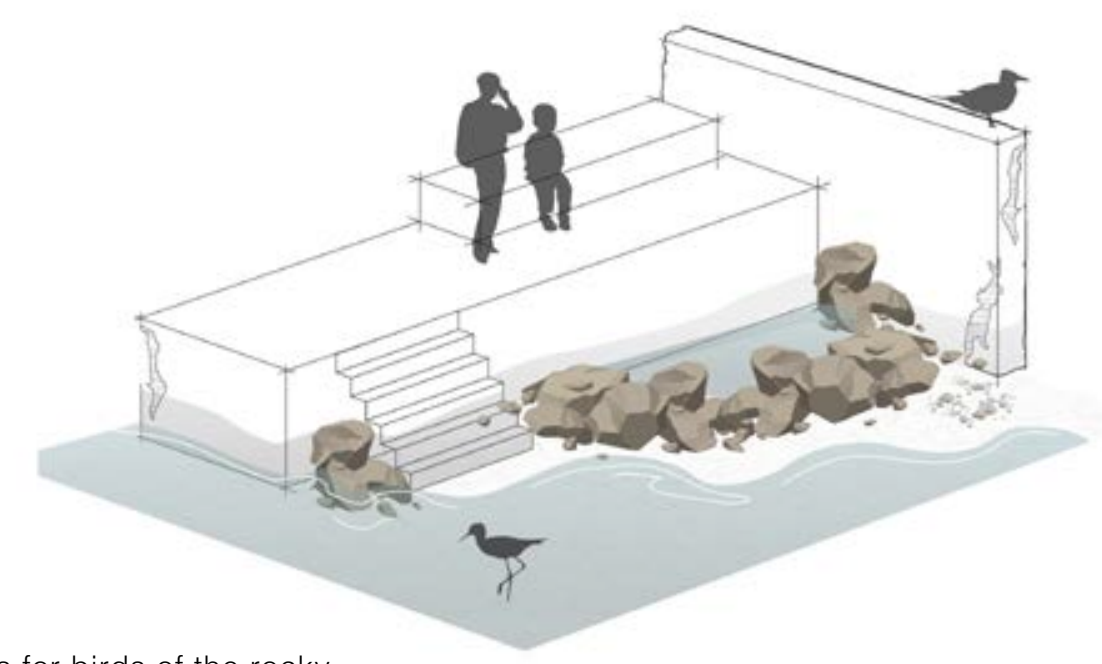

Passive observation:- Rest spots for birds of the rocky shoreline.

feeding spots for scavenging birds

and interactive play for kids.

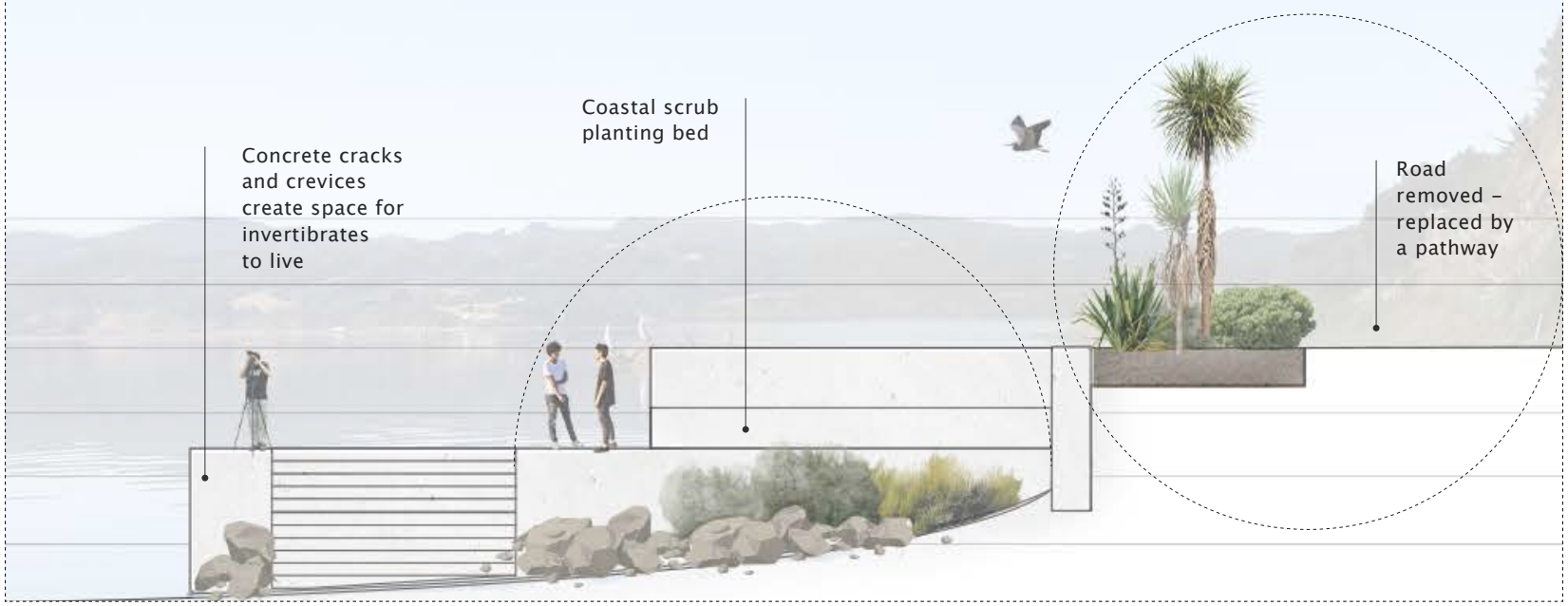

SEDIMENTATION FILLS THE INLET: PLANTING BEDS

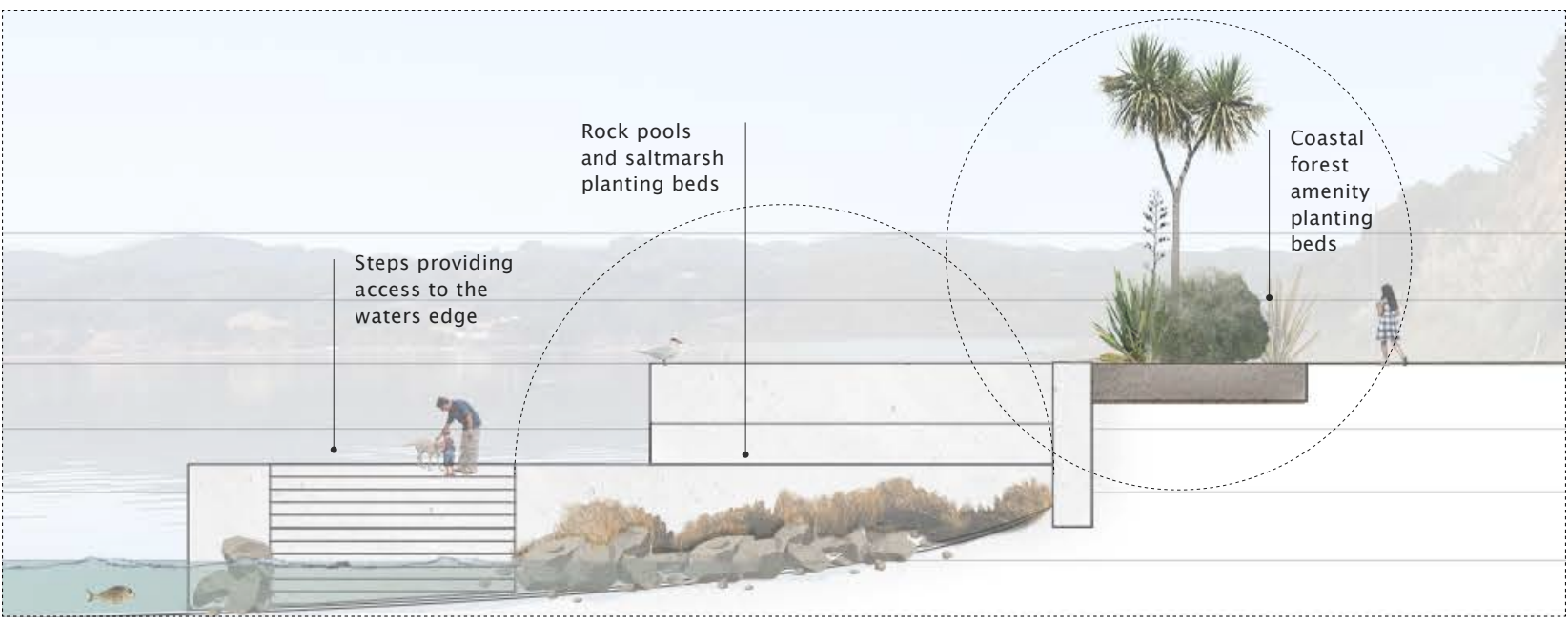

CURRENT TIDELINE: SUBTIDAL ROCKPOOLS OR SALTMARSH BEDS

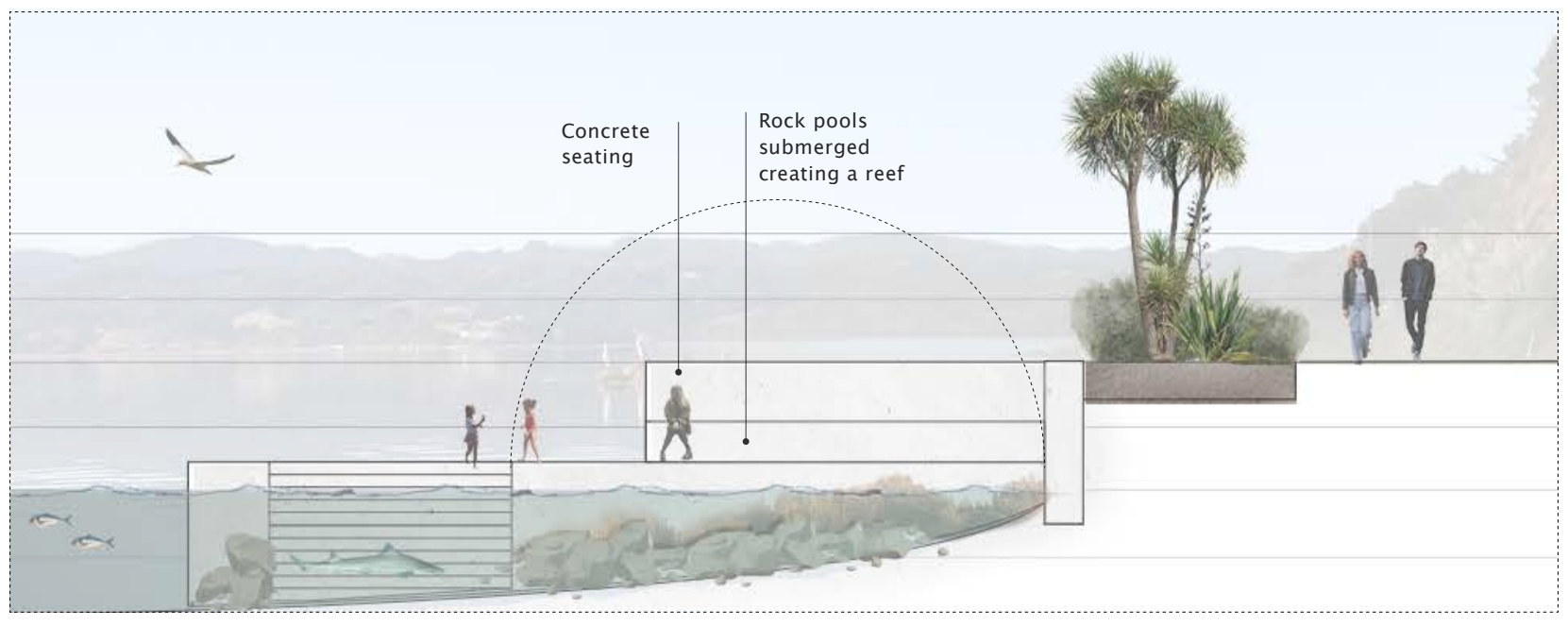

TIDAL INUNDATION: UNDERWATER REEF 


\section{Integrating materiality into design:} timber.

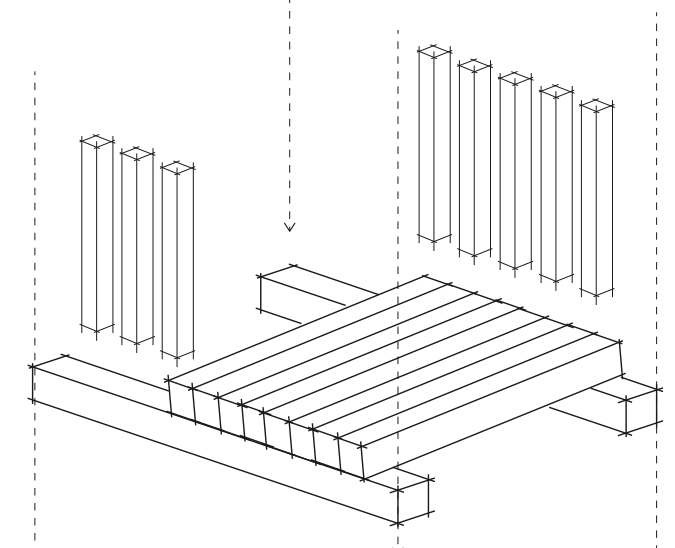

Sho sugi ban timber

charring can be used in the construction of wharfs and jetties as opposed to using treated timber

INTERACTIONS AFFORDED

Passive observation: Timber posts trap logs which stabilise erosion allowing shell banks and saltmarsh plants to built up behind. This creates habitat for birds to nest underneath the walkway structure,

observable but at a safe distance from people walking past.

Interactive

MATERIAL ADAPTION AND THE PROVISION OF HABITAT THROUGH TIME, BASED ON TWO SCENARIOS: SEDIMENTATION AND SEA LEVEL RISE.

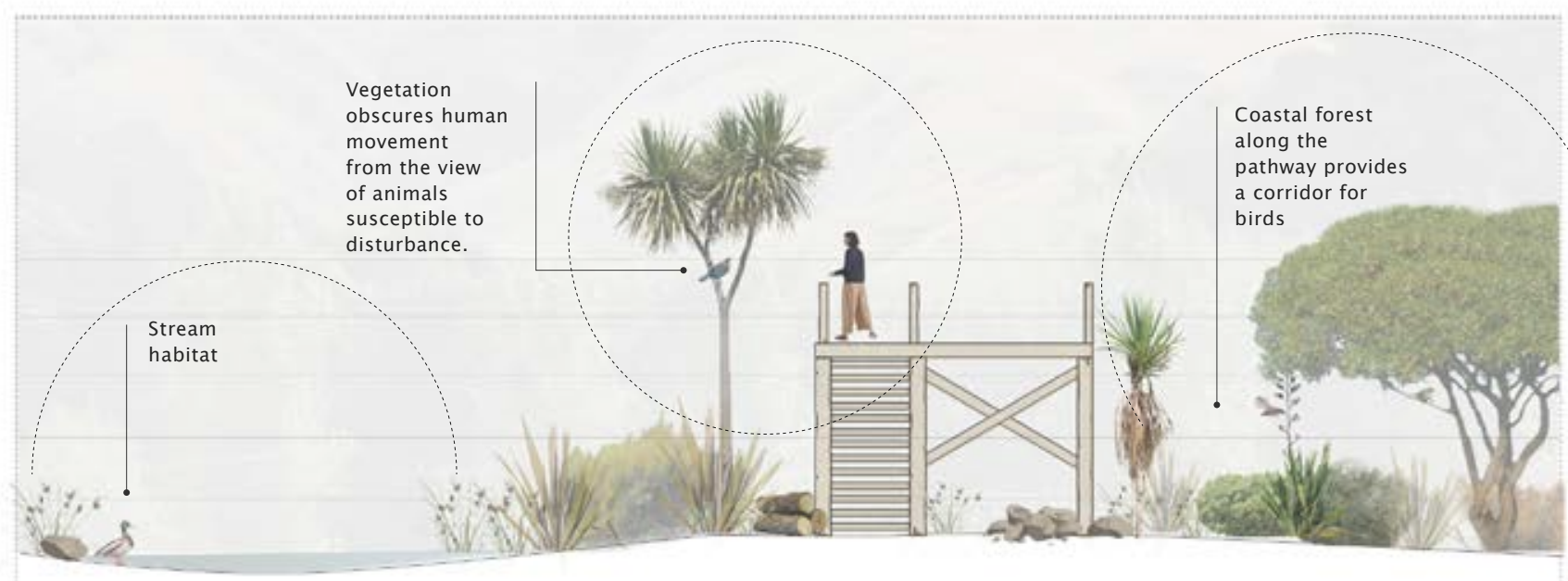

SEDIMENTATION FILLS THE INLET:

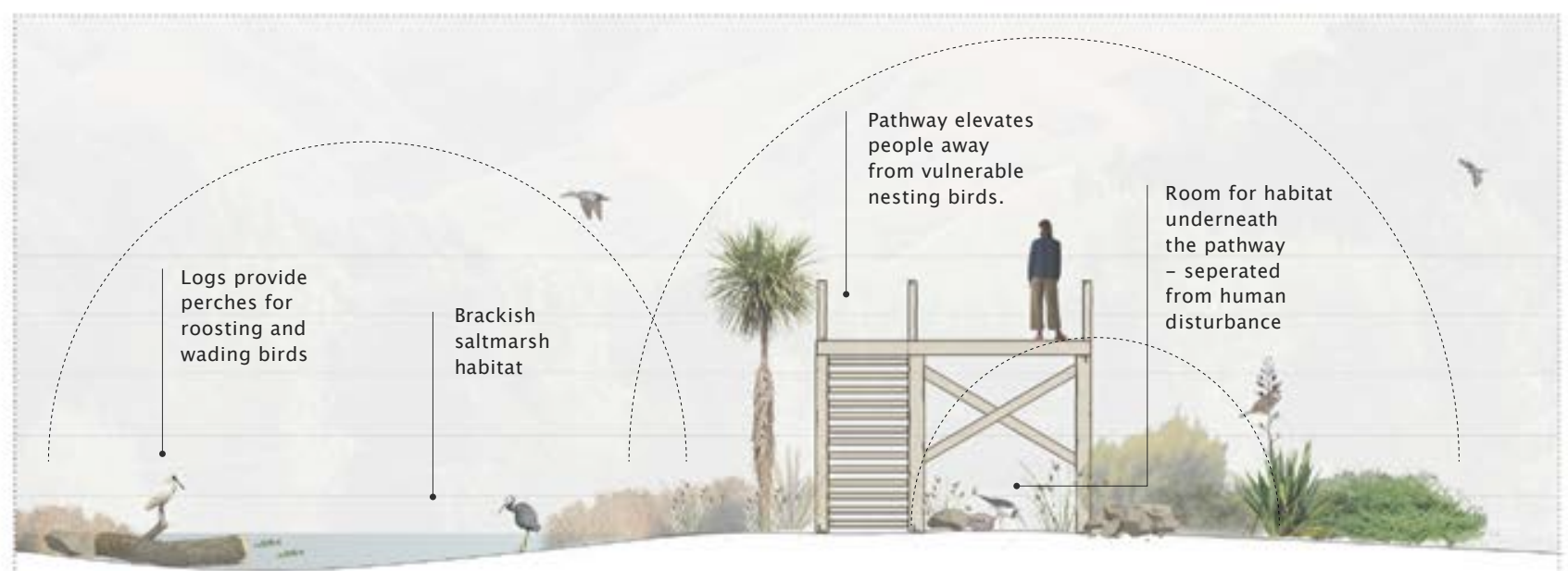

CURRENT TIDELINE:

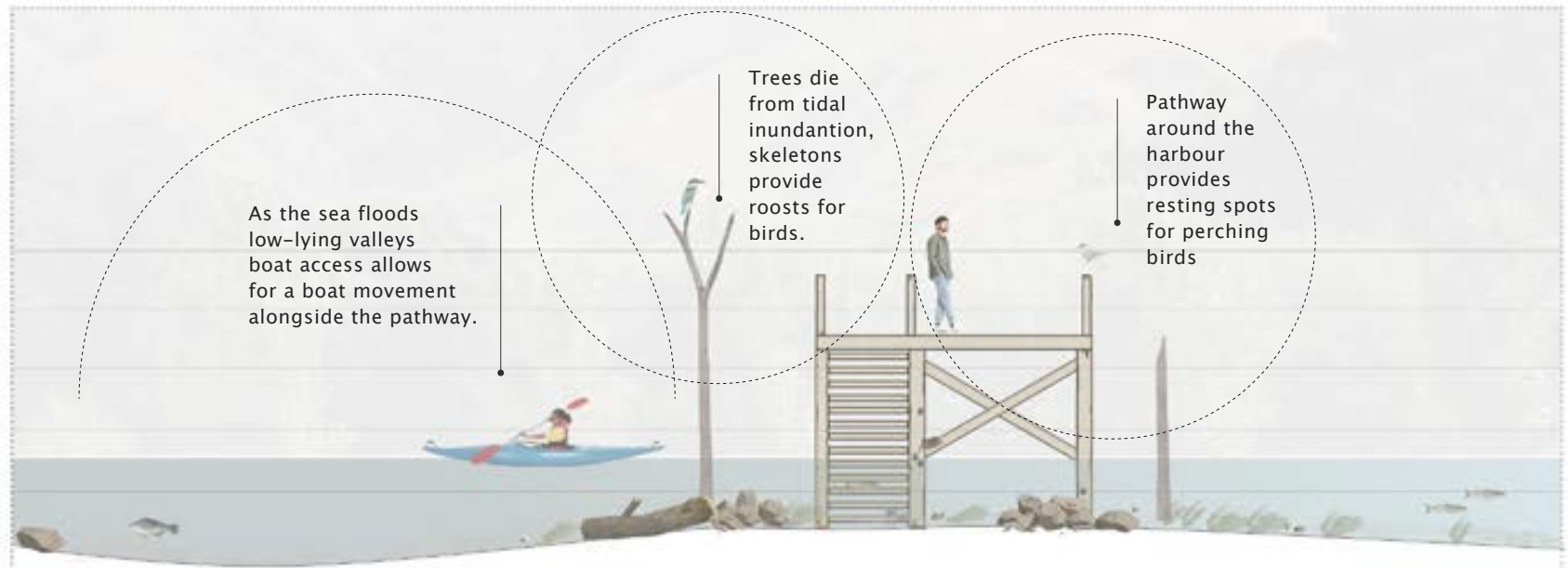

TIDAL INUNDATION 
MATERIAL STUDY

\section{Integrating materiality into design:}

\section{ceramics.}

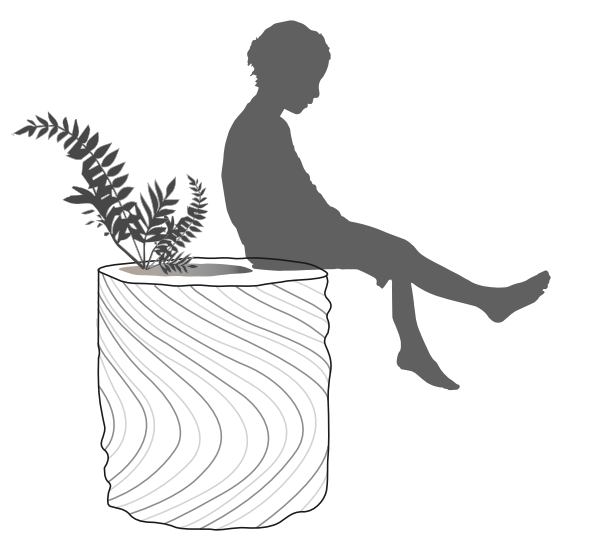
up create retaining wall structures. Cracks and

crevices create room for

observable growth: plants

and crustaceans.

Interactive Clay planters allow

encounters: $\quad$ people to get up close

and touch the substrate.

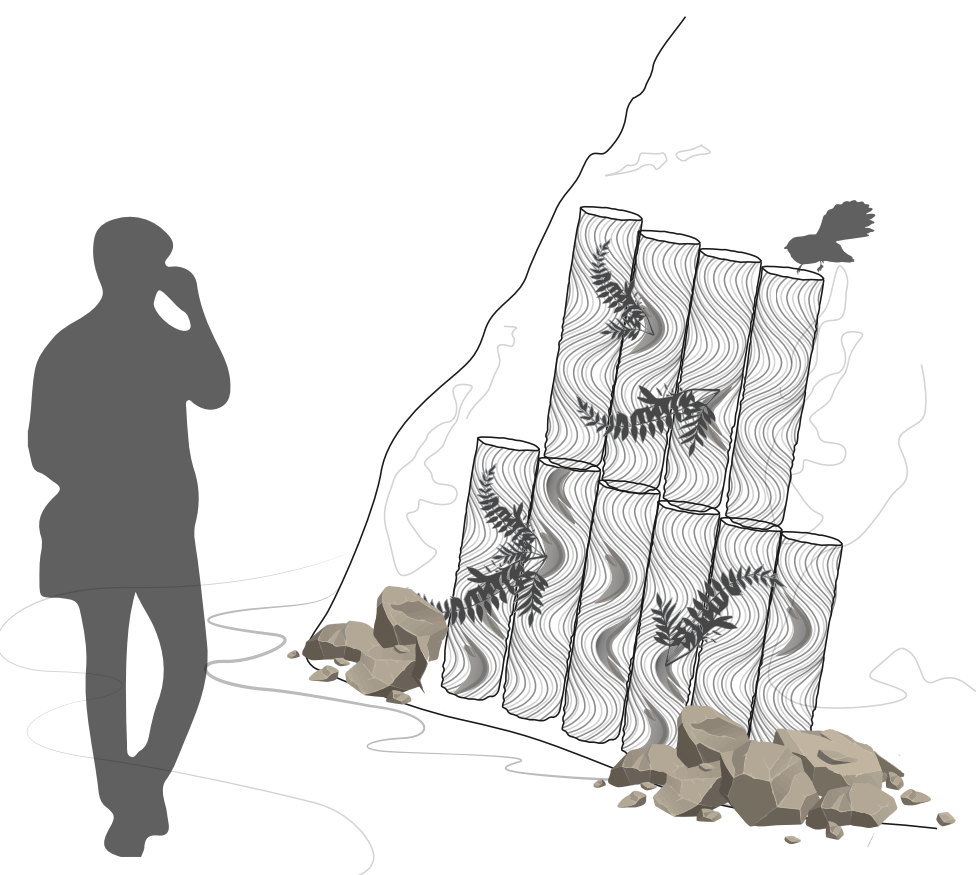

MATERIAL ADAPTION AND THE PROVISION OF HABITAT THROUGH TIME,

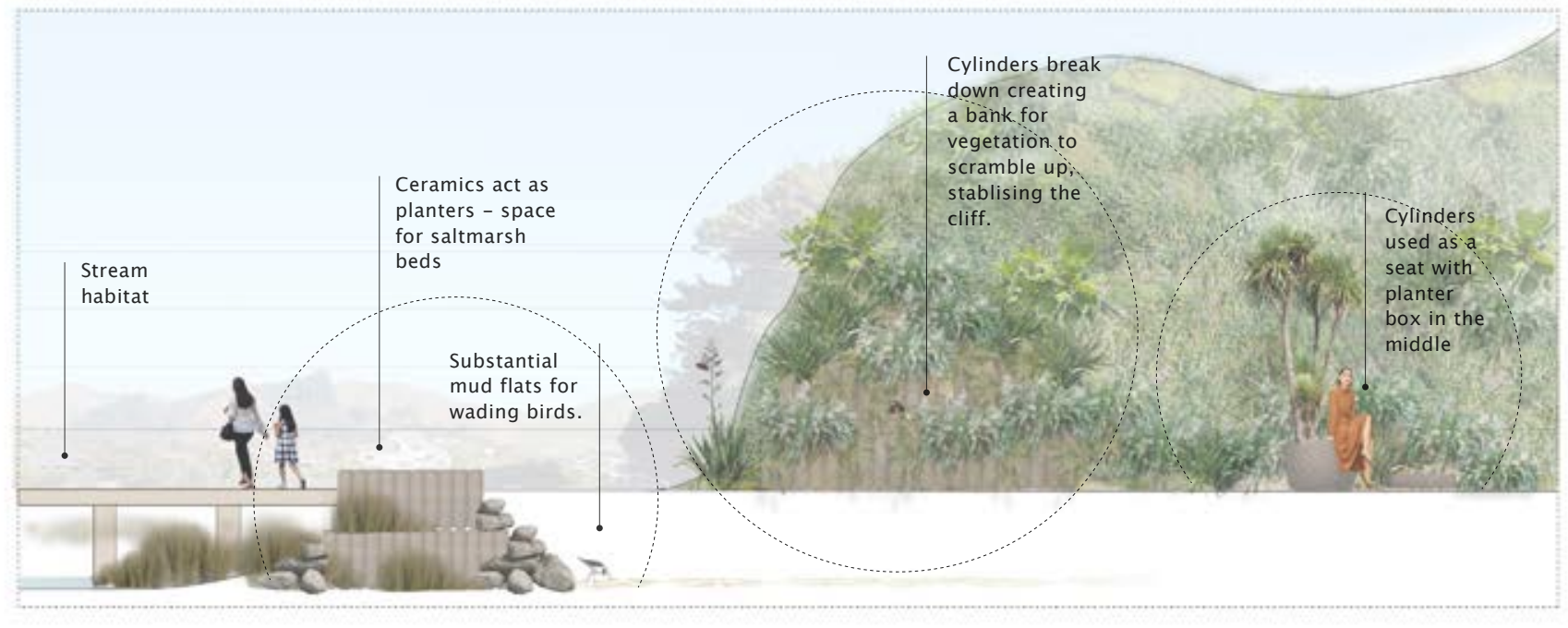

SEDIMENTATION FILLS THE INLET

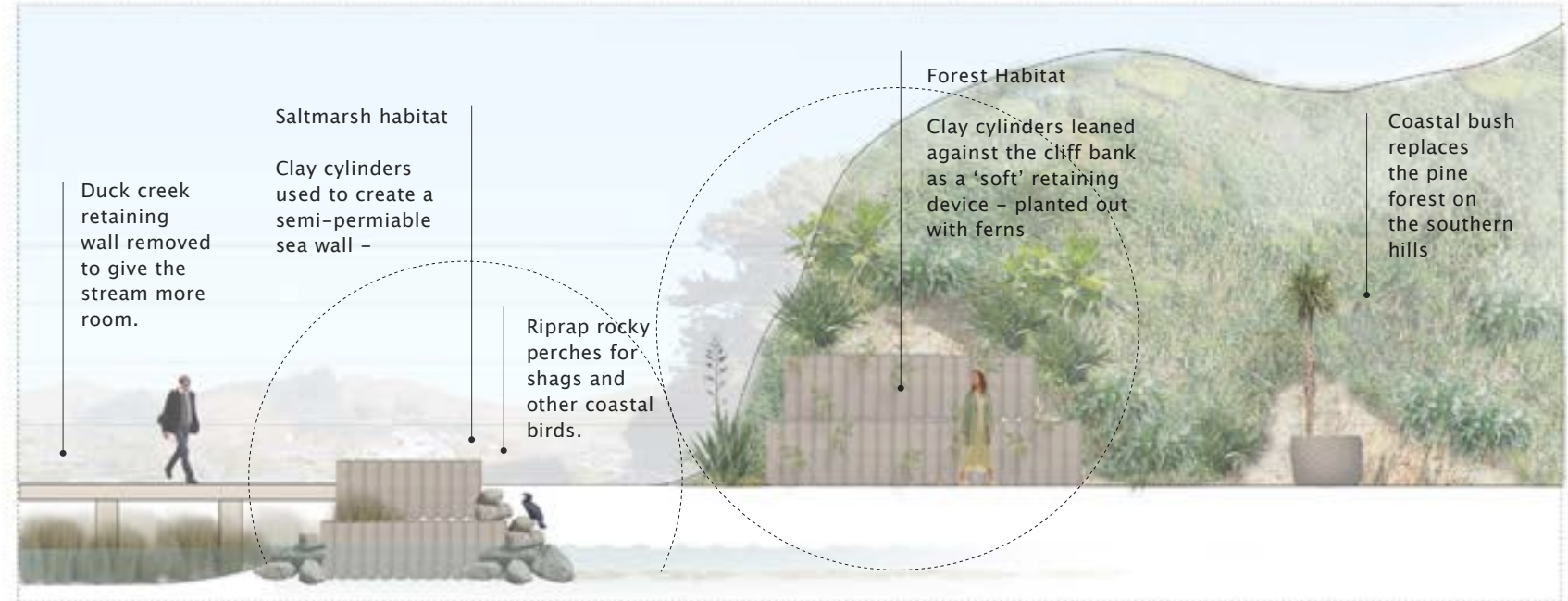

CURRENT TIDELINE:

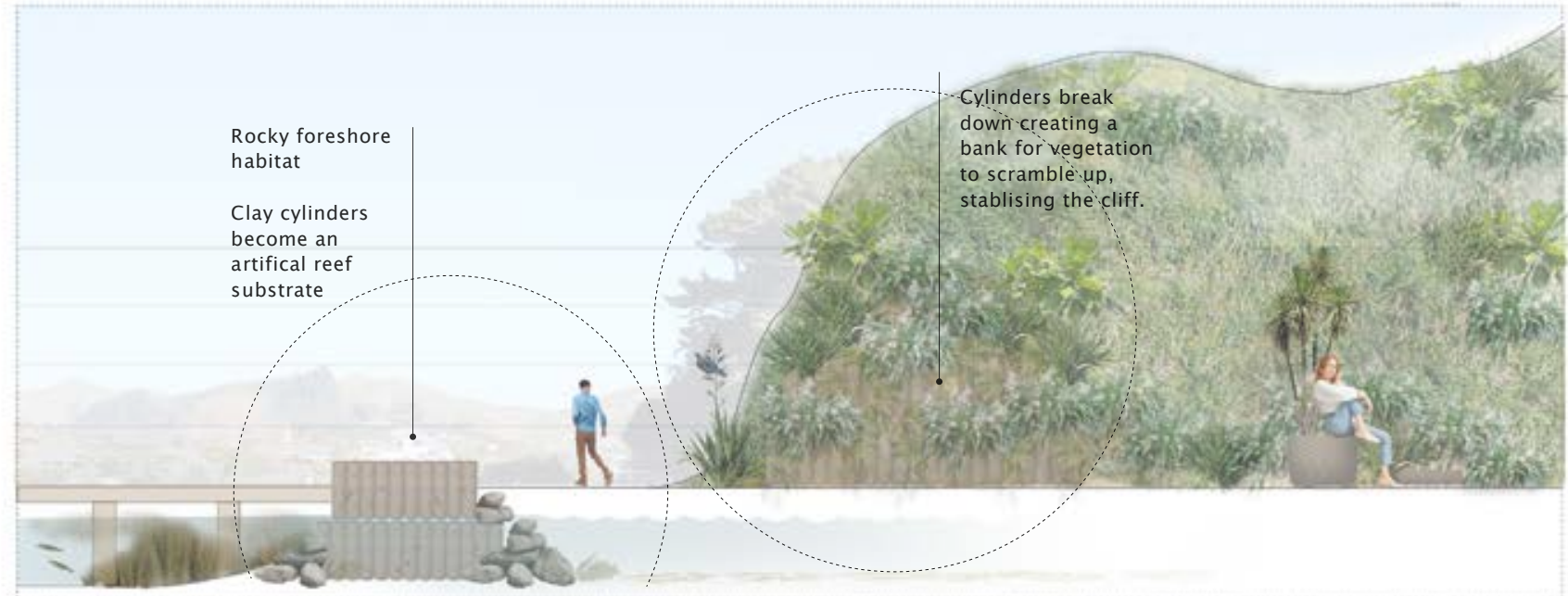

TIDAL INUNDATION 


\section{Conclusion.}

In pursuit of how sympoeisis can express itsell materially, the materials used in this study are sympathetic to the materiality of the inlet: clay, stone, sediment, timber, and shells reflect the beauty of the harbour and can be obtained

from the area - though in small quantities. The method of construction, and synthesis into the design of the pathway allows the material respond to the phenological processes occurring within the harbour and evolve with them rather than trying to resist. As structures decay, the materials disintegrate back into the landscape, providing a new role in their destroyed state- a roosting perch for birds or underwater reef for aquatic life. In this way the materials adapt through time and allow different forms of life to be able

to coexist and move around the harbour

regardless of its future form.

In these ways materiality is bought into the

research inquiry to discover ways in which

sympoiesis can support adaptation in coastal

environments. 


\section{Reclaiming the tidal edge}

07-

Preliminary concept design.

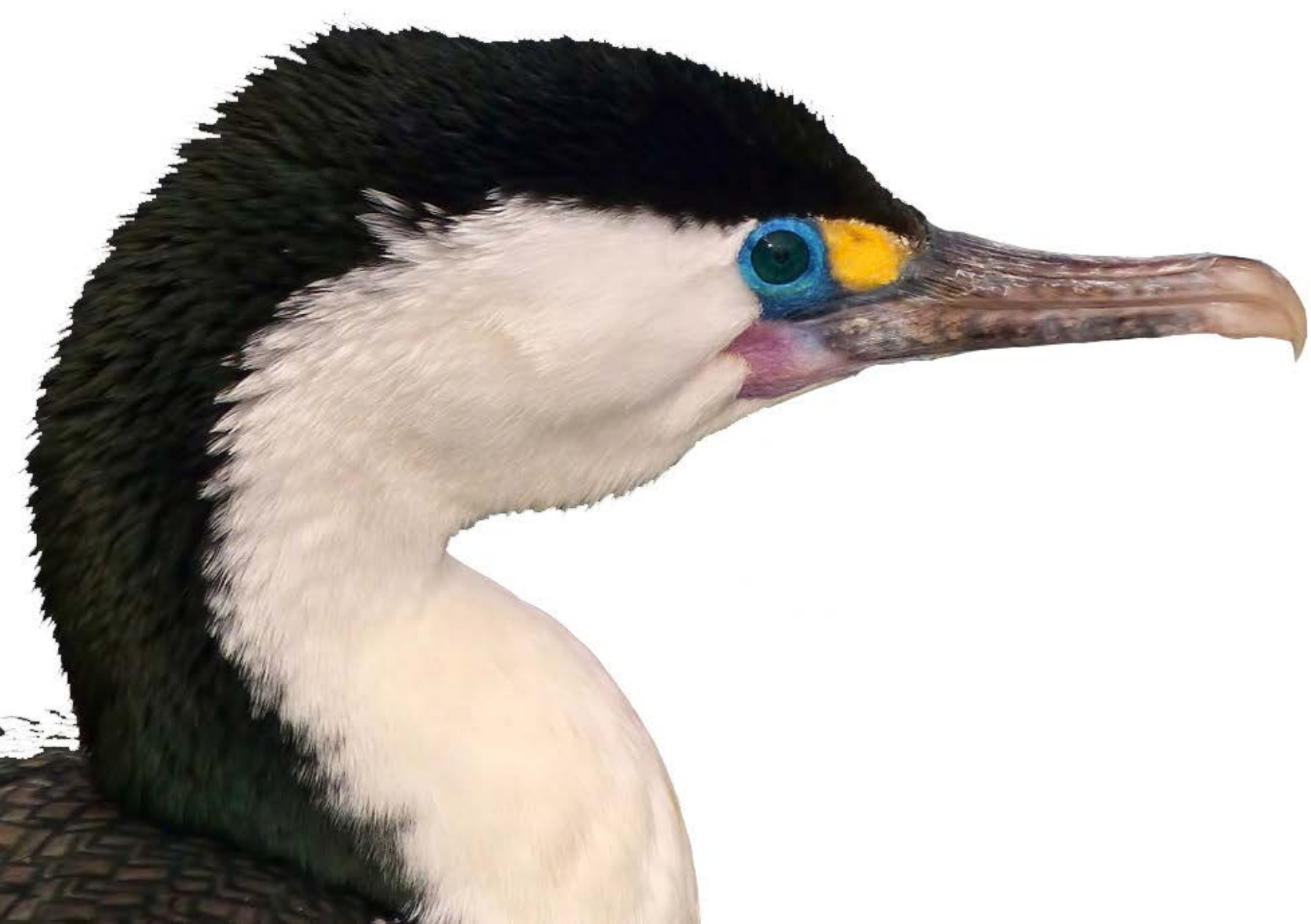

\section{INTRODUCTION}

Working from the ideas of sympoeisis, this chapter tests what the potential pathway might look like. It tests the reconfiguring of movement around the harbours edge to create a multi-species shared movement corridor that affords coastal access and adapts through time to respond to changing sea levels.

Interactions between species are used to catalyse enchantment within those moving around the tidal edge, enhancing their attunement to the biosphere and the beauty of all life within it.

FRAMEWORK

This chapter is divided into the following sections:

1. Preliminary design

2. Whole harbour pathway

3. Northern Edge

4. Southern Edge

Aims and objectives outlined in the proposal create a framework criterion to test against.
AIMS + OBJECTIVES

- Develop a pathway loop around Pauatanahui's coastline, reclaiming the vehicular dominated edge for public recreation and habitat

- Create a publicly accessible tidal realm that facilitates movement for both organic and inorganic systems to traverse and cohab

- Enhance the potential for encounters, by way of proximity through sharing the coastal pathway.

- Generate interventions to enhance the publics affective attunement to the site and its inhabitants through encounter.

- Explore ways in which the materiality of the pathway adapts its purpose through time to suit the changing tidal edge.

- Embraces uncertainty - moving tidal edge. 


\section{Preliminary Design: reconfiguring movement around the harbour.}

EXISTING VEHICULAR ROUTES

PROPOSED VEHICULAR ROUTES

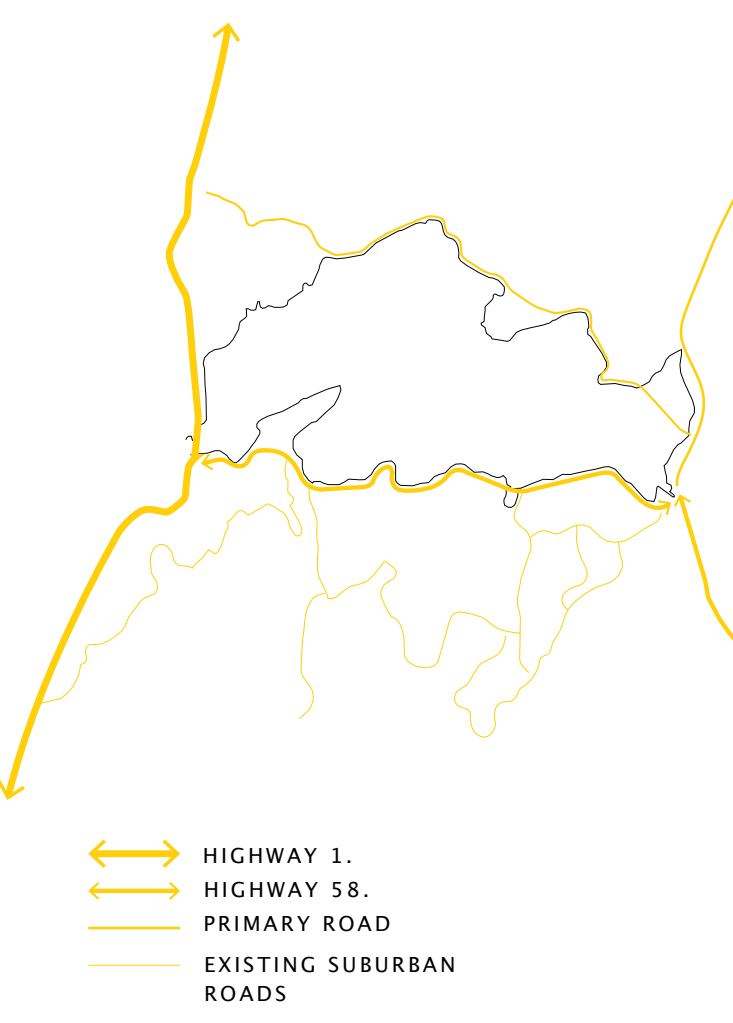

XISTING SUBURBAN
RADS

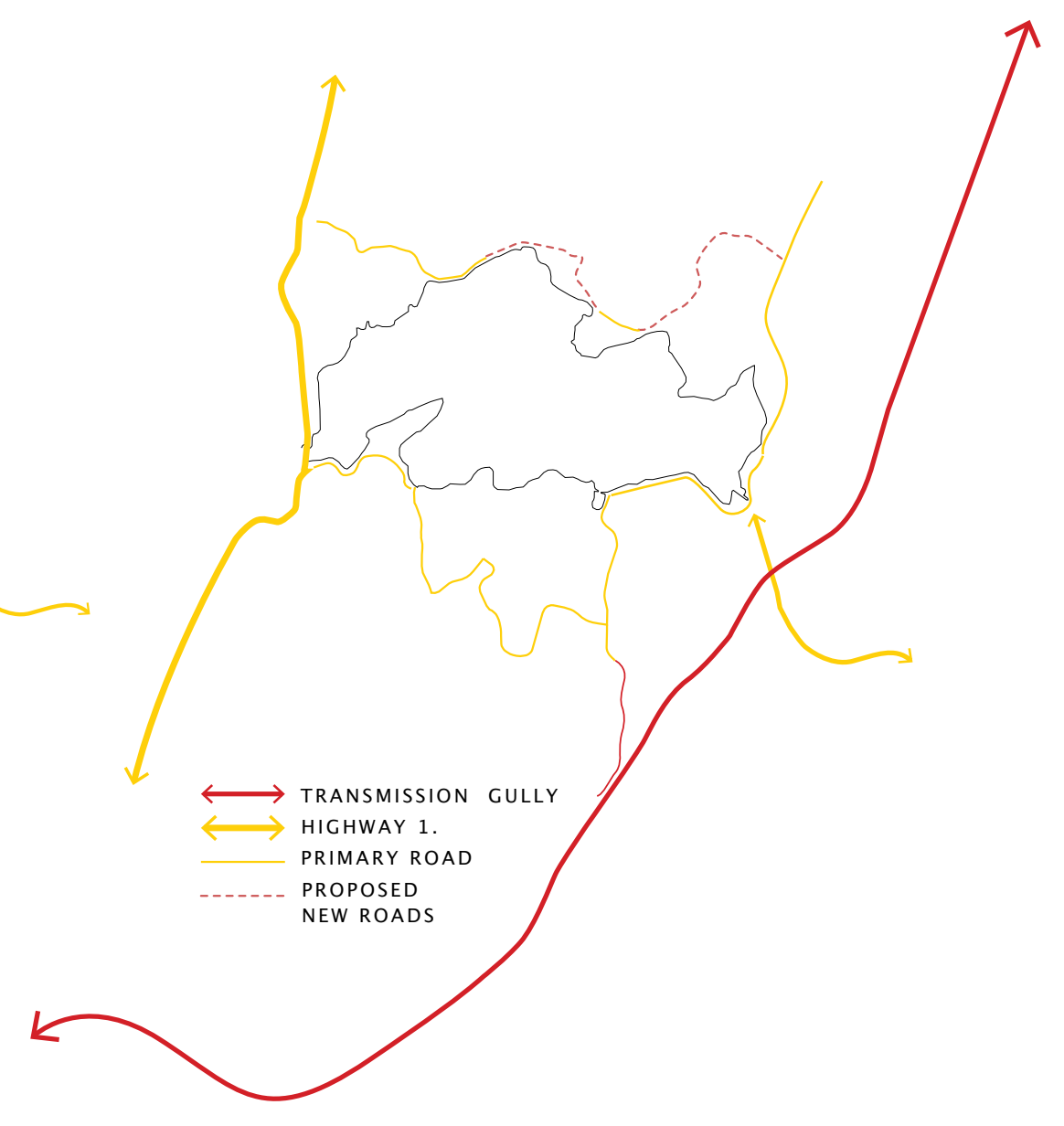

EXISTING PEDESTRIAN ROUTES

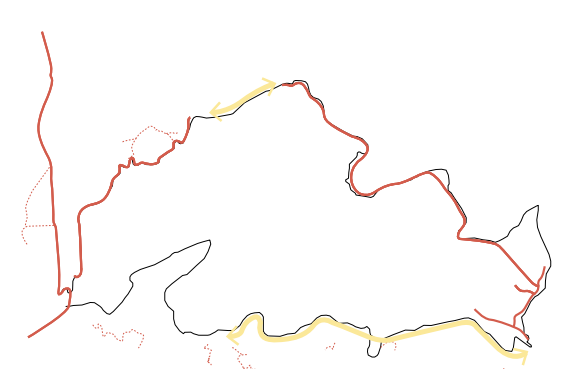

EXISTING HILLIDE PEDESTRIAN PA
EXISTING COASTAL WALKWAY INACCESSIBLE AREA FOR PEDESTIIANS -

INACCESSIB
CAR ONLY
PROPOSED PEDESTRIAN ROUTES

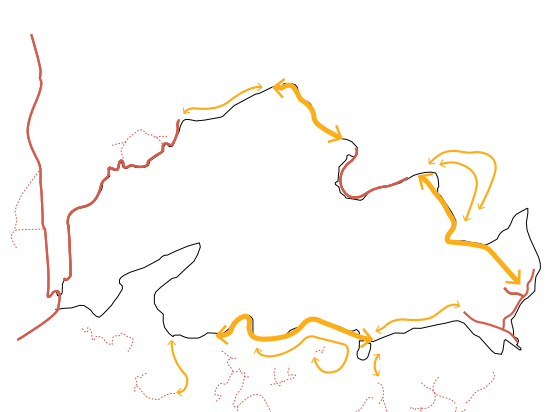

EXISTING HILLSIDE PEDESTRIAN PATHWAYS EXISTING COASTAL WALKWAY RECLAMED ROAD - NOW
Reclaiming the tidal edge for public use starts with the removal of roading infrastructure in places where it is not required for housing access. A portion of the southern edge only services two houses, which can have their driveways rerouted and traffic diverted away from the coast.
A new road is proposed on the Northern edge, freeing up both the Horokiwi and Kahao stream mouths and allowing saltmarsh to migrate inland with the shifting tide
The southern motorway edge is not currently pedestrian accessible and there is no space to fit a pathway alongside the road without encroaching further out into the harbour with detrimental impacts
By removing the motorway on the southern edge, pedestrian acess can be created, linking the new pathway to existing trails in the surrounding hills 


\section{Movement: human}

Scenario: sea levels rise $3 \mathrm{~m}$.

These plans depict how the proposed

reconfiguration of movement around

the harbour can adapt through time,

accommodating both sea level rise and

sediment predictions while still ensuring free

traversal for both humans and non-humans

around the tidal edge.

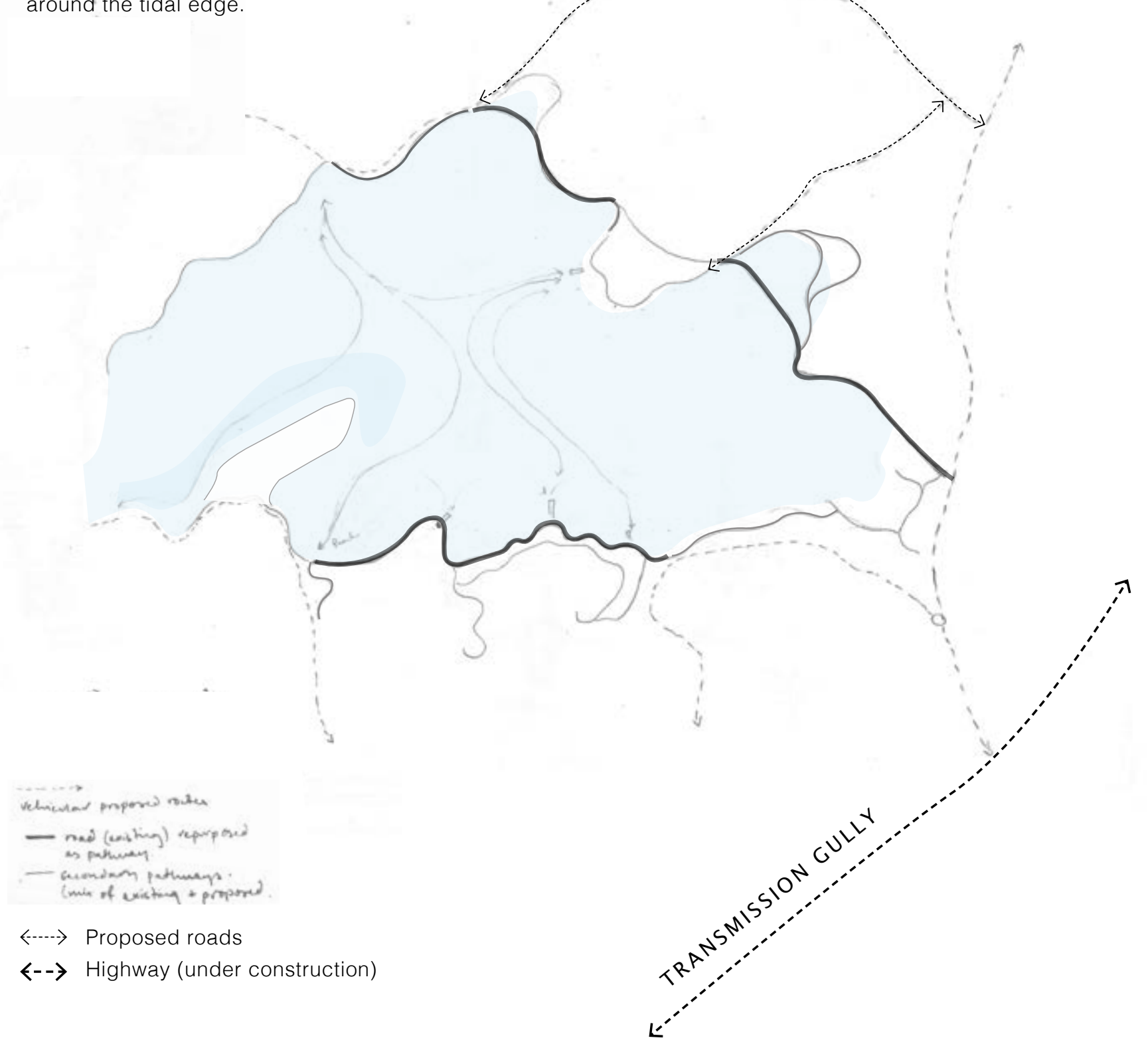

Deeper water facilitates boats to move around

Existing pathways in low lying areas are inundated

Re-routed roads are unaffected by rising sea levels

\section{Movement: human}

Scenario: Sediment fills the harbour.

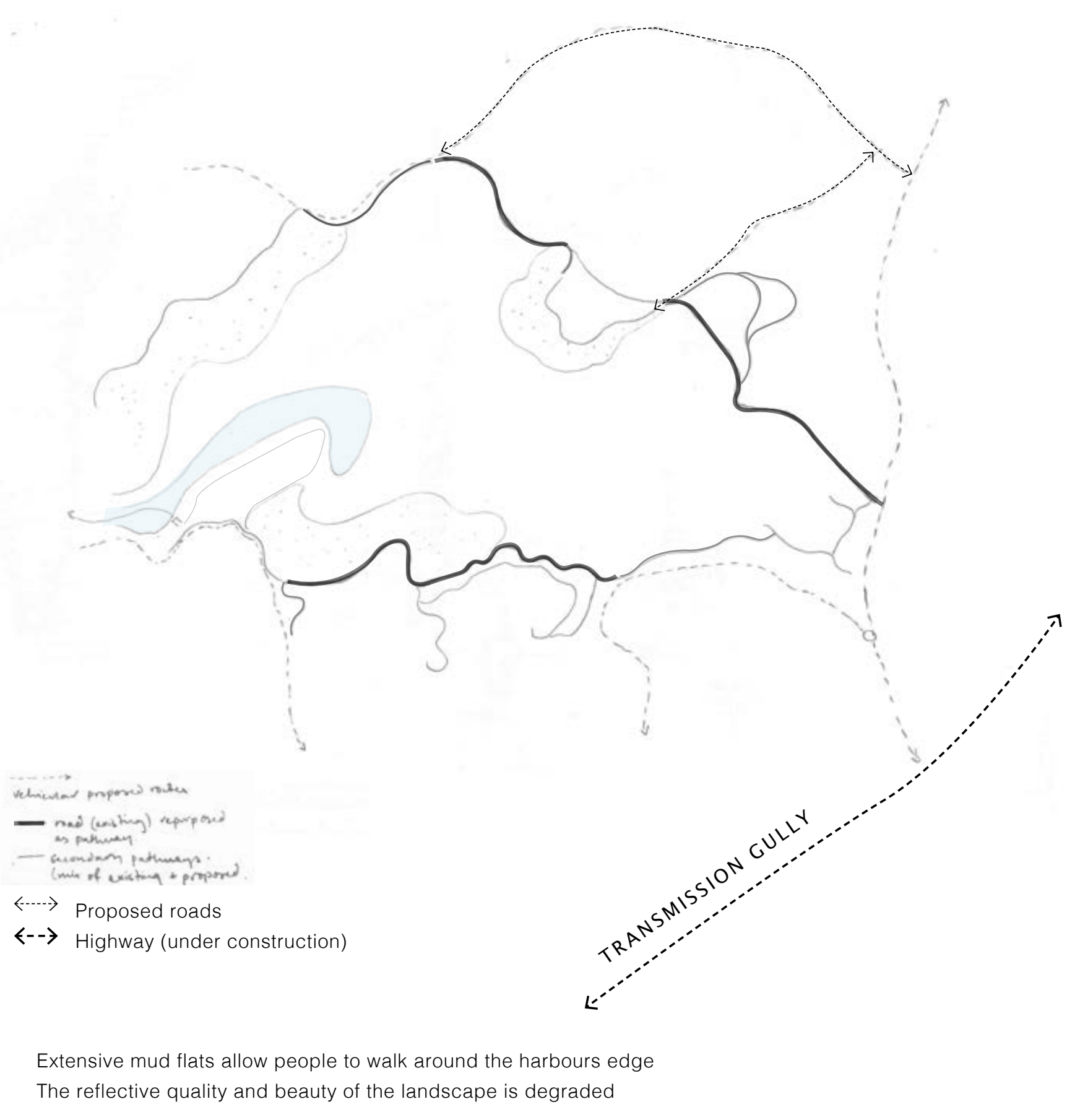




\section{Movement: non-human}

Scenario: sea levels rise $3 \mathrm{~m}$.

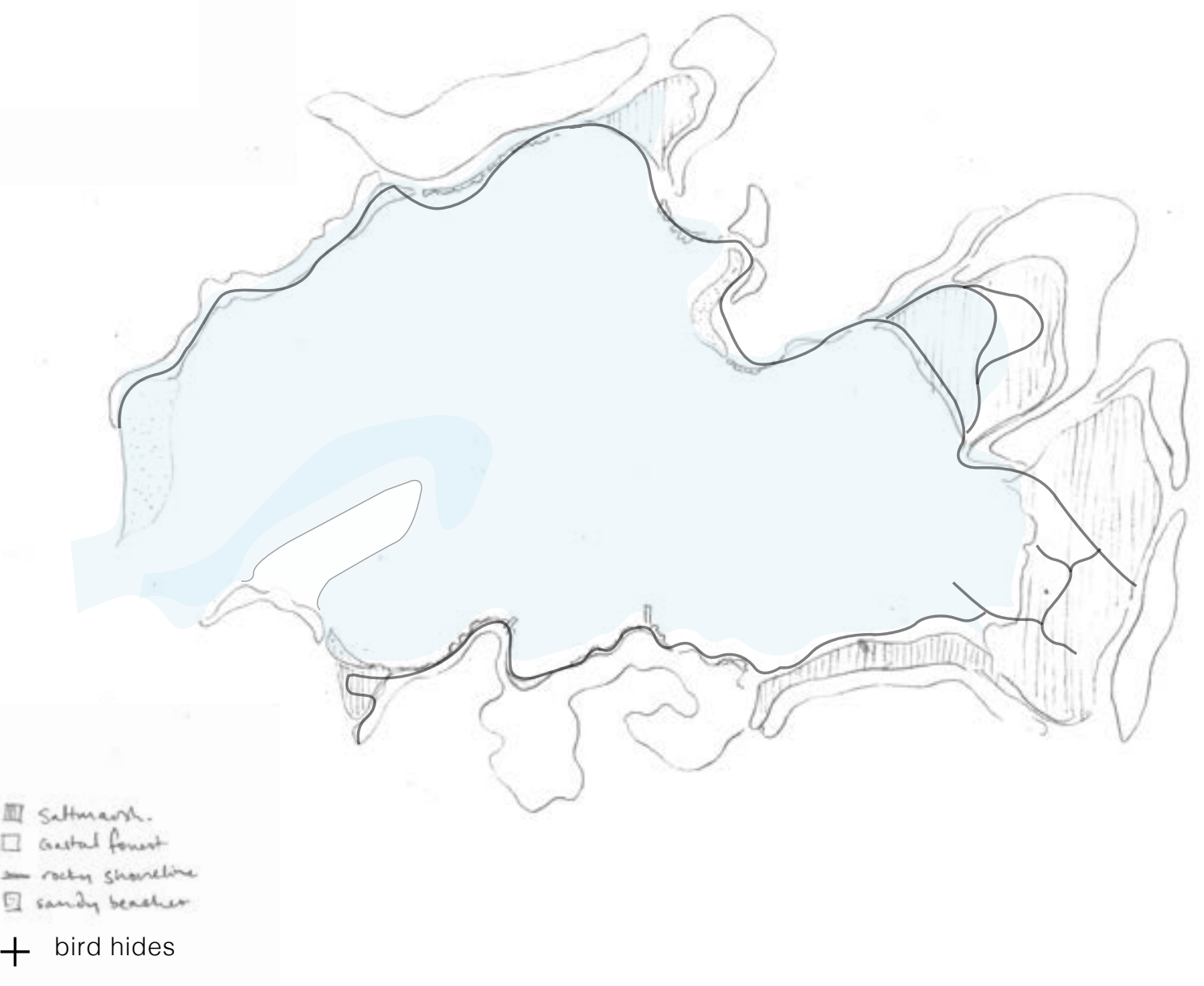

Rising sea levels cause saltmarsh to migrate inland, coastal forest moves with it.

Sandy beaches and rocky outcrop habitat become narrower but some remains

Aquatic animals enjoy freer movement within the inlet
Movement: non-human

Scenario: Sediment fills the harbour.

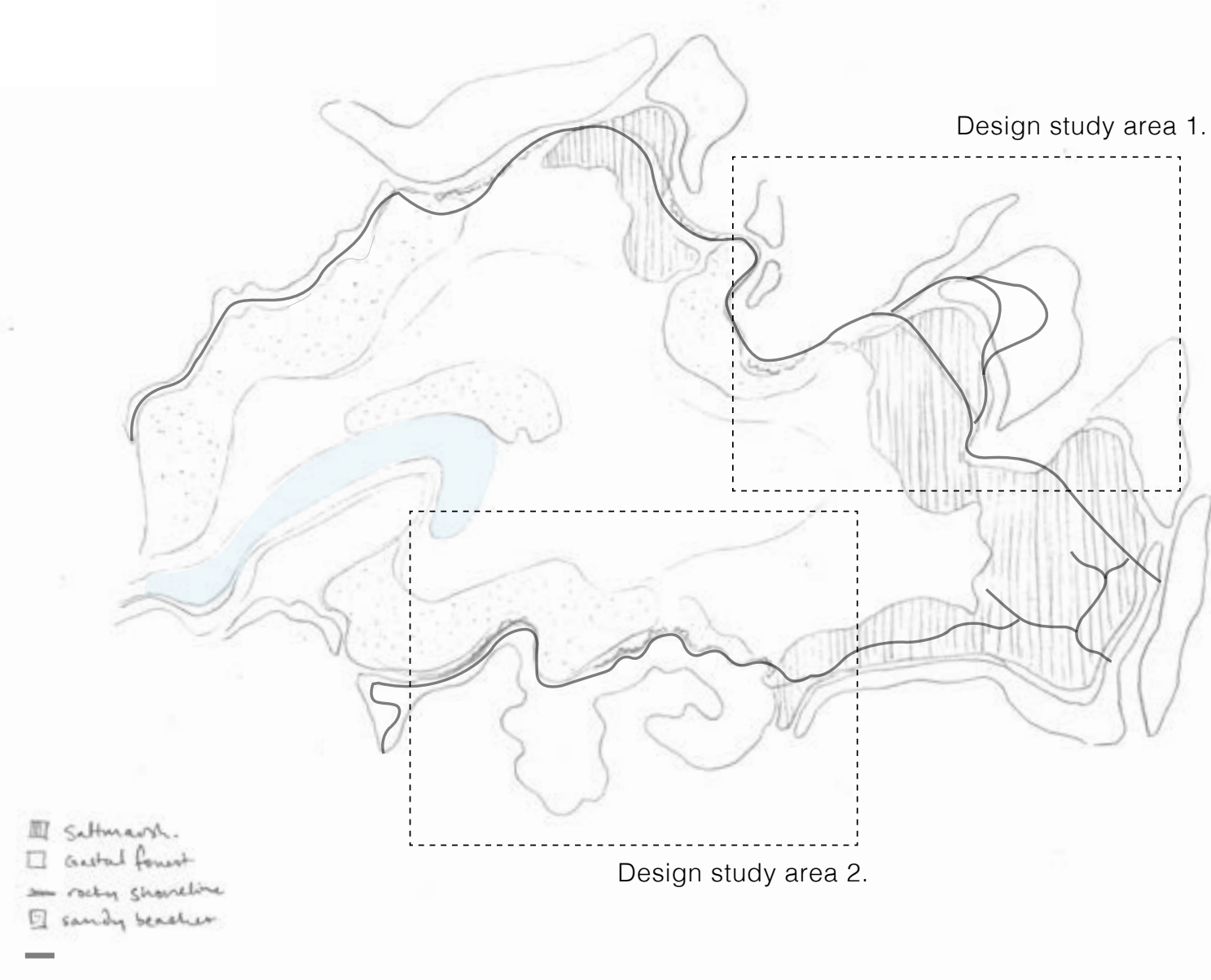

Saltmarsh starts to move out across the extensive mud flats

Large shell banks and some rocky outcrops are exposed

Coastal forest stays much the same 


\section{Design study area 1.}

\section{The Northern edge.}

\section{Saltmarsh wetland}

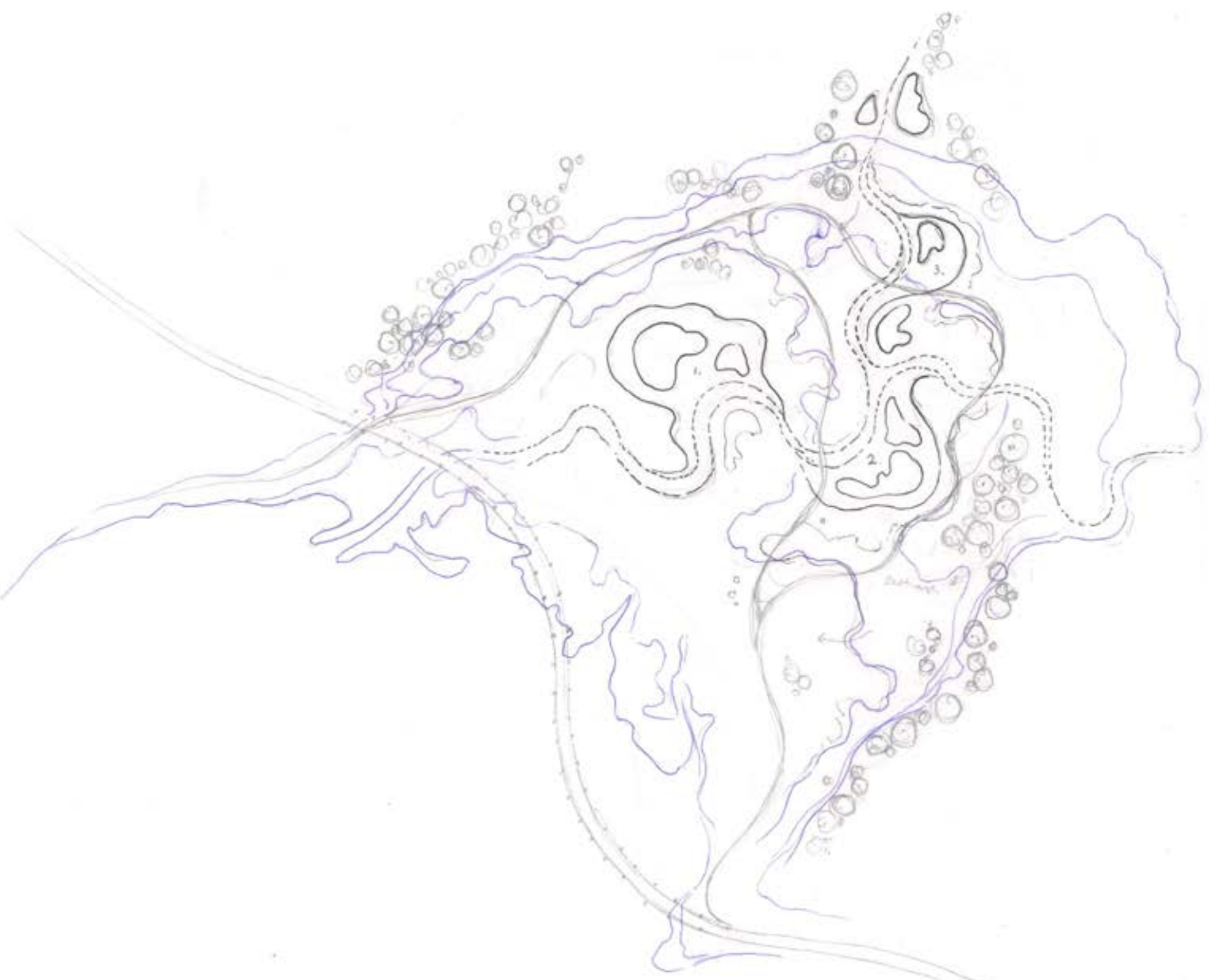

ACCOMMODATING

HYDROLOGICAL FLOWS.

Working towards adaption of the coastal realm for all species under sea level rise this investigation creates a wetland along the Northern Edge of the inlet That will:

- Process and slow down sedimentation runoff from farmland within the catchment

- Create an ecotone of varying salinity to provide habitat for wildlife (including freshwater ponds)

- Allow the tide to move inland in a way that won't negatively affect those who live there.

- Provide a public reserve for all life to enjoy and dwell regardless of where the tideline is (works for either sediment or sea level rise projections)
SITE DESIGN APPROACH

AND OBJECTIVES

This design study proposes the removal of a stretch low lying roading infrastructure on the northern side, one which is already prone to flooding during storm surges and spring tides, and allowing the saltmarsh to move inland as the sea level rises.

This land is currently held as a number of small farming titles so negotiations would have to be undertaken. As this land is prone to flooding (historic alluvial plane with diverted stream running through it) and would be expensive and difficult to fortify from the impending tide, managed retreat is the only viable long term solution for this area.

To allow space for water to move inland without creating significant erosion, the development of a series of ponds are proposed along the length of an existing stream. 


\section{Design study area 2. The Southern edge.} Reclaimed road, the southern walkway.

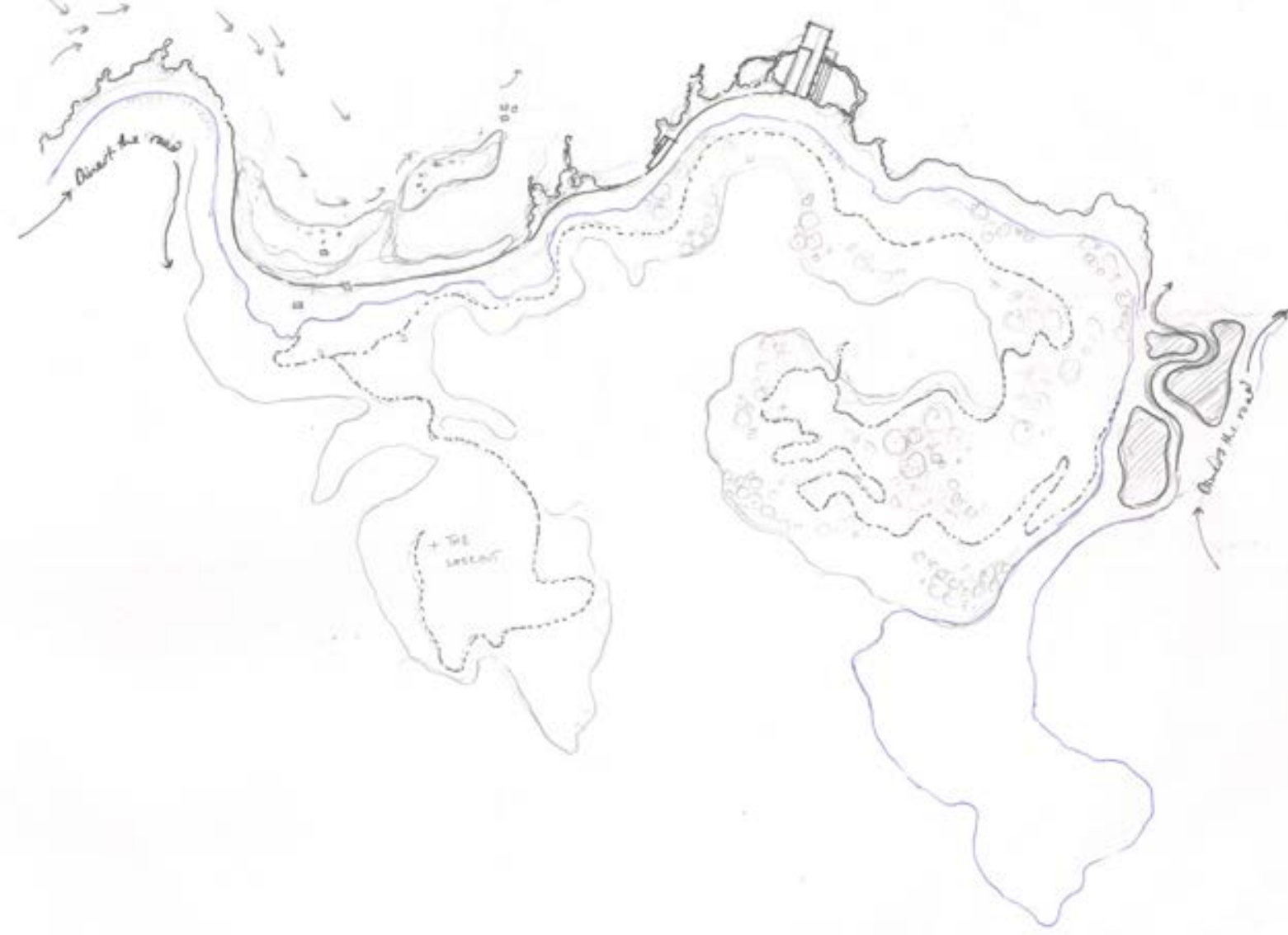

RECLAIMING THE SOUTHERN

EDGE

This design study works with the processes

of erosion and deposition that are taking place along the coastline using sand an shells banks to create moving islands and beaches (or embankments) for birds who dwell and pass through the intet.

Riprap, coastal rocky outcrops and

buildings (jetties, steps, marine education Centre) are used to break the waves in areas with higher coastal erosion, acting like groins, and creating still pockets of water behind them.

Rock pools create nurseries for sprats, shellfish and anemones, accessible along the new pedestrian pathway (old coastal road) by steps leading down to the water. Nodes or points of interest (rest stops and outlooks) break up the length of the pathway.

Parks around the hills are connected together by a series of tracks that lead down to the coastal track - that way if the old road gets inundated then there is still an accessible pathway around the harbours perimeter.
CONCLUSION

By reconfiguring the movement around the harbour through the diversion of roads and development of new paths, a new public realm begins to emerge with greate capacity for recreation and ecological growth. 


$$
E=
$$




\section{Developed tidal realm}

\section{Building upon the previous investigation of edge conditions and proposed adaptations, \\ a new public tidal realm, previously \\ inaccessible, bridges pedestrian areas and \\ connects to existing pathways to create a \\ coastal loop that facilitates movement for all \\ forms of life to traverse the harbour. \\ By reclaiming portions of the road for \\ pedestrian use, and re-routing traffic around \\ the back of the hills, the experience of moving \\ around the harbour has the potential to be \\ completely transformed. With a reduction in \\ noise, pollution and speed, inhabitants have \\ the opportunity to re-enchant themselves with \\ the inlet and their neighbours within it. \\ A council imposed buffer zone of planting \\ should be implemented along the edge of \\ the harbour as part of a managed retreat \\ to the north and condition of surrounding \\ subdivision.}

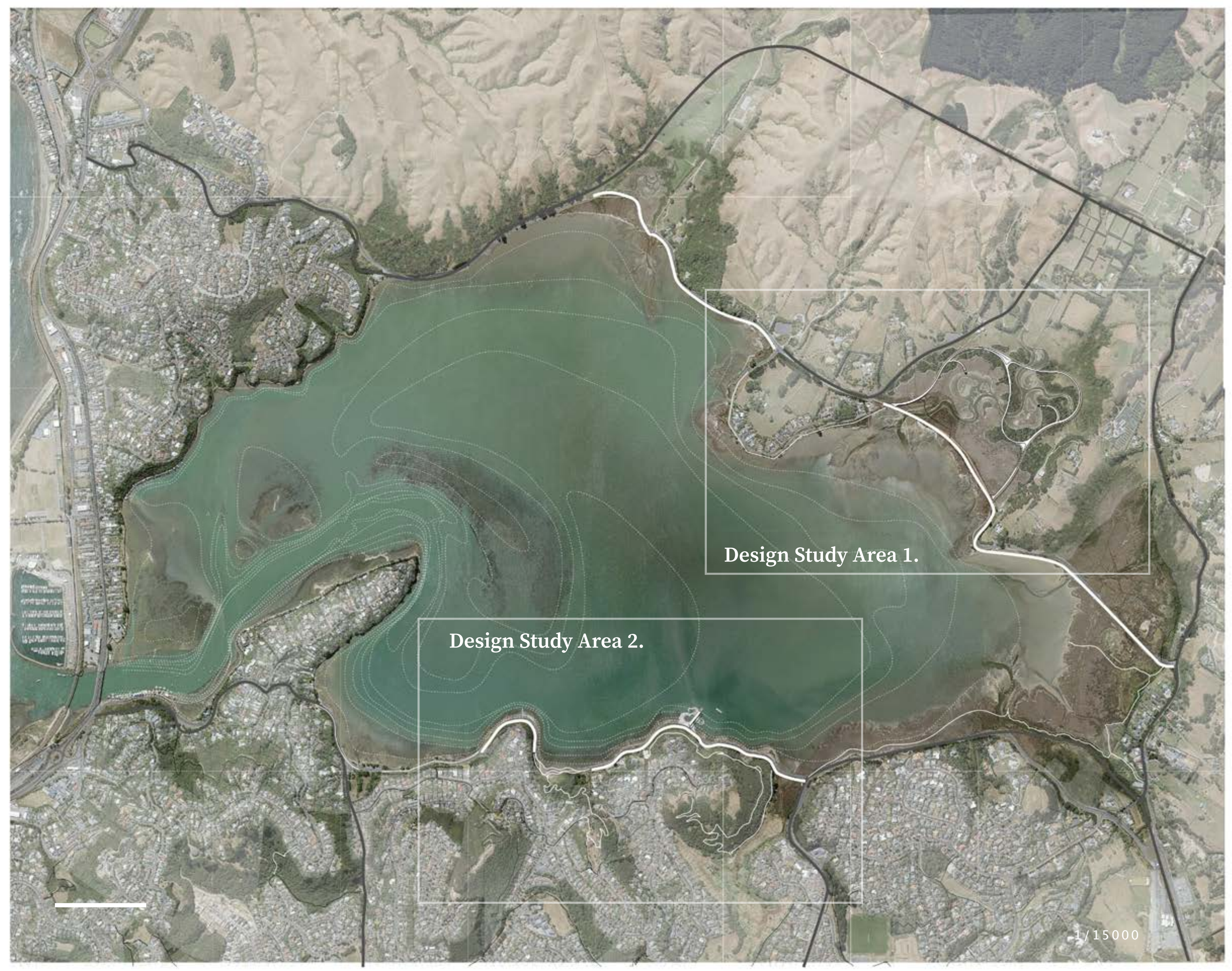


HABITAT CORRIDORS / WILDLIFE MOVEMENT:

\section{SHELL BANK}

EXISTING

Large swathes of cockle beds around the perimeter of

the harbour create shell banks. The

moving bank in the

centre provides a

rest spot for birds

away from danger.

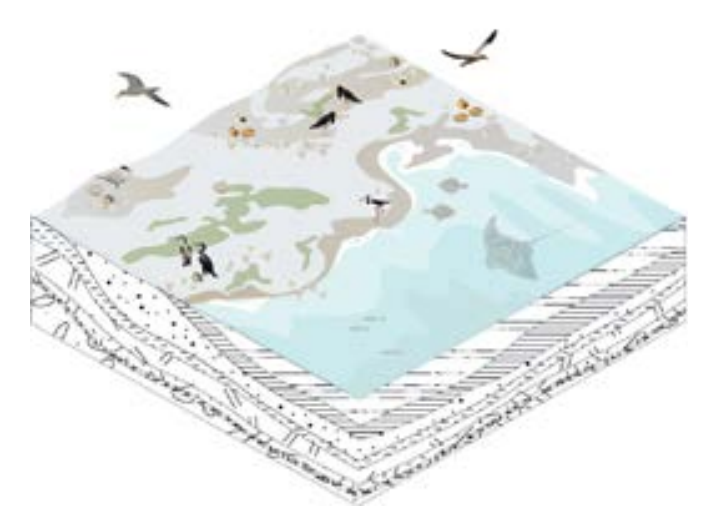

PROPOSED

The central shell

bank is unlikely to

survive storm surge

and the coastal

beaches will narrow.

Two coves on the

southern edge allow

movement landward.
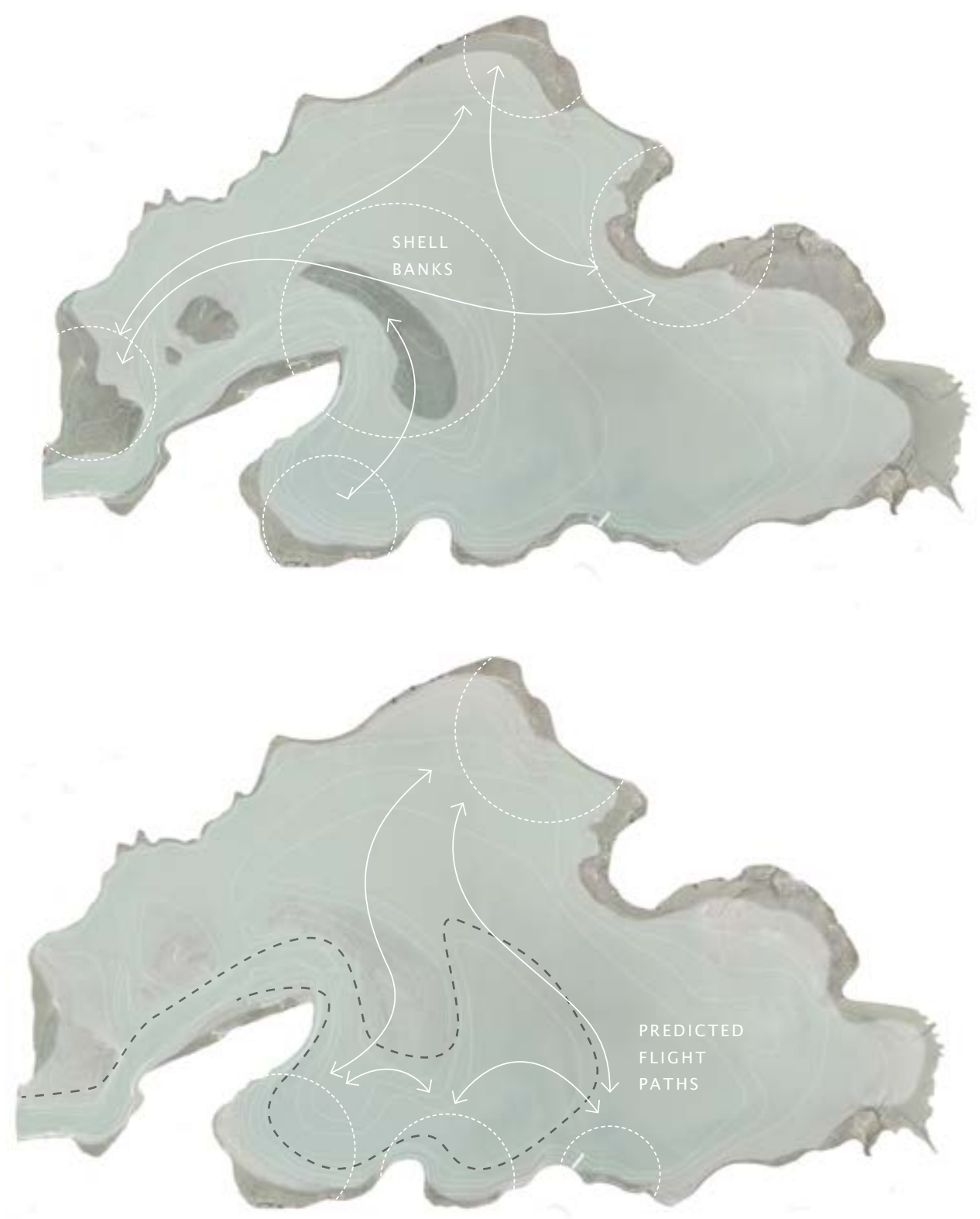

\section{ROCKY COASTAL EDGE}

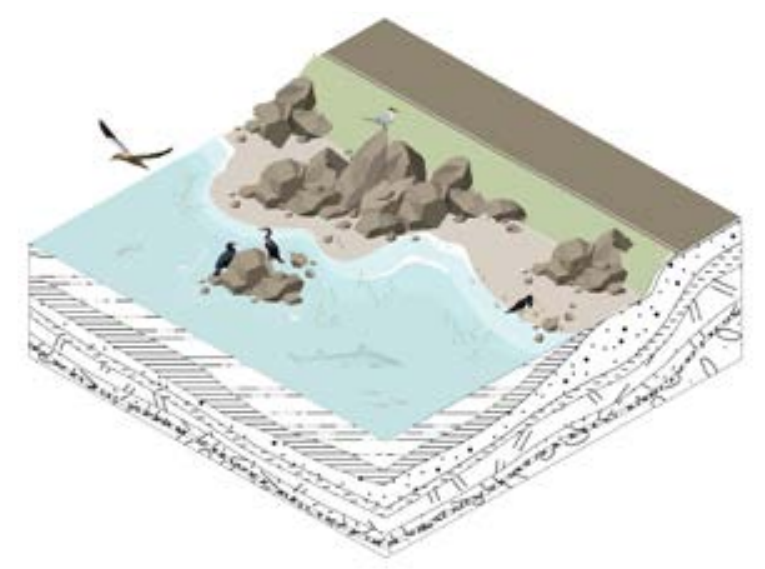

EXISTING

Riprap and

naturally occurring

rock outcrops are

predominantly

found along the

southern road and

in the north western

edge in areas

prone to scouring.

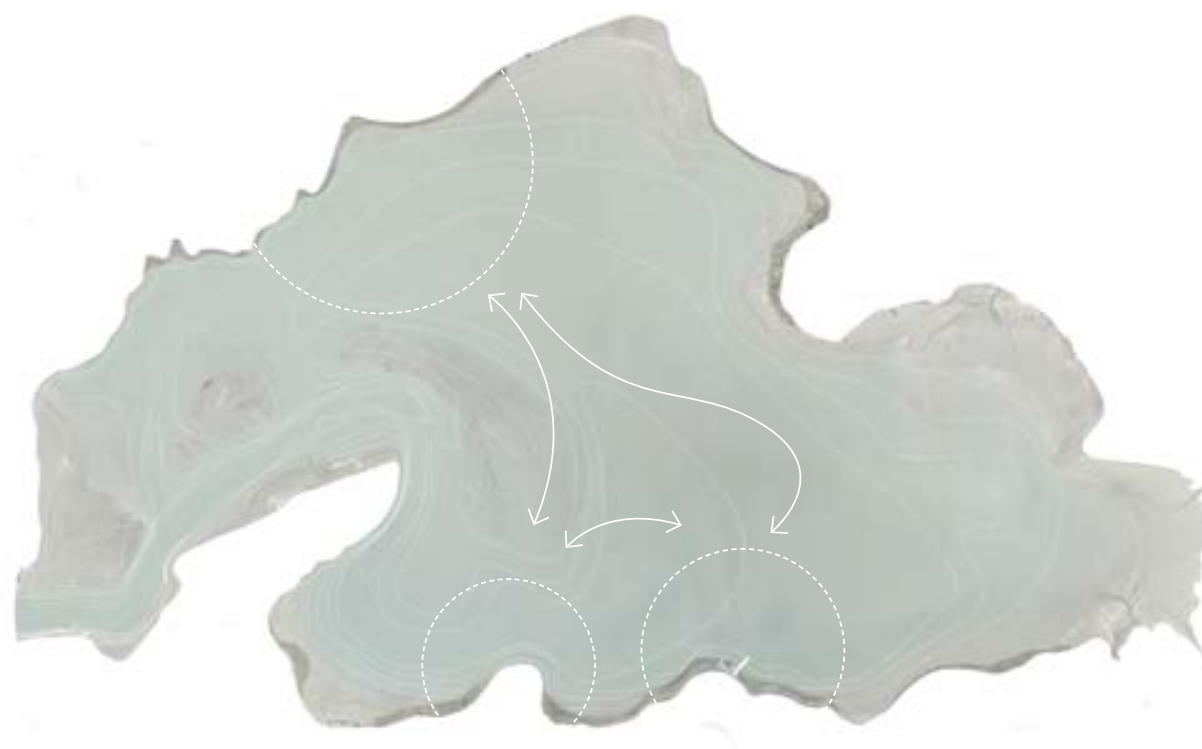

PROPOSED

New riprap rock pools and

built structures such as

jetties provide perches for

bird species that like to

perch in the sun, elevated

above projected sea level

rise predictions.

This type of habitat is

unlikely to be affected

by an increase in

sedimentation.

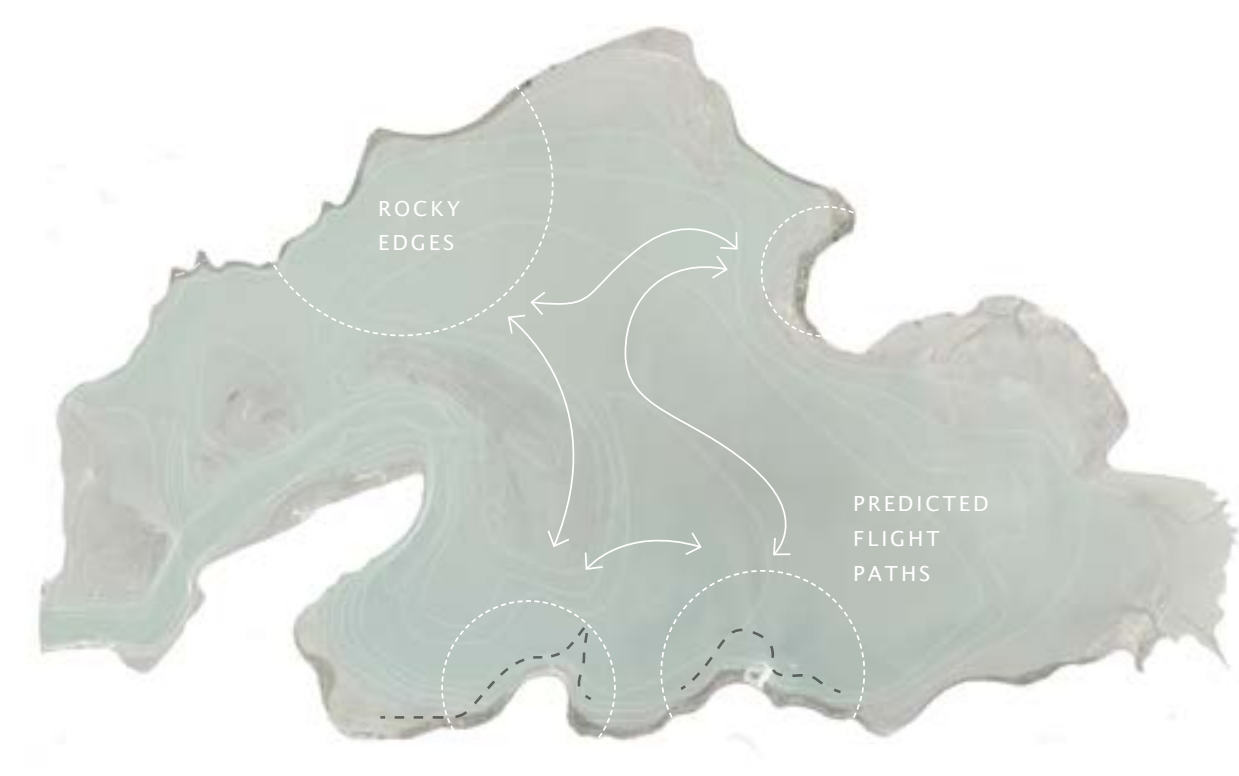

SEDIMENT ADAPTATION 


\section{SALTMARSH}

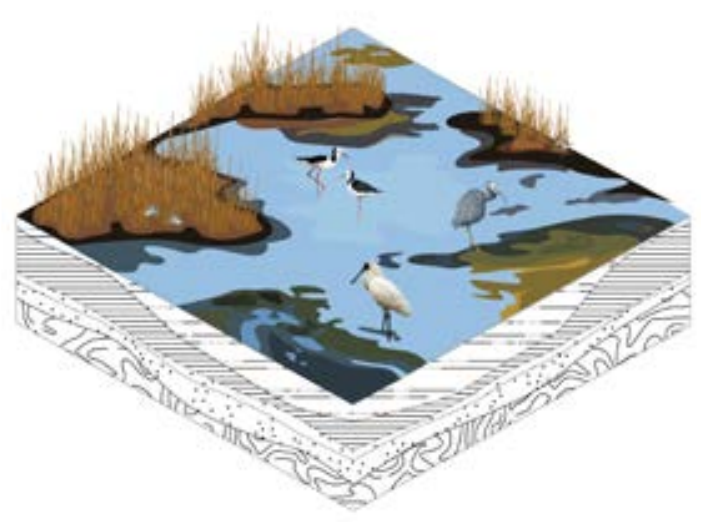

EXISTING

The existing saltmarsh wetlands, though extensive, canno move landward due to roading infrastructure creating a tidal squeeze.

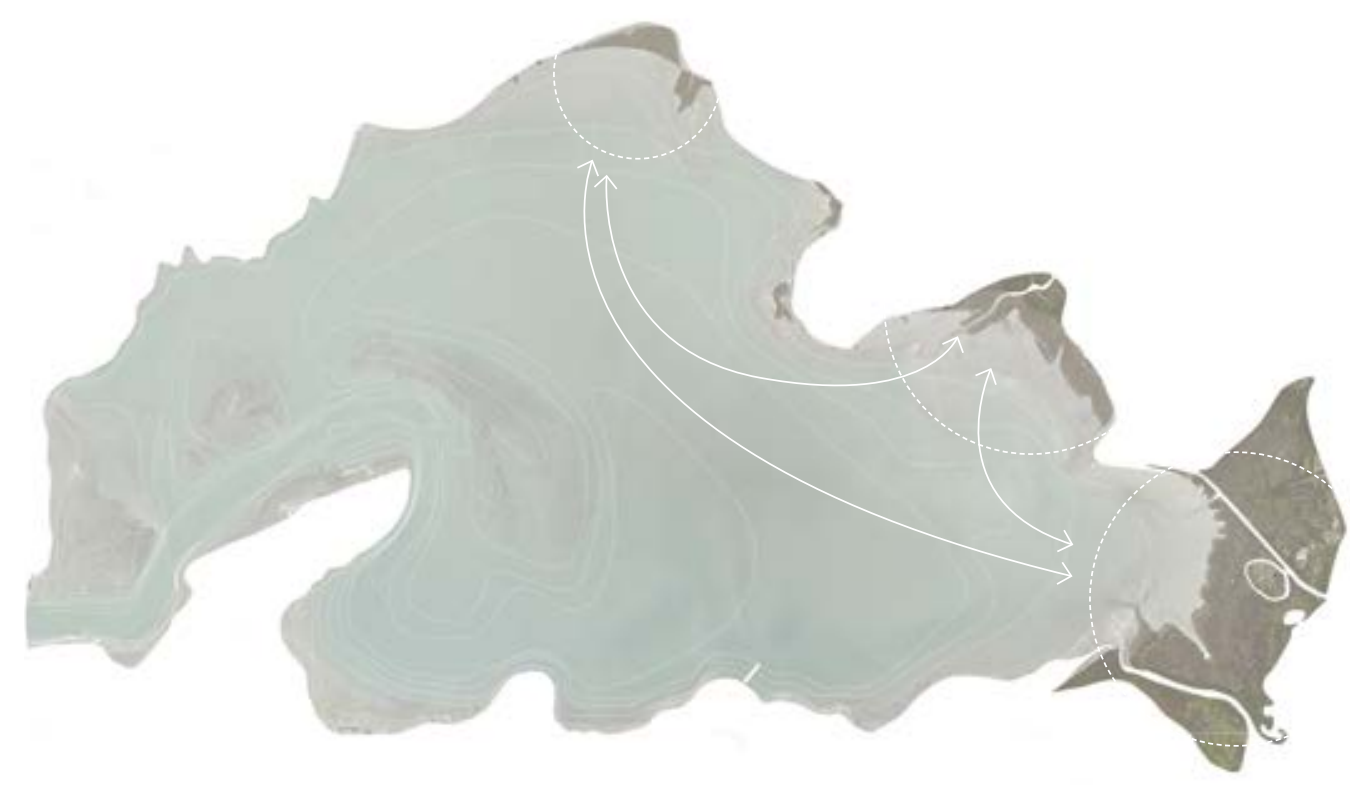

PROPOSED

Roads have been lifted and streams bridged to allow more room for the saltmarsh to migrate landward as the sea level rises. If sediment were to fill in the harbour, the saltmarsh is likely to grow out across the mud flats,

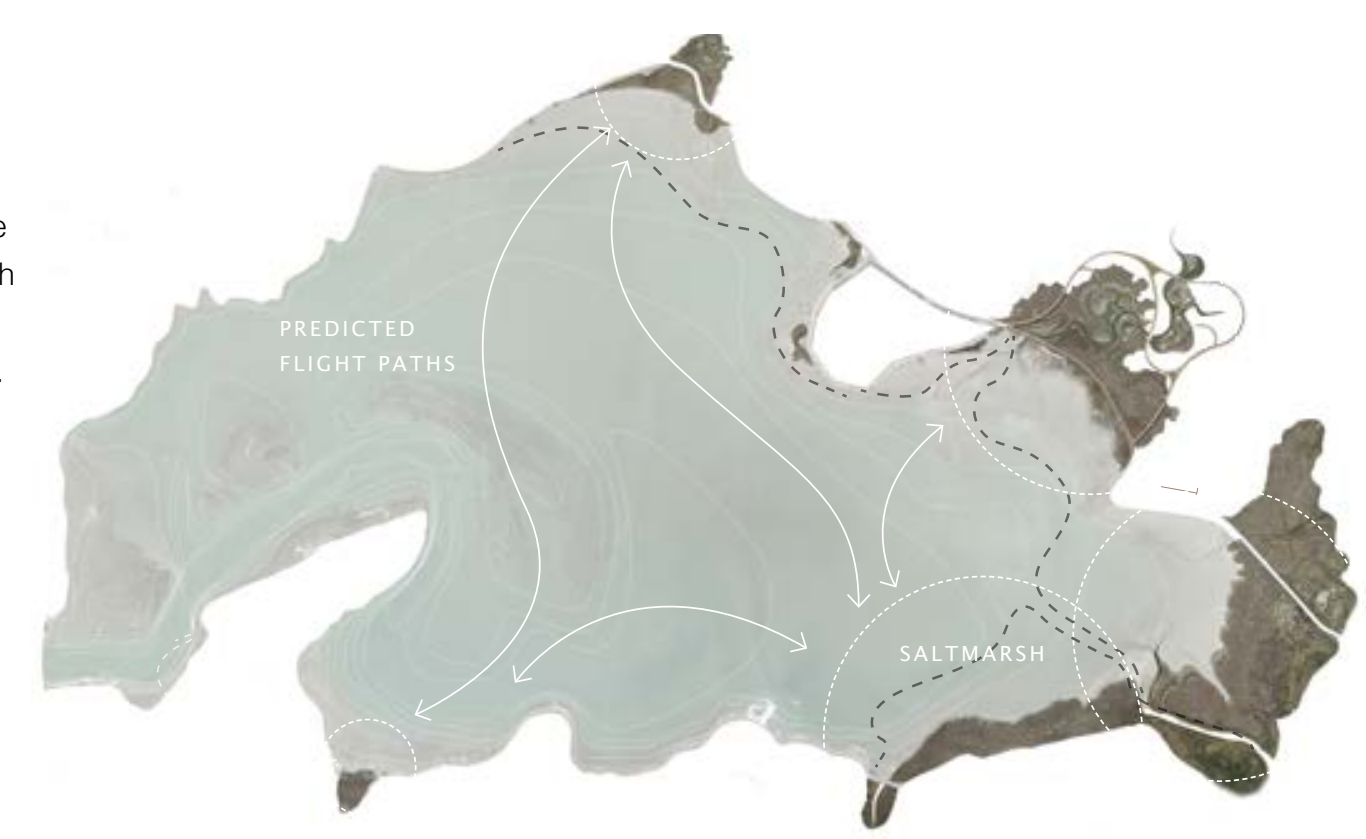

\section{COASTAL FOREST}

EXISTING

A series of

parks around

the perimeter

of the harbour

make up most of

the substantial

vegetation in the

aera, these have

the potential to be

linked to create an

ecological corridor.

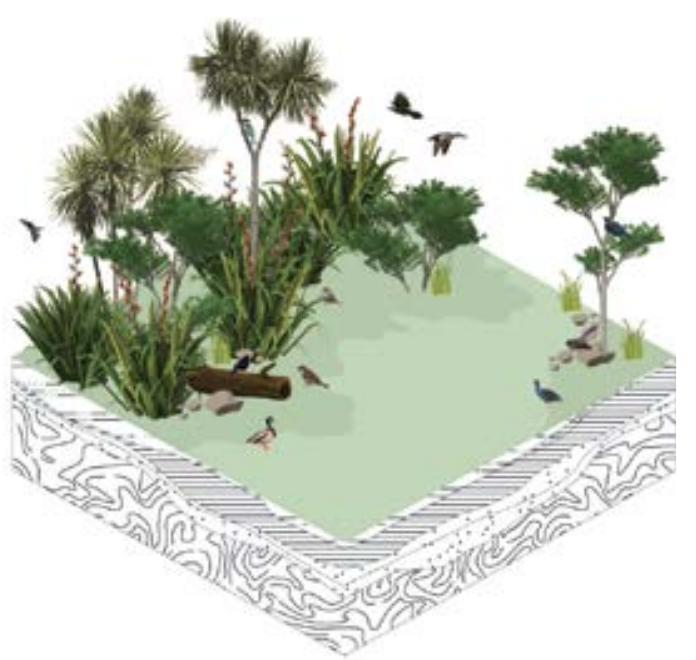

PROPOSED

A significant

amount of planting

is proposed in

both northern

catchments to

flank the new

the northwestern

edge also has

significant

planting proposed

at the edge of the

farmland.

SEDIMENT ADAPTATION
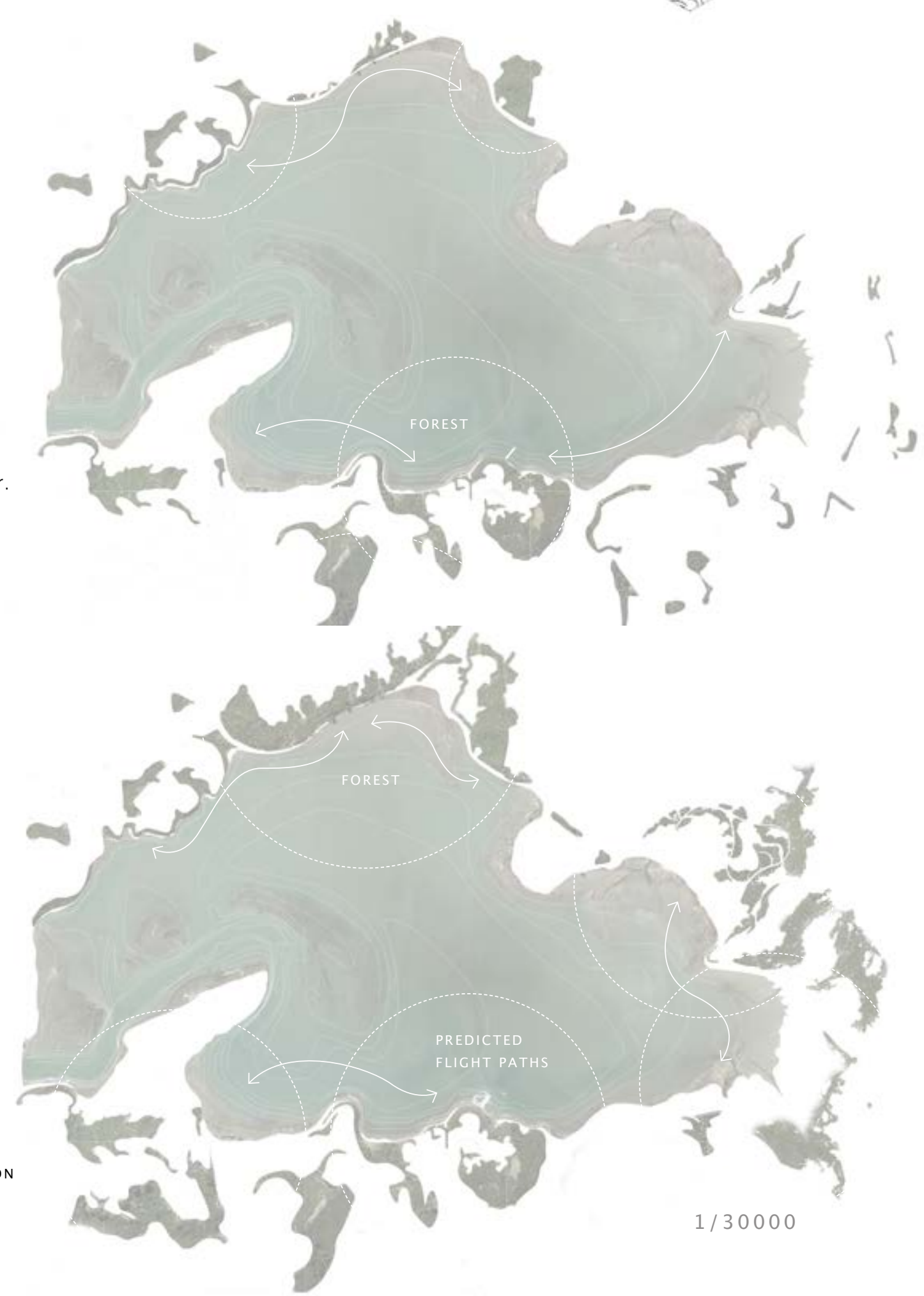


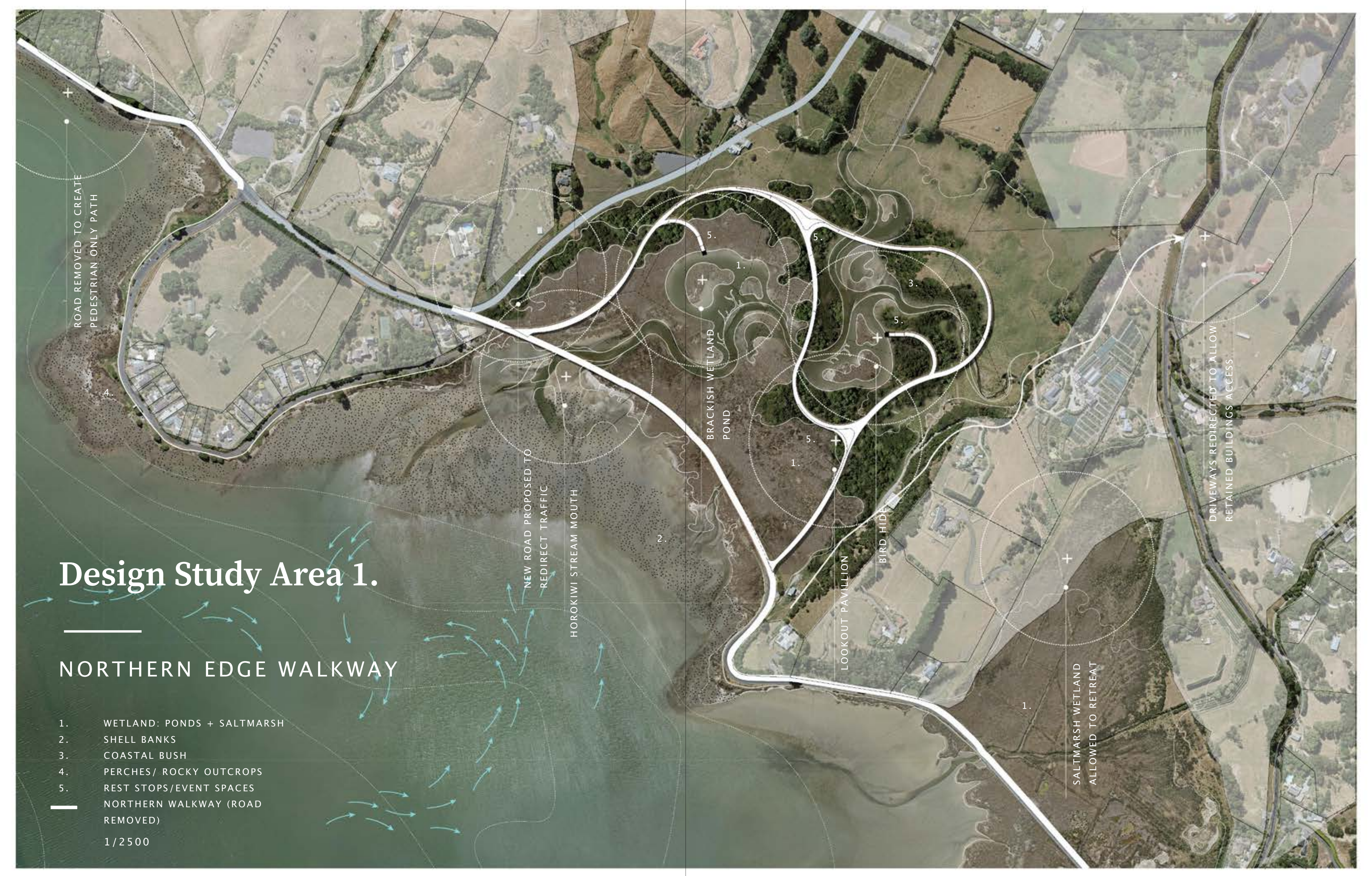




\section{Modes of encounter -}

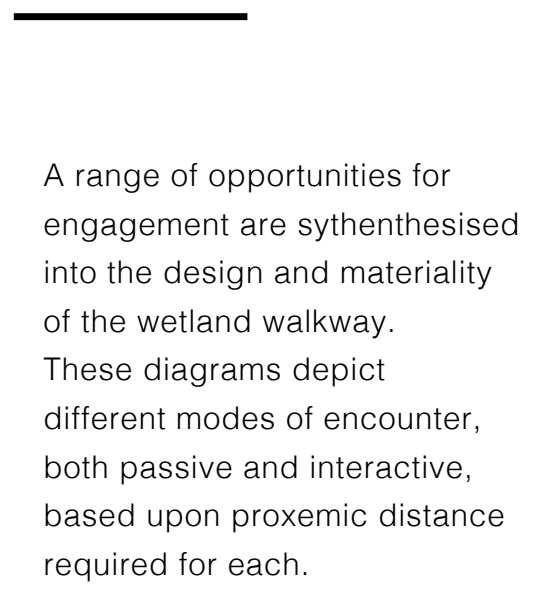

required for each

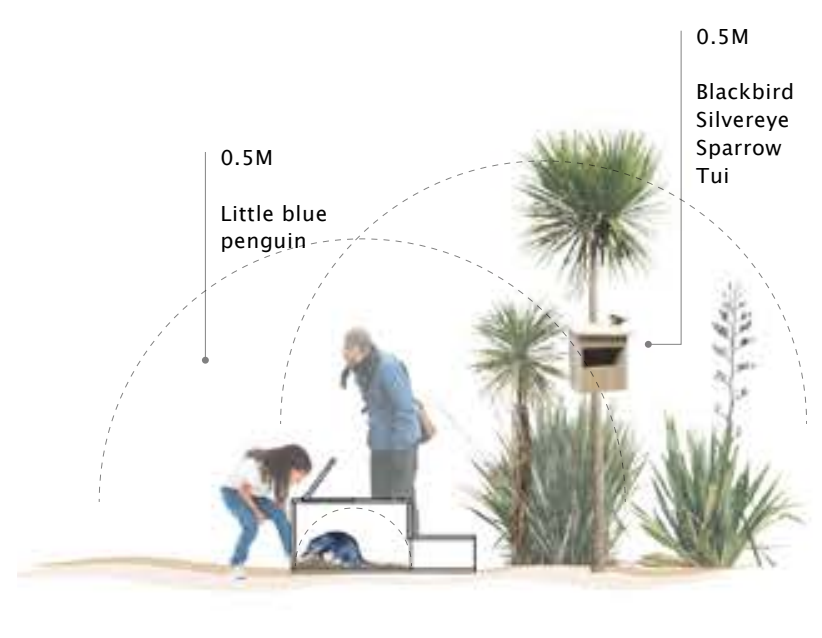

NESTING BOXES

Nesting boxes provide sheltered areas for birds to nest, out danger. They also offer opportunities for people to observe chicks.

INTERACTIVE/TACTILE ENGAGEMENT

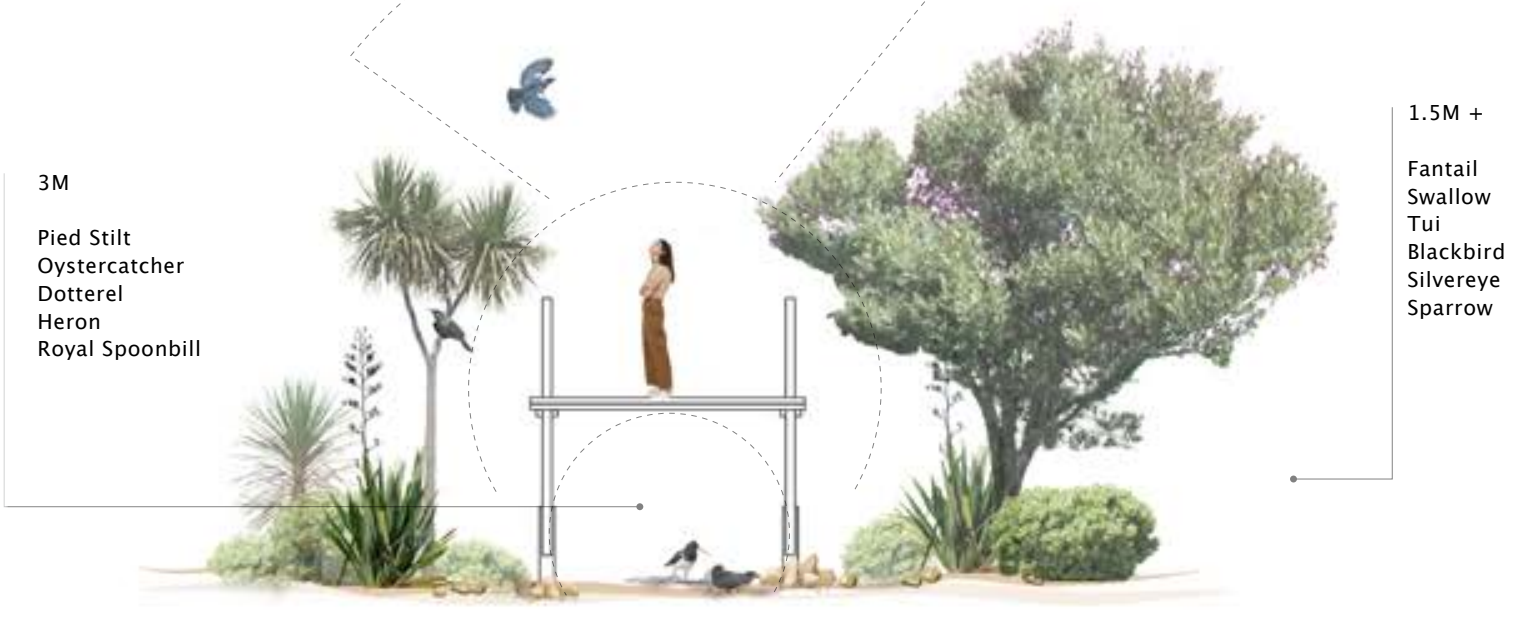

RAISED BOARDWALK

An elevated pathway creates space for birds to nest underneath, lifts people up to the treetops to observe roosting birds and is less likely to be inundated by rising sea levels.

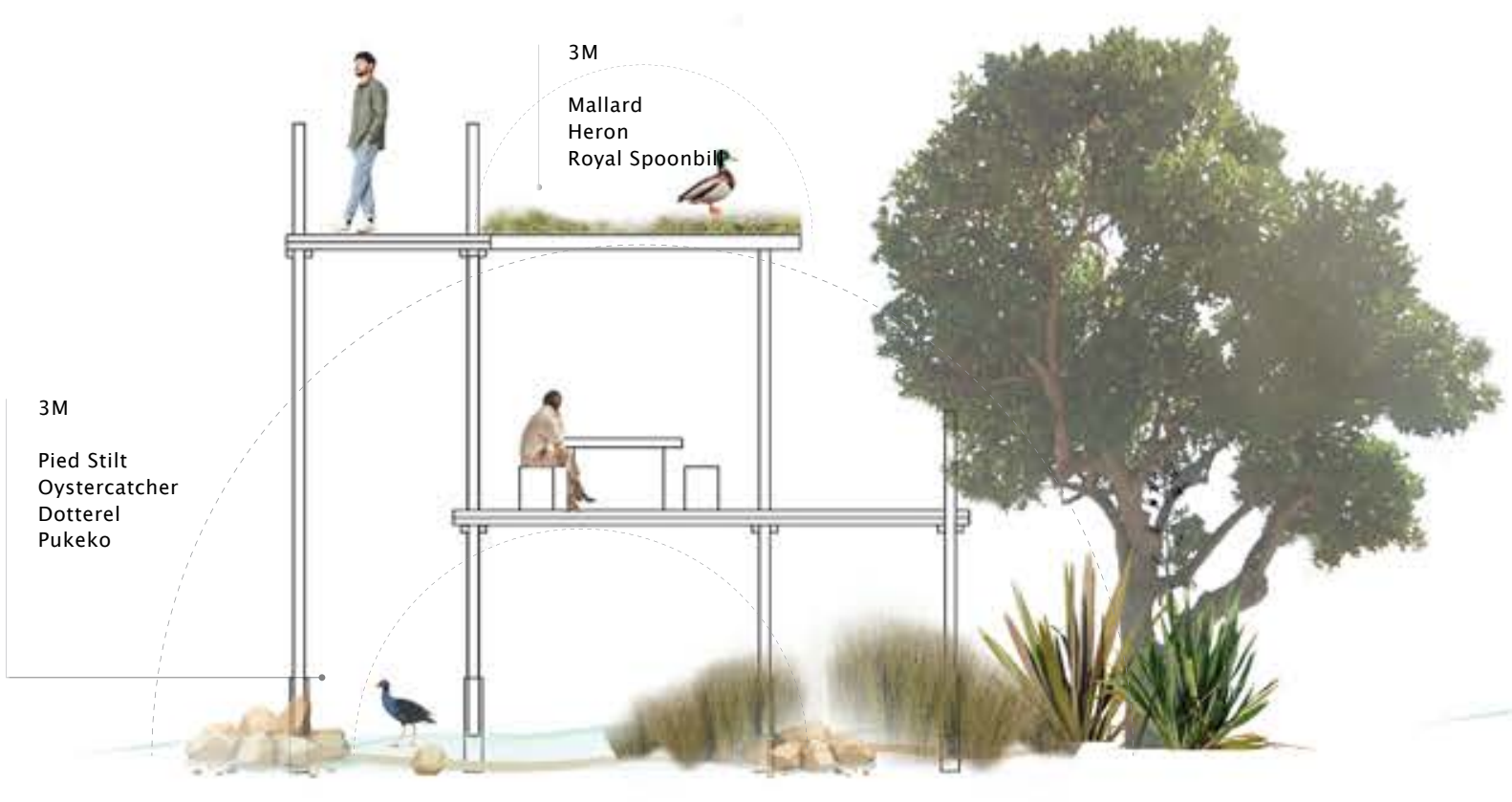

GREEN ROOFS

Green roofs provide habitat for insects and bugs, and can be used as a roost for birds that like to nest on raised platforms (herons, spoonbills etc.)
PASSIVE/OBSERVATION:

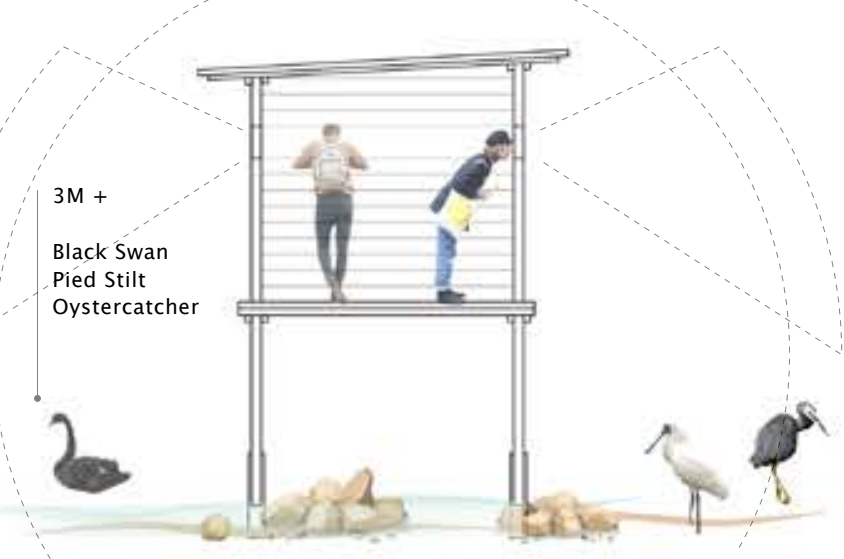

BIRD HIDES

Bird hides allow people to get close to birds with lower tolerances for close proximity.

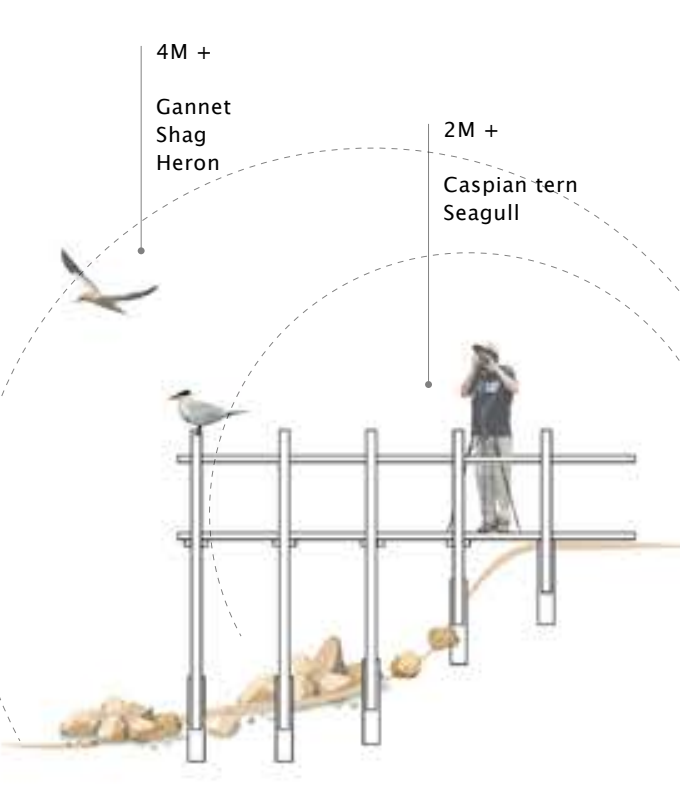

LOOKOUT

Rest spots for both people and birds to stop and observe the surroundings 


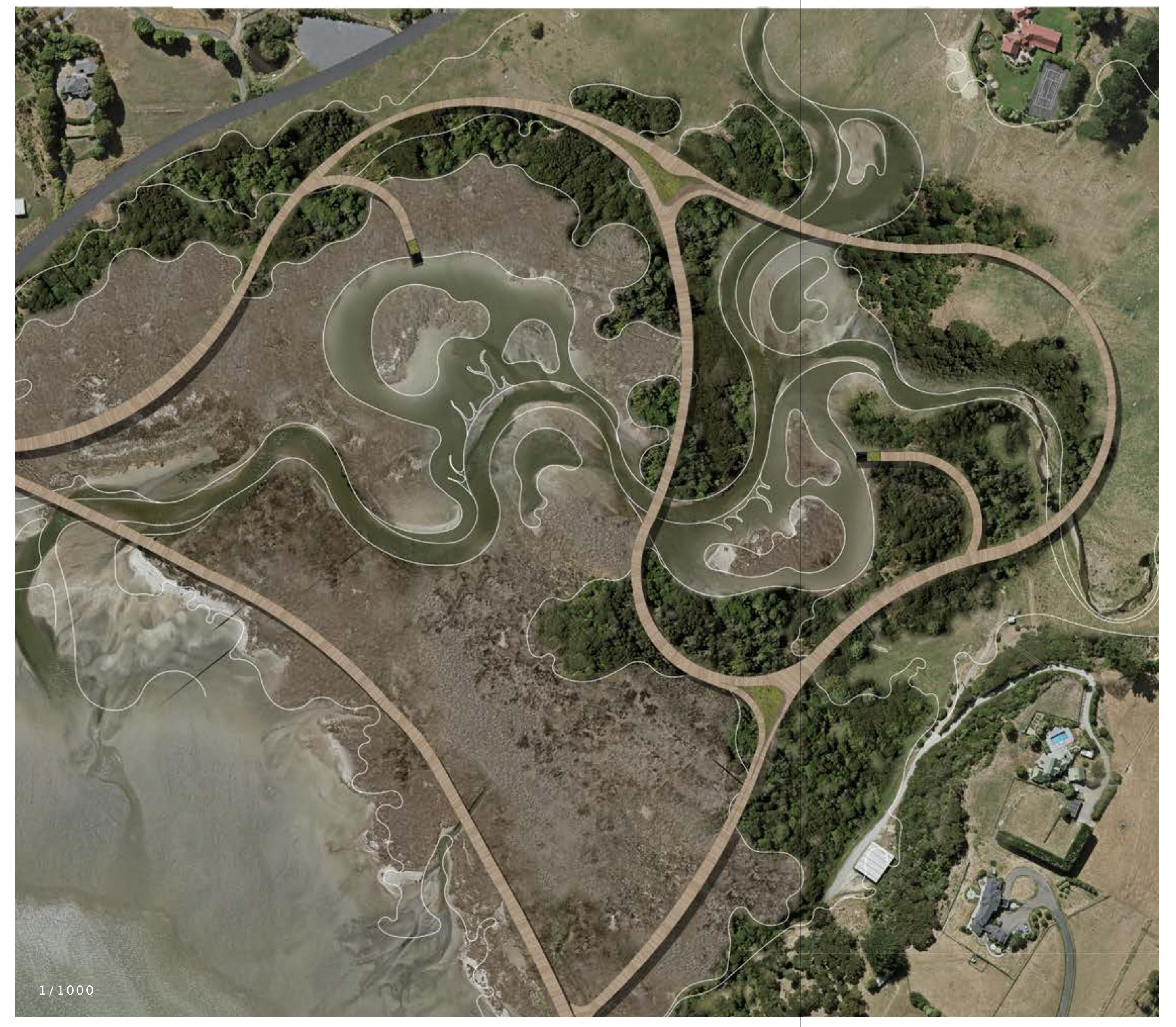

\section{Wetland walkway}

The wetland has been designed to create space for the rising sea levels to move inland. It also filters sediment from within the catchment by slowing the course of the Horokiwi stream and allowing sediment to drop before reaching the harbour.

The development of this saltmarsh wetland would create significant ecological habitat for a wide range of species within the harbour. Animals who frequent these areas have a lower tolerance to human proximity and as such the pathway has been designed to give the ponds a wide berth. Vegetation and bird hides obscure the human

movement, allowing people to get close without disturbing territorial wildlife

MOVEMENT DIAGRAM:

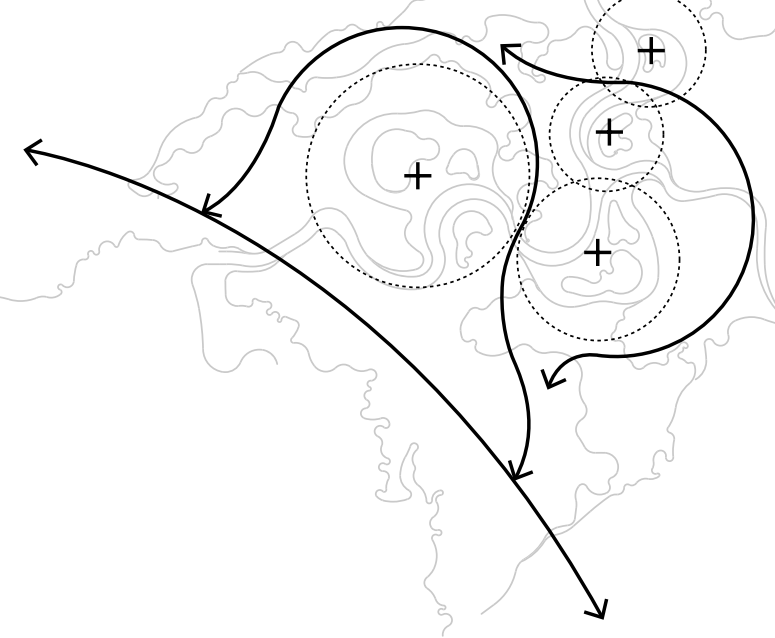

$+\quad$ WADING BIRD TERRITORY $\longleftrightarrow$ HUMAN MOVEMENT 


\section{SUCCESSIONAL GROWTH:}

ADAPTATION TO

SEA LEVEL RISE.

The sections illustrate how the habitat of the wetland adapts to sea level rise, and changing salinity.

\section{An adaptive scenario to the}

'sedimentation scenario' has not been illustrated as an increase in sedimentation in the harbour basin is unlikely to affect the freshwater stream as it makes its way through the wetland and joins the new, lower tideline.
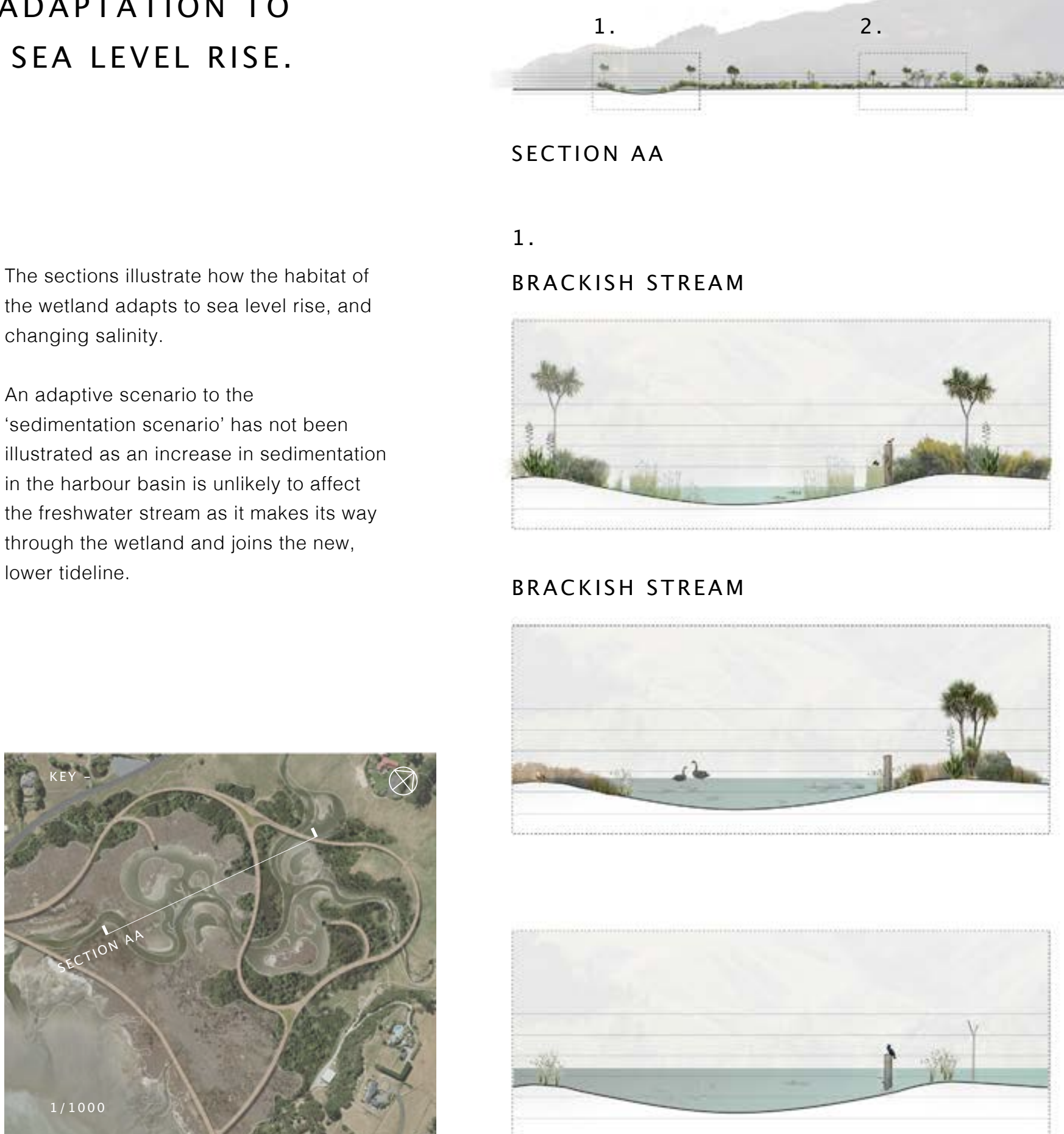

BRACKISH STREAM

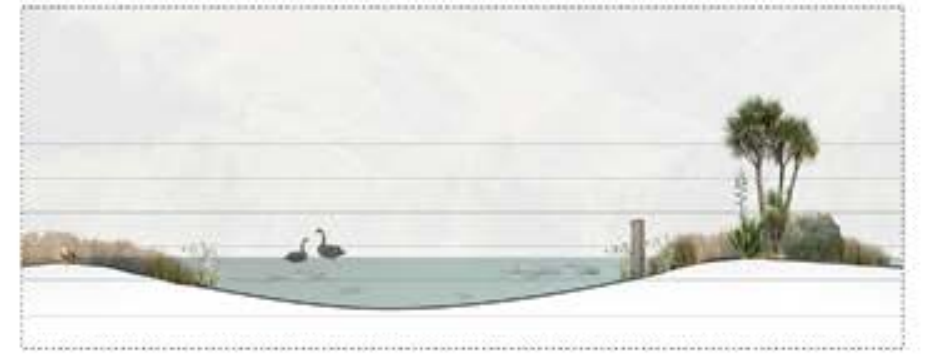

3.

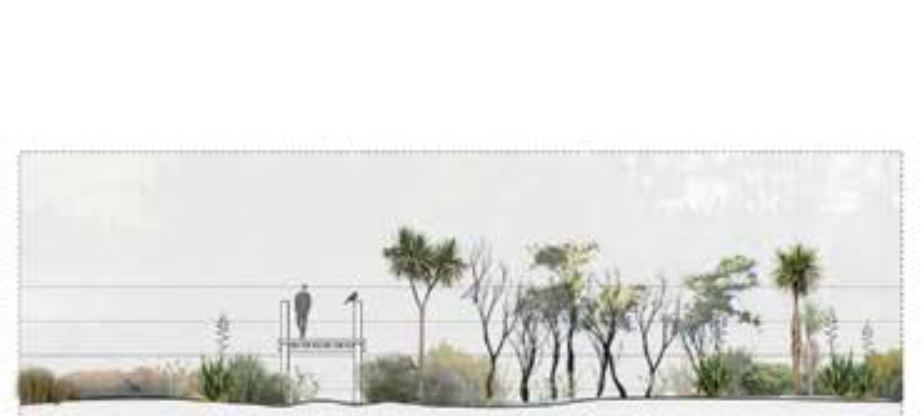

RAISED BOARDWALK/COASTAL BUSH
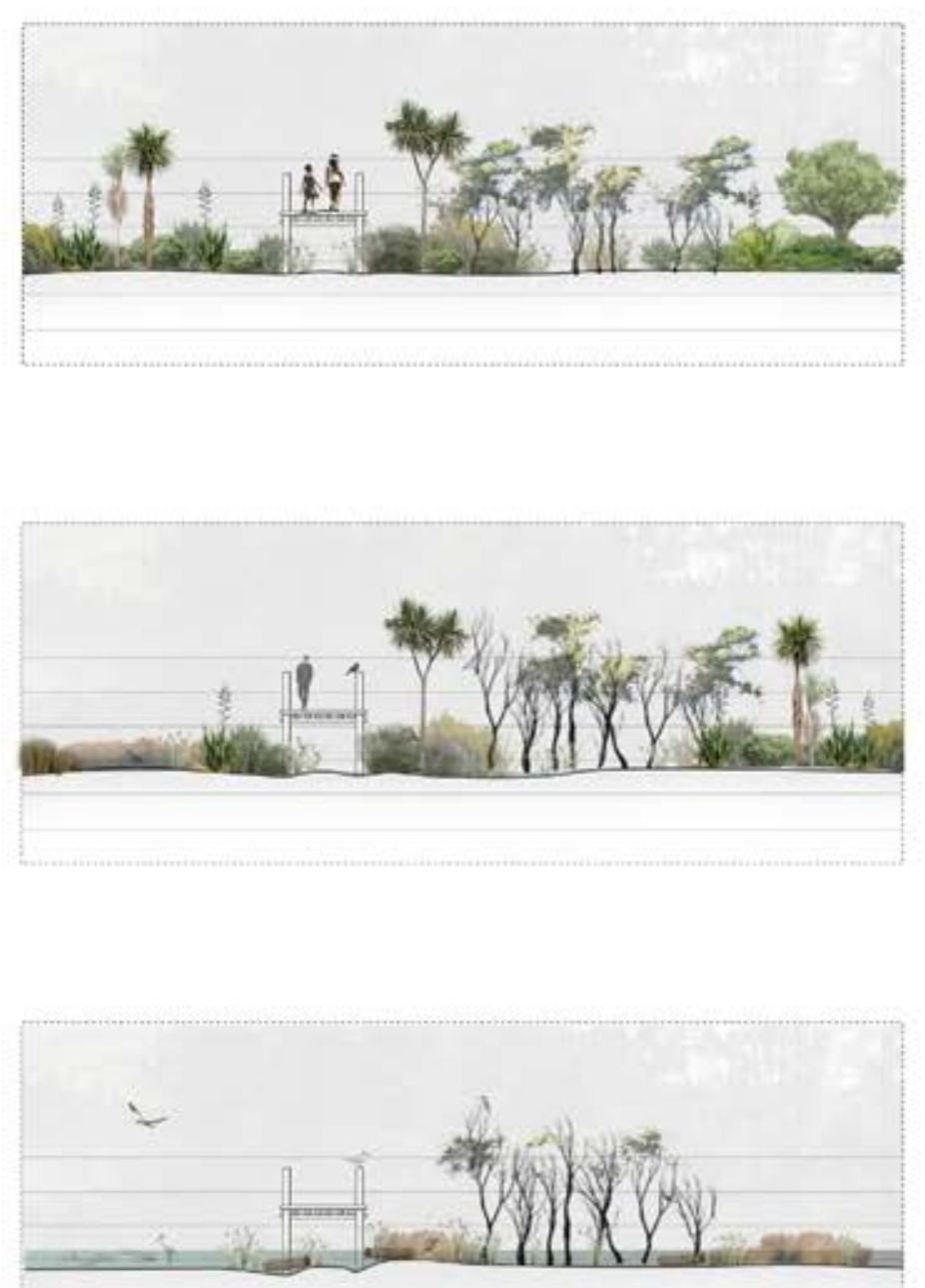

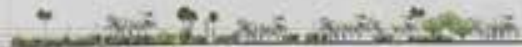

SCALE 1-1000@A3

3.

FIRST RETENTION POND

1M SEA LEVEL RISE
(EST. 50-75YEARS )

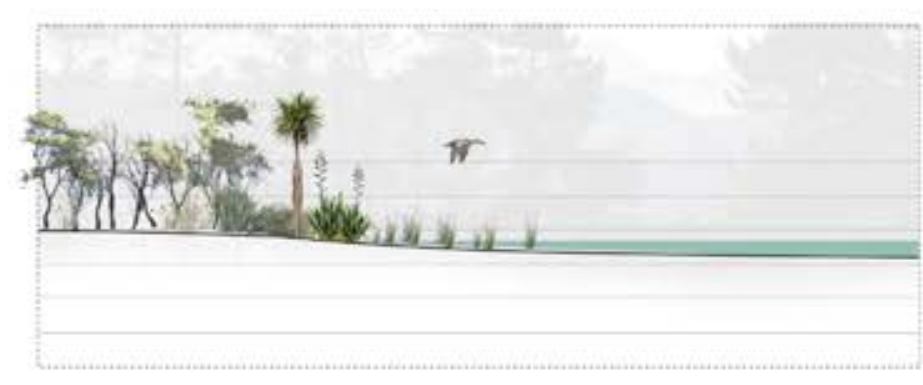
2M SEA LEVEL RISE
(EST. $125-150$ Y YRS )

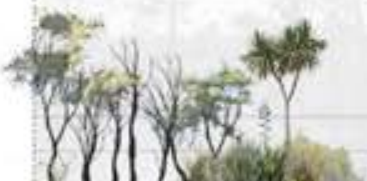

(1) X

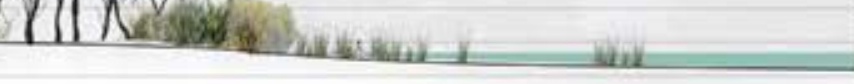
3M SEA LEVEL RISE
(EST. 150-175YRS)

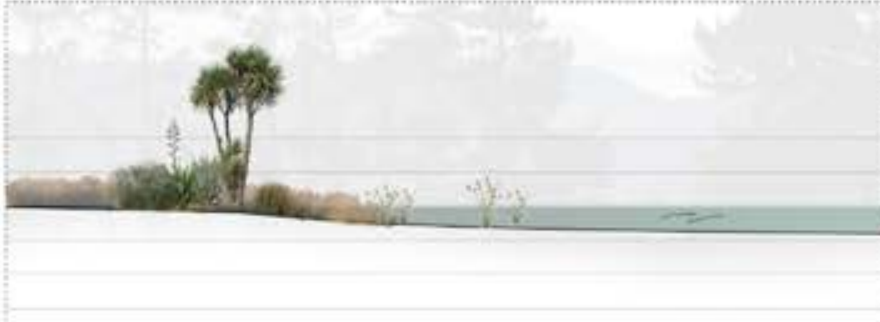




\section{Successional growth:}

Phasing over time.

FLOOD CONTROL AND ECOSYSTEM WETLAND DEVELOPMENT

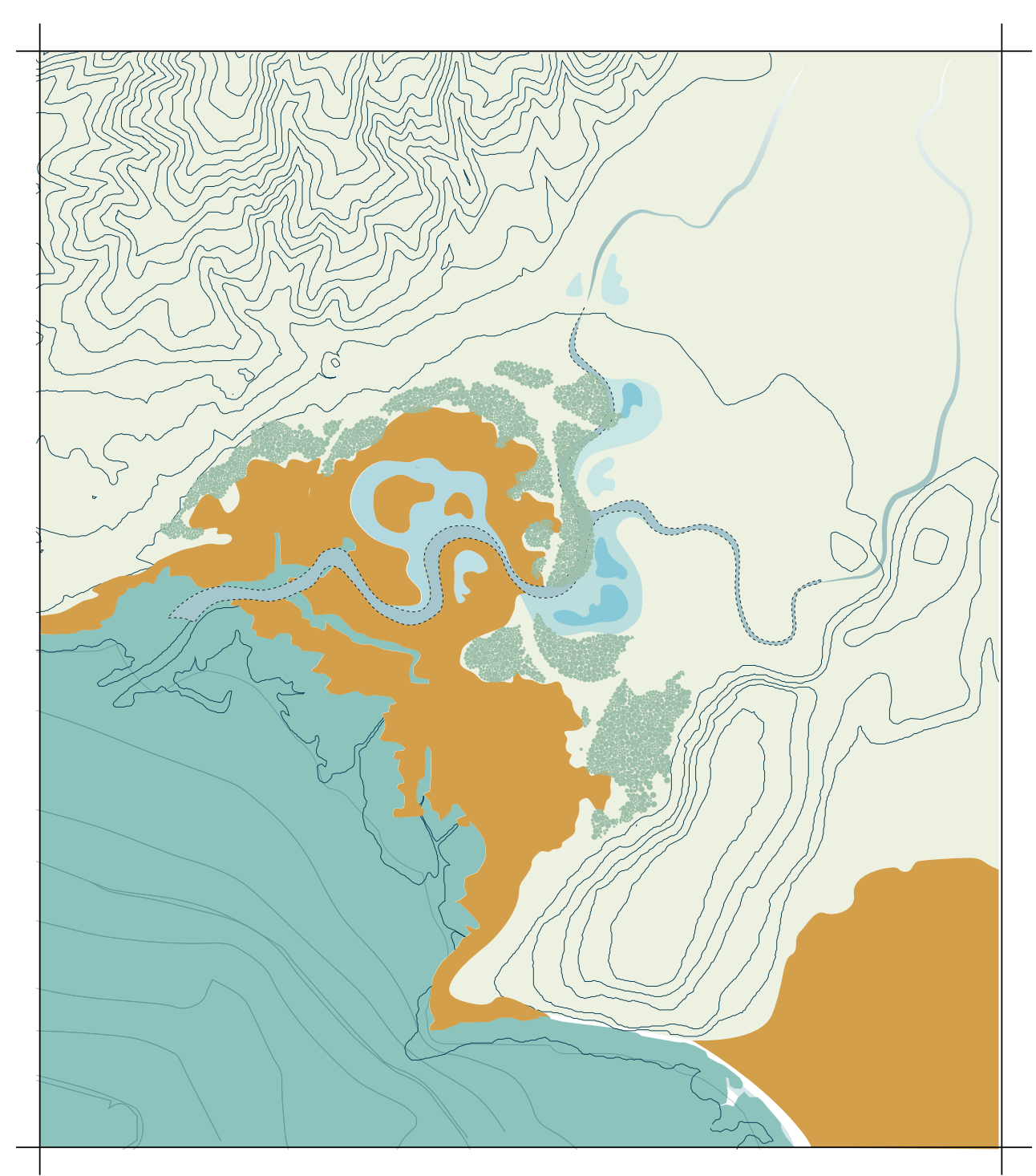

1M SEA LEVEL RISE

(EST. $50-75$ YEARS )

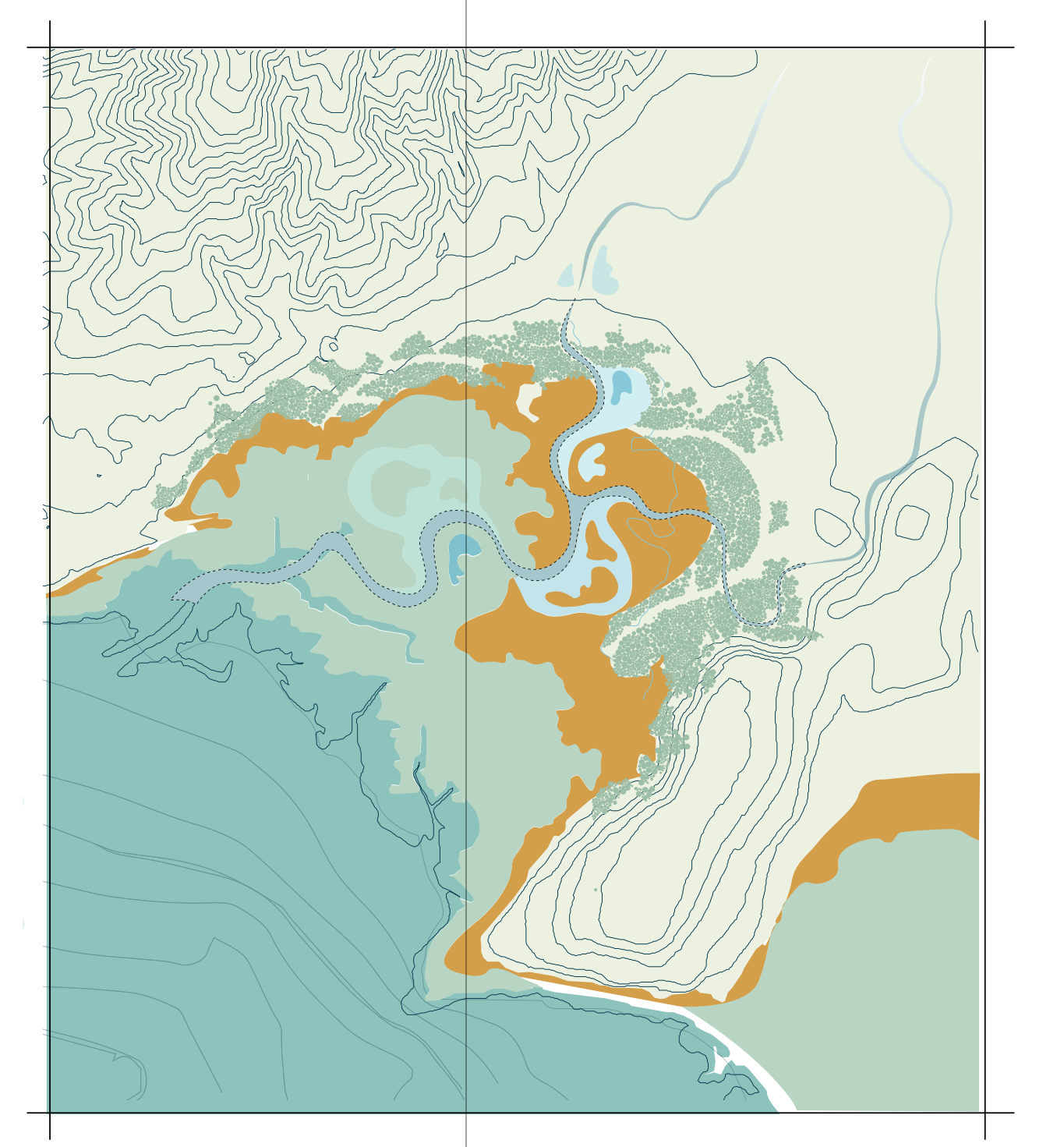

2M SEA LEVEL RISE (EST. $125-150$ YRS)
As sea levels rise, saltmarsh habitat is given room to retreat inland. The salinity of the rentention pools changes as the tideline moves landward with the pool closest to the water eventually being completely submerged. Coastal bush behind the saltmarsh also migrates inland with the tides. 
DESIGNING WITH THE RISING TIDE: SUCCESSION IN SALTMARSH WETLANDS.

This diagram illustrates how water is accommodated as it moves through the wetland - facilitating movement while slowing its impacts on the surrounding environment, both sediment and sea level rise.

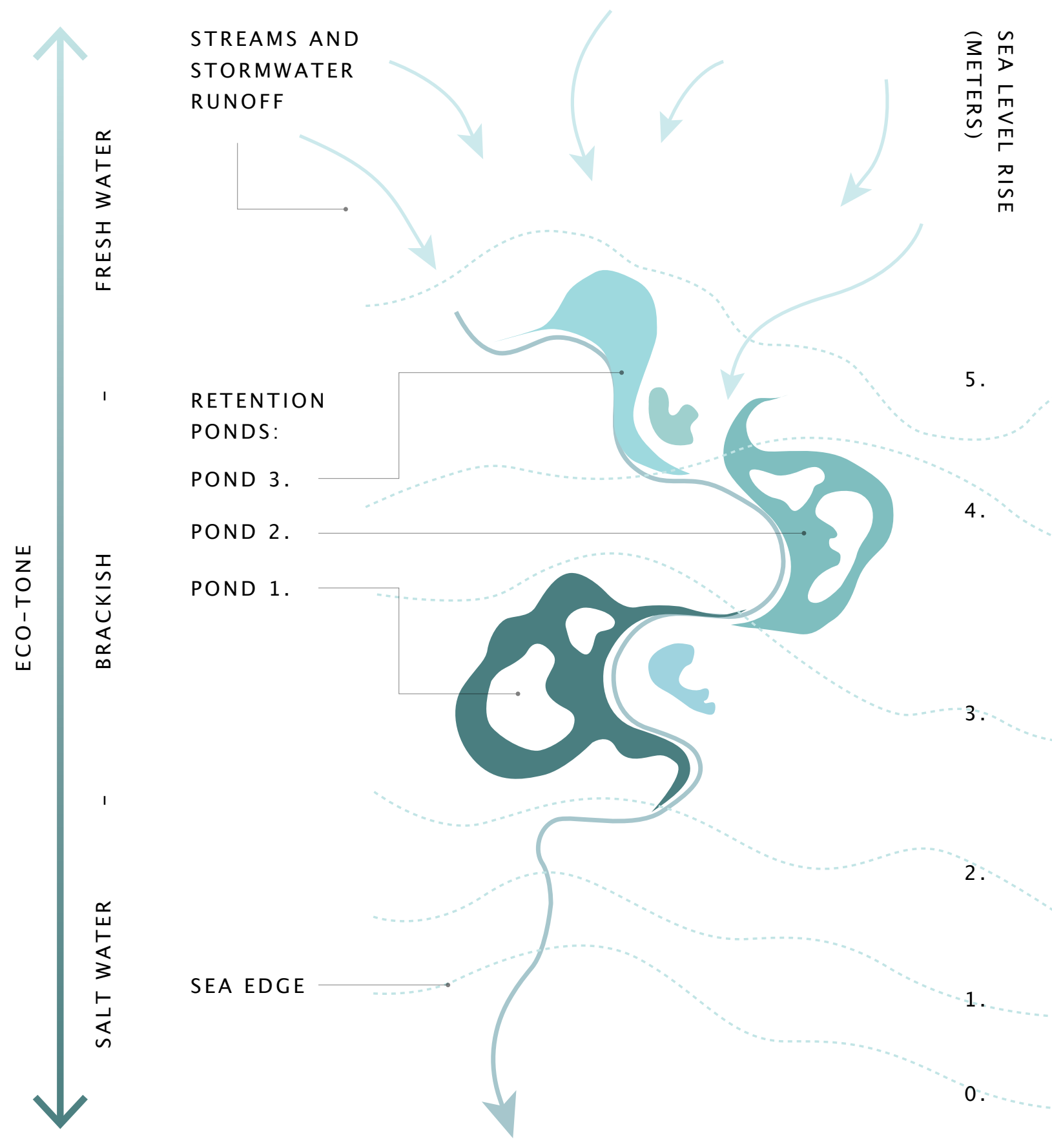

SUCCESSIONAL GROWTH

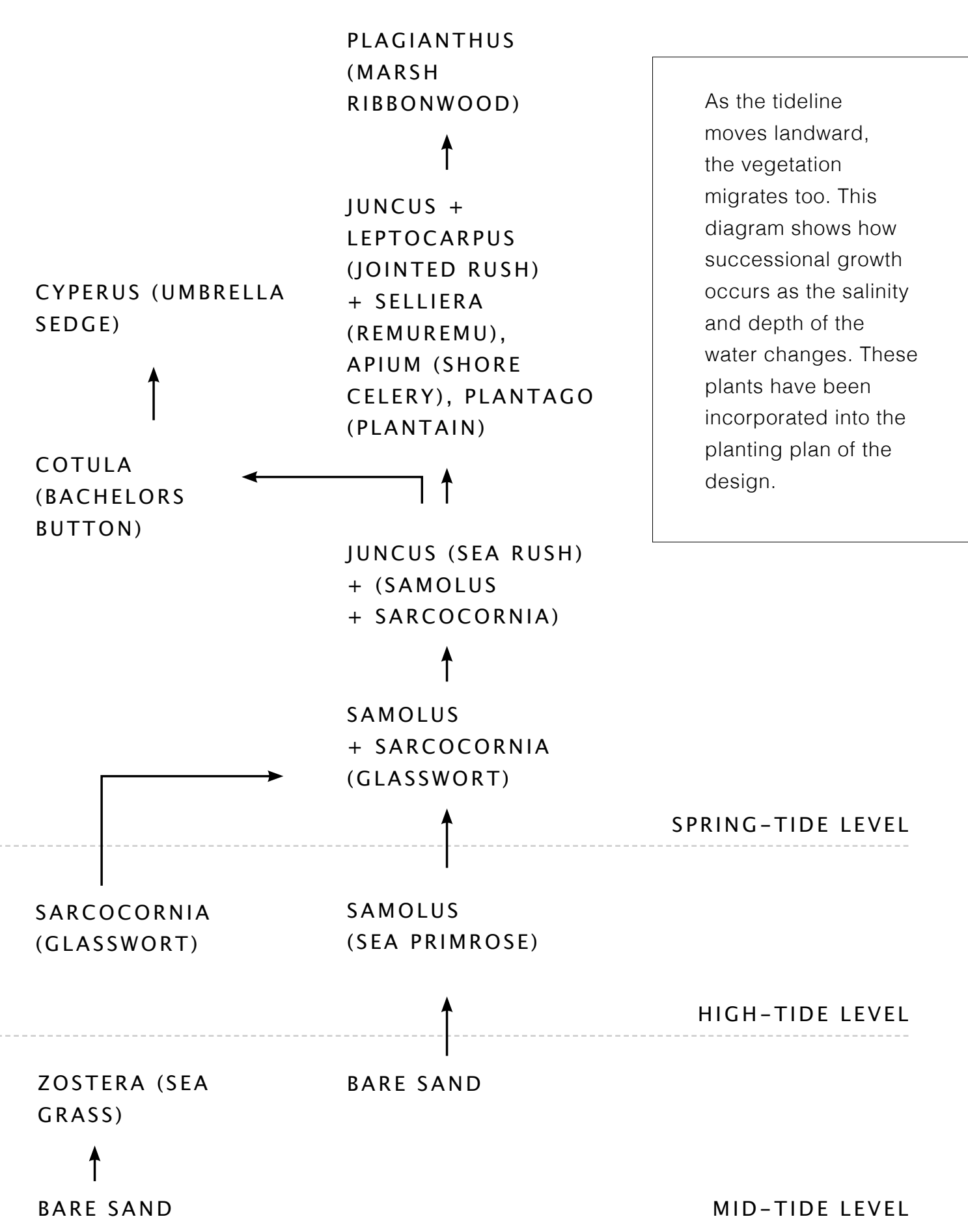




\section{Cohabitation opportunities:} bird hides.

KEY LEARNINGS FROM PROXEMICS STUDY TO INCORPORATE INTO BIRD HIDES:

The design of bird hides that allow humans and wildlife to coexist without disturbing species that are uncomfortable being in close proximity, are explored.

CREATING HABITAT IN THE BUILDING ENVELOPE: SCHEMATIC DESIGN ITERATIONS

HABITAT FOR WILDLIFE CREATED

IN THE FABRIC OF THE WALLS

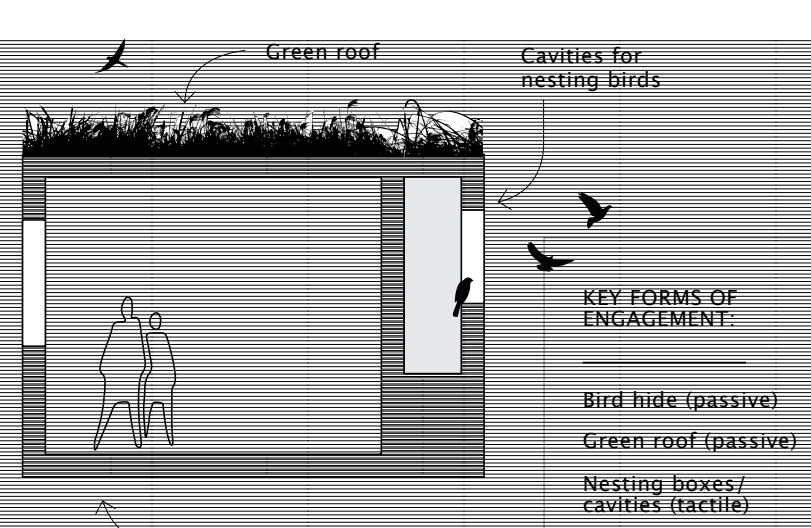

Cohabitation space
SKYLIGHT AND RAFTERS

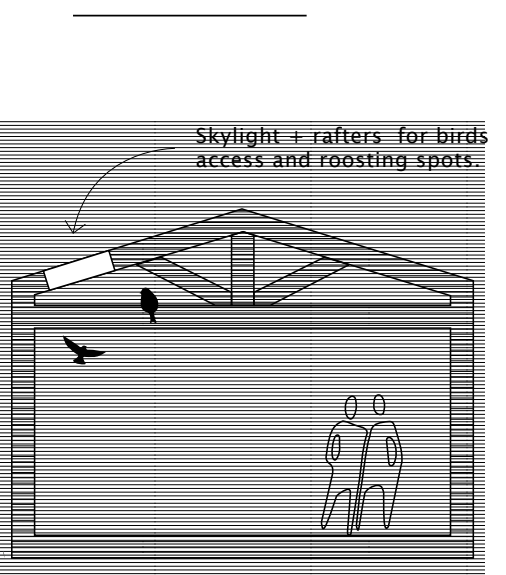

KEY FORMS OF
ENGAGEMENT

Class bottomed
boats
pauildings

Rock pools
(tactile) 


\section{DEVELOPED ITERATION:}

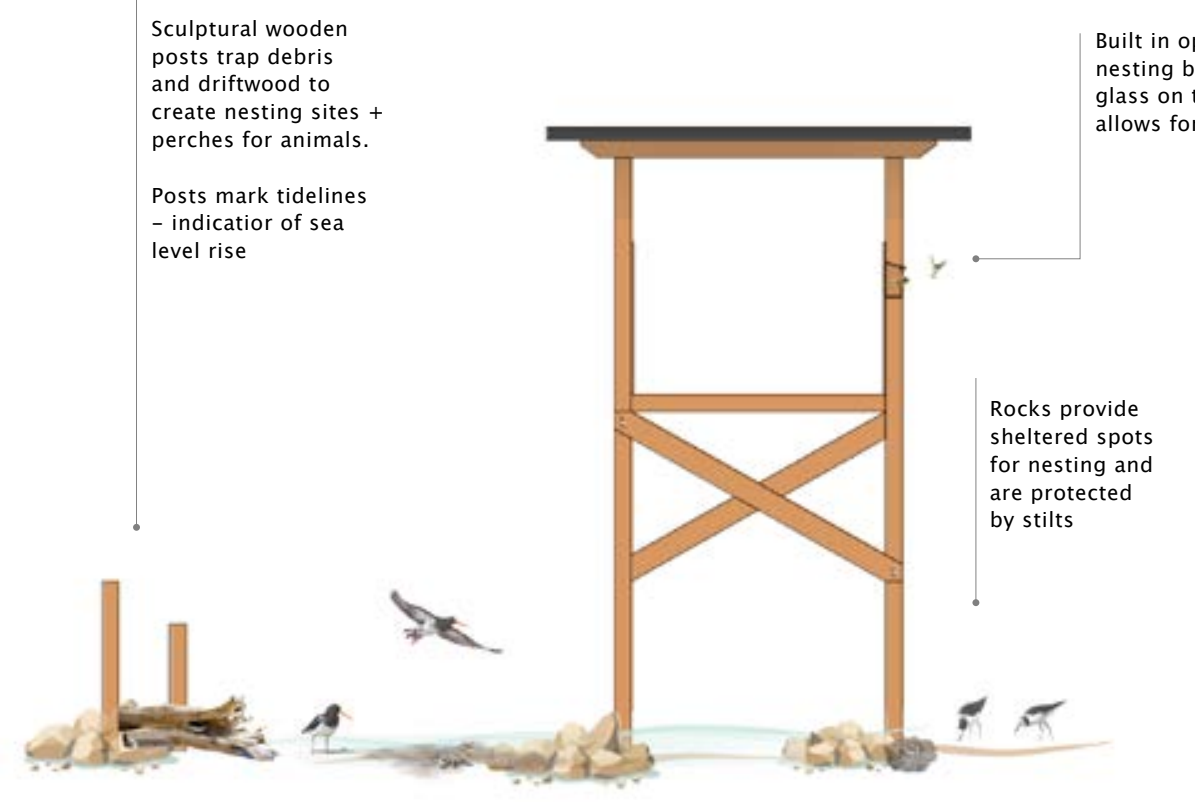

\section{CROSS SECTION}

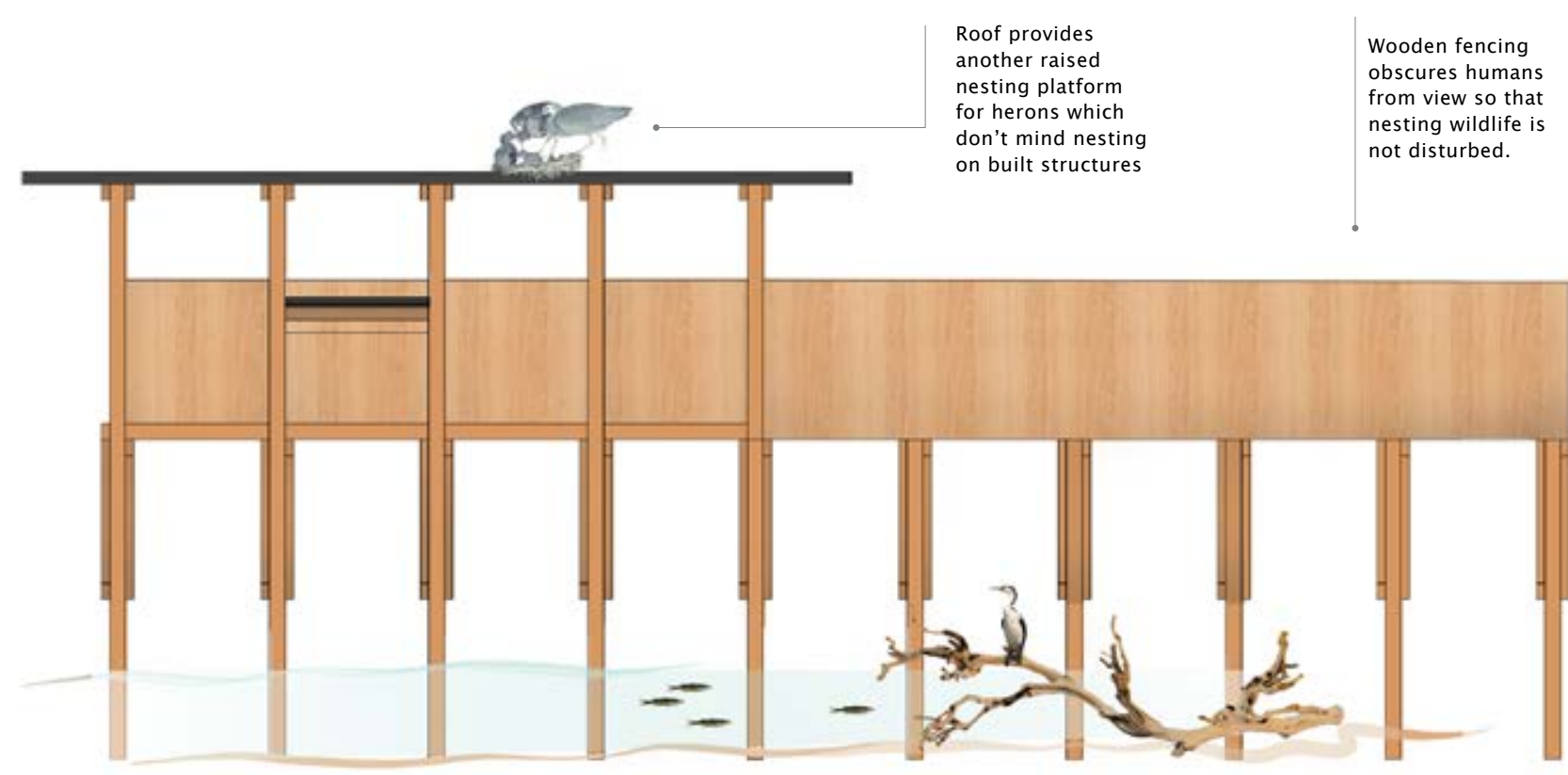

ELEVATION $1 / 100$

\section{BIRD HIDE COHABITATION CONCEPT}

This design test synthesises the schematic

cohabitation iterations into a single built form that

provides a range of different habitats created both in

the building envelope, and around the structure as a

result of its positioning within the landscape.

The form is simple and could be

developed further, though the synthesis

of cohabitation is successful in its

multifunctionality and range of species

it can provide for 
Final design bird hides.

A couple of bird hides are

dotted along the wetland

pathway. These allow people

to get closer to birds nesting

in the saltmarsh and wading in

the ponds without causing them

larm. These species re

greater proxemic distance and

are easily disturbed.

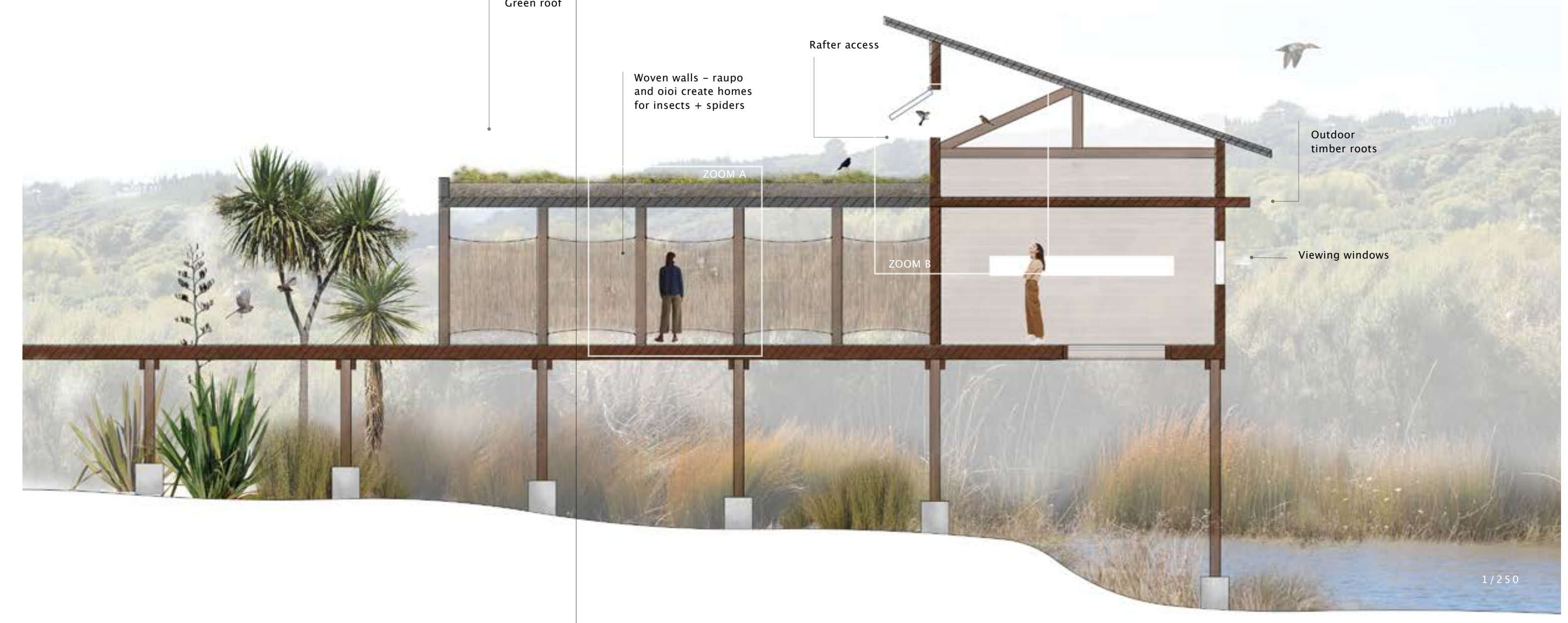

The material fabric of the hides

provide habitat for wild life,

encouraging closer interaction

between species through

shared space. In this way, this

design provides a space for

multiple forms of encounter to

occur.
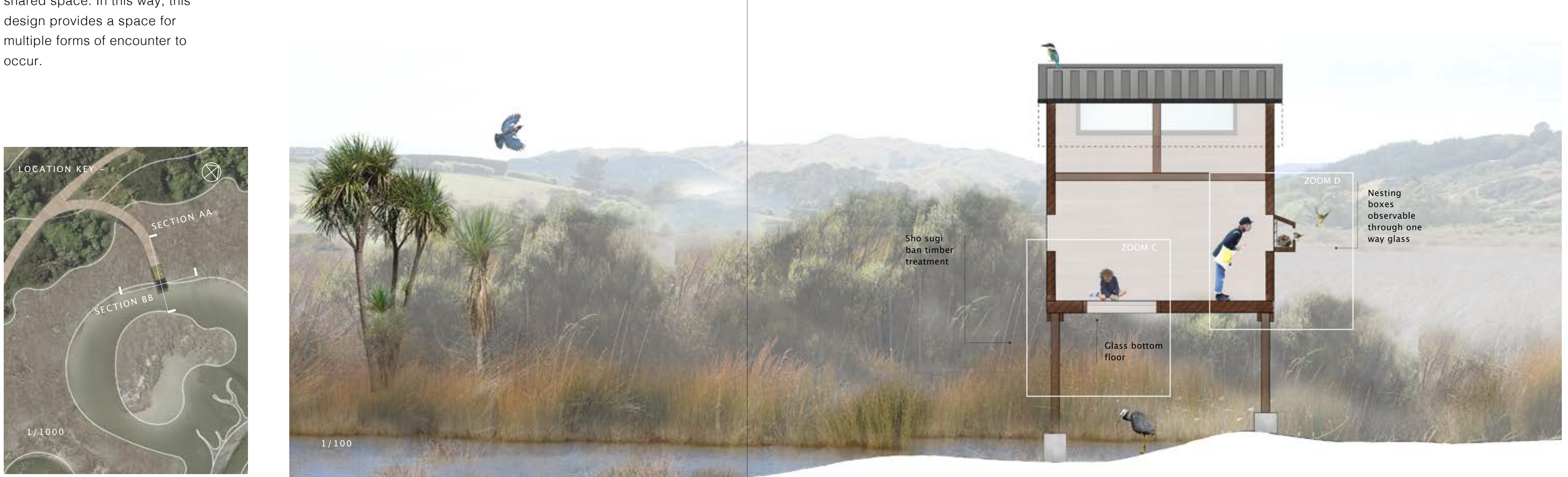


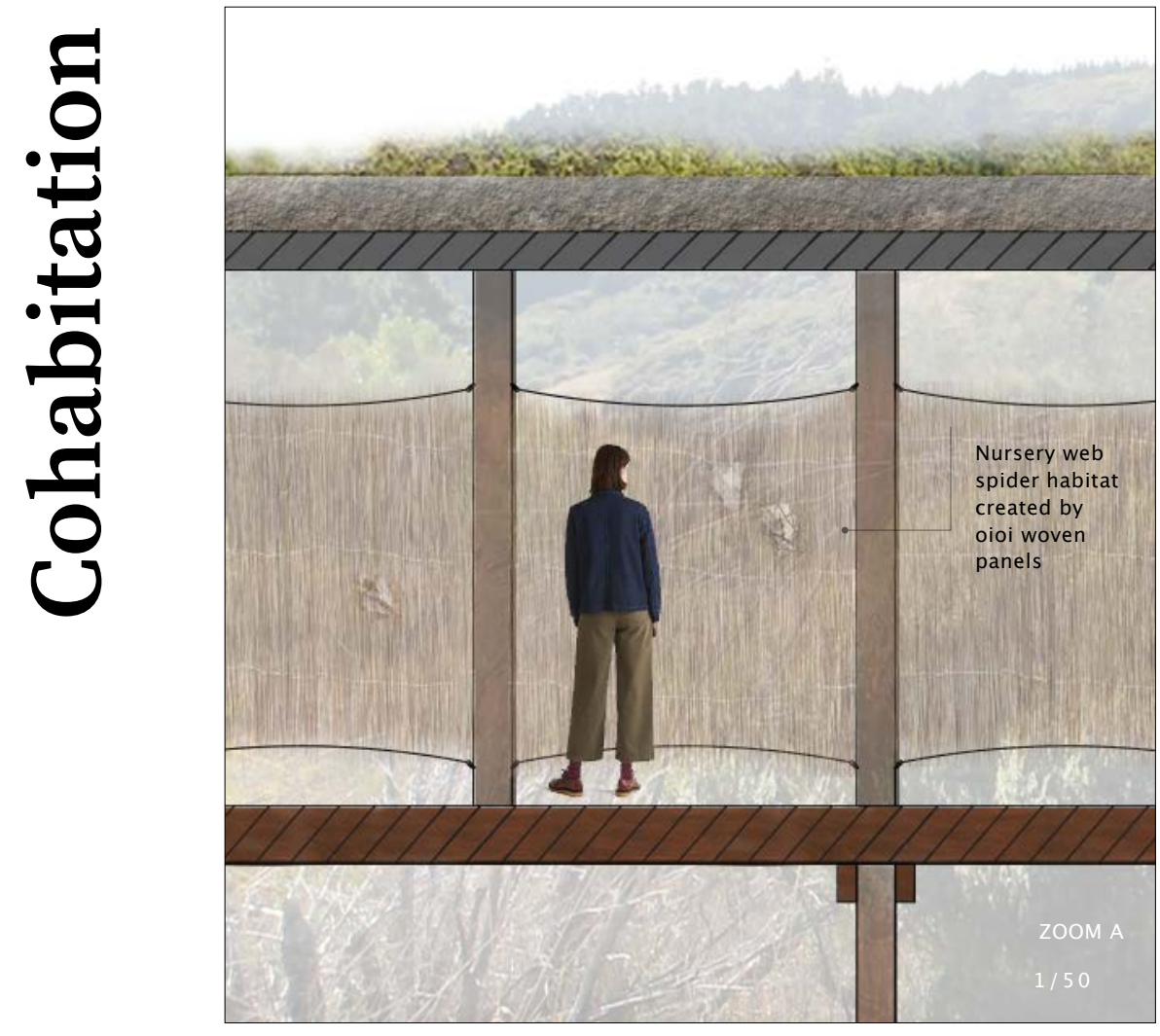

Woven rush panels (oioi and raupo) serve as walls along the pathway to screen people from view near the ponds so as not to disturb vulnerable nesting birds. Their rough thatching also acts as a habitat substrate for insects and spiders.

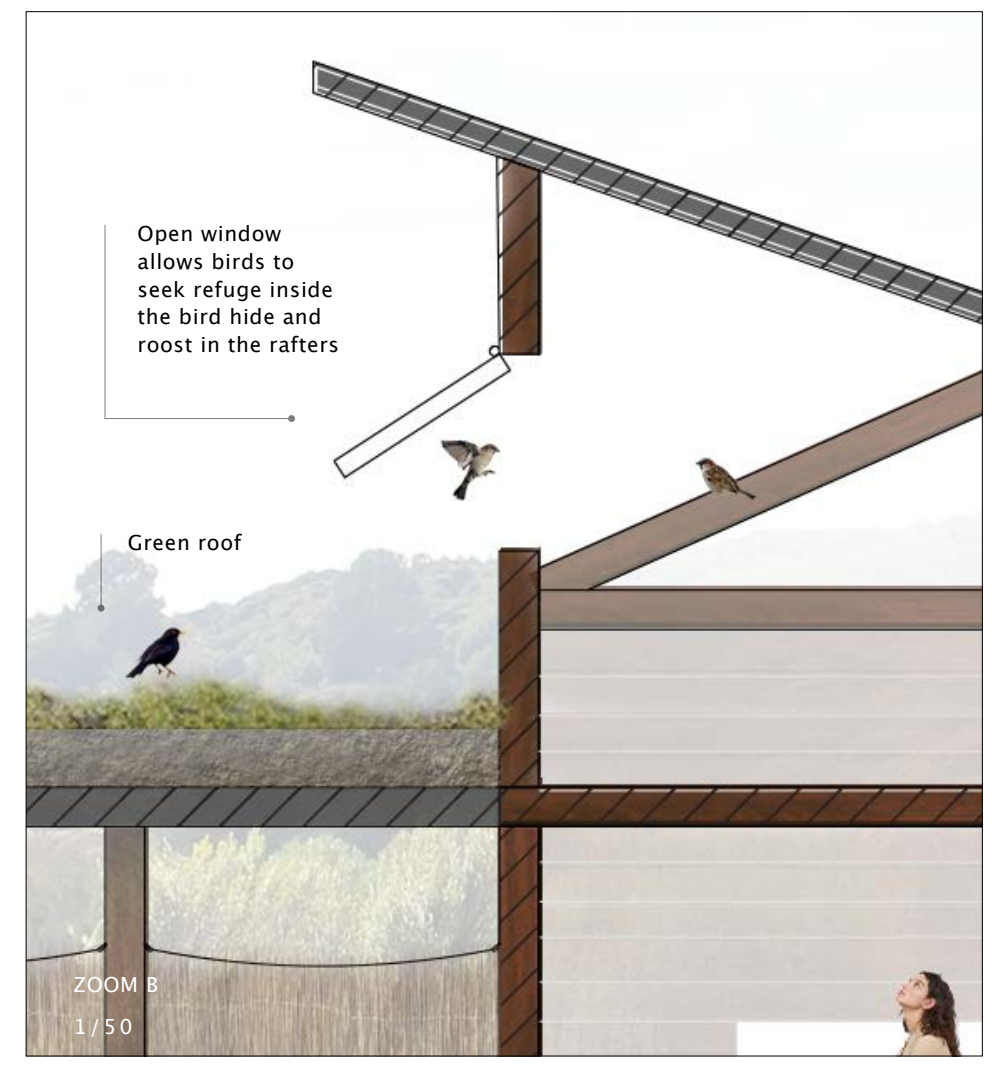

Green roof creates habitat for bugs and insects as well as roosting spots fo treetop birds such as herons and shags to nest.

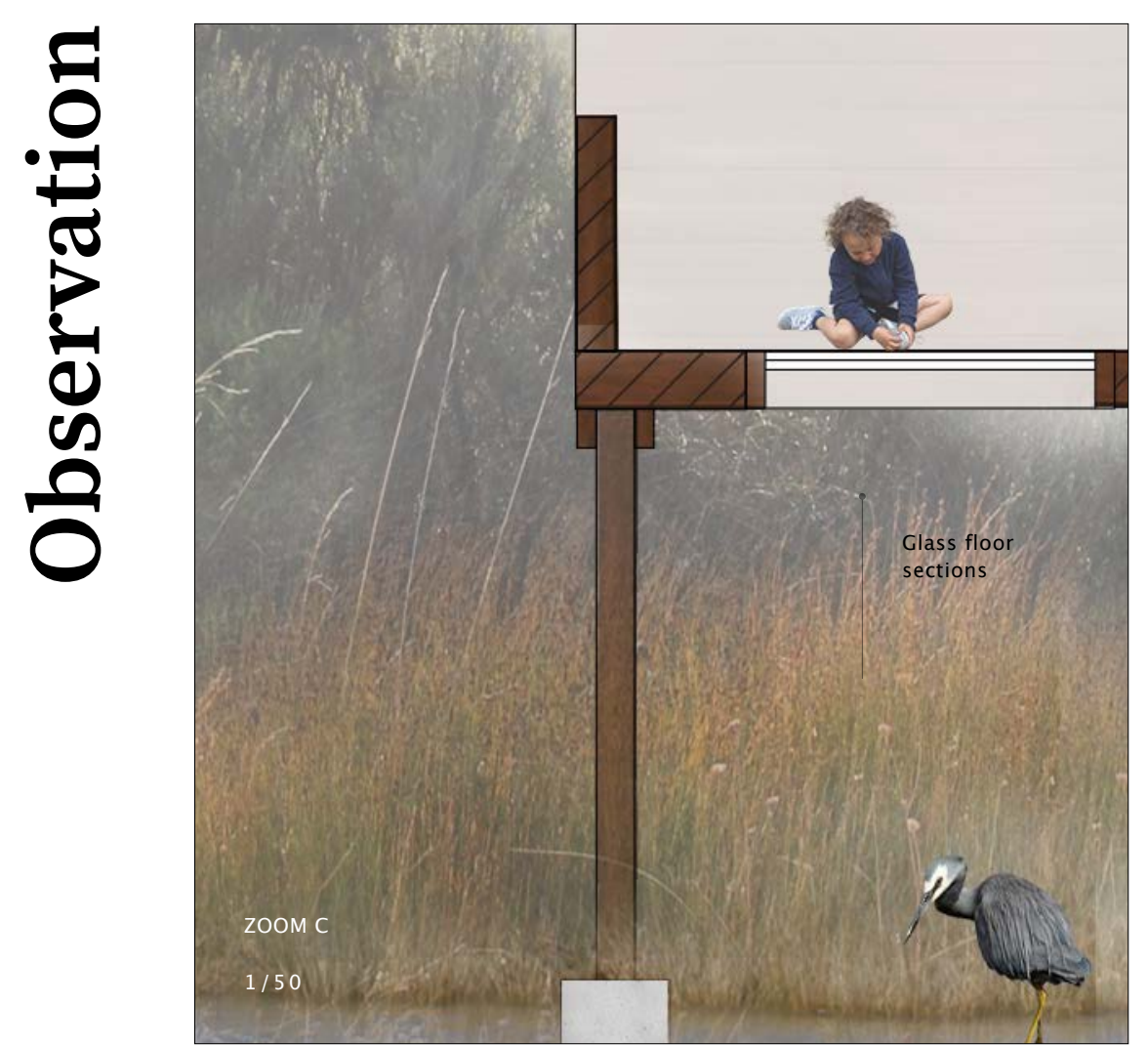

Small sections of glass flooring allow people to observe nesting birds below while keeping a distance so as not to disturb the birds.

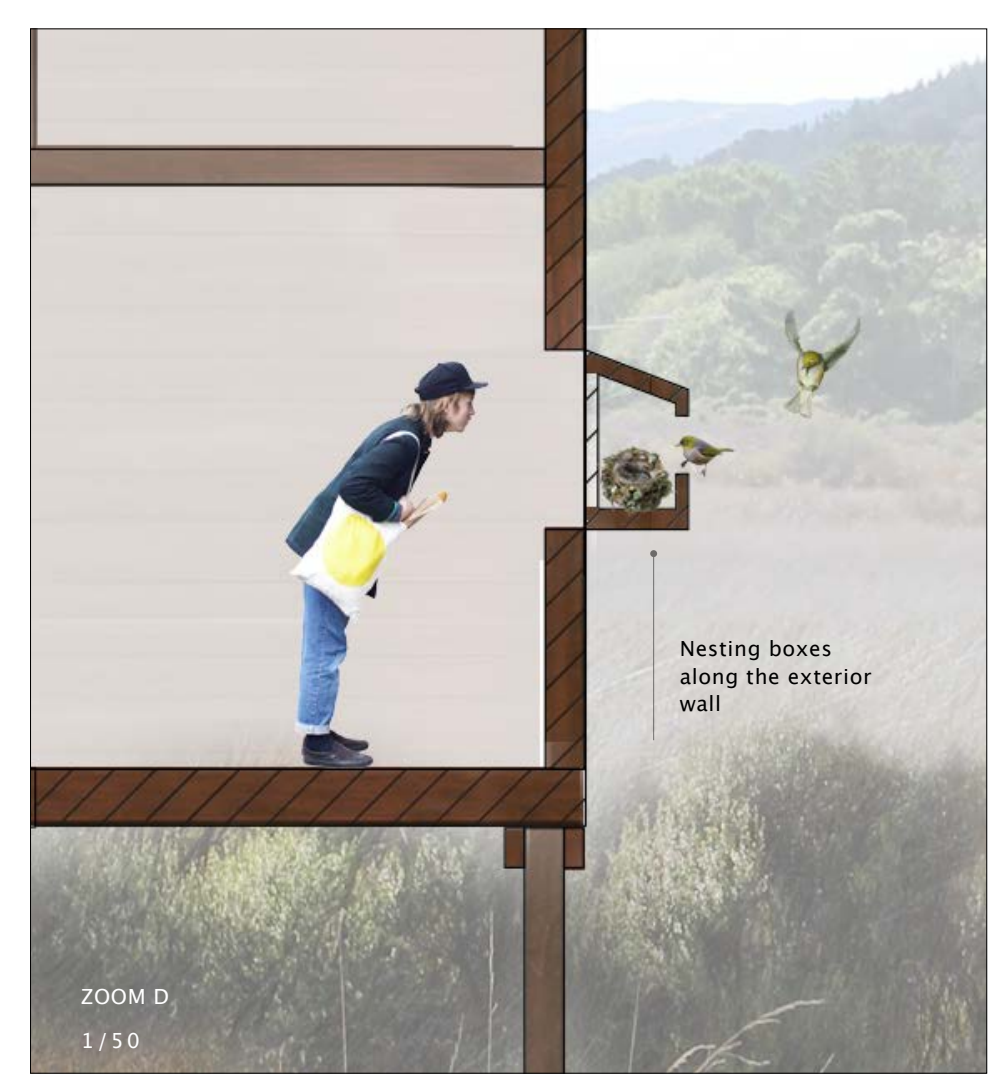

Open sided bird boxes along the exterior wall provide nesting sites for tui, waxeyes, and fantails (only a few native birds are known to use them). One wall glass on the inside of the hide allows people to observe without disturbing nesting birds 


\section{Encounter generated}

DRAWING FROM THE MATERIALITY OF THE SITE: WOVEN PANEL MATERIAL TEST -

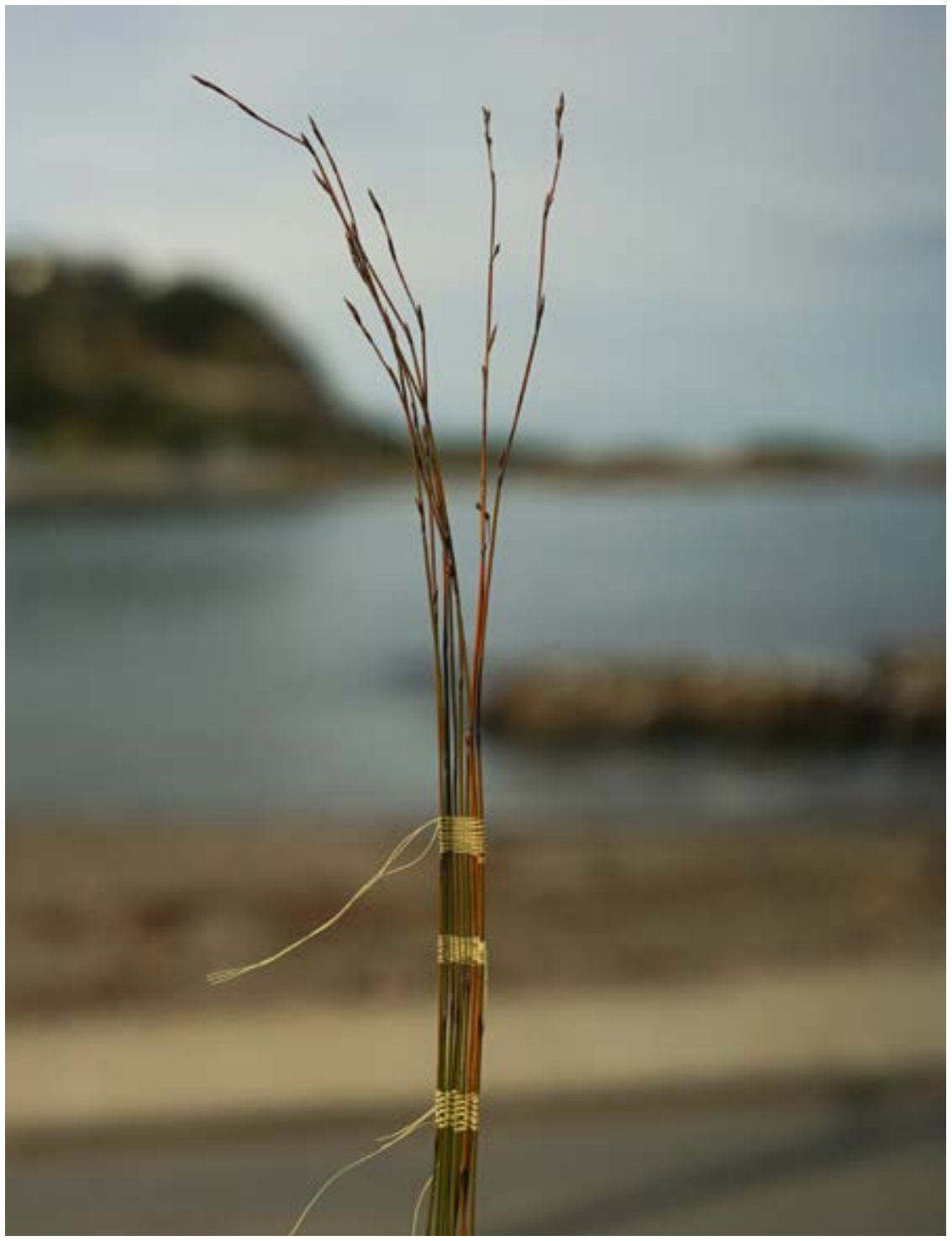

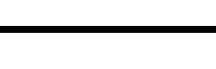
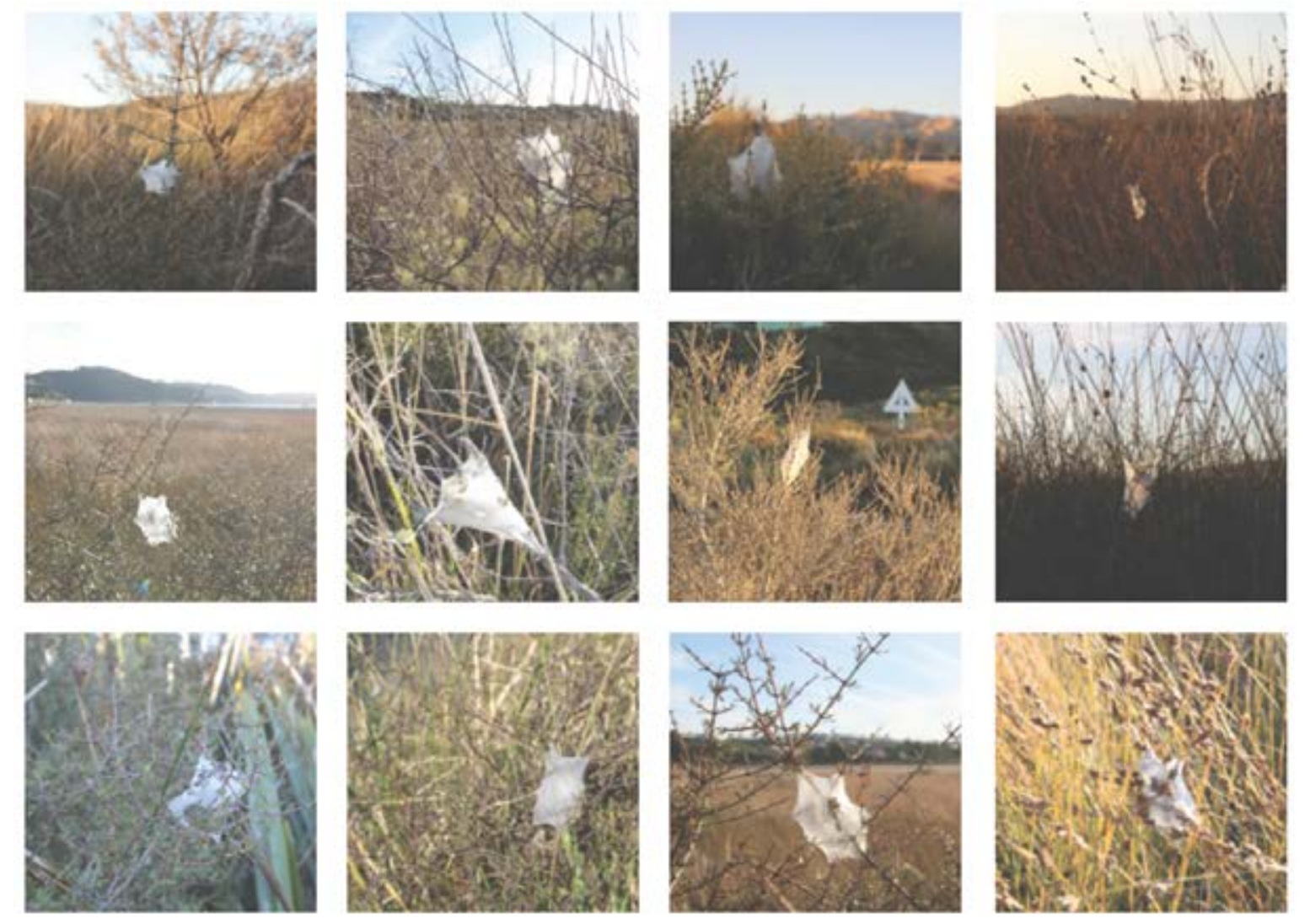

Dolomedes minor nests
(Nursery web spider) 


\section{Green roof pavilion.}

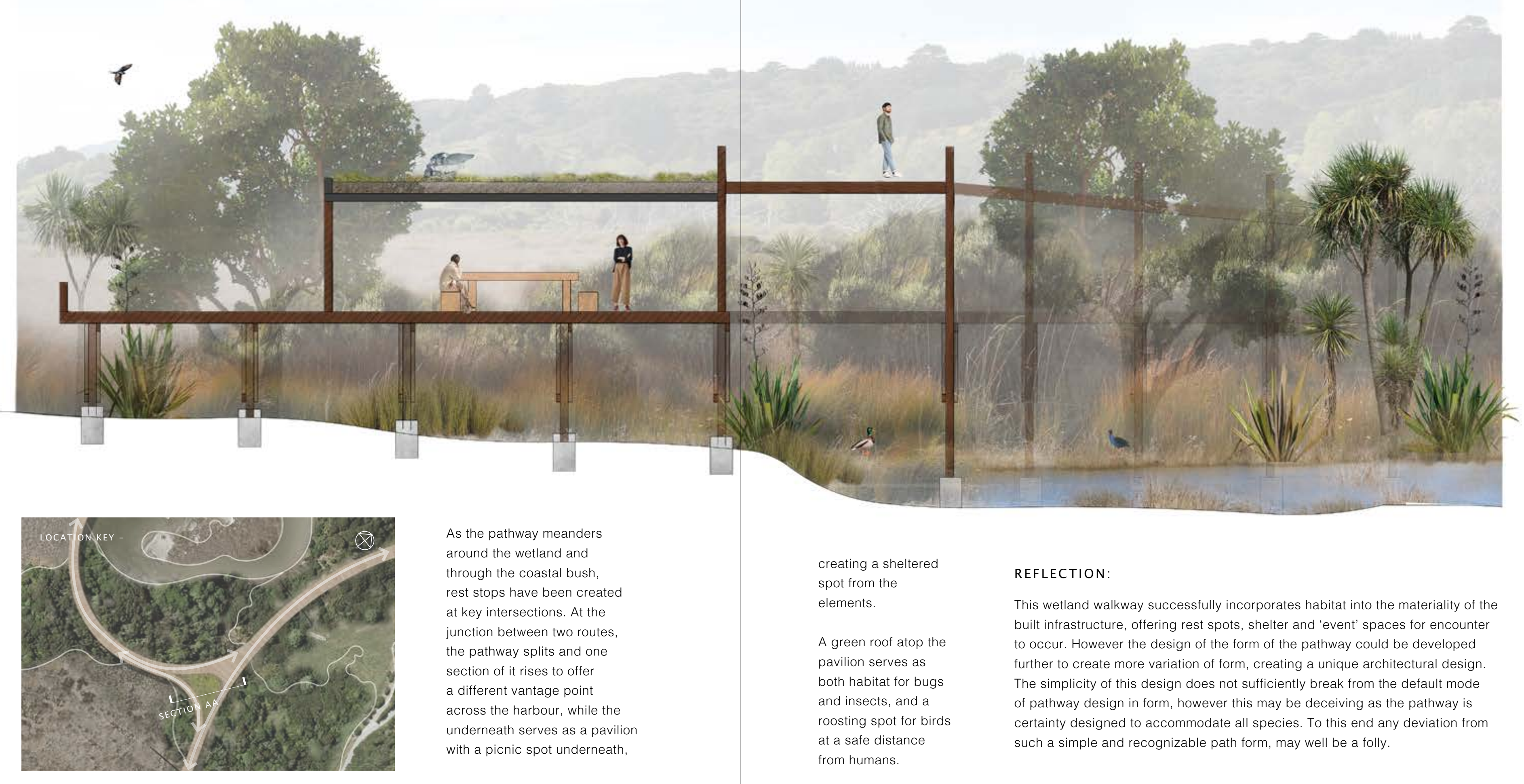




\section{Design Study Area 2.}
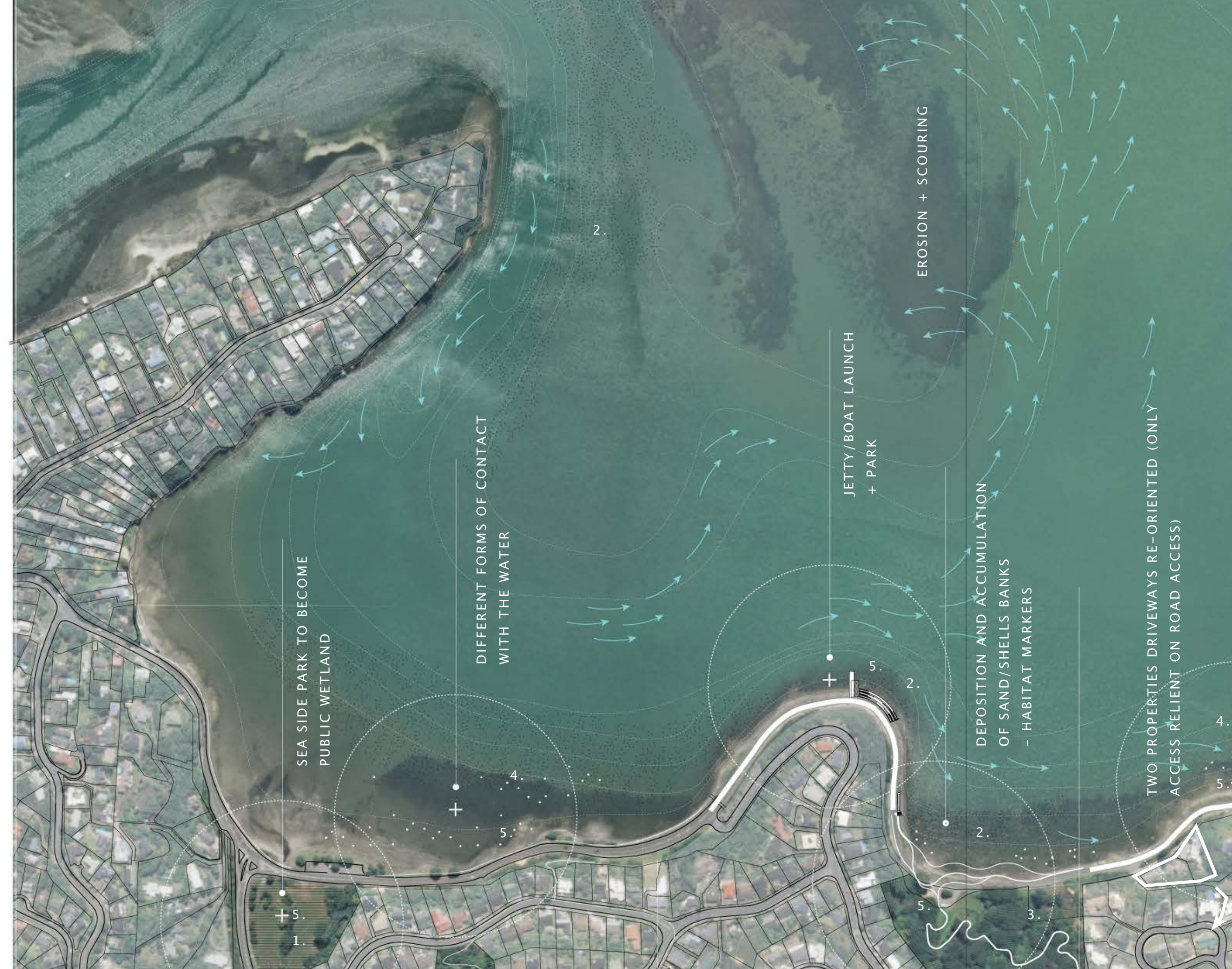

SOUTHERN EDGE WALKWAY

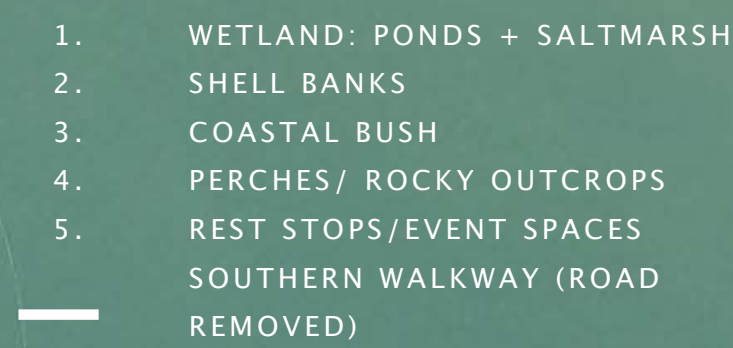

(2) $=1$.

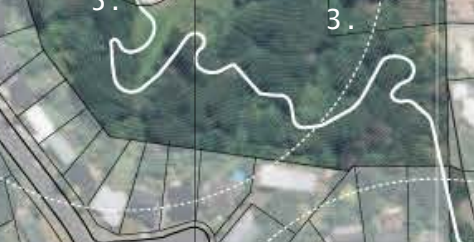

rencerse 25

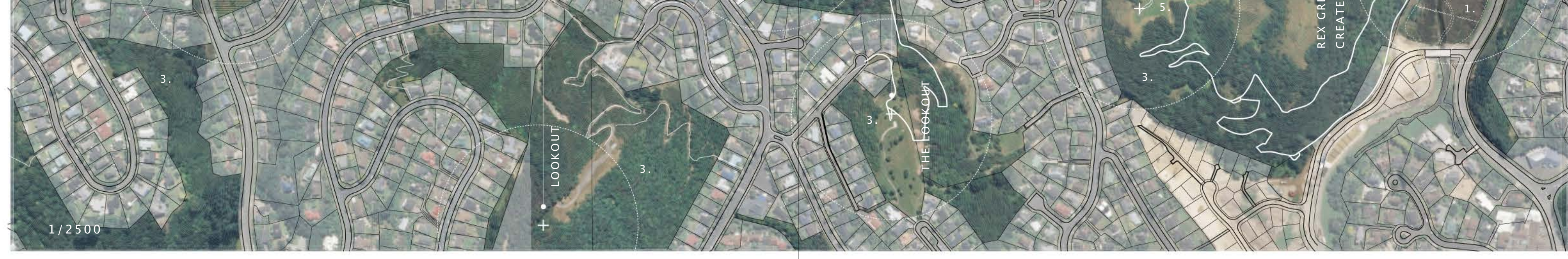




\section{Southern path - modes of encounter.}

\begin{abstract}
The southern path follows the rocky coastal edge, shouldered by clay cliff faces to the south, cloaked in trees. The animals that frequent this type of habitat are relatively comfortable with human presence, requiring rocky perches and shelly beaches on which to rest.

A range of interventions within these conditions are explored to present opportunities for interspecies encounter: both interactive and

passive depending on the tolerance of the individual species.

These diagrams outline proxemic fields for each species to allow enough room for co-existence without disturbance.
\end{abstract}

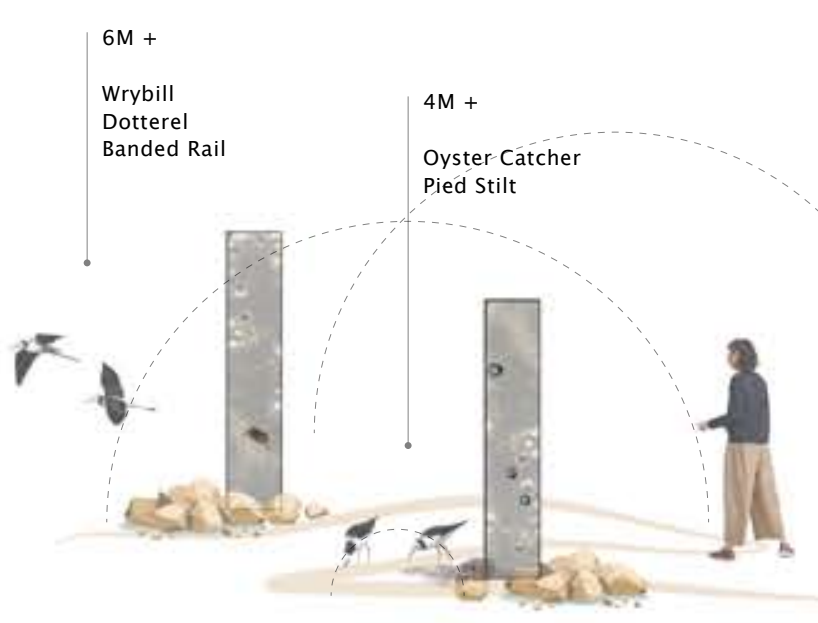

SANDY BEACHES CORDONED OFF WITH POSTS

Allows people, especially children to engage with wildlife and learn

kinaesthetically

LOCATION: Tideline along the southern walkway, come existing, some constructed.
Removes physical danger from vulnerable nesting birds while allowing them to observe people from a distance, and vice versa.

LOCATION: Sandy beaches along the southern walkway.

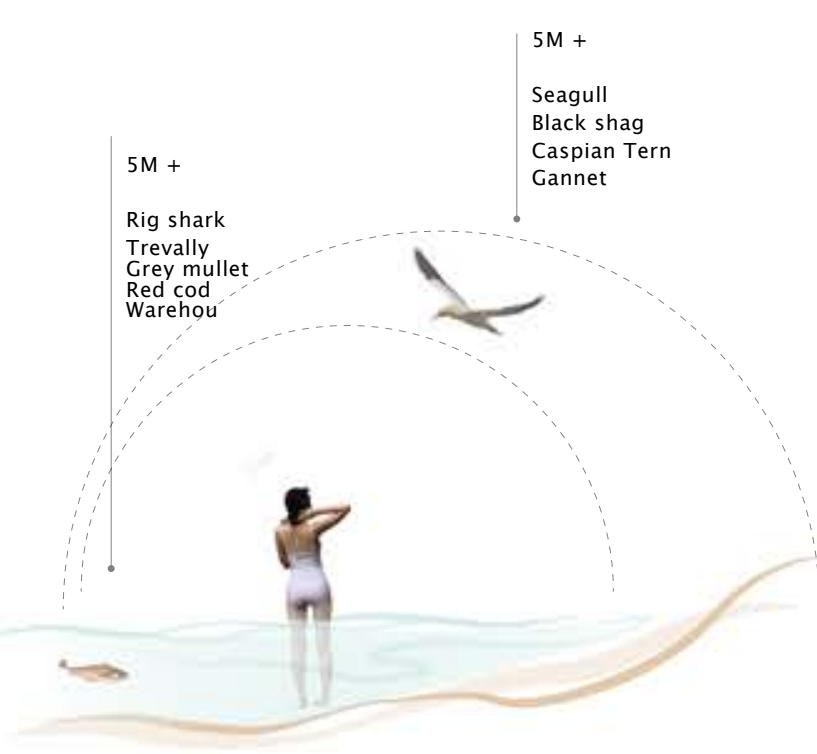

SANDY BEACHES

Swimming beaches allow people direct access with the harbour as the tide rises while facilitating encounters in open water through snorkelling.

LOCATION: Sandy beaches along the southern walkway. 


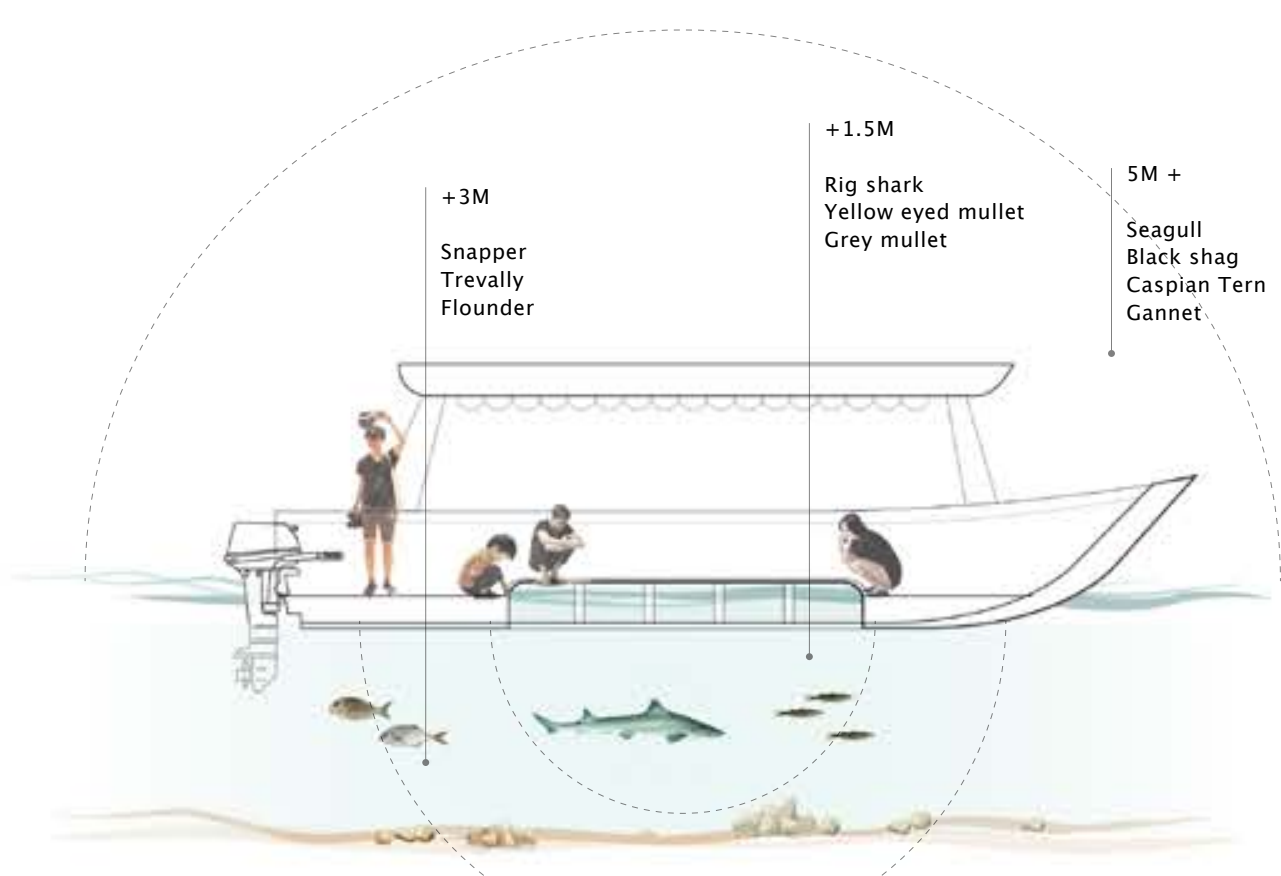

GLASS BOTTOMED BOATS

Allows people to interact with aquatic

species whose presence otherwise may not

be visible when traversing the tidal edge.

LOCATION: Harbour inner

waters $1 \mathrm{~m}$ deep

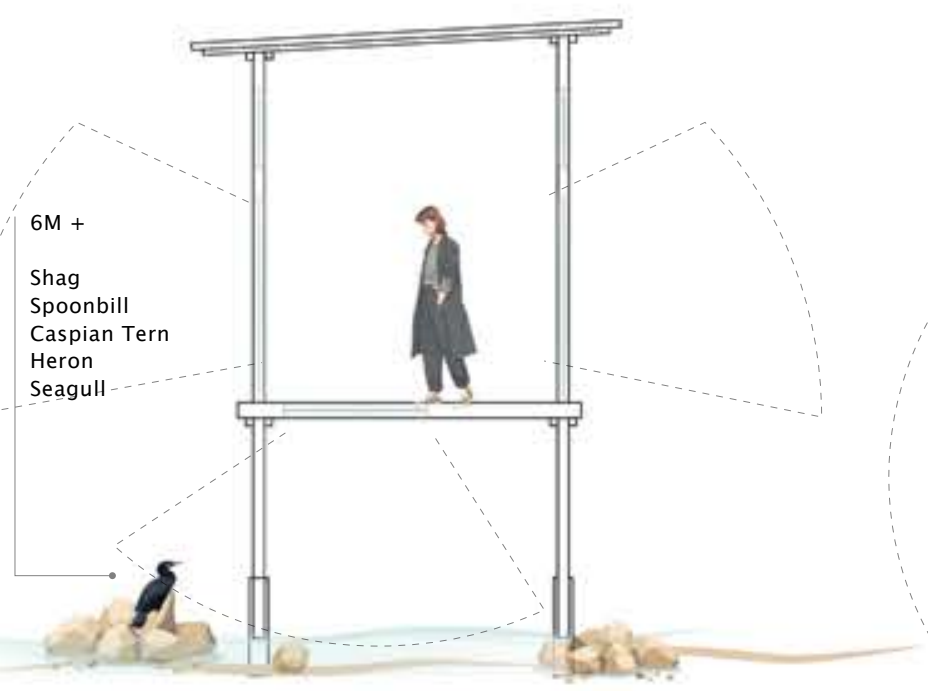

MARINE EDUCATION CENTER WITH

GLASS BOTTOM FLOOR

Educational community space, helping people

learn about life in the harbour through both passive and kinaesthetic means.
LOCATION:
Southern coasta

walkway

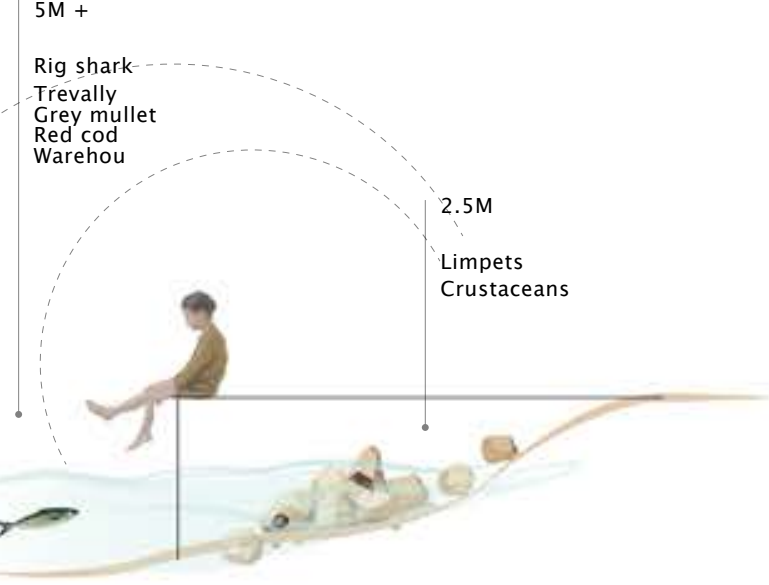

JETTY LOOKOUT

Facilitate swimming, diving and boating. Offer

views across the harbour and habitat for crustaceans and shellfish to adhere to

LOCATION: Placed around the harbour at the edge of deeper waters, primarily along the southern walkway. 


\section{Southern walkway.}

\section{BOAT RAMP}
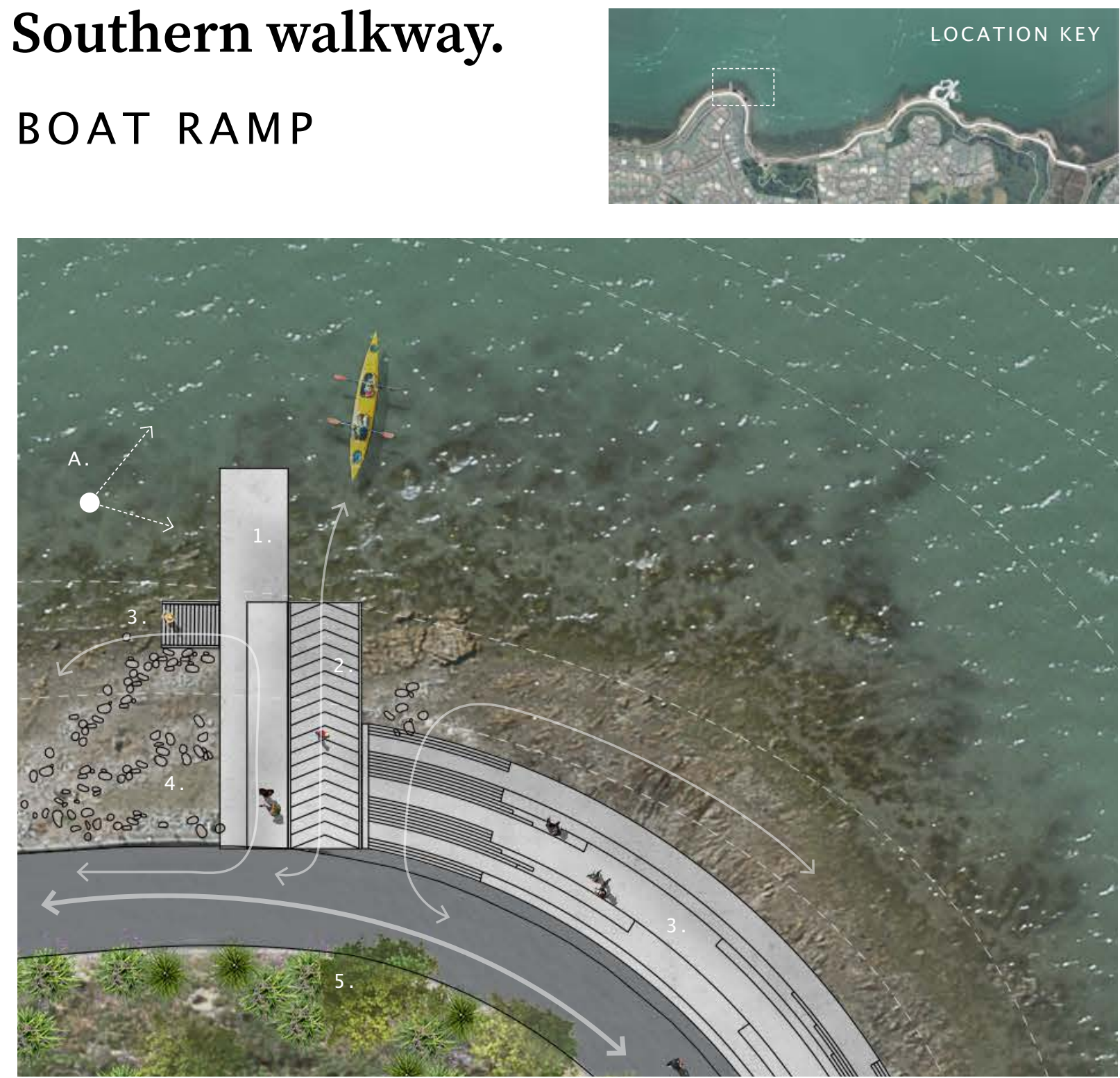

$1 / 250$

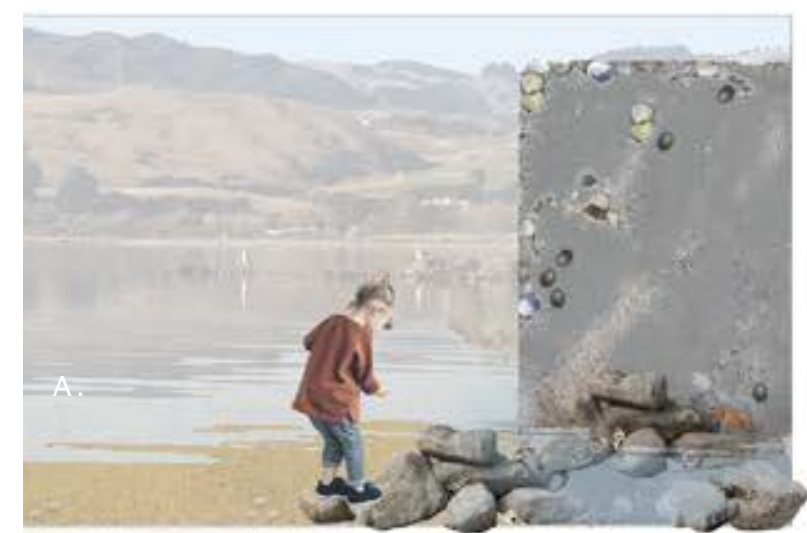

This headland jetty juts out into the providing boat access to the water. Rock pools and concrete tabby walls provide refuge for crustaceans and perches for shags and terns.

JETTY (LOOKOUT - (PASSIVE ENGAGEMENT) BOAT RAMPS (ACCESS)

STEPS (ACCESS)

ROCK POOLS (TACTILE ENGAGEMENT)

ROCKY OUTCROPS (HABITAT)

COASTAL FOREST (HABITAT)

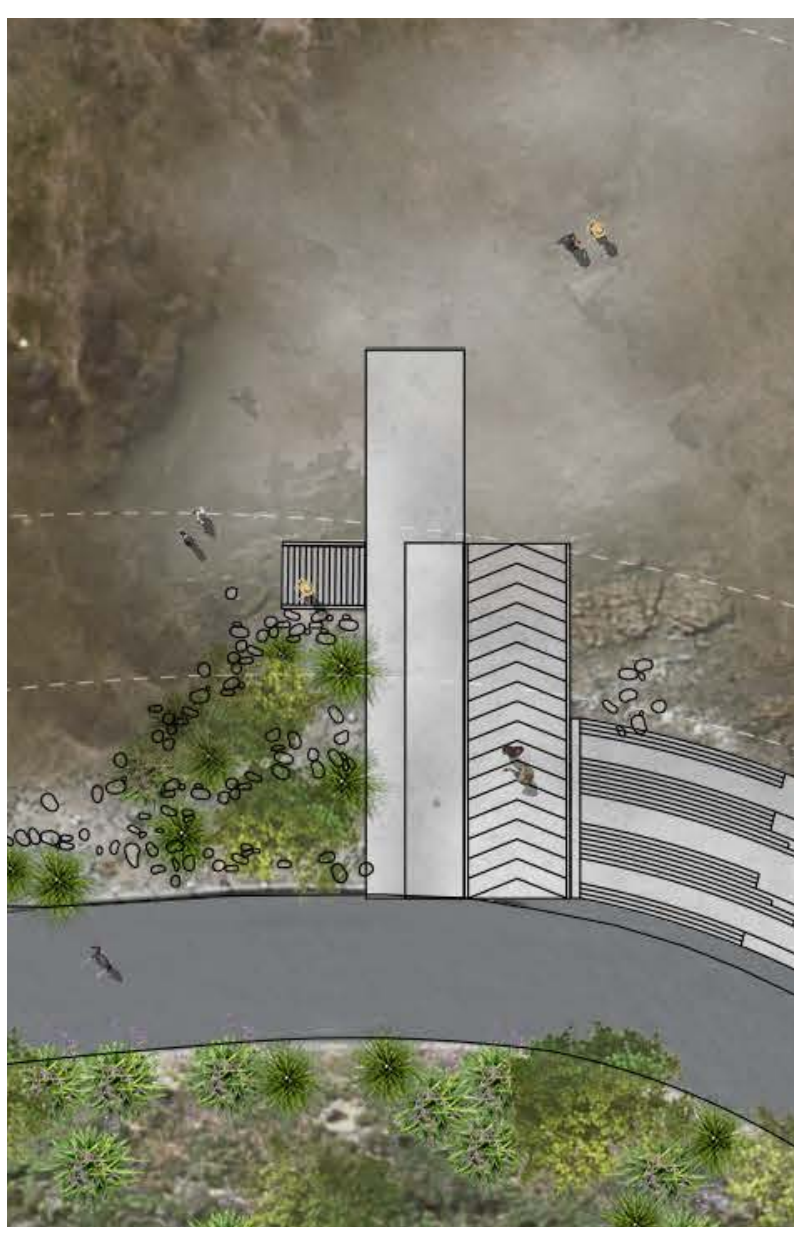

-Rock pools no longer needed by aquatic life can be filled with soil, allowing the coastal forest to start extending out onto the silt mud flats.

- Saltmarsh can also slowly be planted to stablise the silted mud flats and provide habitat.

- Jetty and steps provide resting spots and offer views across the basin
SEA LEVEL RISE ADAPTATION

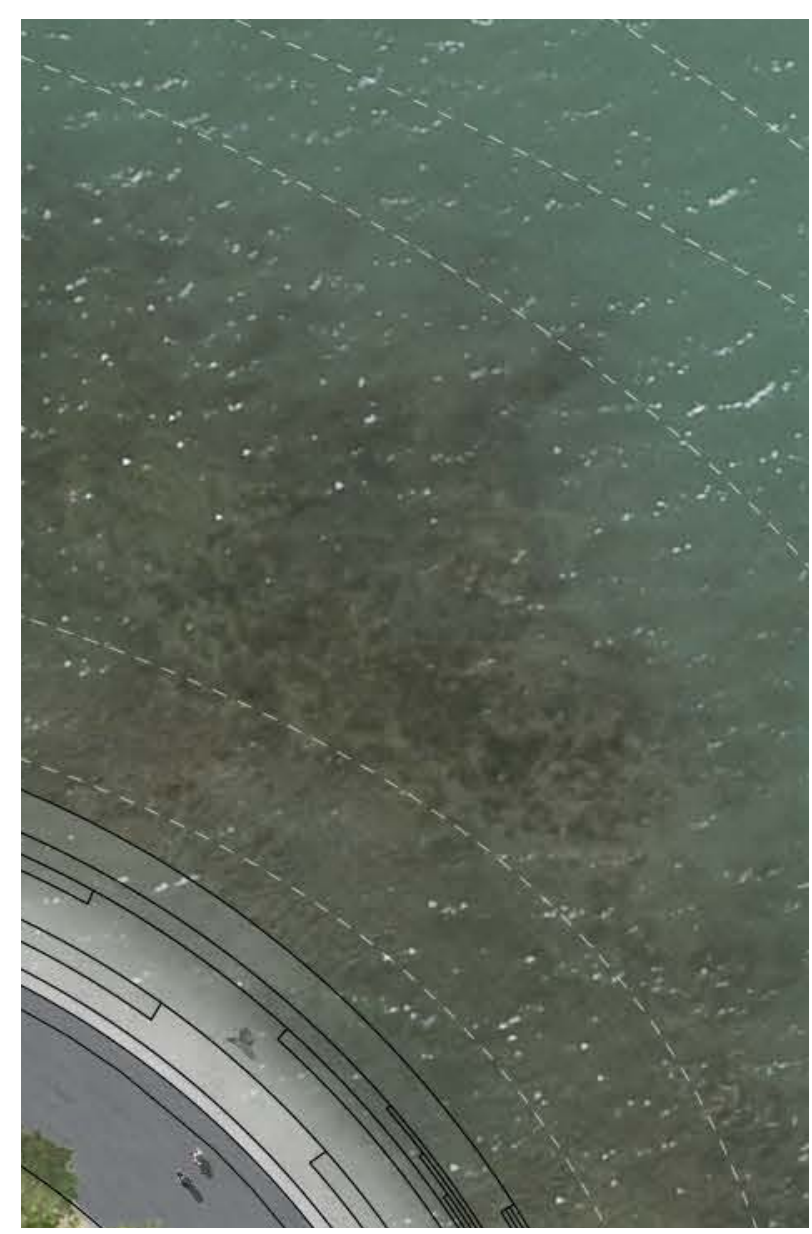

Rock pools become artificial reefs, serving as a nursery for young aquatic life.

Steps facilitate direct access to the water

-The jetty can service deeper hulled boats 
SOUTHERN EDGE WALKWAY

\section{BRADEYS BAY}
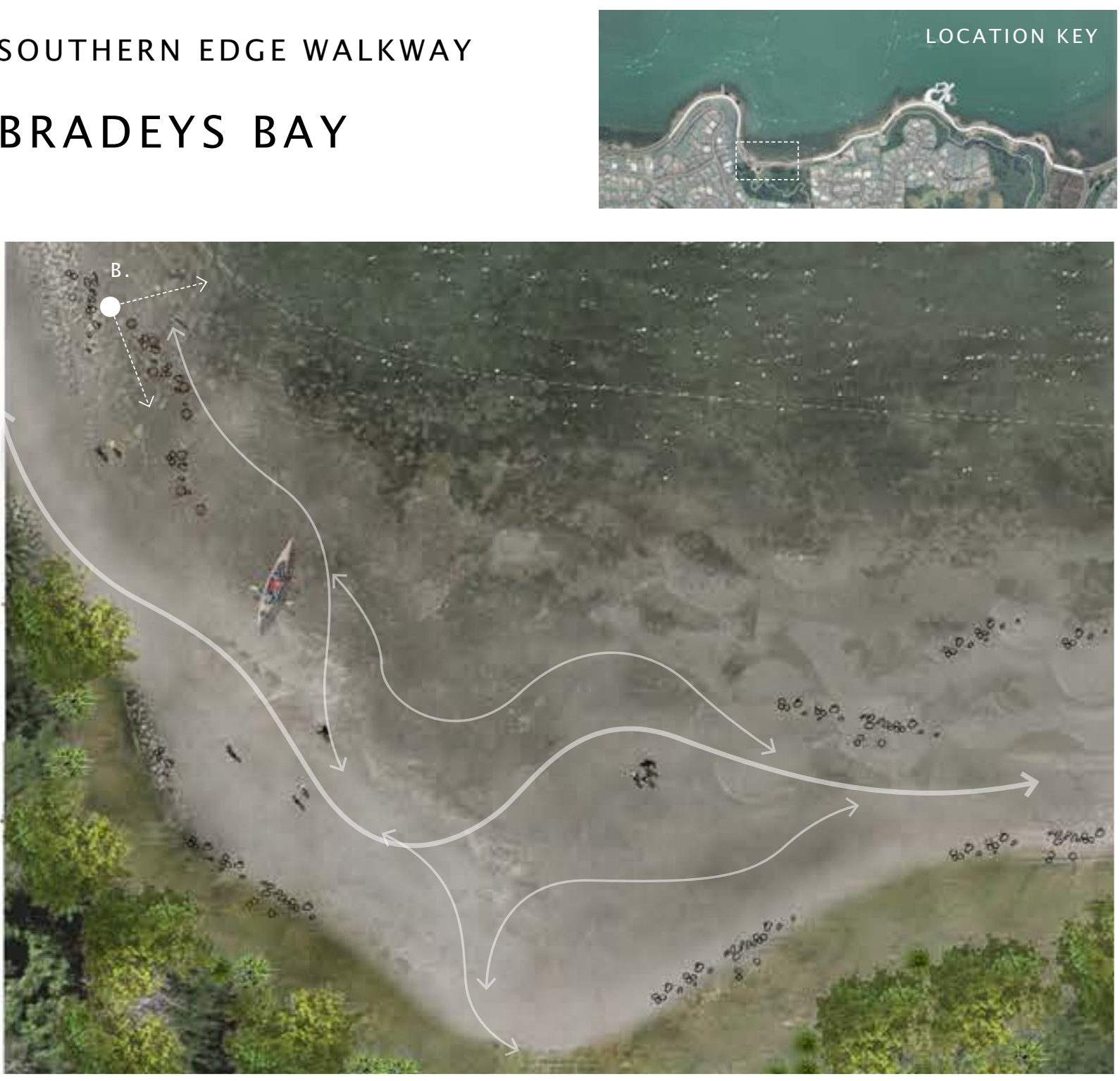

$1 / 250$

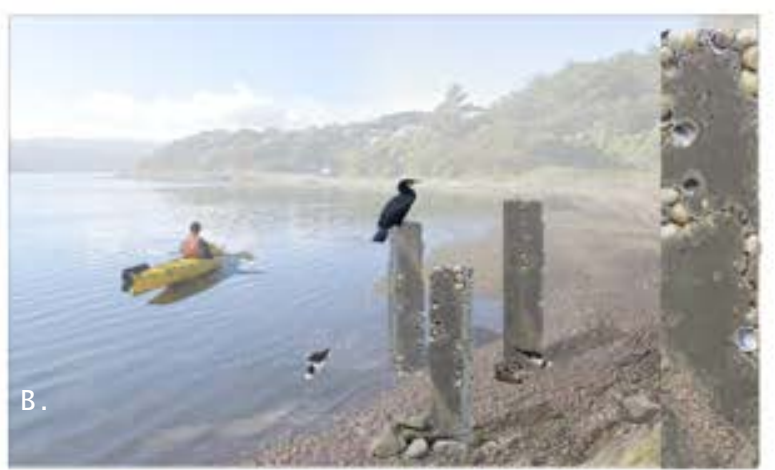

Asphalt has been removed from this section of the southern walkway, creating unrestricted movement and allowing the tida edge to move further inland to create a shelly beach.

HABITAT MARKERS (PASSIVE ENGAGEMENT) ROCKY OUTCROPS (HABITAT)

SANDY BEACHES (HABITAT)

COASTAL FOREST (HABITAT)

PARKSPACE FOR PICNICS

ENOUNTER: SANDY BEACHES CORDONED OFF WITH POSTS
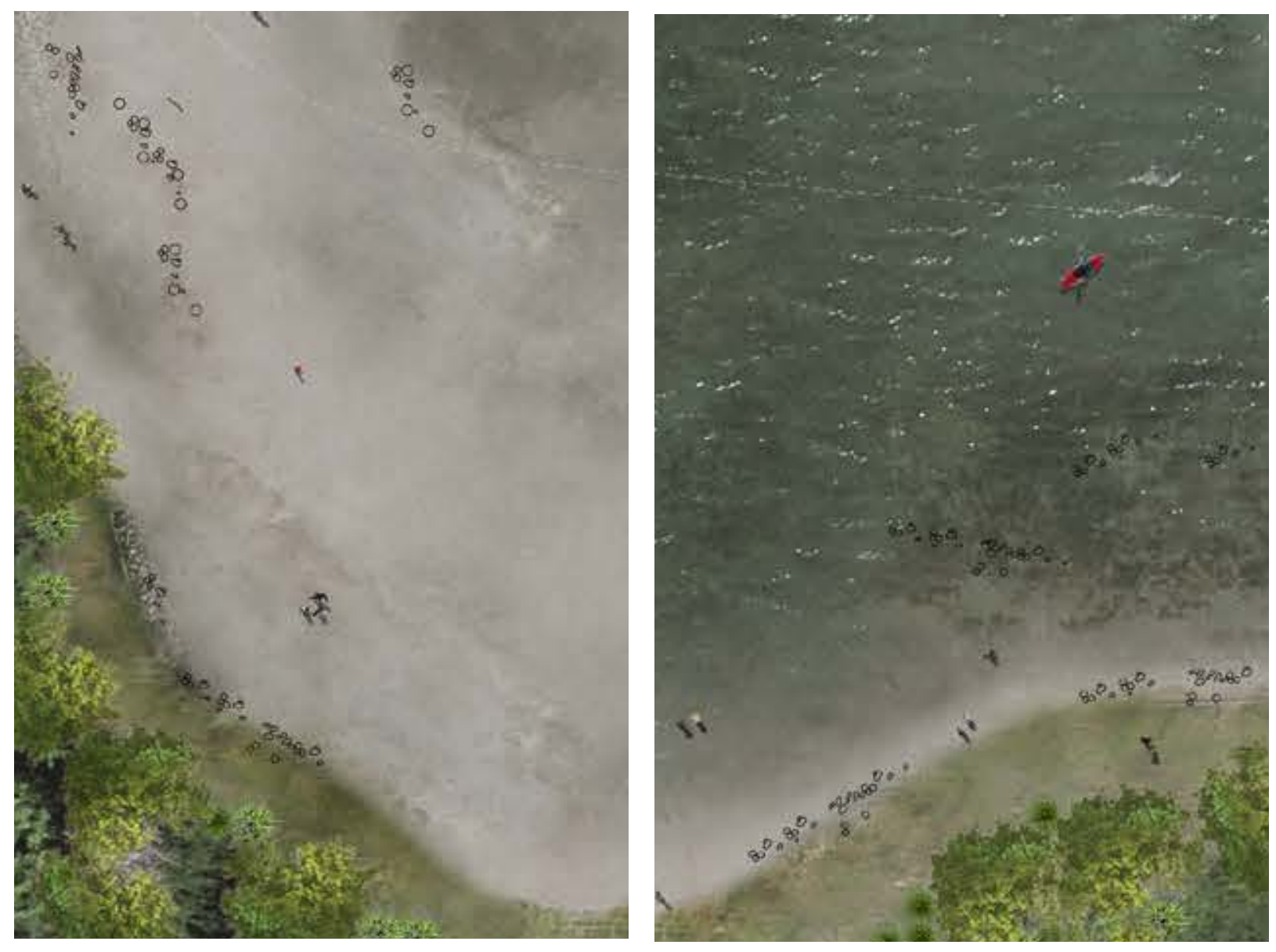

-Habitat marker installations cordon off vulnerable nesting shoreline birds from humans, protecting their habitat while still facilitating passive interspecies engagement through observation.

- Large sandy beach and grassy park space for recreational use, allowing species room who prefer more space (proxemics)
Habitat markers now used as sculptural installations to mark tidal movement and provide habitat for shellfis and crustaceans

- Narrower terrestrial pathway but deeper waters for boats and fish to traverse 
SOUTHERN EDGE WALKWAY

\section{SHELLY COVE}
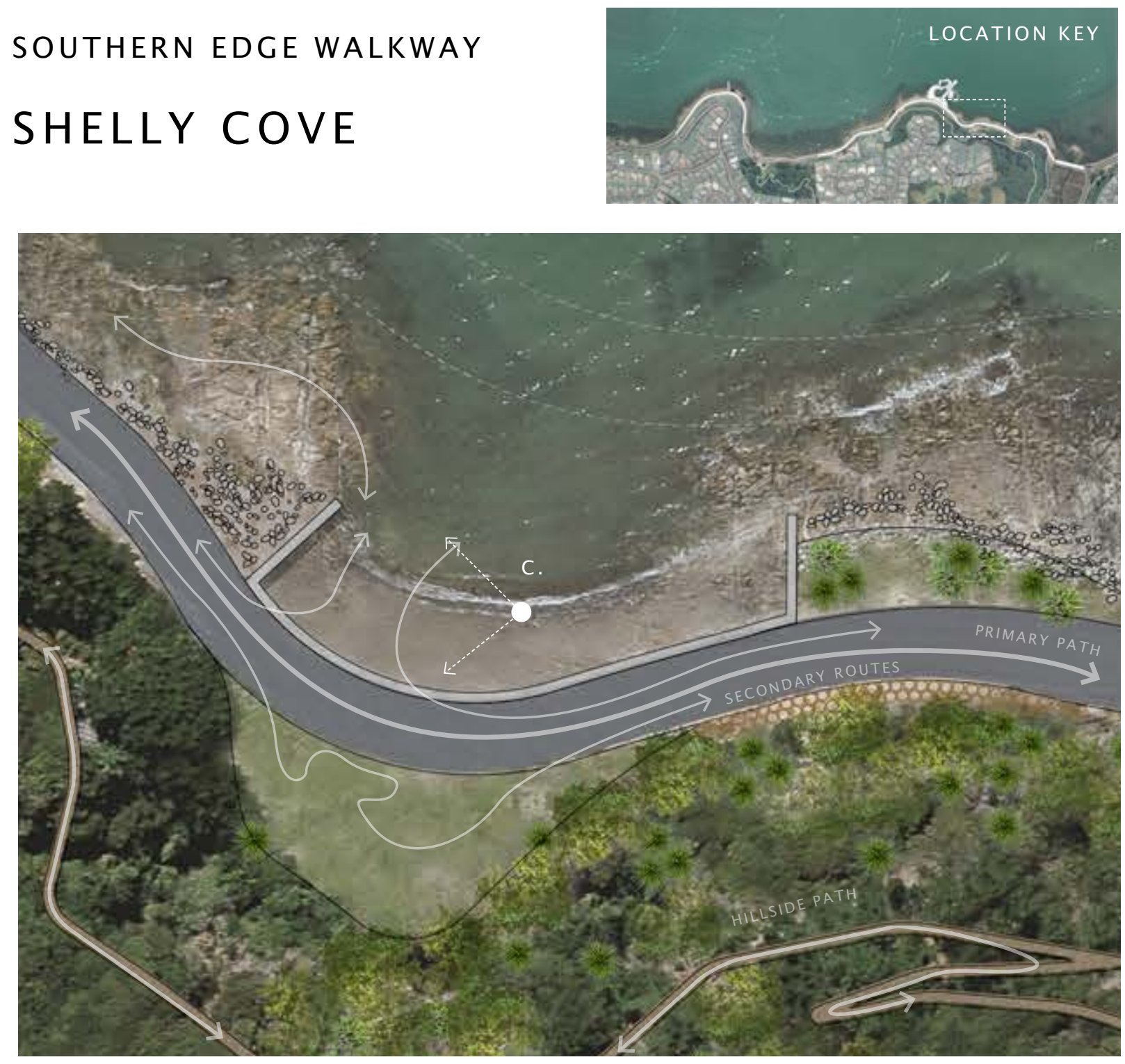

$1 / 250$

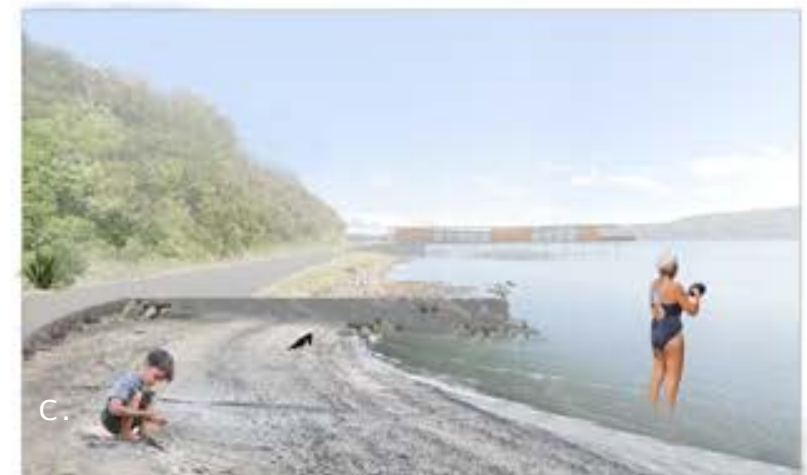

Asphalt pathway has been rerouted closer to the hills to allow a cove to form. Swimming and rock pools provide recreational engagement and soften the tidal edge

1. ROCKY OUTCROPS (HABITAT)

2. SANDY BEACHES (HABITAT)

3. COASTAL FOREST (HABITAT)

CLAY CYLINDERS USED AS PLANTERS

5. PARKSPACE FOR PICNICS

6. PATHWAY LINKING TO HILLTOP LOOKOUT
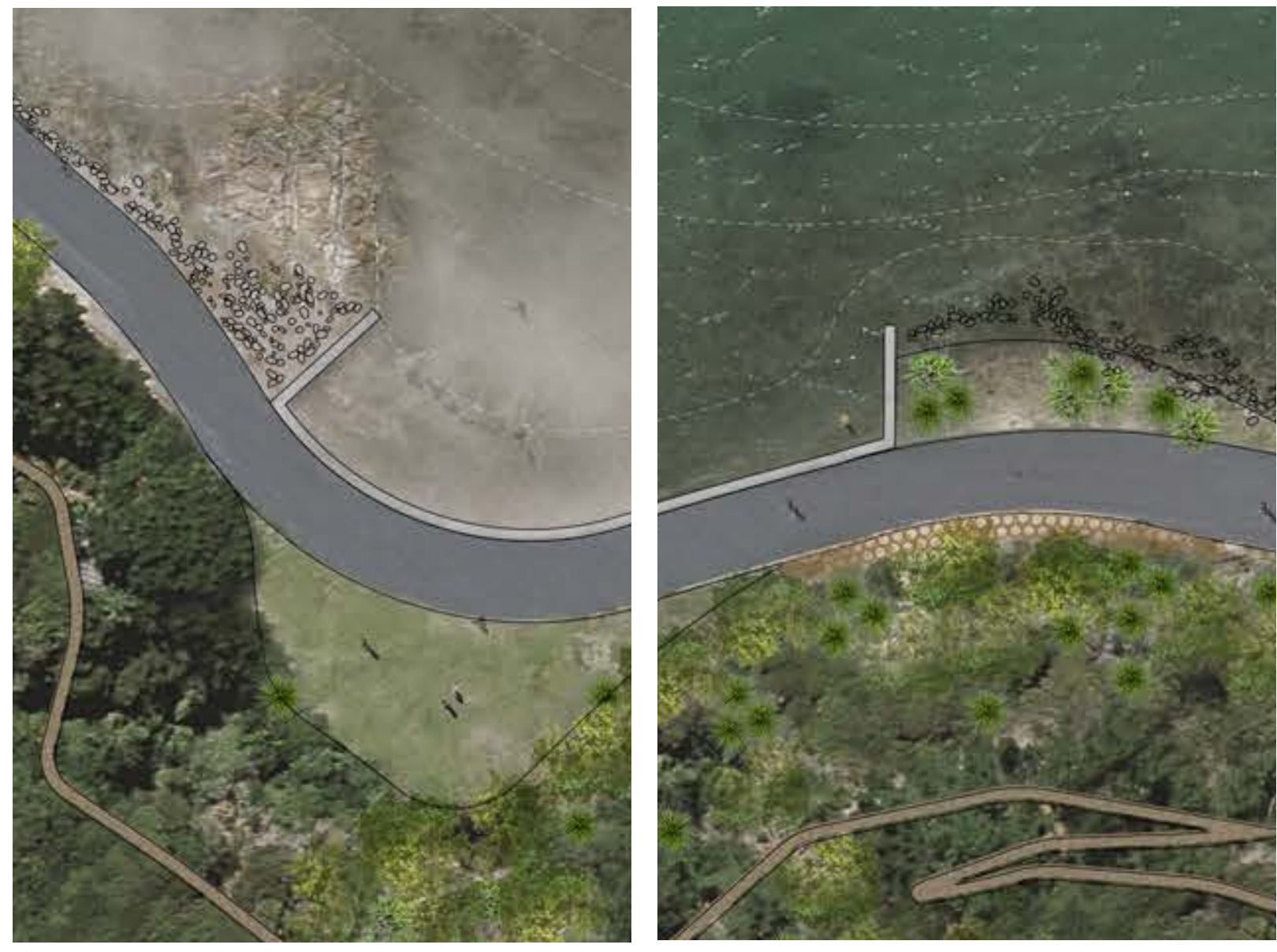

- Large sandy beach and grassy park space for recreational use, allowing species room who prefer more space (proxemics)
Cove wall allows the tidal edge to move landward but only to a certain extent. Deeper waters for boats and fish to traverse

ENOUNTER:

SANDY BEACHES 

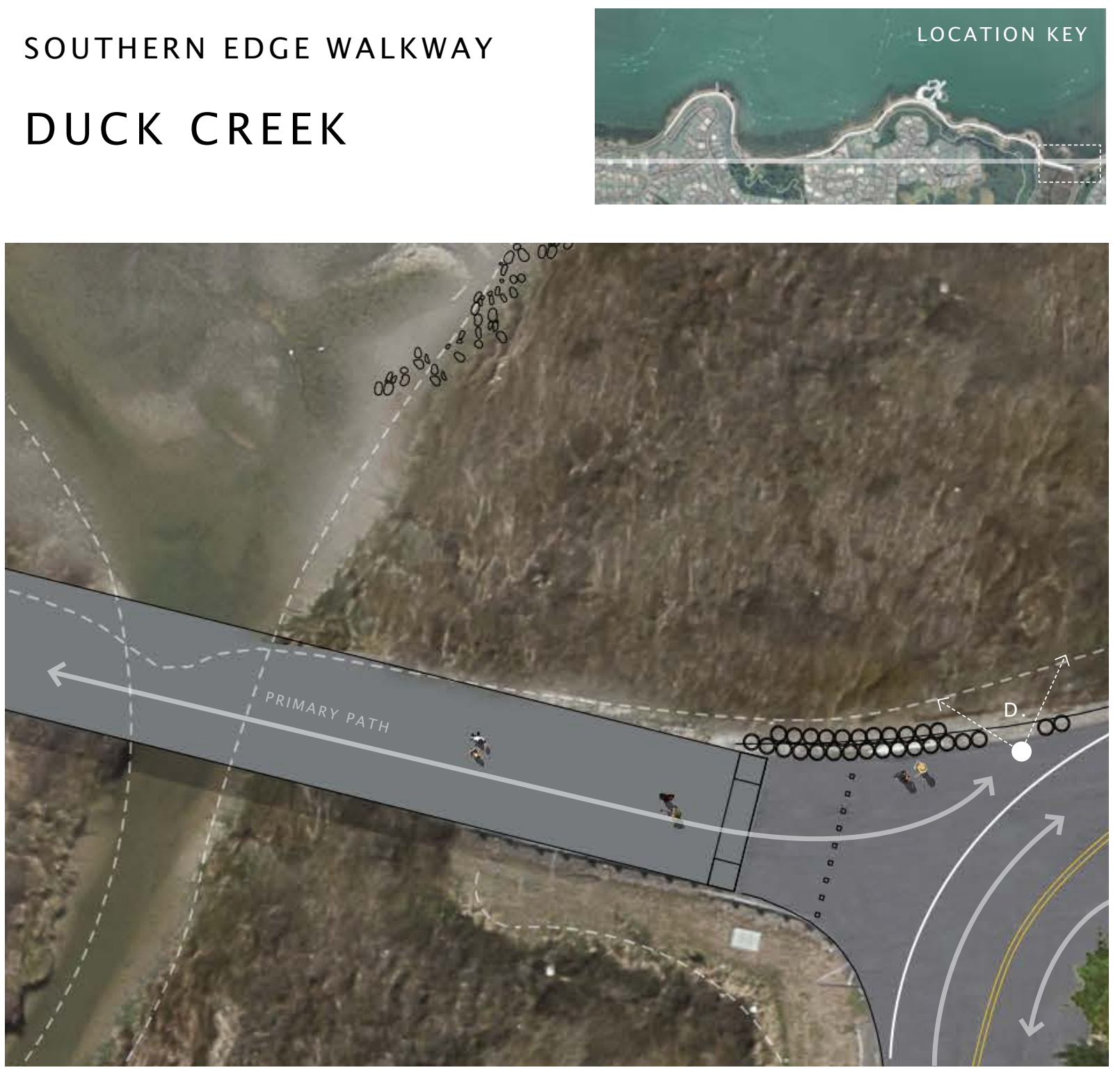

$1 / 250$

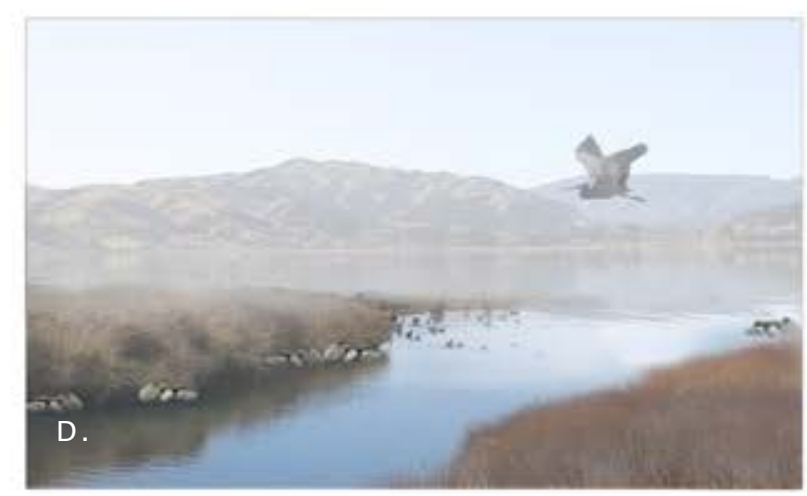

Road and seawall enclosing duck creek has been removed and replaced with a bridge to allow more room for tidal movement and saltmarsh growth.

\section{ENOUNTER:}

SALT MARSH
SANDY BEACHES (HABITAT)

SALTMARSH (HABITAT)

clay Cylinders used as planters

END OF THE 'PEDESTRIAN ONLY' SOUTHERN

PATHWAY STRETCH OF ROAD
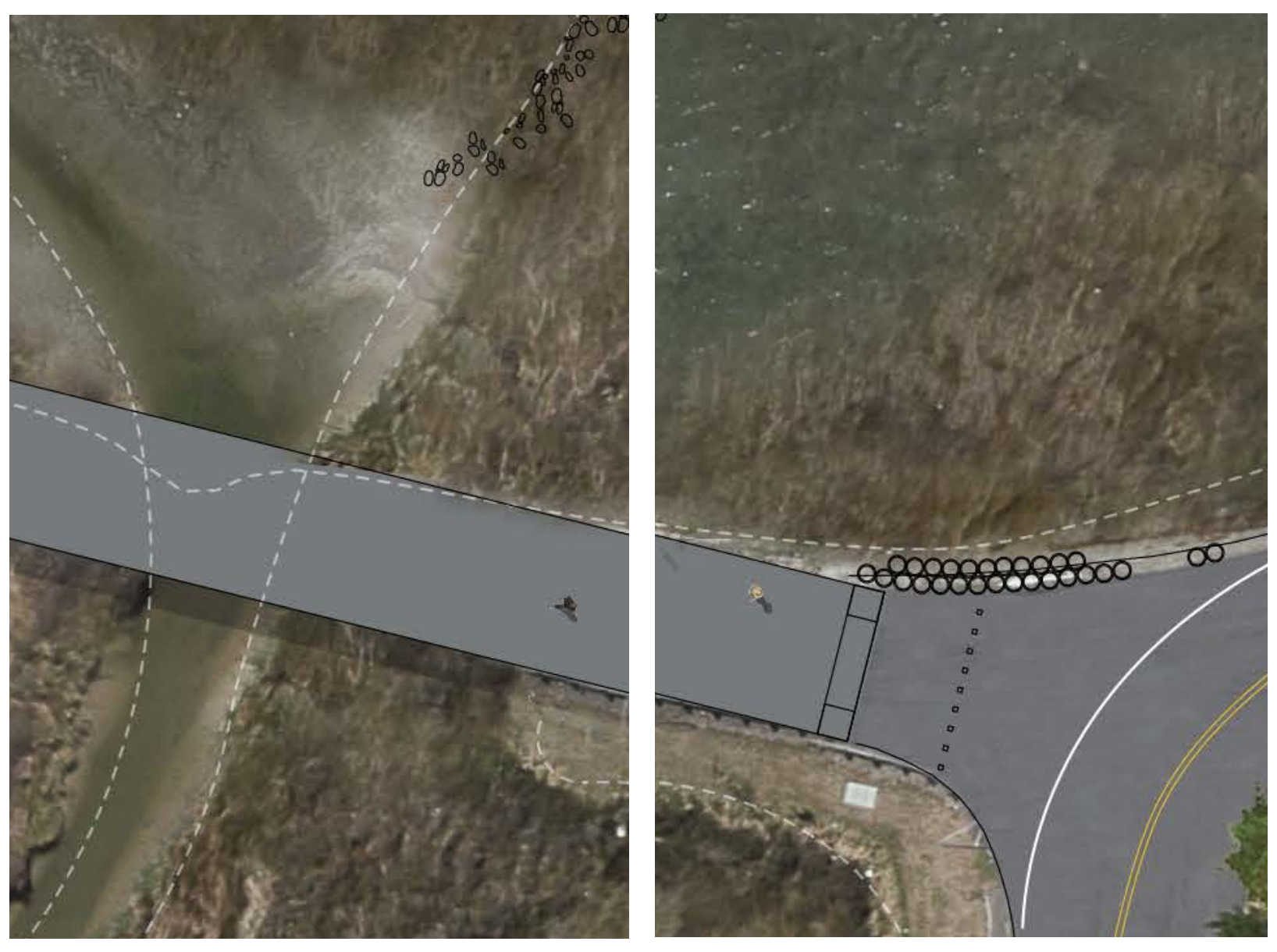

- Duck creek narrows and moves eastward to the new tidal edge. Saltmarsh moves out toward the flats
Saltmarsh becomes inundated with water at high tide and slowly retreats landward. Saltmarsh helps stabilise the coastal embankment against storm surge as sea levels rise. 


\section{Marine Education Centre.}
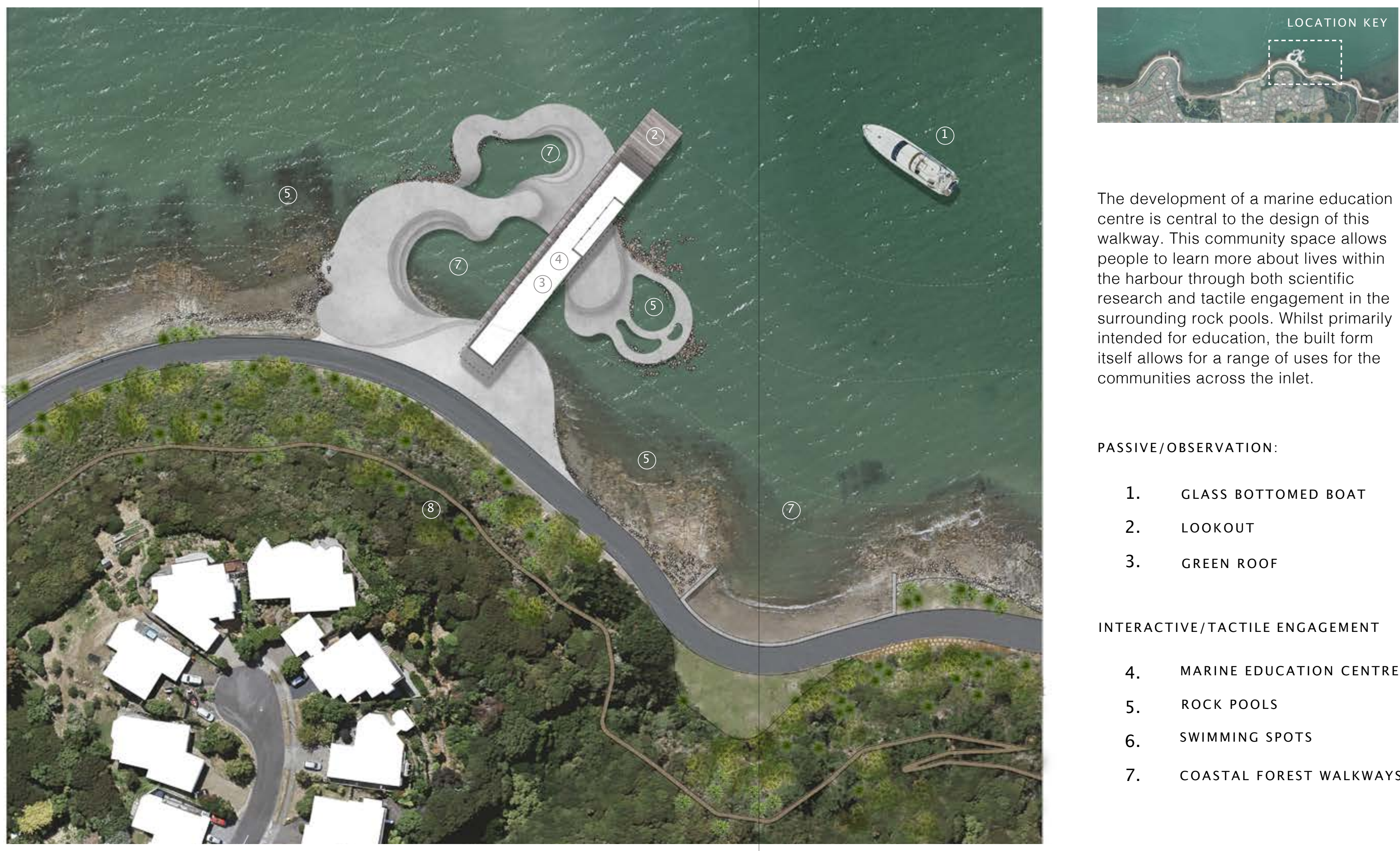

The development of a marine education centre is central to the design of this walkway. This community space allows people to learn more about lives within the harbour through both scientific

research and tactile engagement in the surrounding rock pools. Whilst primarily intended for education, the built form itself allows for a range of uses for the communities across the inlet.

PASSIVE/OBSERVATION:
1. GLASS BOTTOMED BOAT
2. LOOKOUT
3. GREEN ROOF

INTERACTIVE/TACTILE ENGAGEMENT
4. MARINE EDUCATION CENTRE
5. ROCK POOLS
6. SWIMMING SPOTS
7. COASTAL FOREST WALKWAYS 


\section{Marine Education Centre.}

SECTION AA: THROUGH THE TIDAL POOL
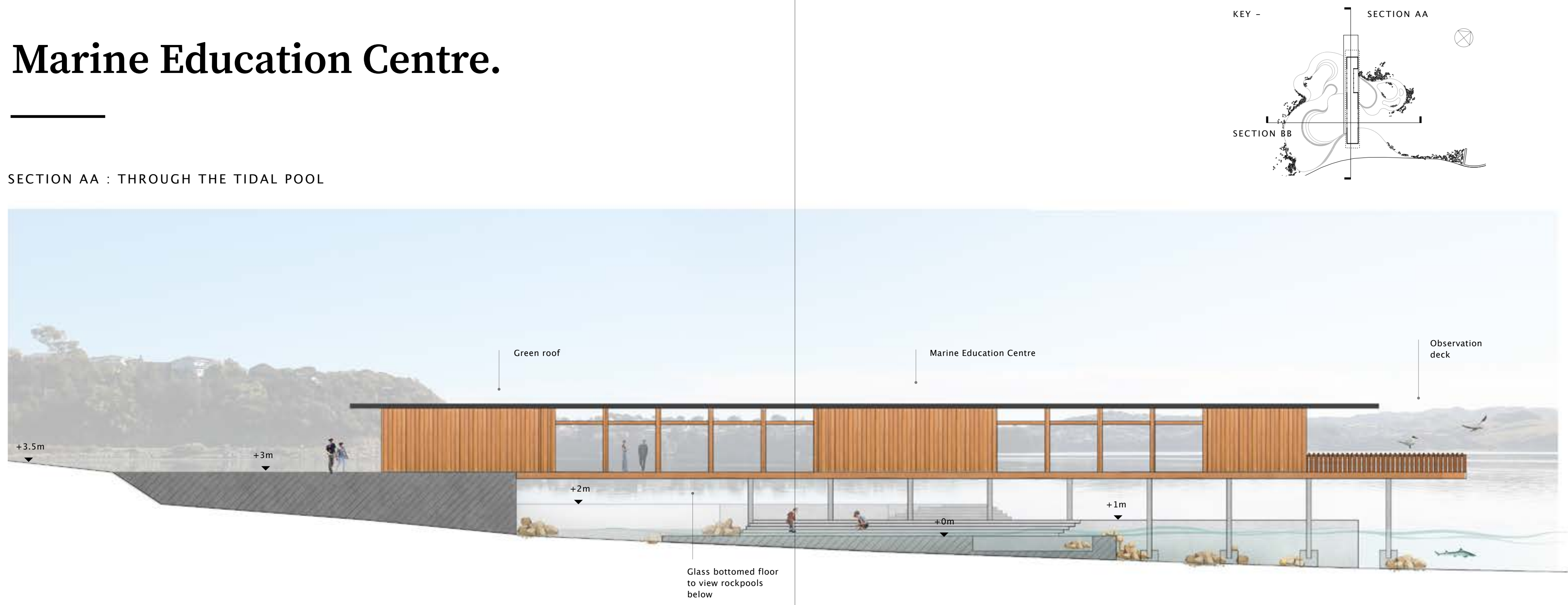

SECTION BB : THROUGH THE EDUCATION CENTRE

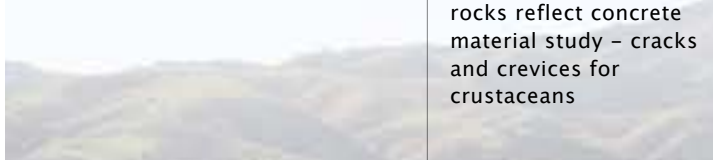

Rock
pools

i) $\quad+2 m$

$\left[\begin{array}{l}\text { Tidal } \\ \text { swimming } \\ \text { pool }\end{array}\right.$

$\therefore$ atisey

4
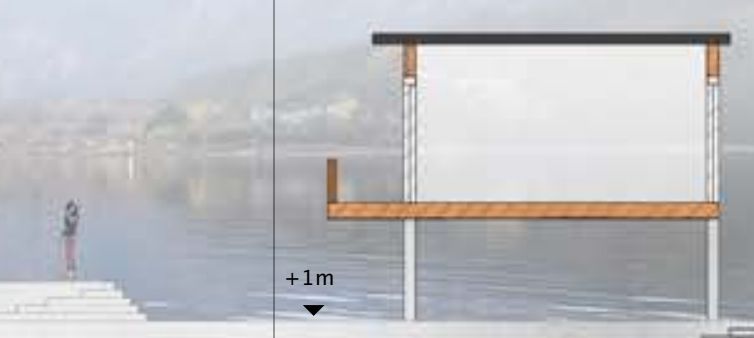

\begin{tabular}{|l} 
Rock pools for tactile \\
enagagement
\end{tabular} 
MARINE EDUCATION CENTRE ITERATIONS

Patterns of erosion and deposition indicate headlands, particularly on the southern edge as it is more vulnerable to tidal scouring and need stabilisation.

This design testing explores how the form of built

infrastructure can engage with

these processes, creating an

and accumulate creating a

coastal beach

The form gradually became more organic through the

iterative process, developing

into a series of terraced rock

pools and swimming holes that

protect from western waves

creating a sheltered inlet to the

The design of the building is indicative at this point only

for the purpose of showing

how its function fits into the

wider landscape. Developed

design and exploration of this

is outside the scope of this

landscape design process.

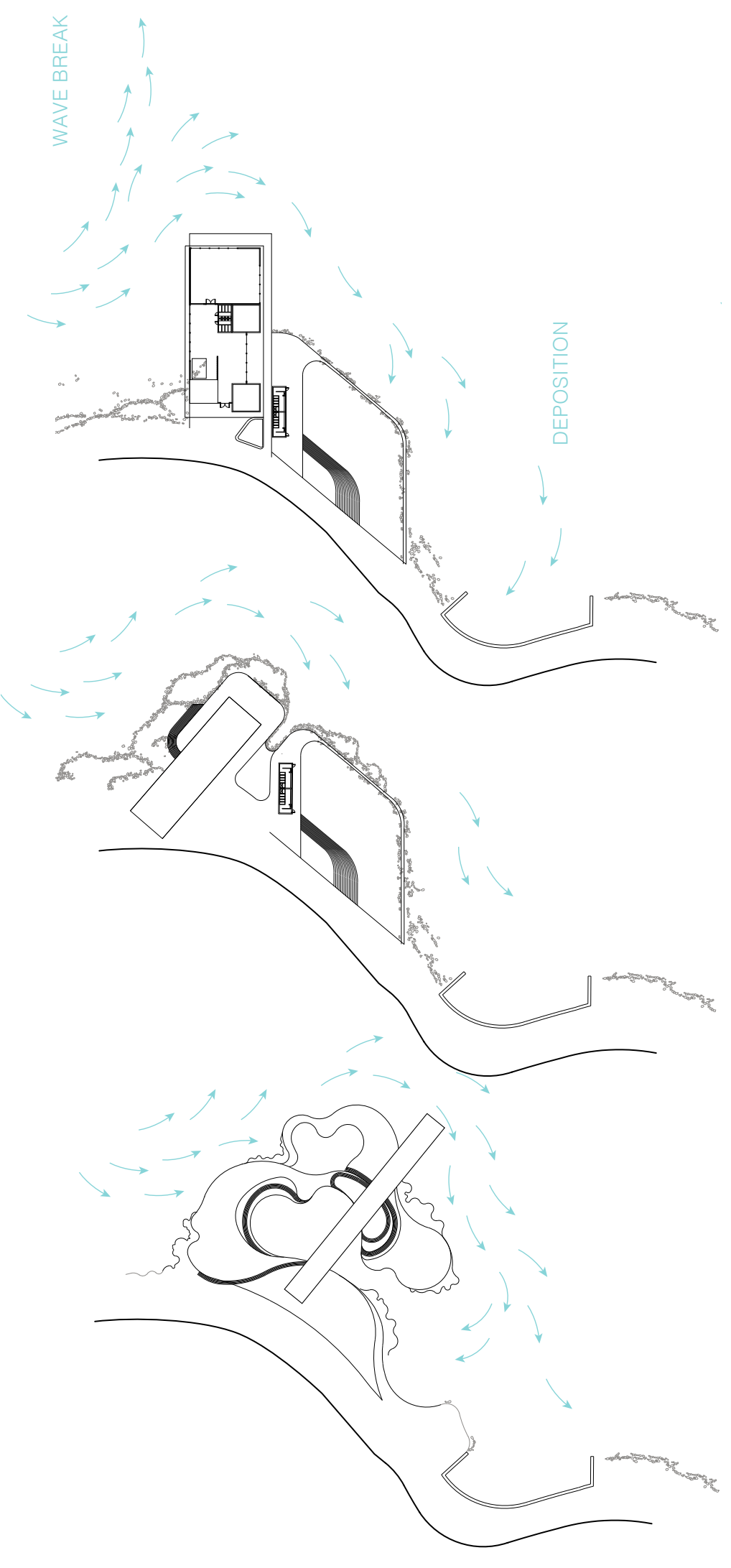

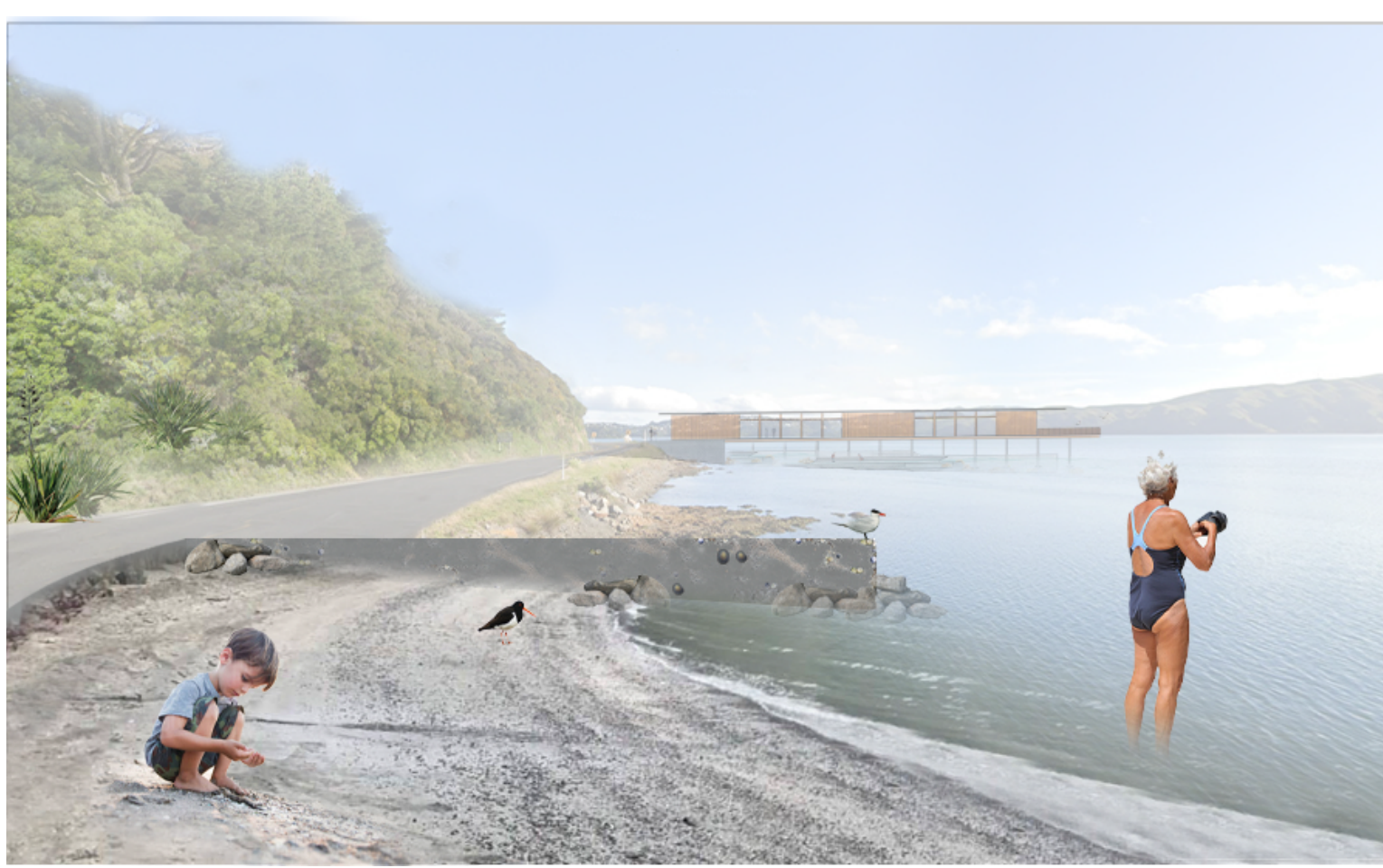

REFLECTION:

By reclaiming a stetch of highway the southern walkway has the potential to completely change the experience of dwelling in the harbour. Slowing down the speed of movement and creating a range of recreational activities creates space for inhabitants to reflect and become reenchanted with the beauty of life unfolding around them. 


\section{Conclusion}

This research explored ways in which the discipline of landscape architecture can approach design with the capacity to adapt, in the face of climate induced uncertainty. This was investigated through the design of a public route around Pauatahanui's coastline, to facilitates movement for all forms of life, and evolve with the changing tide.

It has become clear that built infrastructure within the coastal realm, such as seawalls and roads, impede organic and inorganic migration of species, restricting systems from adapting to shifting tides resulting in what is termed 'tidal squeeze'. This research identifies and innovates ways in which coastal built form can meet the needs of this specific landscape migration Supporting and facilitating this movement by attentiveness to sited tempora phenological systems broadens designs agency in this situation. Here design was used to harness the way materials are affected through time (decay, weathering and a substrate for new plant growth) to co-create sympoietic relations that evolve

\section{to the changing environment.}

Material investigations explored how mediums might be employed as a substrate for this needed movement. They are tested both in isolation, and in the synthesis of a pathway. This pathway is designed to service all forms of life by creating habitat in the fabric of its built form, and the creation of an ecological corridor around it. Through this process of design discovery, new modes of thinking were developed, emerging as a direct response to Pauatahanui's ecologies and affective beauty. Through immersion within the landscape, a sense of introspective tranquillity is achieved, a deliberate slowing down as you move through the landscape, this enchantment has the ability to redress ones understanding within the wider landscape, heightening sensory awareness to life outside of your own. Pauatahanui holds this potential.

ooking toward an uncertain future his research asserts that Landscape Architecture practice has the potential to resist the prevailing anthropocentric focus surrounding the design of coastal pathways - spaces which sanitise and stabilise - to instead create dynamic shared spaces for cohabitation to occur. New materialist movements, and affective methodology offer modes of engaging with design that decentre humans and focus on the impacts that change will have on al forms of life in the face of global warming.

This research acknowledges that when designing for the needs of different life forms, some assumptions must be made as to how they feel based off their reaction to affect. 'Encounters' between species

also tend to be skewed somewhat towards the benefit of humans in observing wildlife. The hope is that though occasions of encounter, compassion will be generated in humans, therefore this research uses design towards an ethic of care of the environment. Further research to expand this knowledge thread should be employed into mutually beneficial encounters,

perhaps through meaningful kinaesthetic engagement. 


\section{Bibliography}

\section{$\longrightarrow$ \\ Barad, Kaaren. "Meeting the Universe Halfway: Quantum Physics and the Entanglement of} Matter and Meaning" (2007), Duke University Press. p. 185

\section{Bellingham, Neil. "Pauatahanui Inlet a Living} Resource Wellington", N.Z: Guardians of Pauatahanui Inlet, 1998. 4. 11

Bennett, Jane. "The Enchantment of Modern Pre. Altachments, Crossings, and Ehics" Pp 3-16.

Bloomfield, Sibyl Ella May. "Inhabiting the Shifting Edge: Increasing the Adaptive Capacity of Coastal Sand Spit Communities in a Changing University of Wellington, 2011

Chris Reed \& Nina-Marie Lister, "Ecology and (Apri 2014). Accessed 23 Feb 2021. hou org/10.22269/140414

Colman, Felicity. "Agency" New Materialism how matter comes to matter, (May 2018)
Accessed 4th February 2020. https: $/ 1$ newmaterialism.eu/almanac/a/agency.htm

Conwell, Rendall. Pauatahanui Wildlife Reserve The First 25 Years, 2010: 11

Corner, James, and Alison Bick Hirsch.

Landscape Imagination: Collected Essays of James Corner 1990-2010. New York: Princeton Architectural Press, 2014

Dolphijn, Rick, and Van der Tuin, Iris. "Interview with Karen Barad", New Materialism: Interviews Press, 2012), pp. $48-70$ (p. 48).

Eiby, George. "Changes to Porirua Harbour in About 1855 : Historical Tradition and Geologica

\section{ealand 20, no. 2 (1990): 233-248.}

FitzGibbon, John, and Kenneth O Mensah. Evalution of the Institutional Context for Rurat Water Management in Ghana." SAGE open 2 no. 2 (2012): 05

Goldman, Michael, and Rachel A. Schurman 'Closing the 'Great Divide': New Social Theory on Society and Nature." Annual Review of Sociology 26 (2000). 563-84. Accessed February 22, 2021. http://www.jstor.org/stable/22345

Gunawan, Sarah. "Synanthropic Suburbia". University of Waterloo, 2015. http://hdl.handle. University of Wats
net/10012/9765

Hall, Edward. "The Hidden Dimension Garden City", N.Y: Anchor Books, 1969.

Haraway, Donna J. "Staying with the Trouble: Making Kin in the Chthulucene." Durham: Duke Unversily Press, (2016). Accessed 15 February.

Healy, W. B. "Pauatahanui Inlet : an Environmental Study" Wellington, N.Z: Science Information Division, DSIR, 1980

Hobbs, R. J., E. S. Higgs, and C. M. Hall. Novel ecosystems. intervening in the new ecological world order" (2013), pp 58. John Wiley \& Sons, Chichester, UK. http://dx.dol.
g/10.1002/9781118354186

Holmes, Rob. "The Problem with Solutions," Places Journal (2020). Accessed 20 June 2020. https://doi.org/10.22269/200714

Kastner, Jeffrey., and Brian Wallis. "Land and Environmental Art." London: Phaidon, 1998.

Knudsen, Britta Timm., and Carsten Stage "Introduction: Affective Methodologies."

Linquist, Greg. "Social Ecologies" Brooklyn brooklynrail.org/2015/11/editorsmessage/socialecologies

Medell, E., and Cantrall, Bradley. Failure. 2019; Univershy of Virginia, Fim. Accessed 16 August,

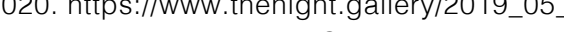

Mehrabi, Tara. "Affective Methodology" New
Materialism: how matter comes to matter, (January 2018). Accessed 4th February 2020. eu/almanac/a/affectivemethod htm

Meyer, Elizabeth K "Sustaining Beauty, The Performance of Appearance: A Manifesto in Three Parts." Journal of landscape architecture (Wageningen, Netherlands) 3, no. 1 (2008): $6-23$.

Meyer, Elizabeth. K. (2015). "Beyond 'Sustaining Beauty': musings on a manifesto." Values in landscape architecture and environmental (2015): 30-45. Baton Rouge: LSU Press.

Milligan, Brett. "Landscape Migration," Places Journal (2015). Accessed 20 June 2020. https: doi.org/10.22269/150629

Morton, Timothy. "Say Nature one more time." September 2020. Accessed January 2021. es/timothymorton

Nichols, Wallace J, "Blue Mind : the Surprising Science That Shows How Being near, in, on, or under Water Can Make You Happier. Healthier. More Connected and Better at What You Do" .Little, Brown and Company, New York (2014).

NIWA. "Pauatahanui inlet: effects of historical catchment landcover changes on inlet

Press, 2018

RG Bell, TM Hume, DM Hicks. "Planning for Climate Change Effects on Coastal Margins" The Ministry for the Environment, New Zealand, 2001. https./Www.mfe.govt.nz/sites/default/files/ effect-coastal-sep01.pdf

Sanzo, Kameron. "New Materialism(s)"

Genealogy of the post human (2018). Accessed //criticalposthumanism.net/ new-materialisms/\#_ftnref1

Selanon, Pattamon. "A Study of the Relevance of Environmental Art to Landscape Architecture in the Context of the United Kingdom". ProQues Dissertations Publishing, 2017.

Tilley, Christopher Y. A "Phenomenology of Landscape : Places, Paths, and Monuments"

Tilley, Christopher Y. A Phenomenology of
Landscape : Places, Paths, and Monuments xford, UK ;: Berg, 1994.

Tono, Dante D., and Gail L. Chmura. "Assessing Coastal Squeeze of Tidal Wetlands." Journal of Coastal Research 29, no. 5 (2013): 1049-061. Accessed February 22, 2021. http://www.jsto org/stable/43215726.

Wessells, Anne Taufen. "Reassembling the Social: An Introduction to Actor-Network-Theory by Bruno Latour: A Review of: 'Reassembling the Bocial. An Introduction to Actor-Nework-Theory. Press. 2005. 312 Pages, ISBN: 0199256047 ." International Public Management Journal. Taylor \& Francis Group, 2007 


\section{Figure List}

ALL IMAGES UNREFERENCED ARE AUTHORS OWN.

Figure 1. Gunawan, Sarah. Synanthropic Suburbia: Design Experiments in the Suburban Biome. June, 2017. Waterloo, Canada.

Figure 2. Gorgoni, Giantranco. Robert Smithson during the building of Spiral Jetty. April 1970. Rozel Point, Great Sall Lake, Ulah. Accessed April, 2020. https://historyofourworld. wordpress.com/2010/10/18/robert-smithson/

Figure 3. Thorkildsen, Morten. Robert Smithson, Stills from the Spiral Jetty Film. 1970. . crystals-at-muma-by-philip-brophy

Figure 4. Drummond, Logan. Paekākăriki escarpment Track. June, 2020. Wellington, New Zealand.

Figure 5. Moller, Teresa. Punta Pite Plan. 2016. Venice Biennale. Chile. Accessed April, 2020 http://www.arquitectes.cat/iframes/paisatge/fitxa/9794

Figure 6. Moller, Teresa. A day trip to Punta Pite for project maintenance. December, 2014. Punta Pite, Zapallar, Chile. Accessed April, 2020. http://teresamoller.cl/a-day-trip-toPunta Pite, Zapallar, Cip
punta-pite-4-92544/

Figure 7. Moller, Teresa. Lines and string show marking out the construction pre development. 2016. A day trip to Punta Pite for project maintenance, Punta Pite, Zapallar, Chile. Accessed April, 2020. http://teresamoller.cl//portfolio/punta-pite/

Figure 8. Moller, Teresa. Punta Pite pathway around the coast. 2016. Venice Biennale. Chile Accessed April, 2020. http://www.arquitectes.cat//frames/paisatge/fitxa/9794

Figure 9. Isthmus. Schematic Plan for Oriental Bay. 2006. Wellington. New Zealand. Accessed April, 2020. hhttps://isthmus.co.nz/project/oriental-bay/

Figure 10. Isthmus. Aerial view of the headland. 2009. Wellington. New Zealand. Accessed April, 2020. https://architectureworkshop co nz/projects/oriental-bay-enhancementwellington-2003/

Figure 11. Isthmus. Construction of the headland. 2016. A day trip to Punta Pite for project

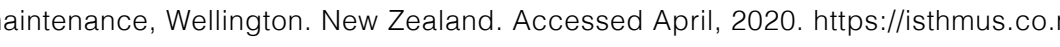
project/oriental-bay/

Figure 12. Isthmus. Construction of the headland. 2016. A day trip to Punta Pite for project maintenance, Wellington. New Zealand. Accessed April, 2020. https://isthmus.co.nz/ project/oriental-bay/
Figure 13. Isthmus. Discovery Trail Map. 2018. Auckland, New Zealand. Accessed April, 2020 https://isthmus.co.nz/project/hobsonville-point-play-strategy/

Figure 14. Isthmus. Habitat Markers. 2018. Auckland, New Zealand. Accessed April, 2020.https:// isthmus. co nz/hobsonvilles-habitat-markers/

Figure 15. Jasmax. Te Whau Pathway aerial. 2018. Auckland. New Zealand. Accessed April 2020. hhttps://isthmus.co.nz/project/https://www.jasmax.com/projects/featuredprojects/te-whau-pathway/

Figure 16. Jasmax. Te Whau Pathway. 2018. Auckland. New Zealand. Accessed April, 2020. hittps://isthmus.co.nz/project/https://www.jasmax.com/projects/featured-projects/tewhau-pathwayl

Figure 17. NIWA, Pauatahanui inlet: effects of historical catchment landcover changes on inlet

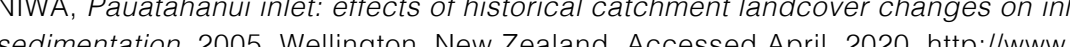
sedimentation. 2005. Wellington, New Zealand. Accessed April, 2020. http://www. historical\%20catchment\%20landcover por 